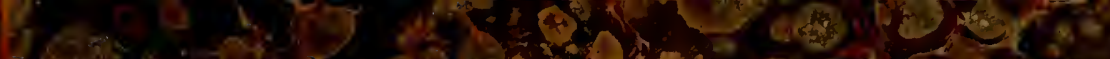

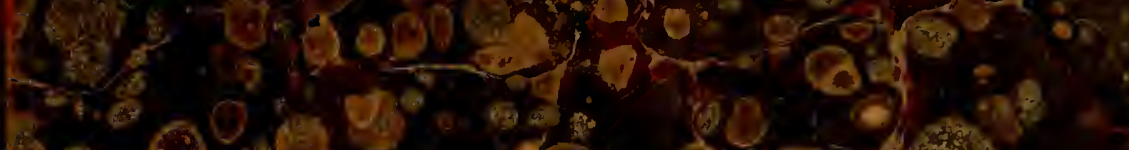

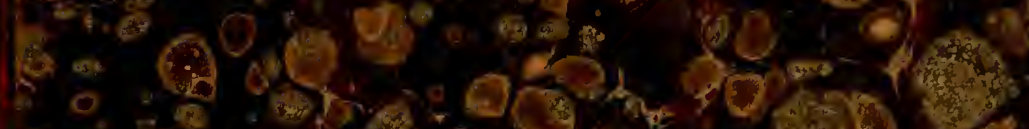

200.000 .0100

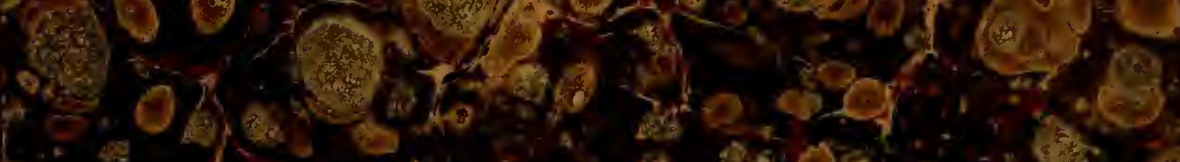

$30.50 \%, 0.5$

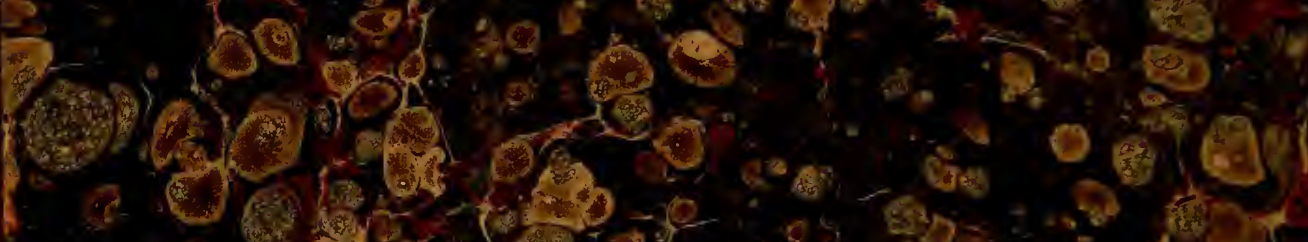

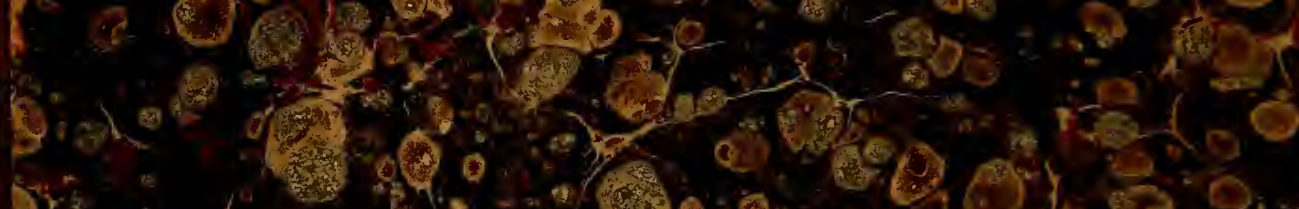

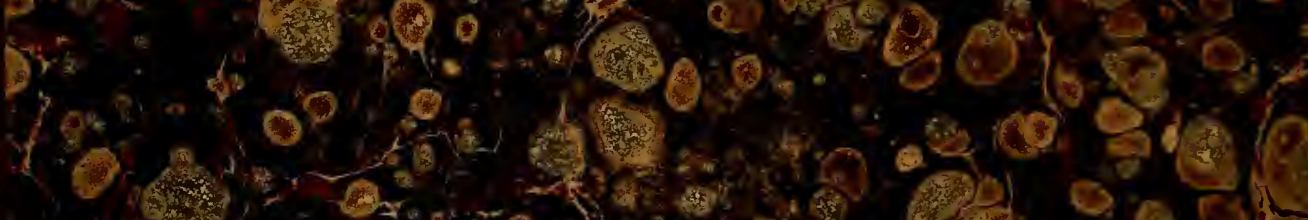
g8 20 1.

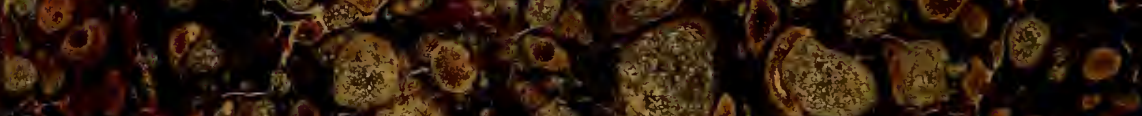

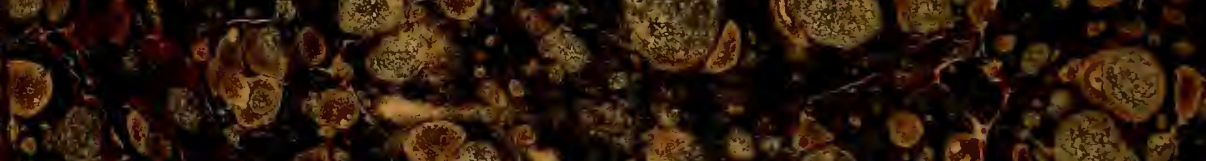

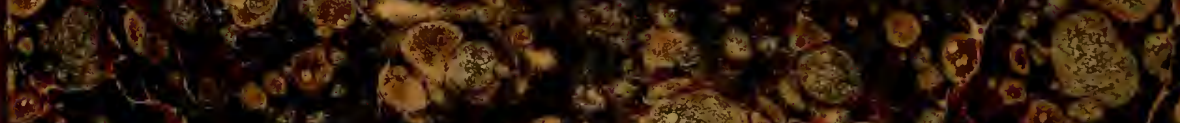
150 olo

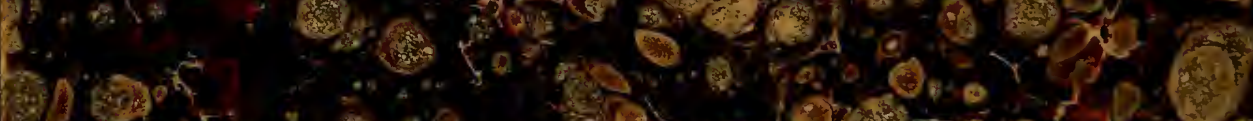

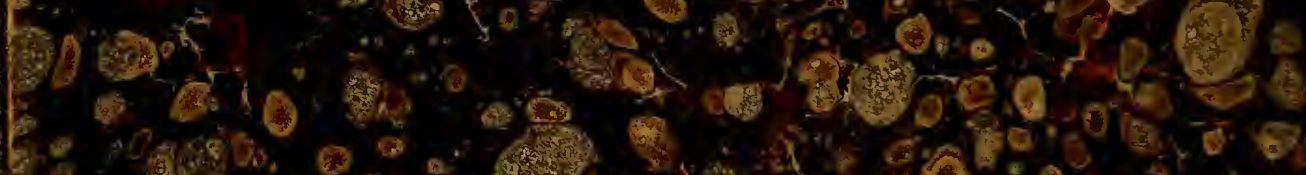



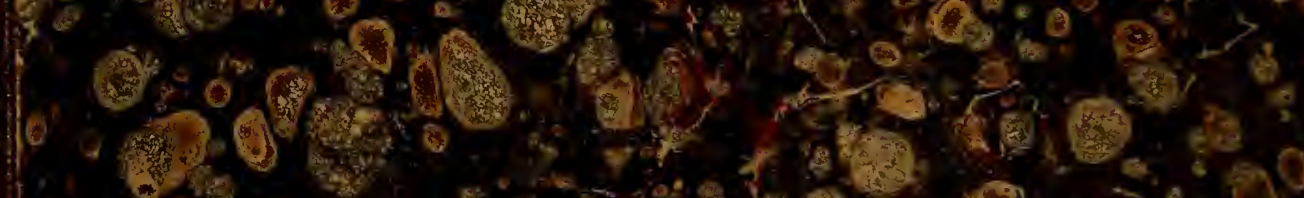
(4)

$500 \%$. 20\%

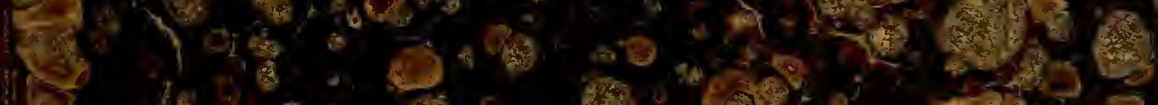


PROPERTY OF THE

PUBT IC LIBRARY OFTHE

CITY OE BOSTON.

DEPOSIT ROSTON UIDAL JPRAL
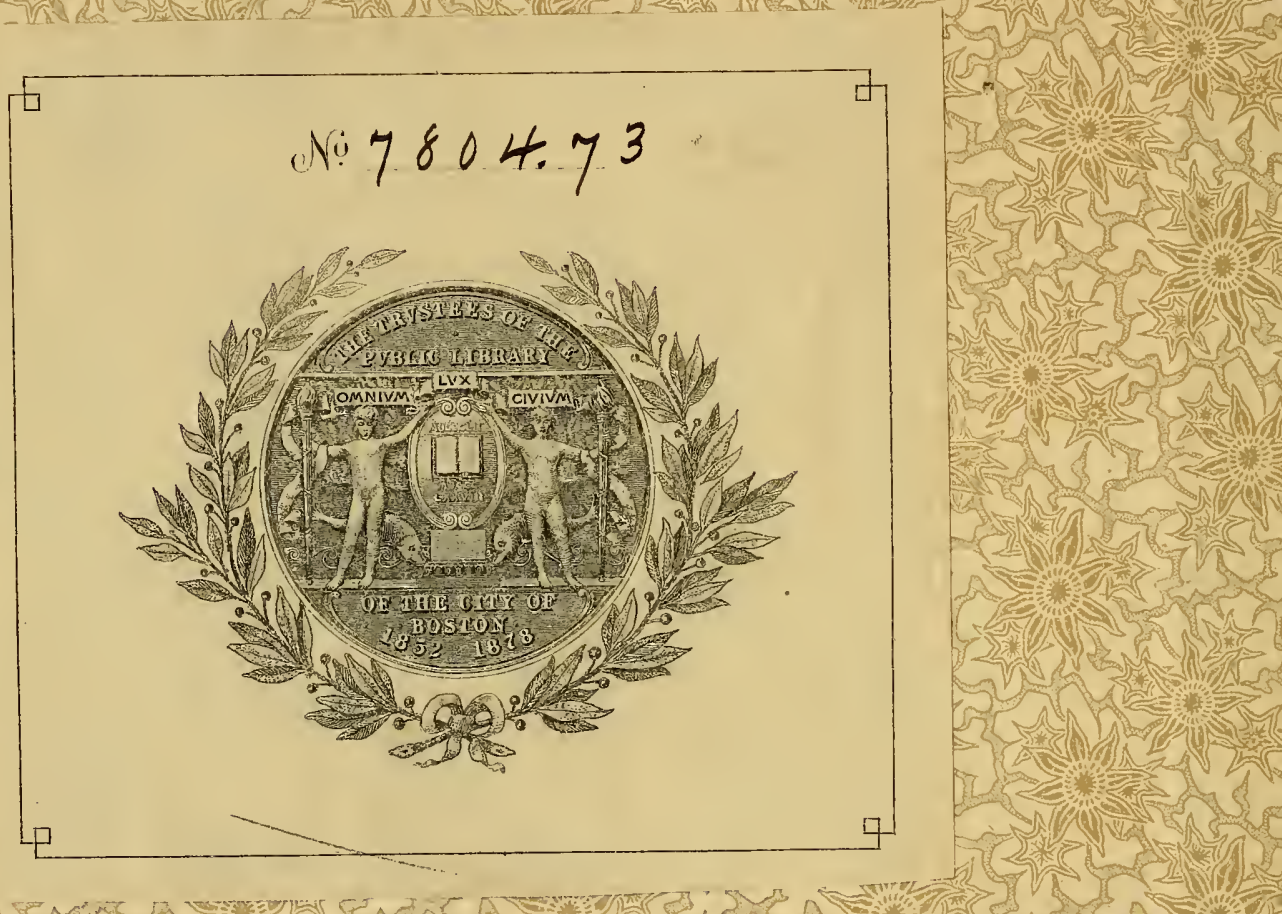



$$
\text { 19. B. } 9 \%
$$




\section{Die Entwickelung}

des

menschlichen Gehirns

während der ersten Monate

Untersuchungsergebnisse

ron

Wilhelm His

Mit 115 Abbildungen im Text

Leipzig

Verlag von S. Hirzel

1904 
Digitized by the Internet Archive in 2010 with funding from

Open Knowledge Commons and Harvard Medical School 


\section{Die Entwickelung}

des

\section{menschlichen Gehirns}

während der ersten Monate

Wilhelm His

Nit 115 Abbildungen im Text

\section{Leipzig}

Verlag von S. Hir\%el

1.904 


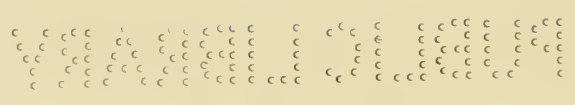

Das Recht der Übersetzadig ist

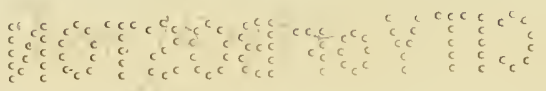




\section{Inhaltsverzeichnis.}

Einleitung. . . . . . .
Methoden der Bearbeitung.
Benitztes Naterial. . . .
Schwierigkeiten der Messing und
der Altersbestimming . .
Verzeichnis der beniitzten Em-
bryonen. . . . . . . .

Die Entwicklung des Zentralnervensystems bis zum Schluß des ersten Monats

Grundform des Wirbeltierhirns und jüngstemenschlicheGehirnformen.

Das Markrohr und seine histologische Entwicklung. . . 11

Das IIarkgeriist . . . . 11

Schichtung und Mm. limitantes 12 Verhältnis zur Glia . . . . 16

Die Keimzellen. . . . . 17

Die Nenroblasten und deren diagnostischen Merkmale

Die Gliederung des ILdullarrohres in Längszonen. .

Die Schichtensonderung in den Wandungendes Markrolires. . . . . . . 24

Kritsche Bemerkungen . . 29

Das erste Auftreten ron Neuroblasten und ron $\mathrm{Ner}$ venfasern . . . . . .

Das Markrohr beim rierwächentlichen Embryo. . Rïckemmark, Strïnge und Nervenwurzeln . . . . . . 37

Spinalganglien . . . . . . . 41

Die Nemroblasten und Faserbahnen tles Gehirns bei $\mathrm{Br} 3$.

Seite

1

2

4
Die Entwicklung der Großhirnhemi-

sphären . . . . . . . . . . $5 t$

Die erste morplologische Entwicklung des Hemispluärenhirns. . . . . . . . . 5t

Die Abgliederung und friiheste Gestaltung der Hemisphären . . . . . . . 5

Grenzsäume des Hemisphärenhims . . . . . . . 56

Riechhirn und Hemisplä̈renmantel . . . . . . . 54

Streifenhügel und Riechhirn in ihrengegenseitigen Bezielnugen. . . . . . .

Die Bildungder medialen llemisphä renwand. . . . . . Die Schlnfplatte. . . . . . lit Das Trapezfeld . . . . . . 66 Corpus chorioideum. . . . . 6i Der Hemisphïrenstiel . . . . tis Der Anschluf des streifenhügels an den Hrpothalamus . . 65

Dickenwachstum der Yorderhirnwand . . . . . . . . 69

Zur Kritiknormaler und postmortaler Furchen der Hemisphärenoberfläche . . T

Die Fissura prima . . . . 76 Das Trapezfeld, die Bogen- 
zone und der Limbus hemisphaericus . . . . . Limbus corticalis und medullaris, Taenia, Lamina chorioidea und infrachorioidea

Hintere und mittlereBogenfurche. . . . . . .

Die accessorische Bogenfurche : . . . . . . . 85

Fissura calcarina . . . . . 91

Die Schichten der Hemisplärenwand und deren histologisches Verhalten. . Siebschicht (Stratum eribrossumu). . . . . . . . .

Auftreten der Pyramidenzellen Verbalten der Hemisphärenwand in der Mitte des dritten Monats... . Eintretende Fasermassen . Gliageriist der Hemisphärenwand . . . . . . .

Zweite Hälfte des dritten Monats . . . . . . Erstes Auftreten einer Markschicht . . . . . . .

Die Hemisplärenwand im vierten Monat. . . .

Die Retziuss chen Wärzehen an der Oberfläche foetaler Grobhirnhemisphären Die Blutgefäße des Vorderhirns. Basalvene . . . . . . . . Primäre Hirnsichel. . . . . Tela chorioidea und Plexus chorioidei . . . . . . . Vordere Bogenvene . . . Commissura anterior und Balken. . . . . . . . Commissura anterior . . . Die Ausbildung von Koutaktflächen. Auftreten der Fornixsänlen und des lialkens.
Balkengebiet und Hippocampus (Übersicht) . . . . . . 128

Balkenanlage bei Foetus Ce von $8.3 \mathrm{~cm} \mathrm{Nl.} \mathrm{.} \mathrm{.} \mathrm{.} \mathrm{.} \mathrm{.} 129$

Lage der ersten Balkenfasem 135

Balkenanlage bei Foetus Pl von 12 em SSl. . . . . 136

Balkenknie . . . . . . . 142

Balkenwulst und Psalterium . 146

Literarische Bemerkungen zur Frage der Kommissurenbildung . . . . . 147

\section{Über intrameduilare Faserbahnen} und die Zeit ihres ersten Auftretens

Die Reihenfolge der Entwicklung intramedullarer Faserbabnen. . . . . Bemerkungen zu einzelnen Strällgen . . . . . . . 156

Fasciculns spinalis Trigemini und Fasciculus solitarins . 156

Das mediale Längsbiundel . . 157

Die Namillarbiundel . . . . 158

Nu. olfactorii und Stria olfactoriae mediales. . . . . 159

Commissura cervicalis . . . 160

Die Schleifen. . . . . . . 162

Der Thalamus und seine Verbindungen . . . . . 163

Stabkranz des Thalamms . . 163

Innere Kapsel . . . . . . 164

Das Mernert sehe Bündel (Fasciculus retroflexus) . . . 167

Die Stria meoullaris des Thalaums . . . . . . . 168

N. opticus und Chiasma . . 169

Cerebellum und Fasciculus restiformis . . . . . . 173

Bindearme. . . . . . . . 175

Basis pedunculi, Pyramidenbiindel und Querfaseru der Brücke . . . . . . . 175 


\section{Einleitung.}

Im Verlauf der $80 \mathrm{er}$ und im Beginn der $90 \mathrm{er}$ Jahre des vorigen Jahrhunderts habe ich eine Anzahl von Arbeiten ïber die Entwicklıng des Zentralnervensystems erscheinen lassen, teils rein morphologischer, teils histologischer Natur. Ich habe damals auch begonnen, die innere Gehirnorganisation in ilrer Entwicklung zu verfolgen. Nach Publikation eines Aufsatzes über das Rautenhirn habe ich indessen die beziigglichen Arbeiten unterbrochen, einesteils um noch mehr Material zu sammehn, vor allem aber deshalb, weil in jener Zeit eine besonders fruchtbare Periode auf dem Gebiet der Hirnanatomie angebrochen war. Flechsig, GOLGi, RAMON Y CAJAL, Kölliker, Retzius, Held, van Gehuchten, v. Lenhossek, Edinger u. a. Iehrten uns soviel tatsächlich Nenes kennen, daß es mir erwïnscht scheinen mußte, erst einen Abschluß der Forschungsperiode abzuwarten, um an die festgestellten neuen Ergebnisse meinerseits wieder ankniipfen zu kömnen. Ich wage nun im nachfolgenden den Versuch, die Arbeiten wieder da anzuknïpfen, wo ich sie s. Z. unterbrochen hatte. Noch ist mein Material im VerhäItnis zu den zu behandclnden Fragen recht sparsam, indessen lassen sich vielleicht doch gewisse Grundlagen damit gewinnen, auf denen in der Folge mit ansgiebigerem Material weiter gebant werden kam.

So dankbar, wie manche andere der neneren Forschungsmethoden, die Methoden ron Flecheig, Weigert, Golgi n. a., ist ja die rein entwicklungsgeschichtliche Methode, das Studium embryonaler Durchschnitte nicht. Die Arbeit muß aber gemacht werden, denn es zeigt sich anch hier, daß erst die Geschichte eines Organes runs das volle Verständnis für dessen inneren Aufbau gewährt. Aus der anfangs so einheitlich erscheinenden Markplatte sondern sich schrittweise die granen Massen und die Faserbahnen, von den einfachsten zu immer verwickelteren Gliederungen fortschreitend. Auf die Anlage eines Nerrensystems ohne Nerrenzellen und Nervenfasern folgt die eines Systems mit den ersten motorischen Elementen, dann treten aus unabhängigen Anlagen die zentripetal leitenden Bahnen auf, die Spinalganglien mit den sensiblen Wurzeln und die Bahnen der ins Zentralorgan einwachsenden Sinnesnerren. In sehr früher Zeit erscheinen aber auch die Vermittler intramedullärer Verbindungen, der Verbindungen von hinten nach vom, von unten nach oben, ron rechts nach links. Und 
während die das Zentralorgan verlassenden nud die in dasselbe eintretenden Bahnen in einer zeitlich sehr beschränkten frülen Periode sich anlegen, entwickeln sich die der imneren Verknüpfung zentraler Vorgänge dienenden unabsehbar lang weiter. So erscheint es z. B. mehr als zweifelhaft, ob zur Zeit der Geburt beim menschlichen Kinde die Bildung nener Bahnen (nener Neuronen, oder doch nener Kollateralen) in den Großhirnhemisphären endgiiltig abgeschlossen ist. Was aber einmal angelegt ist, das bleibt im allgemeinen bestehen. Das nen Hinzukommende lagert sich dem bereits Vorhandenen an, oder es schiebt sich zwischen dasselbe ein. Im ersteren Fall wird der Querschnitt durch die bezaigliche Gehirnprovinz, ähnlich einem geologischen Gebirg'squerschnitte, zur historischen Urkunde.

Die Riicksicht anf den Zusammenhang der Darstellung hat mich veranlaßt, besonders im ersten Teil dieser Arbeit mancherlei Wiederholung. früherer Arbeitsergebnisse zu bringen. Ich habe gesncht den betreffenden Abschnitten durch neue Abbildmgen einen originalen Charakter zu wahren, und zwar habe ich diesmal reichlichen Gebranch von der Wiedergabe von Photogrammen gemacht. Von den mitgeteilten Photogrammen habe ich einige wenige (z. B. Fig. 3 ur. 9) völlig überzeichnet, bei anderen hat entweder keine Retouche stattgefunden oder eine nur unwesentliche (Verstärken von zu blassen Linien oder Auswaschen ron Unreinigkeiten).

Die diesmal mitgeteilten Abschnitte bilden keine fortlanfende Reihe, ich teile mit, was mir mehr oder minder abgeschlossen vorliegt. Die fehlenden Zwischenkapitel hoffe ich, falls mir Leben und Arbeitskraft bleiben, in absehbarer Zeit nachliefern zı können.

Man wird in meiner Arbeit, wie ich von vornherein hervorhebe, eine nur ungenügende Berïcksichtigung der so unfangreichen Hirnliteratur finden, und ich gestehe dies gern als einen empfindlichen Mangel zu. Ein jeder gibt indessen, was er geben kann. Wir haben bekanntlich eine Reihe vorziiglicher, die Gesamtliteratur berïcksichtigender Werke und darunter auch solche, die von hervorragenden Hirnforschern heransgegeben sind. Mir ist die Gabe leichter Literaturbeherrschung nie verliehen gewesen, und ein alterndes Gehirn wird bekanntlich darin nicht besser. Anderseits hat sich bei mir im Laufe der Jahre allerlei Beobachtmg'smaterial aufgespeichert, das einer eingehenden Bearbeitung wert ist, und das ich auch andern zugänglich zu machen die Verpflichtung fühle. Ich gebe also, was ich bieten kann, d. h. was ich selber beobachtet und durchdacht habe. Selbstrerständlich werde ich, soweit wie möglich, Anschluß an die Hanptwerke der Hirnliteratur suchen.

\section{Methoden der Bearbeitung.}

Die wichtigste Grundlage meiner Ergebnisse bilden die Konstruktionsbilder von Embryonen. Über deren Herstellung labe ich mich vor Jahr- 
zehuten ausgesprochen. ${ }^{1}$ ) So hoch ich die Plattenmodellierung schätze und so reichlichen Gebranch ich sclber davon gemacht habe, so habe ich doch die Konstruktionsmethode nie eutbehren kömnen. Sie liefert schärfere Ergebnisse als die Plattenmodellierung und erlaulot es, jeden einzelnen Sclnitt an richtiger Stelle unterzubringen und in allen seinen Einzelleiten zn verstehen. Handelt es sich z. B. darum einen Schnitt heranszusuchen, der ein Organ genan senkrecht zu seiner Achse schneidet, oder zu wissen, in welcher Wirbelhöhe ein Organ liegt, oder wo cin Gefäß oder ein Nerv umbiegt und dergl. mehr. so gibt eine gute Konstruktion auf alle derartigen Fragen rasche und sichere Antwort. Ich betrachte daher seit langem eine Schnittreilie nur dann für allseitig branchbar, wenu ich sie in Profilund Frontalansichten durchgearbeitet habe.

An Stelle der mühsam und meist nur unvollkommen zı beschaffenden Prismenzeichnungen habe ich längst Photogramme von Schnittreihen verwendet, ïber deren Herstellung ich mich ja anch bei verschiedenen Gelegenheiten ansgesprochen habc. $\left.{ }^{2}\right)$ Nenerdings habe ich anstatt der direkten Aufnahme der Schnitte anf Bromsilberpapier den etwas bequemeren Weg eingeschlagen, die Schnitte je eines Objektträgers auf Platten ron mäßiger Größe $(13: 18 \mathrm{~cm})$ bei mäßiger Vergrößerung (4- oder 5 fach) aufzumehmen und diese vom Photographen entsprechend weiter vergrößern zu lassen. Es hat dies den Vorteil, daß man die Negative noch zu Projektions- oder anderen Zwecken verwerten kann. Ich darf indessen nicht verhehlen, daß ich bei den direkten Aufnahmen mit 10-15 facher Vergrößerung schärfere Bilder bekommen habe, als bei der fraktionierten VerọröBerung von $4 \times 2,5$ oder $3 \times 5$.

Über die Verwendung von lithographiertem Linienpapier zu Konstruktionen, sowie über die Möglichkeit, mit Hilfe des Proportionalzirkels die Konstruktionszeichnung in einem andern Maßstabe auszuführen, als dem der Photogramme, habe ich mich schon frïher geänßert.

In der vorliegenden Arbeit habe ich mich der Konstruktionsmethode auch bedient, um die Anordnung von Neuroblasten und von Faserzïgen in die Profil- oder Flächenzeichnung des Gehirns einzutragen. Ersteres ist nur für jüngere Stufen einigermaßen befriedigend durchzuführen. Sowie die Verhältnisse etwas verwickelter werden, hat man es meist mit schräg-oder längsgetroffenen Nenroblasten zu tun und gelangt nicht mehr zu unanfechtbaren Anschauungen, wogegen die mittlerweile entstandenen größeren Faserbahnen, hinteres Längsbündel, Schleife usw. nunmehr meistens klar rerfolgbar sind, besonders dann, wenn man ans derselben Entwicklnngsstufe verschiedene Embryonen teils in Quer- teils in Sagittalschnitten durcharbeitet und

1) 1880 ; Anatomie menschl. Embryonen I. S. 6 ff.

2) Zuletzt in der KöLLıKer gewidmeten Gratulationsschrift: „Der mikrophotographische Apparat der Leipziger Anatomie." 40. Leipzig 1892. F. C. W. Vogel. 
so die Ergebnisse der einen Konstruktion durch die einer anderen kontrolliert und ergänzt. Eine solche Kontrolle ist deshalb notwendig, weil sich nicht alle Schnittreihen für die Rekonstruktion gegebener Faserbahnen gleich giinstig erweisen. Abgesehen von Unterschieden der Konservierung und Färbung kommt dabei die Schnittrichtung in Betracht. Ein Faserzug, der längs- oder quergetroffen durch verschiedene Schnitte hindurch scharf sich hervorhebt, kann sich weiterhin bei schräger Streifung zwischen den Nachbargebilden mehr oder minder rerstecken.

Die Konstruktionsmethode mit Linienpapier und Zirkel hat den Nachteil, daß sie keine körperlichen Bilder gibt, sie zwingt dafuir sehr zum genanen Durchdenken der beziiglichen Formen. Senkrechte und horizontale Projektionen desselben Objektes kommen dabei selbstverständlich sehr zu Hilfe. Körperliche Bilder innerer Gehirnstrukturen lassen sich durch Anlegung von Glasmodellen erreichen. Über solche Glasmodelle habe ich in der oben zitierten Gratulationsschrift berichtet und beim Anatomenkongreß in Göttingen (1893) Muster davon vorgelegt. ${ }^{1}$ ) Weiterhin hat in meinem Laboratorium Francis Dixon mittels der Methode der Glasmodelle die Entwicklung der Trigeminusganglien verfolgt. ${ }^{2}$ ) Im Jahre 1899 hat Vosurater, der unsere früheren Versuche nicht gekannt hat, vorgeschlagen, durchsichtige Modelle aus Celloidinplatten herznstellen. ${ }^{3}$ ) Ich habe mir dies Material anch verschafft, bin aber davon nicht besonders befriedigt, da es in mehrfachen Schichten gelagert triib erscheint, und da sich iiberdies die Platten werfen. Die frïher von mir angewandte Technik der Herstellung von Glasmodellen, wobei ich auf zuvor gefirniste Platten zeichnete, hat sich übrigens auch als verbessermugsbedürftig erwiesen, da sich in Laufe der Jahre die Firnisschichten getrübt und die Modelle dadurch sehr gelitten haben. Neuerdings werden Glastinten in den Handel gebracht, mittels denen man auf unpräparierte Glasplatten zeichnen kann. ${ }^{+}$) Frisch hergestellt zeigen Glasmodelle eine wunderbare Plastik. Es eignen sich dazu besonders sagittale Schnittreihen, die zn Zirkelkonstruktionen sonst weniger günstig zu sein pflegen.

\section{Benutztes Material.}

Im nachfolgenden gebe ich eine Aufzählung der Embryonen und Fötus, deren Schnittreihen der nachfolgenden Arbeit zugrunde gelegen haben. Dabei

1) 1. c. S. 19 u. Verhandlungen der anatom. Gesellschaft, т. Versammhnng zı Göttingen 1893. S. 209.

2) Francis Dixon, On the development of the branches of the fifth cranial nerve in man. Transactions of the Royal Dublin Society, Vol. VI Serie II 1896 S. 22 ff.

$\left.{ }^{2}\right)$ Vosmatr, Eine einfache Modifikation zur Herstelhng von Plattendiagrammen. Anatom. Anzeiger 1899 Bd. XVIII S. 269 ff.

4) Von den bis jetzt versuchten Glastinten scheint mir die Sorte "Pelikan“ von Günther \& Wagner in Hannover die guinstigsten Ergebnisse zn liefern; ob sie haltbar ist, muß die Zeit ergeben. 
sind einigé erläuternde Bemerkungen vorauszuschicken. Gemäß den in früheren Arbeiten gemachten Angaben ${ }^{1}$ ) habe ich bei Embryonen der vierten bis siebenten Woche die längste, von dem Beckenende zur Gegend über der Nackenkriimmung zu ziehende Linie, die sog. Nackenlinie, (Nl) als nützlichstes Maß befunden und vorzugsweise benutzt. Wenn dann in der zweiten Hälfte des zweiten Monats der Kopf mehr und mehr sich hebt, wird die Bestimmung des oberen Endpunktes dieser Linie unsicher, und nun läßt sich zweckmäßigerweise eine Linie messen, die die untere Beckenwölbung mit dem höchstgelegenen Teil des Scheitels verbindet, die sog. Scheitelsteißlänge (SSl). Das Maß kann bis zur Zeit der Geburt genommen werden. Immerhin ist es nicht unbedingt zurerlässig. Wird der Kopf etwas mehr gehoben oder gesenkt, so kann dies, besonders in späteren Stufen, einen nicht unerheblichen Unterschied in der Länge des Maßes ausmachen. Als ein nützliches und im allgemeinen recht zurerlässiges Kontrollmaß habe ich seit langem die Kopftiefe (Kt) mitbenutzt, die von der Mitte des zweiten Monats ab mit der Kopfhöhe (Kinn bis Scheitel) annähernd gleichwertig zu sein pflegt. Dies Maß (Kt) habe ich schon bei jüngeren Frïchten brauchbar befunden. Unzuverlässig wird es nur bei starker Erweichung des Gehirns oder bei gequetschten Präparaten. Ein mißlicher Umstand bei allen Messungen liegt darin, daß wir häufig genug die Früchte nicht frisch, sondern in Alkohol oder sonstwie aufbewahrt bekommen. Solche Vorbehandlung ändert die Maße mehr oder minder erheblich, und so sind auch die Maßangaben meiner Tabellen immer nur annäherungsweise unter sich rergleichbar. $\left.{ }^{*}\right)$ Dazı kommt noch der keinesweg's zu unterschätzende Betrag individueller Schwankungen.

Noch unsicherer als mit den Messungen steht es mit den Altersbestimmungen der Friichte. In meiner Anatomie menschlicher Embryonen habe ich s. Z. für einige Embryonen der ersten zwei Monate, für die mir die Daten der Ananmese vorlagen, solche Bestimmungen aufzustellen gesucht. Es stellte sich dabei heraus, daß man bei einer größeren Zahl ron Früchten das Alter auf die erste ausgebliebene, bei anderen aber auf die zuletzt stattgehabte Periode zu berechnen hat. Aus späterer Zeit besitze ich nur sehr vereinzelte Stïcke mit anamnestischen Angaben. Es liegt nun nahe, sich an die Altersbestimmungen anderer Autoren zu halten, deren wir schon von Sömmering, von E. H. WEBER, von ARNOLD und weiterhin ron EckER,

1) Anatomie menschl. Embryonen II. S. 5 ff.

2) Die Behandlung der Embryonen mit Fixationsmitteln und weiterhin ihre Aufbewahrung in Alkohol führen zu ziemlich bedeutenden Schrumpfungen. Um ein Beispiel anzuführen, so maß bei einem frisch dem Uterns entnommenen Embryo die N1. $18 \mathrm{~mm}$, bei dem fixierten und in Alkohol aufbewahrten nur noch $15 \mathrm{~mm}$. Noch weitergehende Schrumpfungen bedingt bekanntlich das Einschließen in Paraffin. Vorläufig wird es auch kaum möglich sein, feste Schrumpfungskoeffizienten aufzustellen. Solche wïrden wohl nur anf Grund systematischer Versuchsreihen erhältlich sein. 


\begin{tabular}{|c|c|c|c|c|c|}
\hline Bezeichnung & Nl. & SSI. & Kt. & Alter & $\begin{array}{l}\text { Schnitt- } \\
\text { richtung }\end{array}$ \\
\hline $\mathrm{EB}$ & - & 3.1 & 0.9 & 2 Wochen & quer \\
\hline $\left.\operatorname{Lr}^{1}\right)$ & - & 4.2 & 1.05 & & " \\
\hline $\mathrm{Mi}$ & 3.2 & - & 1.5 & & $"$ \\
\hline$\Leftrightarrow$ & 4 & - & 1.7 & 3 Wochen & , \\
\hline $\mathrm{Bl}$ & 4.25 & - & $1 . \overline{7}$ & & , \\
\hline Oc & 4.4 & - & 1.5 & & $"$ \\
\hline $\mathrm{R}$ & 5 & - & 1.9 & 4. Woche & $"$ \\
\hline $\mathrm{T}$ & $6.5(?)$ & - & 3.2 & I & $"$ \\
\hline $\mathrm{Br}_{3}$ & 6.9 & - & 3.4 & 4 Wochen & $"$ \\
\hline B & 7 & - & 2.9 & $"$ & 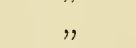 \\
\hline Hoe & 7 & - & 3.2 & $"$ & $"$ \\
\hline A & 7.5 & - & 2.9 & $\eta$ & $"$ \\
\hline $\mathrm{Dl}$ & $8.5(?)$ & - & - & $"$ & $"$ \\
\hline Ru & 9.1 & - & 4.8 & Anfang der & $"$ \\
\hline $\operatorname{Pr}$ & 10 & - & 4.4 & 5. Woche & , \\
\hline Ko & 10.2 & - & $4.8(?)$ & & \\
\hline $\operatorname{Rg}$ & 11 & - & 5 & & $"$ \\
\hline $\mathrm{Ha}$ & 10.5 & - & $6.3(?)$ & I Gegen Ende & $"$ \\
\hline $\mathrm{N}$ & 10.9 & - & 6.25 & f der 5. Woche & $"$ \\
\hline$S_{1}$ & 12.5 & - & 6.4 & & $"$ \\
\hline $\mathrm{CR}$ & 13.6 & - & 7.8 & Anfang der & $"$ \\
\hline Sch & 13.8 & - & 7.6 & 6. Woche & $"$ \\
\hline $\mathrm{Hg}$ & 14 & - & 8.4 & & $"$ \\
\hline Fo & 15.6 & - & 7.2 & 6 Wochen & $"$ \\
\hline $\mathrm{Ob}$ & 15.5 & - & 8.8 & & sagittal \\
\hline Wi & 15.7 & - & S.4 & & ", \\
\hline $\mathrm{Se}$ & 16 & - & - & & quer \\
\hline So & 17 & - & 8.6 & & $"$ \\
\hline $\mathrm{Bu}$ & 17 & - & 9 & & $"$ \\
\hline Bo & 17.5 & - & - & & , \\
\hline FUI & 17.8 & -- & 10.4 & 7 Wochen & sagittal \\
\hline Lhs & 17 & - & 8.75 & $\frac{\overline{i \text { Wochen }}}{2 \text { Tage }}$ & quer \\
\hline $\mathrm{Zw}$ & 18.5 & - & 11.2 & & $"$ \\
\hline Мy & 19 (?) & - & - & & $"$ \\
\hline
\end{tabular}

1) Bei den beiden ersten Embryonen der Tabelle EB und Lr habe ich das Längenmaß noch als SSl. eingetragen. Bei Lr ist eine Nackenkrïmmnng noch kanm angedentet, und anch bei $\mathrm{EB}$ beträgt die meßbare längste Limie erheblich mehr als. der Nl. zulkommt. Dagegen zeigen Mi und besonders a eine starke Zusammenkrümmung des Körpers. 


\begin{tabular}{|c|c|c|c|c|c|}
\hline Bezeichnung & N1. & ssi. & Kt. & AIter & $\begin{array}{l}\text { Schnitt- } \\
\text { richtung }\end{array}$ \\
\hline Dd & $20(?)$ & - & - & & quer \\
\hline $\mathrm{Mr}$ & 22 & 29 & 11.5 & 8 Wochen & $"$ \\
\hline $\mathrm{Wt}$ & - & $2 S$ & 13.7 & & sagittal \\
\hline Lo & - & 29 & 14 & & quer \\
\hline $\mathrm{Bg}$ & - & 30 & 16 & & sagittal \\
\hline $\mathrm{Cl}$ & - & $31(?)$ & $16(?)$ & & $"$ \\
\hline Re & - & 31 & 17 & & quer \\
\hline No & - & - & $1 \mathrm{~s}$ & & sagittal \\
\hline$O e$ & - & 42 & 20 & 11 Wochen & quer \\
\hline Stg & - & 46 & 20 & & ", \\
\hline Doed & - & $\left.50^{1}\right)$ & 20 & & $"$ \\
\hline Mordell & - & 50 & 20 & & $\begin{array}{c}\text { Modelle Ziegler } \\
\text { No. } 6 \text { bis S }\end{array}$ \\
\hline $\mathrm{Bi}$ & - & 53 & 22 & & $\begin{array}{c}\text { gezeichnet } \\
\text { Figg. } 9,46,4 \overline{7} \text {, } \\
53,54\end{array}$ \\
\hline $\mathrm{Ma}$ & - & 56 & 24 & & quer \\
\hline $\mathrm{Cr}$ & - & 60 & 25 & & , \\
\hline $\mathrm{Pi}$ & - & $60(?)$ & $25(?)$ & & $"$ \\
\hline $\mathrm{Ce}$ & - & $\$ 3$ & $33(?)$ & 4. Monat & , \\
\hline $\mathrm{Z}$ & - & 90 & 35 & & $\begin{array}{l}\text { Zeichmung } \\
\text { Fig. } 48\end{array}$ \\
\hline $\mathrm{Pl}$ & - & 120 & $50(?)$ & $\begin{array}{l}\text { Ende des } \\
\text { 4. Monats }\end{array}$ & quer \\
\hline $\mathrm{CP}$ & - & 160 & 60 & $\begin{array}{l}\text { Mitte des } \\
\text { 5. Monats }\end{array}$ & " \\
\hline
\end{tabular}

Nl. Nackenlänge, SSl. Scheitelsteißlänge, Kt. Kopftiefe der Embryonen und Foetus. Die unterstrichenen Zeitwerte sind nach der zuletzt stattgehabten oder der zuerst ansgebliebenen Periode berechnet. Die iibrigen Werte beruhen auf Schätzungen. Hinsichtlich der Schnittrichtungen unterscheide ich nur zwischen quer und sagittal und fasse unter ersterer Bezeichnung alle Schnittrichtungen zusammen, die senkrecht zur Mittelebene geführt sind, also anch Frontal- und Schrägschnitte. Bei der Krïmmung der Embrỵonen läßt sich ja ïberhaupt eine andere Unterscheidnug nicht machen. Maße in mm. Da, wo hinter den Zahlen Fragezeichen stehen, beruhen sie auf Schätzung. Die in frïheren Arbeiten besprochenen jüngeren Stufen Lg, Rf, BB и. a. habe ich in die Tabelle nicht mit aufgenommen.

1) In meinem Anfsatz iiber Nasen- und Gaumenbildung (Abh. der Königl. sächs. Ges. d. Wiss., Math.-phys. KI. Bd. XxVIII, III S. 353) habe ich die Ssl. ron Foetus Doed. z11 $46 \mathrm{~mm}$ angegeben. Es liegt, wie ich nachträglich gefunden habe, eine Verwechshung mit einer anderen Aufzeichnung vor. Die SSl. betrug am frischen Präparat $50 \mathrm{~mm}$. 
KöLLIKER, TOLDT ${ }^{1}$ ) n. a. besitzen. Dabei stößt man aber zunächst anf die Schwierigkeit verschiedener Meßlinien. AnNoLd mißt die Scheitelsteißlänge, TOLDT die Fersenscheitellänge, KöLlIKER, der das letztere Maß mit Recht als unsicher verwirft, mißt die „Rumpflänge“, womit aber anscheinend anch die Scheitelsteißlänge gemeint ist. Die Figuren von SömmeRING sind in natürlicher Größe wiedergegeben und sie eignen sich somit zu genanen Nachmessungen. Ecker (Archiv f. Anthropol. Bd. III S. 205 ff.) gibt Körperlängen an ohne Angabe der Endpunkte der Messung, ebenso v. Mihalkovics (Entw. d. Gehirns 1877 S. 158). E. H. Weber, auf den sich ECKER bezieht, hebt ansdriicklich hervor, daß die Altersangaben der Antoren bloß Schätzungen sind und fügt bei, daß man sich gewöhnlich an Vergleichnng mit den Abbildungen von Sömmering halte. Bei keinem der Autoren finden sich aber die Unterlagen verzeichnet, auf denen ihre Altersschätzungen beruhen. Nach meinem Dafürhalten ist es ein dringendes Bedürfnis, daß an einer größeren gynäkologischen Anstalt systematische Messungen aller Friihgeburten vorgenommen und zu den Daten der Anamnese in Beziehung gebracht werden.

\section{Die Entwicklung des Zentralnervensystems bis zum Schluß des ersten Monats.}

\section{Grundform des Wirbeltierhirns und jüngste menschliche Gehirnformen.}

Das Gehirn aller kranioten Wirbeltiere stellt sich anf frïhen Stufen der Entwicklung als ein gekrïmmtes Rohr dar, das sich in bekannter Weise in die drei Hanptabschnitte: Vorderhirn, Mittelhirn und Rautenhirn gliedert. Die basale Achse des Rohres trifft in der Area remiens mit dem Ende des Vorderdarmes und dem der Chorda zusammen (Fig. 1, S. 9). Diese Verbindung löst sich indessen frühzeitig, und indem sich zunächst das blinde

1) S. Th. Sömmering, Icones embryonum hnmanorum. Frankfurt a/M. 1799. Fr. Arnold, Handbuch d. Anatomie d. Nenschen. Freiburg i/B. 1851. Bd. II S. 1210. E. H. Weber in der Anatomie von Hildebrandt, Bd. IV S. 22. - A. Kölliker, Grundriß der Entwicklungsgeschichte des Menschen usw. Leipzig 18s4 S. 150. C. ToLDt, Über die Altersbestimmung menschlicher Embryonen. Prager medizinische Wochenschrift 1879. Sep.-Abz. 


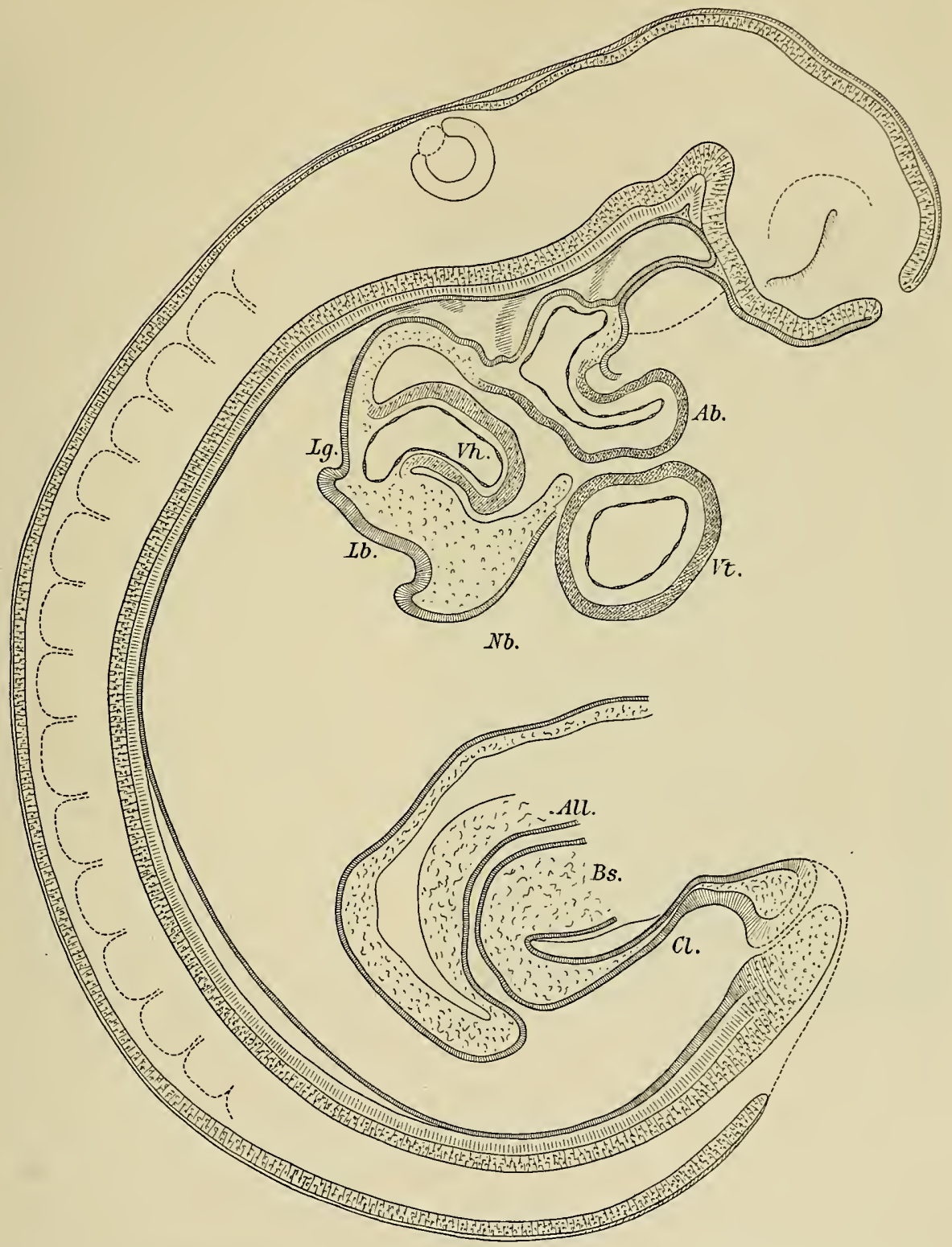

Fig. 1. Mittelsehnitt des Enbryo EB (L. $3.2 \mathrm{~mm}$ ) nach den Schnittphotogranmen konstruiert. Vergr. 60 fach. $\mathrm{In}_{\mathrm{r}}^{\mathrm{r}}$ der Area reuniens treffen das Ende der Chorda, das des Vorderdarmes, die basale Hirnachse und die noch undurchbrochene Rachenhaut zusammen. Die Chorda liegt dem Medullarrohr nuch allenthalben an. In Vorderhirn findet sich noch ein offener Neuroporus. Im übrigen sind die Hauptabteilungen des Gehimrohresi bereits erkennbar. Der Zugang zur Augenblase ist noch ein hoher schlitz. I)er Ort der schlundtascheri ist durch Schraffierung angegeben.

$$
\begin{aligned}
& A b .=\text { Aortenbulbus } \\
& \text { Cl. = Cloake } \\
& \mathrm{Nb} .=\text { Nabelblase } \\
& \text { All. = Allantoisgang } \\
& L b .=\text { Leberanlage } \\
& \text { 1\%. = Herzrorhof } \\
& \text { Bs. = Bauchstiel } \\
& L g .=\text { Lungenanlage } \\
& \text { It. }=\text { Herzrentrikel. }
\end{aligned}
$$


Vorderdarmende (die SEEssel sehe Tasche) von der Gehimbasis zuriickzieht, entsteht zwischen beiden ein Raum, in den von der Mundbucht ans die Hypophỵsentasche sich eindräng.t. $\left.{ }^{1}\right)$ Die Anfänge der Gehirngliederung nud insbesondere die breiten Ausladungen der Angenblasenanlagen machen sich an der Medullarplatte schon geltend, bevor noeh deren Ränder zum Rohr zusammengetreten sind. $\stackrel{2}{)}$

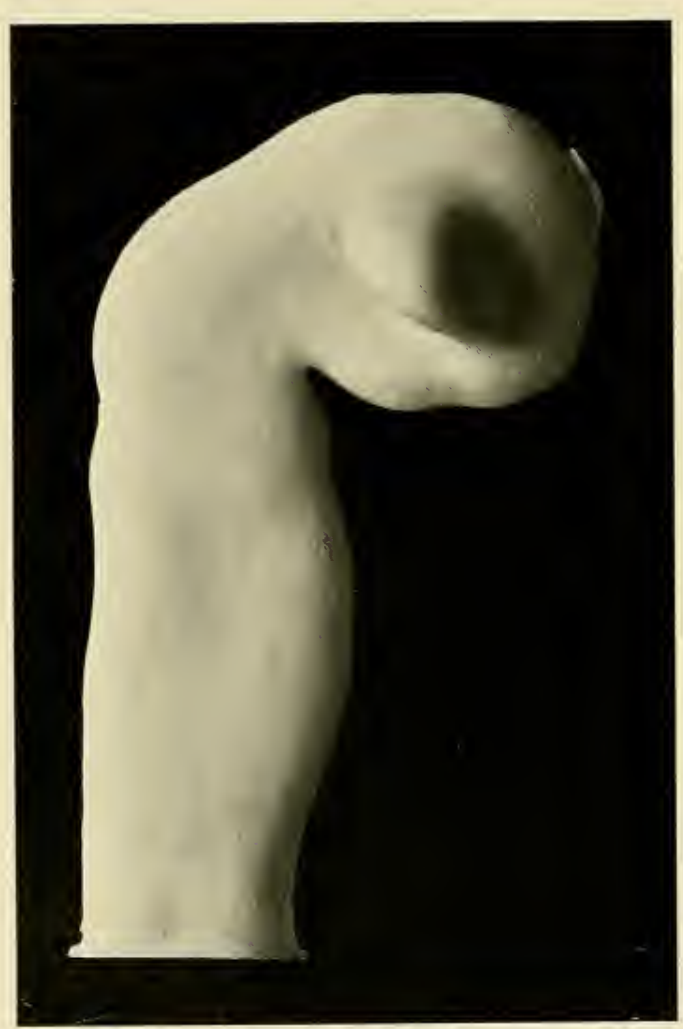

Fig. 2. Modell des Gehirns rom Embryo EB, ron der Seite her gesehen. Die Hemisphärengrenze ist bereits erkemnbar. Die stelle des Neuroporus ist dureh den ektodermalen I'mschlagsrant bezeichnet.

Ton menschlichen Gehirnen bald mach erfolgtem Schlub habe ich in der Anatomie menschlicher Embryonen (Taf. IX, Fig. 6 bis 10 und Fig. 12, Lg, BB, Rf) einige Konstruktionsbilder mitgeteilt. Seit jener Zeit habe ich (1S94) den rorzüglich erhaltenen Embryo EB (3.2 1 mm lang) aus der Leiche einer, vierzehn Tage nach ansgebliebener Periode suizidierten Fran bearbeiten kömnen. Dessen Gehirn ist nach den photograplierten Schnitten bei 100 facher VergröBerung als Plattenmodell hergestellt worden (Fig. 2). Es erscheintabseschen von den Augen, blasen, in seinen rerschiedenen Strecken seitlich abgeflacht, durehweg höher als breit und ist bis anf eine enge, im $\mathrm{Vor}^{-}$ derhirn befindliche Öffnung geschlossen. Die beiden $\mathrm{Ab}$ sehnitte des zweischenkligen Rohres bilden miteinander einen nahezu rechten Winkel. Der Grund der Sattelspalte schneidet tief in die Basis des die beiden Schenkel rerbindenden Mittelhirns ein. Noch ist das Rautenhirn erheblich länger als das Vorderhiru. Läings der Mittelachse des Konstruktionsbildes gemessen fallen auf das

1) Zn rergl. meine älteren Aufsätze: „Zur allgeneinen Morphologie des Gehirus“, His u. Bratxes Archiv 1 992 S. 346 ff. und "Über die Vorstufen der Gehirn- nud Kopfbildme bei Wirbeltieren", ebeudas. 1994 S. $313 \mathrm{ff}$.

-) Für den menschlichen Embryo erlïntert dies das von Fr. Ziegcler in den Handel gebrachte Modell von Etrixon (Anat. Anz. 1599 Bd. XYI S. $134 \mathrm{ff}$.). 




Die Angenblase luängt zur Zeit mit dem Vorderhirn noch jederseits durch einen hoch hinaufreichenden Stiel zusammen, ist aber bereits etwas nach hinten iibergelagert. Vom Hemisphürengebiete sondert sie sich durch eine seichte, rostralwärts breit anslaufende Furche. An der Basis leeginnt die Hemisphärenanlage schmal, scheitelwärts länft sie mit gerundeter Anschwellung aus. Die Basis bis zur Höhe des Neuroporus entspricht dem späteren Rhinencephalon, die obere Anschwellung dem späteren Pallium. ${ }^{1}$ ) Die die Hemisphärenanlage an der Außenfläche begrenzende Furche veranlaßt innen eine niedrige, rostralwärts breit auslaufende Emporwölbung der Wand, die Anlage des Streifenhügels. Auf diese Verhältnisse, sowie auf die weitere Formentwicklung des Gesamthirns werde ich später zuriickkommen und ich wende mich zur histologischen Besprechung des frühembryonalen Markrohres.

\section{Das Markrohr und seine histologische Entwicklung.}

\section{Das Markgeriist.}

Über die histologische Gliederung des Narkrohres habe ich mich bei frühern Gelegenheiten wiederholt ansgesprochen. ${ }^{2}$ ) Sie beginnt mit der Bildung des ron Liickenräumen allseitig durchzogenen II arkgeriistes oder If yelospongin ms, das seinerseits ans der urspriinglich rorhandenen undurehbrochenen Epithelplatte herrorgeht. Die Elemente des Markgerüstes, die Spongioblasten, rerteilen sich anf jüngeren Stufen durch den Raum

1) Die Sonderung des Hemisphïrengebietes rom ïbrigen Vorderhirn ist schon in sehr früher Zeit. d. h. sobald die Augenblasen als selbständige Wülste herrortreten, möglich. Demgegeniiber findet sich in Monographien und in Lehrbuichern vielverbreitet die Lehre, daß das Hemisphärenhirn ein sekundär entstehender Auswuchs des primüreu Torderhirns, daß es, wie r. Minalkorics (Entw. d. Gehims 1si7 S. 34) sich ausdrïckt, keine mit den ïbrigen Gehirnbläschen homologe Bildung sei. Noch weiter geht RAuber, der das Endhirn geradezu als einen ..Auswuchs des Zwischenhirns" bezeichnet (Lehrbuch 6. Aufl. II 941). Diese Darstellungsweise gibt leicht Anlaf zu Mifrerständnissen und ist daher zu verlassen.

2) Von meinen älteren Arbeiten zitiere ich die ron $1 \varsigma s 3$., L̈ber das Auftreten der weifen Substanz und der Wurzelfasern", HIs u. Bracses Archiv $19 \varsigma 3$ S. 165 und ..Zur Geschichte des Riickenmarks", 1ss6, Abhandl, der k. s. Ges. der Wissensch. math.-phỵs. Kl. Bd. XIII S. 455 und „Die Neuroblasten und deren Entstehung ete.". 15s9: ebendas. Bd. XV S. $313 \mathrm{ff}$. 
der Platte derart, daß ihre Kerne beiderseits bis nahe an deren Grenze heranreichen, anch sind sie zu der Zeit noch nicht scharf orientiert. Immerhin stehen die Kerne schon jetzt vorwiegend radiär und auch die Plasmabälkchen verlanfen, besonders im inneren Abschnitte, meistens senkrecht zur Oberfläche. Sowohl an der innern wie an der äußern Oberfläche der Platte fließen die Plasmabalken zu einer fortlanfenden Schicht, der M. limitans interna und M. limitans externa zusammen (Fig. 3). Von der vierten

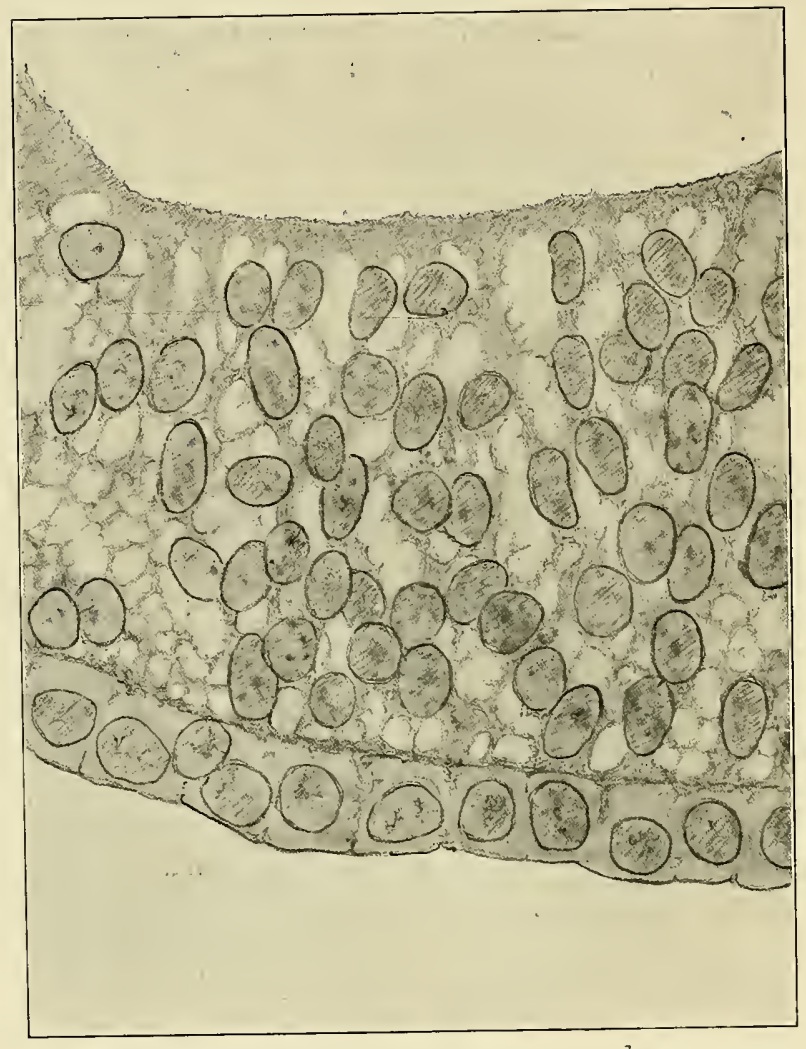

Fig. 3. Markgerüst vom Embryo EB mit den beiden Mm. limitantes. An die M. limitans externa stößst das epitheliale Hornblatt. Die meisten Kerne sind noch rundich oval, eine Schichtentrennung ist noch kaum eingeleitet. Überzeichnetes Photogramm.
Woche ab tritt im Markgeriist die Schich: tengliederung schärfer hervor. Die Kerne sammeln sich in einer breiten Mittelzone, welche nach einwärts und nach answärts von kernlosen bez. keruarmen Zonen iiberragt wird. Sie liegen innerhalb dieser Zone dicht gedräıgt, an dichtesten im innern Abschnitte, und hier treten anch am schärfsten ihre gestreckten Formen und ilıre radiäre Anordnung zutage (Fig. 4, S. 13). Vielfach zeigen sie Birnenform mit einwärts gerichteter Zuspitzung. Der innere T'eil der zugehörigen Zellenleiber geht in je einen, mehr oder minder schmalen, längsstreifigen Pfeiler über, der mit trompetenartiger Verbreiterung in die M. limitans interna sich einfügt. Demgemäß erscheint die an die imnere Grenzhaut anstoßende Schicht des Markgeriistes (die Columnar- oder Sänlenschicht) ron einem System paralleler, senkrecht zur Oberfläche stehender Spalten durchsetzt.

Der äußere Abschnitt der Kermzone zeigt die Kerne etwas minder dicht und auch weniger scharf orientiert gelagert. An ihn sehließt sich ein engmasehiges kernfreies Plasnianetz an, der R andschleier (Fig. 5, S. 14). Die Maschen sind im allgemcinen rundlich und enger als die Durchmesser 
der Kerne. Ich habe dies Masehenwerk von Anfang ab für ein geschlossenes gehalten, in dem Simn, daß die benachbarten Spongioblasten untereinander in synevtiale Verbindming treten. Dagegen ist eingewendet worden, daß Silberpräparate das ans den Epithelzellen hervorgehende Gerïst mit frei

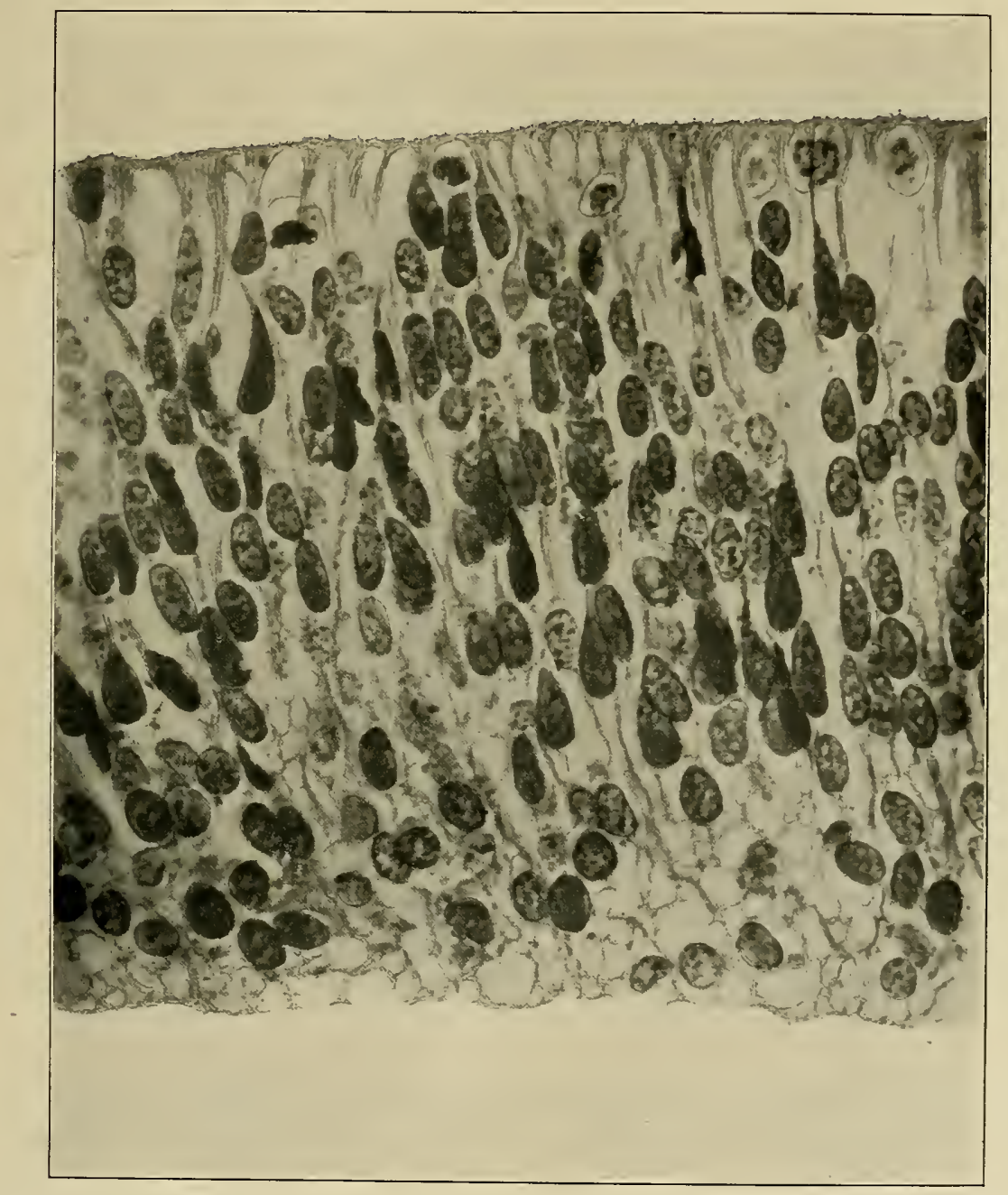

Fig. 4. Rückenmarksgerïst eines Embryos aus der vierten Woche (Pt.). Der Schnitt zeigt die M. limitans interna und die in sie eintretenden Spongioblastenpfeiler, zahlreiche spongioblastenkerne und nach auben hin die Anfänge eines Randschleiers. Neuroblasten sind keine rorhanden, dagegen erkennt man einige Keimzellen (Photogramm ein wenig retuschiert). (Zn Seite 12.)

auslaufenden Stiimpfen zeigen. Ich lasse es dahingestellt, ob dies Verhalten als rorïbergehendes auftritt; der bleibenden Anordnung entspricht es, meiner Überzengung zufolge nicht, die Plasmabälkchen treten in der Tat zu einem allseitigen Maschenwerk zusammen, und anch das Vorhandensein der Grenz- 
häute beweist das Zustandekommen von Verbindungen zwischen Bestandteilen verschiedener Zellenterritorien. ${ }^{1}$ )

Die M. limitans externa vermisse ich bei manchem meiner Schnitte, und das Markgeriist erscheint hier nach außen hin offen und ron einem klaffenden Spaltraum umgeben. Es handelt sich dabei wohl stets um eine durch die Präparation bedingte Losreißung der äußern Grenzschicht vom übrigen Markgeriist. Losgerissene Reste vom Randschleier finden sich häufig. der Mesenchymwand anhaftend. Bei den jüngeren Stufen habe ich die Limitans externa nie vermißt. ${ }^{2}$ ) Da wo die Schicht an mesenchymatöses Ge-

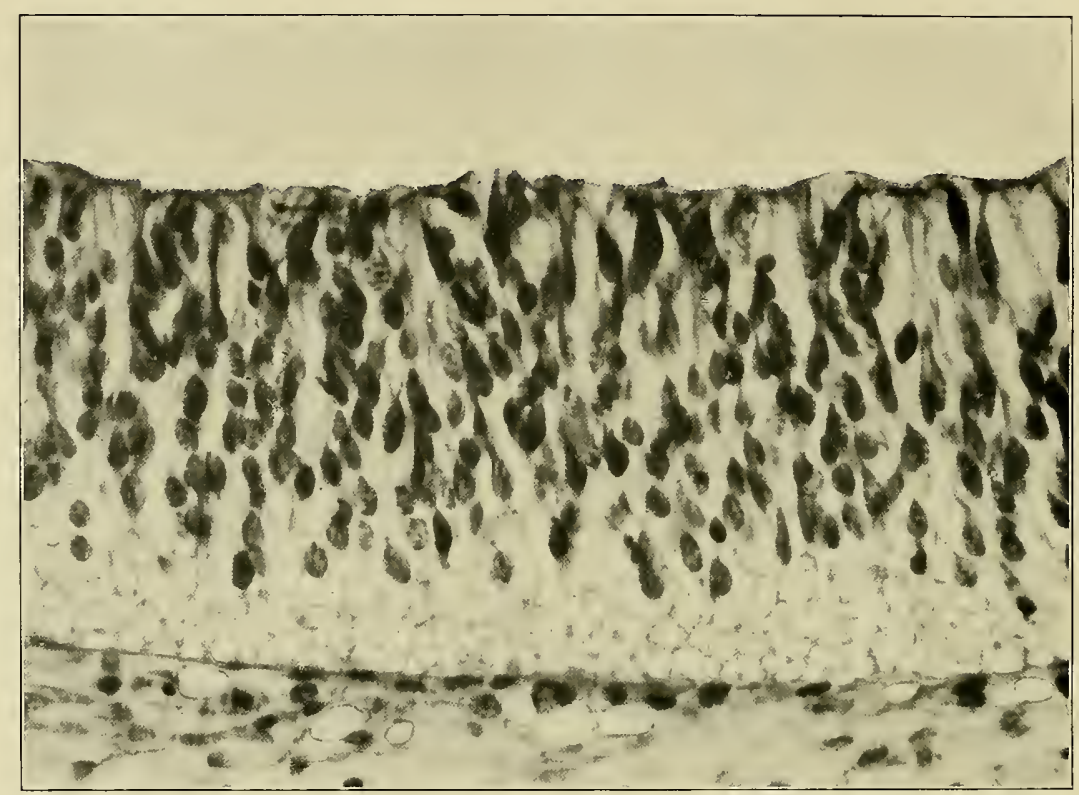

Fig. 5. Markgerïst aus der Hemisphärenwand rom Embryo N (N1. 10.9). Das Präparat zeigt den von eingelagerten Nervenzellen und Fasern freien Randschleier dicht bis an die Limitans meningea heranreichend. (Zu Seite 12.)

webe anstößt, verdichtet sich dieses zul einer dïmnen Haut, der MI. limitans meningea, unter der in der Folge reiche Kapillarnetze anftreten.

1) KöLliker, Gewebelehre 6. Aufl. 1596 II 137 spricht sich in der Hinsicht vorsichtig ans. Er hebt zwar hervor, daß GoLgische Präparate keine Spur ron Verschmelzung der Ependymfasern zeigen, meint aber, es bleibe dahingestellt, welche Behandlungsweise der Präparate mehr Vertrauen verdiene. Bei der Spezialbeschreibung eines fünfwöchentlichen menschlichen Embryo (S. 133) schildert KöLLIKER die Neuroglia der weißen Substanz als "ein zierliches feinstes Gitterwerk".

2) Über das konstante Vorkommen und die Rolle der M. limitans externa rergleiche man den Aufsatz von Hewd: „Über den Bau der Neuroglia“, Abl. der k. s. Ges. der Wissensch. math.-phys. Kl. 1903 Bd. XXVIII S. $201 \mathrm{ff.}$ 
Die M. limitans interna finde ich im allgemeinen nicht grlatt, sondern etwas rauh abgesehlossen. Auf jüngern Stufen begegne ich iilserdies unregelmäßig gestalteten, nach einwärts iiber die Hant hervorragenden Protoplasmafortsätzen. Selbst kernhaltige Keimzellen können stellenweise an der Innenseite der Limitans liegen. Solehe innere Protoplasmafortsätze finde ich anch an Sehnitten frisch eingelegter tieriseher Embryonen (Katze, Kaninchen). Ob sie eine physiologisehe Bedentung haben, oder ob sie im Moment des Absterbens und unter dem Einfluß des Fixationsmittels herrorgetreten sind, das bedarf noch genaner Priifung. - Die innere Grenzhaut zeigt sich in der Flächenansicht aus mehr oder minder unvollkommen geschlossenen Ringen gebildet (Fig. 6). Die von den Ringen umgebenen Felder sind ron Doppellinien ein-. gefaßt, im iibrigen aber leer. Es zeigt dies, daß das in den Spongioblastenleibern sich sondernde

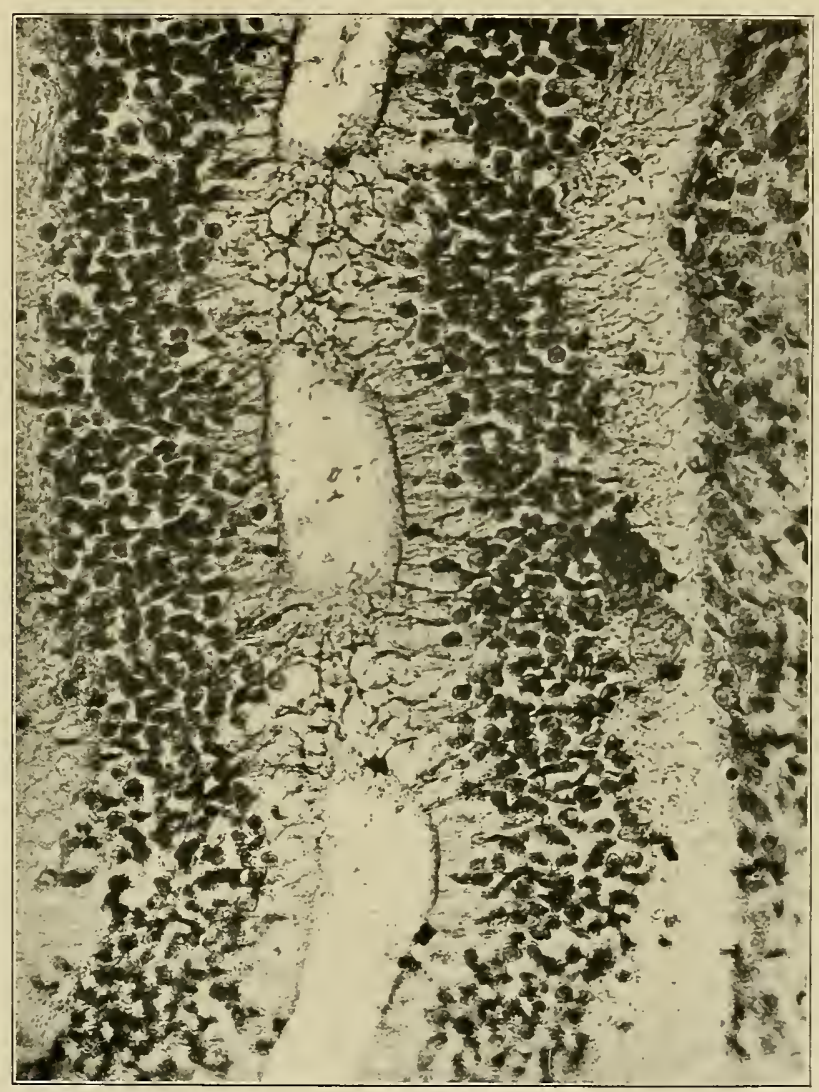

Fig. 6. Streifschnitt durch die innere Wand des Markrohres rom EmbryoT. An zwei Stellen ist die M. limitans interna als gefelderte Bildung zu sehen.

Faserwerk unmittel-

bar unter deren Oberfläche sich anlegt. Dasselbe Verhalten läßt sich auch für die Gerïstbildnng im Anßenteil der Spongioblasten erschließen.

Das Markgeriist des Rückenmarks und des Gehirns ist ursprïnglieh ron Nerrenzellen und Nervenfasern frei, die Einlagerung erfolgt sehrittweise und, da die Entwicklung der Nerrenzellen nicht allenthalben gleichzeitig ror sich geht, so zeigen-gewisse Bezirke ein leeres Markgerïst, wenn andere schon reich an Zellen und Fasern sind. So finde ich bei Embryo $\mathrm{X}$, bei dem das Riiekenmark und das verlängerte Mark sehon weit fortgesehritten sind, das Markgeruist der Hemisphären zierlich angelegt, aber noch völlig inhaltsleer (Fig. 5). 
Das so früh sich ausbildende Markgerüst erhält sich als bleibender Bestandteil der späteren Neuroglia. Die Glia enthält aber melır, als das primäre Markgerüst: Z $\mathrm{n}$ den radiär angeordneten Spongioblasten, die aus den anfangs vorhandenen Epithelien hervorgegangen sind, kommen in der Folge als neue Bildungen die Deiters schen Sternzellen hinzu und die von Weigert so eingehend bearbeiteten Fasersysteme. Auf gewisse Beobachtungen gestiitzt, hatte ich frïherhin angenommen, daß, außer den ins Mark hineinwachsenden Blutgefäßen noch anderweitige mesodermale Elemente einwandem und an der Bildung der späteren Glia teilnehmen, speziell glaubte ich die Deitersschen Zellen als Bindesubstanzzellen denten zu müssen. Dagegen haben sich Ramon y CAJAL, Kölliker, Retzius, LenhosseK n. a. ausgesprochen, and ich habe in der Folge, auf Grund meiner erweiterten Erfahrungen die Annahme aufgegeben. Ich halte jetzt gleichfalls dafür, daß die säntlichen Zellen des Gliagerüstes aus Elementen der ursprïnglichen Markplatte hervorgegangen sind. Die Deitersschen Sternzellen fügen sich als spätere Bildungen dem primären Markgerïst ein, dessen ursprtinglichen Charakter sie mehr oder minder anffällig verändern. In betreff der WeIGERTschen Fasern verweise ich auf die oben zitierte Arbeit von HELD, der dargetan hat, daß sie durch eine Differenzicrung innerhalb des protoplasmatischen Zellengeriistes entstehen.

Als die verschiedenen Entwicklungsstufen der Neuroglia haben wir somit:

1) das primäre Spongioblastengèrüst mit ausgeprägt radiärer Anordnung seiner Bestandteile;

2) das sekundäre, dureh DeITERs sche Zellen erweiterte Markgerüst, dessen Maschengefüge in den verschiedenen Bezirken von Gehirn und Rückenmark cin wechselndes zu sein pflegt;

3) die voll ausgebildete Neurogli a mit Weigert schen Fasern.

Von welchem Zeitpunkt ab man von differenzierten WEIGERT schen Fasern reden darf, mag hier unerörtert bleiben. Dagegen ist zu betonen, daß wenn man der Neuroglia die Bedeutung eines Stützgeriistes zuschreibt, diese Leistung zunächst den WEIGERT schen Fasern und den Grenzhänten zukommt. Das plasmatische Zellengeriist ist lebende Substanz, und es ist vorauszusetzen, daß ihm als solcher noch besondere physiologische Aufgaben zufallen. In erster Linie kommt, solange die Entwicklung der Zentralorgane andanert, das selbständige Wachstum des Markgeriistes in Betracht. Ganz allgemein geht die Geriistentwicklung dem Auftreten von Nervenzellen und von Nervenfasern voraus und da wo es zur Verwachsung vorher getremnter Teile kommt, wie z. B. bei der Bildung der vordern Kommissur und des Balkens, da vermittelt zunächst das Markgeriist die Verbindıng, und erst nachträglich erfolgt das Einwachsen von Fasern. Inwieweit überdies dem plasmatischen Markgerüst der ausgebildeten Zentralorgane eine ntitritive oder 


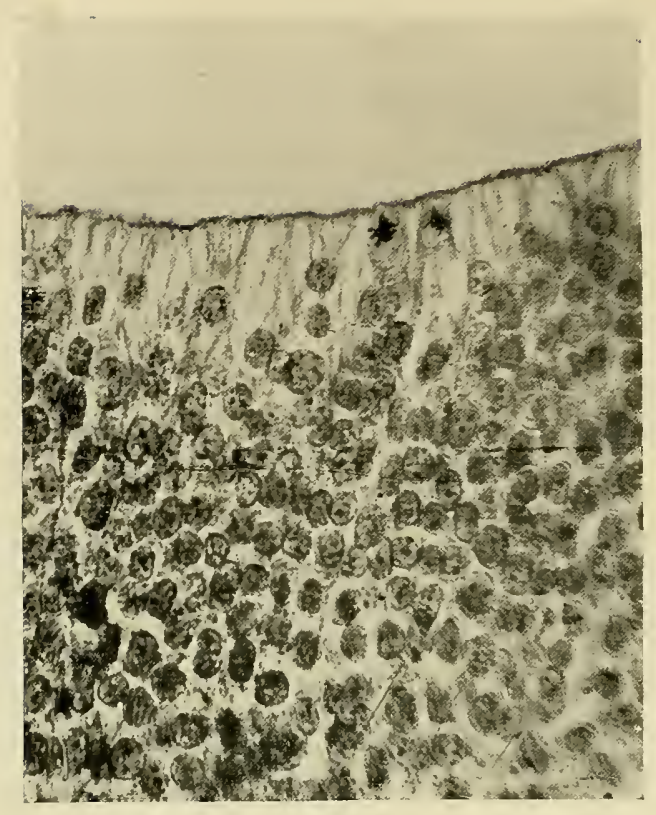

Fig. 8. Aus demselben Präparate. Säulenschieht mit Keimzellen. (Zu Seite 17.) früherem Anlaß zugegeben habe ${ }^{1}$ ) auch bei der Bildung von neuen Generationen von Gliazellen beteiligt. Ihrerseits scheinen sie aber nicht, wie ich früher voranssetzte, in ununterbrochener Reihenfolge auseinander herrorzugehen, denn man begegnet Entwicklungsstufen, in denen streckenweise keine Keimzellen vorhanden sind, so z. B. in der Hemisphärenanlage. - Wenn in solchen Strecken nachträglich Keimzellen und Neuroblasten sich entwickeln, so mïssen sie, wie dies SCHAPER ${ }^{2}$ ) angenommen hat, aus undifferenzierten Markzellen hervorgehen.

Meine besten Präparate über Keimzellen und deren Mitosen



Fig. 9. Aus demselben Präparat, photographiert wit Apochromat Zeiß 2 mm und naehträglieh, da das Photogramm zu blaß war, uberzeichnet. In den großen runden Keimzellen zeigen sich die frei hervortretenden Chromosomen als kurze gerundete Stäbehen. Die M. limitans_interma wird stellenweise von Plasmafortsätzen iiberragt. (Zu Seite 19.)

1) Im Aufsatz „Über das Prinzip der organbildenden Keimbezirke und die Verwandtschaft der Gewebe“ His, Archiv 1901, S. 330 ff.

2) A. SCHAPER, Die frïhesten Differenzierungsrorgänge im Zentralnervensystem. Archiv für Entwicklungsmechanik 1897 Bd. V S. S1ff. 
lieferte mir der etwa $3^{1} / 2$ Wochen alte Embryo $\mathrm{T}$. Er war von einem hiesigen Arzt durch Auskratzen der Uterushöhle gewonnen und mir sofort iiberbracht worden. Ich fixierte mit RABL schem Platingemenge und schnitt, allerding's etwas dick, zu $10 \mu$. Die hellen kugligen oder ovalen Keimzellen heben sich sehr schön ron ihrer Umgebung ab, sie liegen meist in kleinen Gruppen

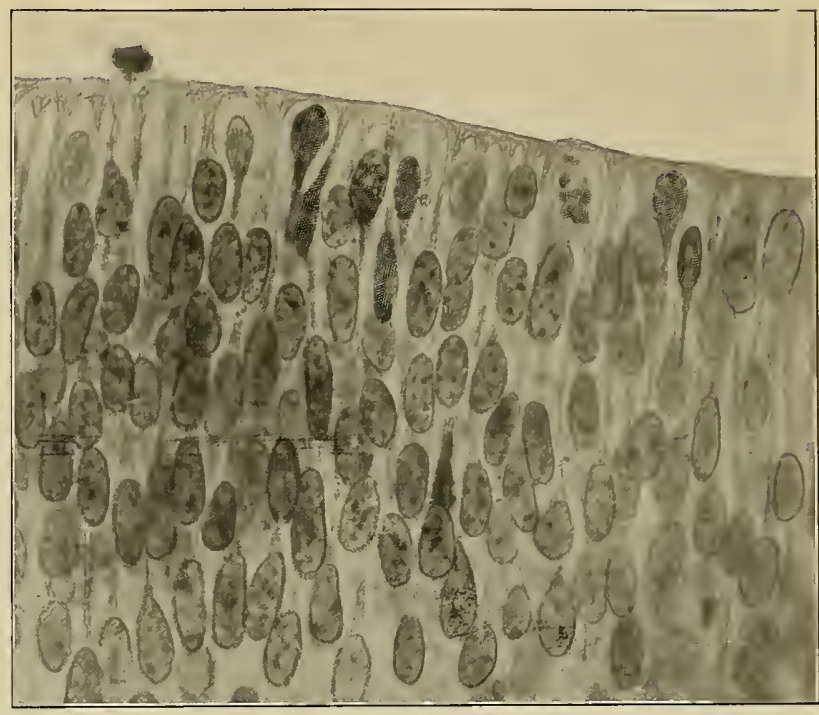

Fig. 10. Aus der Rückemmarkswand vom Embryo Br 3. Spongioblasten und Neuroblasten, links eine die Grenzhaut iiberragende Zelle. (Zu Seite 21.) von zwei oder drei

beisammen. Ihr Durchmesser beträgt zwischen 10-14 $\mu$. Die Chromosomen erscheinen als kurze, häufig etwas gekrïmmte Stäbchen (Fig. 9, S. 18). Die Zahl der Chromosomen schätze ich zu 24 in einer Zelle. Ich konnte zwar nie bis 24 zählen, dageg'en fand ich wiederholt, daß wenn ich dentlich bis zwölf zählen konnte, dies ungefähr die Hälfte des Chromosomenkomplexes ausmachte. Fig. 9 zeigt solche Keimzellen in einer ïberzeichneten Photographie.

\section{Die Neuroblasten und deren diagnostische Merkmale.}

Von frïh ab nimmt, zugleich mit der Wanddicke des Markrohres, die Menge der in ihm sich anhäufenden Zellenkerne zu. Je gedrängter sie liegen, um so mehr nehmen sie gestreckte Formen an, und es fragt sich, welche diagnostische Merkmale wir haben, um in dem Gewirre ron Kernen Spongioblasten- und Neuroblastenkerne voneinander zu unterscheiden. In beiden Kategorien begegnen wir Birnformen, aus dieser Formeigentümlichkeit läßt sich somit keine Unterscheidung ableiten. Entscheidend ist nur das Verhalten der Zellfortsätze,

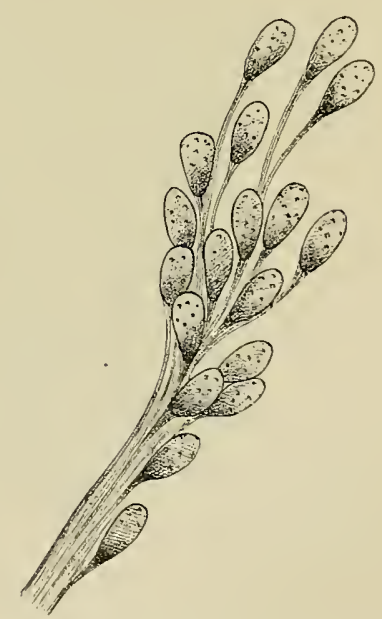

Fig. 11. Neuroblasten in kornihrenförmiger Anorduung. Verlïngertes Mark rom Embryo se (X1. $18 \mathrm{~mm}$ ). Trsprung seusibler Schleifenfasern. Prismenzeichmung. (Zu Seite 22.)

$$
2 \div
$$


und wo diese letzteren nicht sichtbar sind, wie z. B. bei quer- oder schräggeschnittenen Kernen, da wird, wenigstens in früheren Stufen, die Diagnose

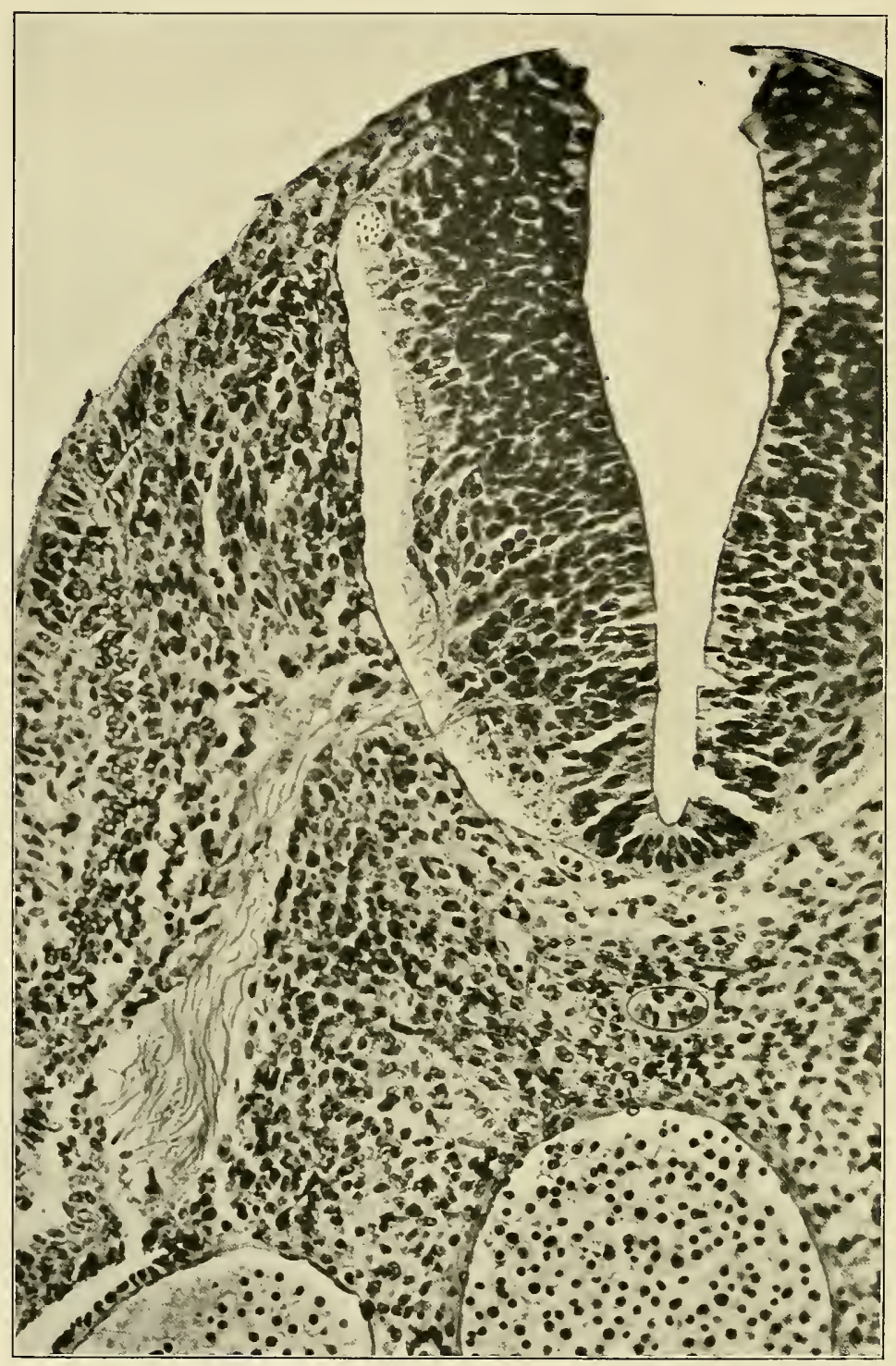

Fig. 12. Quersehnitt durch das Rückenmark rom Embryo Br. 3. Motorische Wurzeln und Stumpf eines Rumpfnerven. Das helle Feld des Hinterstranges ist nach anderen Durchschnitten eingezeichnet, da es im vorliegenden Photogramm nicht besonders scharf hervortrat. (Zu Seite 22.)

oft recht mißlich. Von den zahlreichen Zellen mit gestreckt birnförmigem Kern, die die Wand des Markrohres gegen Ende des ersten Monats enthält, entsendet die Mehrzahı je einen längsgestreiften Pfeiler nach einwärts zur 
inneren Grenzhant. Damit eharakterisieren sich diese Zellen olme weiteres als Spongioblasten, und dasselbe gilt von den Zellen, deren Anschluß an das allgemeine Markgeriist nach außen hin nachweisbar ist (Fig. 10, S. 19).

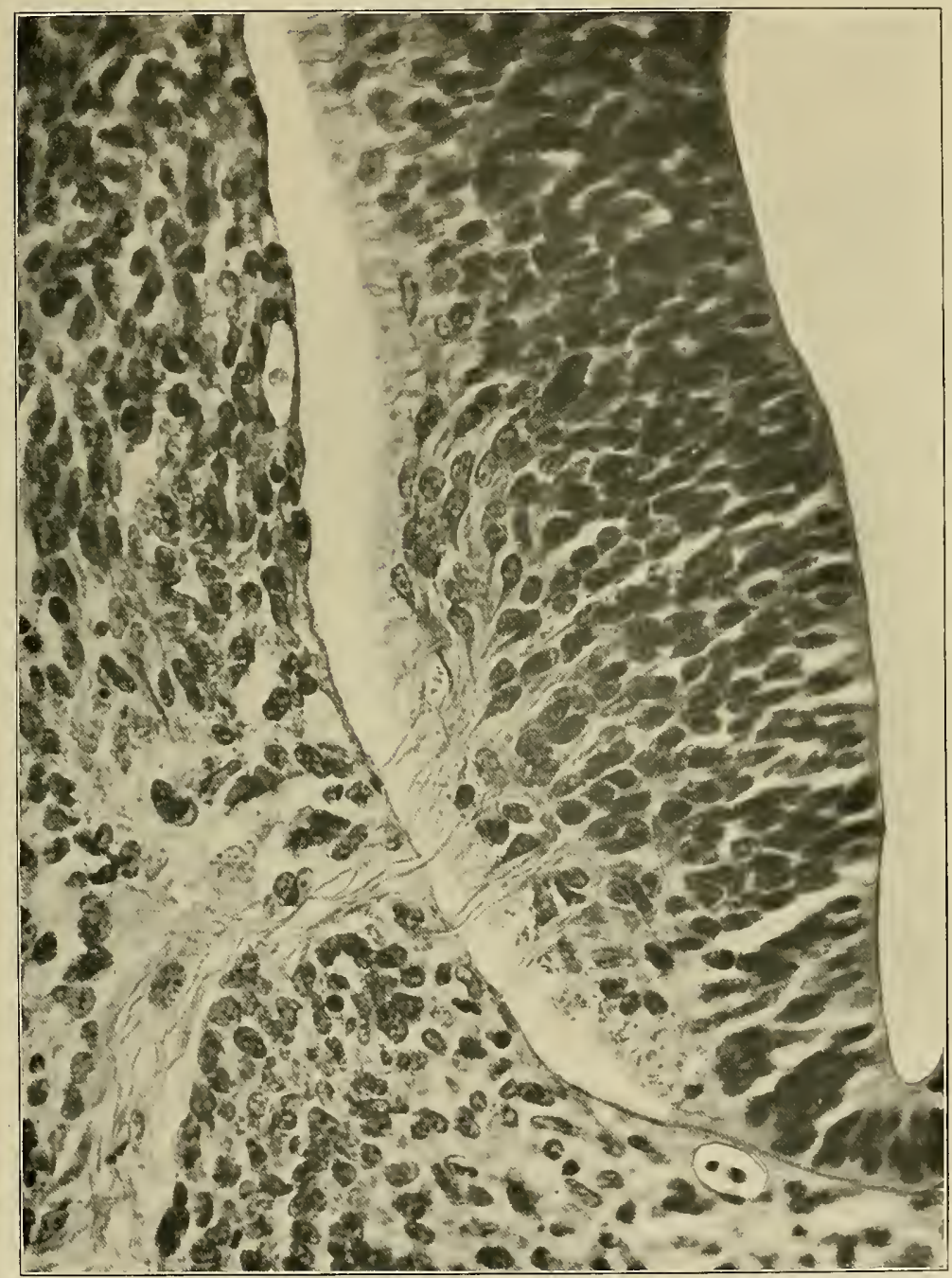

Fig. 13. Aus demselben Präparat, etwas stärker vergrüßert. Man sieht die Neuroblasten, deren Fortsätze teils gegen den Wurzelaustritt konvergierend zusammenlaufen, teils aueh die rorderen Wurzelfasern kreuzen. Die Anlage des Vorderstranges gibt sich in Form dunkler Punkte zu erkennen, die in den Maschen des Randsehleiers liegen. (Zu Seite 23.)

Der positive Beweis für die Neuroblastennatur einer Zelle ist dann geleistet, wem deren Zusammenhang mit einer Nerrenfaser feststeht. Das histologische Gepräge, anch der frïhembryonalen Nerrenfasern ist aber ein sehr eharakteristisehes, sie zeiehnen sieh ans dureh ihr gleiehmäßiges Kaliber, 
ihren leicht wellenförmigen Verlauf, und sie können nicht übersehen werden, wenn ihrer auch nur wenige vorhanden sind. Die aus benachbarten Neuroblasten stammenden Nervenfasern pflegen unter konvergentem Verlanf zu Bündeln zusammenzutreten. Als solche Bündel erschẹinen schon die ersten motorischen Wurzeln. Die an der Bildung von Faserbündeln beteiligten Neuroblasten, soweit sie nicht endständige Gruppen bilden, liegen den Bündeln der Länge nach ein- oder seitlich angelagert, ein dabei häufig

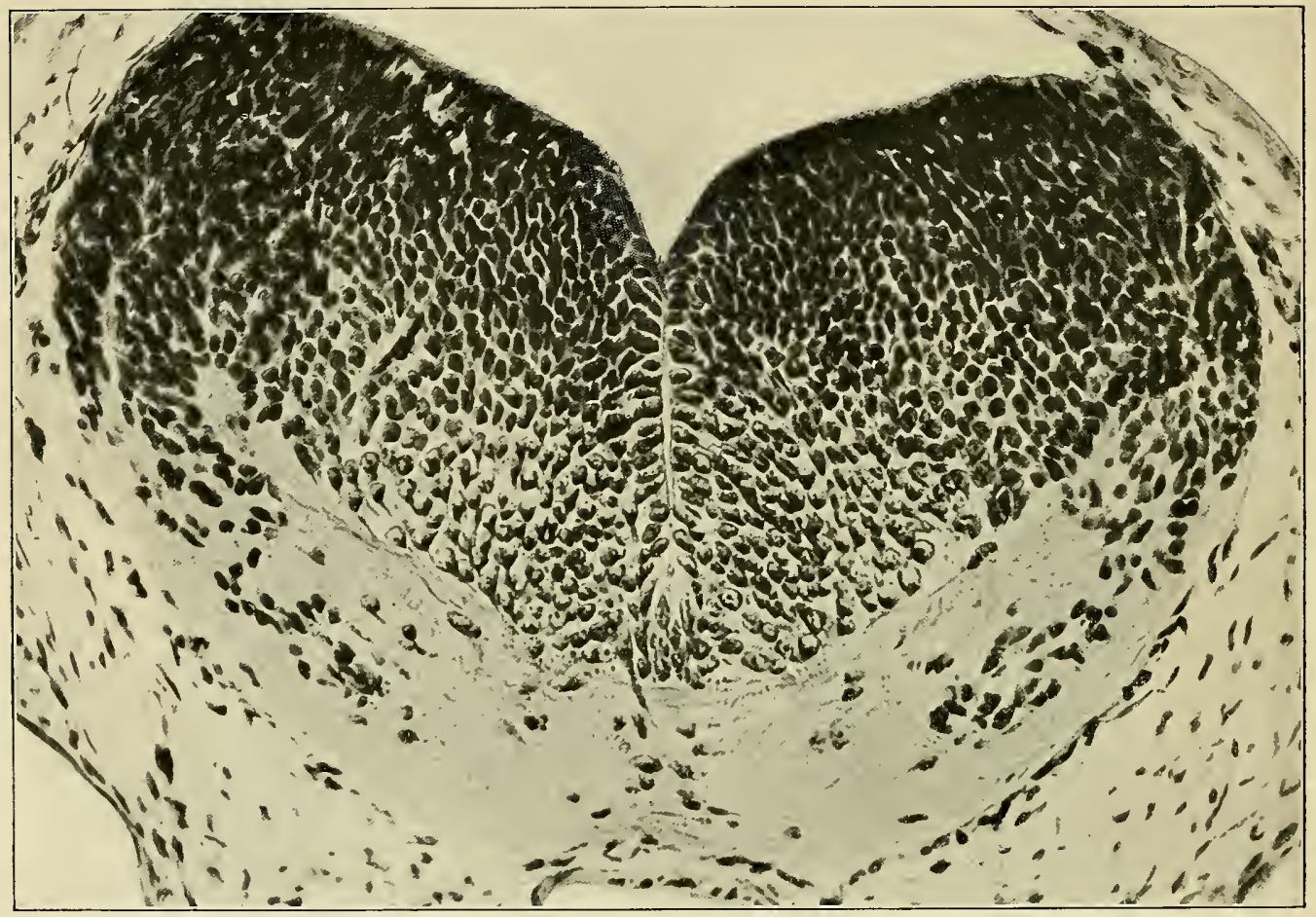

Fig. 14. Sehnitt dureh das verlüngerte Mark eines Forellenembryos von $\mathbf{6}^{1} / \mathbf{2} \mathrm{mm}$ Länge. Man sieht (besonders links vom Besehauer) Scharen von Neuroblasten mit dunkeln Spitzen. (Zu Seite 23.)

wiederkehrendes Bild ist das einer kornährenartigen Anordnung (Fig. 11, S. 19). Da, wo Neuroblasten zwischen vorhandenen Faserbïndeln regellos zerstreut liegen, haben wir keinen Grund, sie als deren Ursprungszellen anzusehen. Ziemlich früh beginnt der Protoplasmaleib der Neuroblasten etwas anzuschwellen, und gegen Ende des zweiten Monats haben auch manche derselben ihre einfache Birnform aufgegeben und am Gegenpol ein oder mehrere kurze Fortsätze entwickelt.

Das auswachsende Ende der in Bildung begriffener Nervenstämmchen pflegt sich während der Dauer seiner Ansbreitung als ein von der Umgebung dentlich sich abhebender Stumpf darzustellen (Fig. 12, S. 20). Solange der Stumpf beisammen bleibt, vermag man dessen successires Vor- 
riicken schrittweise zu verfolgen. Dies gilt nicht allein von peripherischen Nervenstämmen, sondern anch von zentral auswachsenden, wie z. B. von der spinalen Trigeminuswurzel.

Im Querschnitt erscheint jedes Fïserchen als dunkler Punkt. Da wo die Fäserchen noch sparsam vorhanden sind, z. B. auf frühen Stufen der Stränge des Rïckenmarkes und des verlängerten Markes, finden sie sich zerstreut in den Maschen des Markgerüstes, in der Regel den Gerïstbälkchen ummittelbar anliegend (Fig. 13, S. 21). Mit zunehmender Menge erfïllen sie die zuror freien Räume. Allein anch bei peripherischen Nervenstämmen ist das Gefüge anfangs sehr locker, indem zwischen den wellig sich biegenden Fäserchen viel offener Raum frei bleibt. Solche junge Nerrenstämmchen heben sich demnach als helle Straßen vom umgebenden Gewebe ab.

Eine Eigentümlichkeit junger Neuroblasten, die ich hier nicht ïbergehen darf, ist die leichte Färbbarkeit ihres Übergangsteils zur Faser. Diese Eigentümlichkeit findet sich weit verbreitet. Ich habe sie schon sehr anffällig bei Neuroblasten des Forellenhirns und Riickenmarks gefunden (Fig. 14, S. 22) und ich begegne ihr wieder in höchst bezeichnender Weise bei den in die Rindenschicht ïbergehenden Pyramidenzellen der Großhirnhemisphären menschlicher Embryonen. Wo solche dunklen Zellenkegel in größeren Gruppen beisammen liegen, da gestaltet sich das Bild zu einem sehr charakteristischen und es erlanbt keine Verwechslung mit Spongioblasten.

\section{Die Gliederung des Medullarrohres in Längszonen.}

Im allgemeinen besteht das Markrohr nach erfolgtem Schluß aus zwei dicken Seitenwandungen, die durch diume Verbindungsstreifen untereinander zusammenhängen. Letztere habe ich bei früheren Anlässen als Bodenplatte und als Deckplatte bezeichnet. ${ }^{1}$ ) Die Seitenwandungen zerfallen in eine rentrale und eine dorsale Hälfte. Für das Rückemmark reichen diese Bezeichnungen ans, beim Gehirn dagegen treten Verschiebungen ein, welche es wünschbar machen, Ausdrïcke zu besitzen, die nnabhängig von den Beziehungen zu Rücken und Bauch sind. Ich habe s. Z. die Ausdriicke Grundplatte und Fliigelplatte vorgeschlagen, die mir selber indessen nur ein Notbehelf gewesen sind, und die ich gern gegen bessere rertauschen werde. Vielleicht erweisen sich die Bezeichnnngen eines e pencephalen und eines hypencephalen Bezirkes als brauchbar. Einen Hypothalamus haben ja in zweckmäßiger Weise schon die BNA eingeführt. Epencephale Teile sind demnach die Hemisphären ron Grob- und Kleinhirn, der Thalamus, die Vierhiigel und die Bindearme. Zı den Gebilden epencephalen Ursprunges gehören aber auch die in der ventralen Markhälfte gelegenen Olivenkerne, sowie ein Teil der Brïckenkerne.

1) 1886 ; S. 483 und 1888 ; S. 350 . 


\section{Die Schichtensonderung in den Wandungen des Markrohres.} scheiden:

Nach ihrer histologischen Verwendung lassen sieh am Markrohr unter-

1) Strecken, die stets epithelial (ependymal) bleiben. Dahin gehören die Deckplatten des vierten, des dritten und der Seitenventrikel und das kaudale Endstiick.

2) Solche, aus denen Neuroblasten, d. h. Nervenzellen und Nervenfasern hervorgehen; es sind dies die beiden dicken Seitenwandungen des Rohres.

3) Solche, in denen zwar keine Neuroblasten entstehen, die aber sekundär von Nervenfasern durchwachsen werden. Dahin gehören die verschiedenen Kommissurengebiete, die Bodenplatte des Rückenmarkes, des Rantenhirns und des Mittelhirns, sowie teilweise die Deckplatte der letztgenannten Teile und des Thalamushirns (Vermis cerebelli, Velum medullare anterins, Vierhügel, Commissura posterior und superior usw.). Man kann die Wandstrecken 2 n. 3 den e pend ymalen als neurale gegenüberstellen und unter sich als ne uroblastische und neurophore (oder kommissurale) Bezirke unterscheiden.

Vom Ende der vierten und noch deutlicher von der fünften Woche ab lassen sich in den Seitenwandungen des Markrohres zwei kernhaltige Hauptschichten, die Innenplatte oder Matrix und die Mantelschicht, sowie eine kernfreie Randschicht, der sog. Randschleier unterscheiden (Fig. 15, S. 25). Die Innenplatte bewahrt längere Zeit hindurch den Charakter der primären Markplatte, sie enthält dicht gedrängte, radiär gestellte Kerne und zu innerst Keinzellen. Anch ist sie die Bildungsschicht der nảch anßen von ilır folgenden Gewebslagen. In der Mantelschicht lockert sich das Gefïge, und frühzeitig treten in ihr tangential gerichtete Neuroblasten und Bogenfasern anf.

Die grundlegenden Vorgänge histologiseher Scheidung sind im gesamten Markrohr dieselben. In den verschiedenen Abschnitten des Markrohres, im Rückenmark, Rautenhirn, Mittelhirn und Vorderhirn tritt nach und nach der oben erwähnte Gegensatz hervor zwischen der dicht gefügten radiärstreifigen Innenplatte, der locker gefügten, Neuroblasten führenden Mantelschicht und dem kernfreien Randschleier. Wo die Wand an Dicke zunimmt, sind es Mantelschicht und Randschleier, die sich verbreitern, und zwar geschieht dies um so mehr, je rascher das Wachstum erfolgt; die Dicke der Innenplatte schwankt wälrend der verschiedenen Entwicklungsstufen nur imnerhalb enger Grenzen. Stellen, die in Dickenwachstrm zurïckbleiben, entwickehn ïberhaupt keine Mantelschicht und sind frei 
von Neuroblasten. Der Randschleier erscheint, wie oben grezeigt wurde, zuerst als ein ron Einlagerungen freies Maschenwerk. Anfangs als schmaler
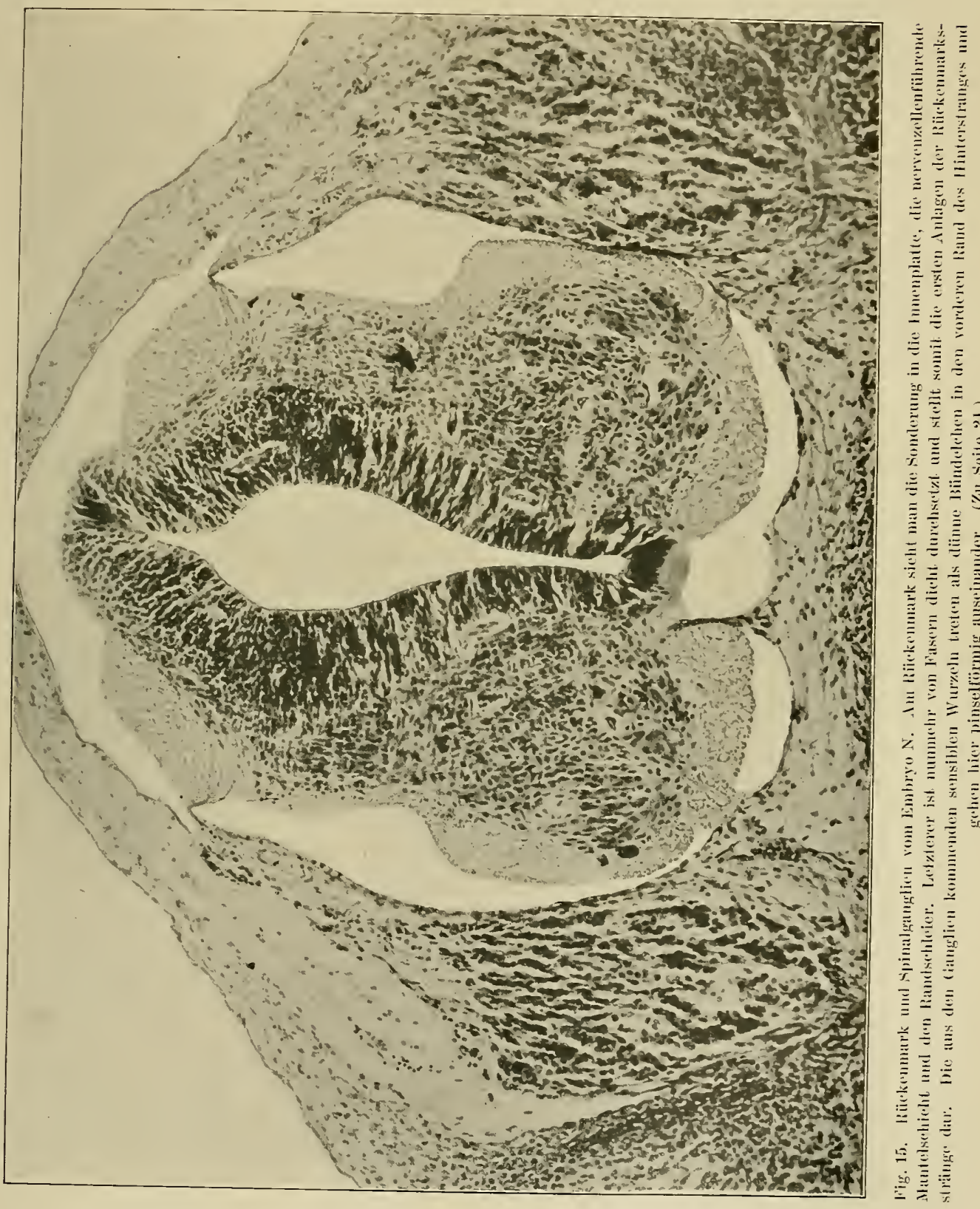

peripherischer Saum auftretend, nimmt er während geraumer Zeit an Breite stetig zu, und wird zum Lager für neu auftretende nerröse Bestandteile. An bestimmten Stellen häuft sich der Randschleier reichlicher an, als an 
anderen. So pflegt er in frühen Entwicklungsperioden in der ventralen Hälfte des Rohres breiter zu sein, als in der dorsalen. An solchen Stellen aber, an denen durch Einwärtsbiegung der Wand eine äıßere Rinne entsteht, gestaltet er sich mancherorts zu einem besonderen, die Rinne ausfüllenden Polster.

Da die Nervenzellen im Bereich des gesamten Markrohres in den an die Innenhöhle stoßenden Wandschichten entstelıen, so verhält sich auf friihen Entwicklungsstufen die Anlage der granen Substanz durchweg als „Höhlengran" im Simn von Mervert.

Alle zentralen Nervenzellen, sie mögen später noch so verwickelte Formen annehmen, gehen dureh die Anfangsstufe von Neuroblasten hindurch, d. h. sie besitzen anfangs einfache Birnform und entsenden nur einen Fortsatz, den Neuriten. Auf dieser Entwicklungsstufe pflegen die Nervenzellen den Ort ihrer Entstehung zur verlassen und damit die Bildung anderweitiger graner Massen einzuleiten. Dabei können die nen angelegten granen Massen:

1) im Nachbarbereich der Matrix verbleiben und nach anßen hin von weißen Fasermassen ïberlagert werden. Dies ist beim Rückenmark der Fall, in dem die Neuroblasten im allgemeinen bis zur Grenze des Randschleiers yordringen und hier entweder zu motorischen Wurzelzcllen oder zu intramedullar verbleibenden Bogenzellen werden, während der Randschleier die Grundlage der weißen Snbstanz liefert;

2) können die Neuroblasten, in radiärer Richtung fortschreitend, die Wand bis in die Nälıe der Außenfläche durchsetzen und hier zu einer selbständigen Schicht sich ansammeh. Auf einer solchen radiären Auswanderung der Zellen aus der Matrix des ursprünglichen Höhlengranses berult die Rindenbildung der Großhirnhemisphären;

3) können infolge bestimmter Verbiegungen der Medullarwand und ausgiebiger, tangential gerichteter Zellenwanderungen grane Massen aus dem dorsalen ins ventrale Markgebiet iibertreten. So entstehen die Formationes arcuatae, die Oliven, Nebenoliven und ein Teil von den in der Brücke liegenden Kernen. Bemerkenswert erscheint, daß dieser zu den allerkompliziertesten Anordunngen führende Bildungsmodus der in der Entwicklung zeitlich vorangehenden Medulla oblongata zukommt, wogegen der Typus rein radiärer Zellenwanderung in den spät sich anlegenden Hemisphären des Grofhirns ausschließlich Platz greift.

Die Periode der Neuroblastenbildung ist eine beschränkte und mit dem Schwinden von Keimzellen versiegt die Qnelle der Weiterbildung. Die Daner der Bildungsperiode ist für die verschiedenen Bezirke des Markrohres eine verschiedene. In der ventralen Hälfte des Rohres beginnt und erlischt sie im allgemeinen früher, als in der dorsalen. Im Hemisphärengebiet beginnt die Neuroblastenbildmo erst spät, sie danert hier aber durch lange Perioden hindurch an. Die Zellen und Fasern späterer Bildung finden ganz andere Ausbreitungsbedingungen als die von früheren Generationen, und es 
ist ersiehtlich, daß die Zeitpunkte der Bildung, sowie die Ansgiebigkeit der entstehenden Neuroblastenbruten das weehselnde Ineinandergreifen der Gestaltungsvorgänge bestimmen und jedem Ort sein besonders arehitektonisches Tepräge verleihen.

Bildung und Umlagerung der Nervenzellen sind das eine die innere Organisation der einzelnen Markstrecken bestimmende Noment. Ein anderes Noment liegt in der Entwieklung der Faserbahnen. Von den aus den Neuroblasten des Markrohres hervorwachsenden Fasern verläßt nur ein Teil dessen Wand als motorisehe Wurzeln. Anderseits findet vou den Spinalganglien ans der Eintritt von sensibeln Wurzelfasern statt. Die ïberwiegend große Mehrzahl der im Markrolır entstehenden Neuriten breitet sieh intramedullär aus, indem sie mehr oder minder zu Strängen gesammelt und den dureh das Markgerüst gegebenen Bahnen folgend, sehrittweise weiterwaehsen. Der Hergang kann lange Zeit andanern, auch erreieht er bei den einen Bahnen früh, bei andern erst spät sein Ende. Naturgemäß kommt es dabei zu einer zunehmenden Verwieklung der ursprünglieh einfachen Organisation der versehiedenen Markbezirke. Was von Zellen und Faserbahnen einmal da ist, das bleibt, und der Bau kompliziert sieh, wenn wir zunäehst rom Auswachsen von Dendriten- und von Kollateralfasern absehen, dadureh, daß zu den zuerst angelegten Zellen und Faserbahnen nene sich hinzufiigen, und daß Fasermassen in Bezirke gelangen können, die von ihren Ursprungsbezirken weit entfernt sind.

MEYNERT und seine Schule haben die ,Einfleehtung fremdartiger Babnen" als einen besonderen Begriff in die Hirnanatomie eingeführt. In dem Sinne haben sie z. B. von einer Einfleehtung der Kleinhirnsehenkel in die Projektionssysteme gesproehen. ${ }^{1}$ ) Der dieser Darstellung zugrunde liegende Gedanke besagt, daß in die besondere Organisation eines Bezirkes eine von außen herkommende Fasermasse als etwas Neues, dem Bezirk von Hause aus nieht Angehöriges hinzukommt. Der Gedanke ist, wenigstens seinem Wortlante nach, ein genetiseher, und um ihn etwas sehärfer zu fassen, unterseheiden wir am besten zwisehen a ut oehth onen und eingewanderten bez. eingewaehsenen Zellen und Fasermassen. Als antoehthone Massen sind dabei nur die aufzufassen, die in dem betreffenden Bezirke unmittelbar entstanden sind. In dem Simne sind nur solehe Bahnen antoehthon, die ans Neuroblasten des betreffenden Bezirks hervorgegangen sind, wie z. B. im Rüekenmark die vordern Wurzeln, die vordere Kommissur und die Faseru der Formatio arenata, wogegen sehon die sensibeln Wurzeln eingewandertes Material sind und ebenso die simtliehen Längsstränge. Als eingewanderte Zellenmassen sind im rerlängerten Iark die Olivenkerne zu verstehen, die aus dem Dorsal- in den Tentralbezirk übergetreten sind. Die granen Rindenmassen rom Groß- und Klein-

$\left.{ }^{1}\right)$ Mervent in Strickers Handbuch der Lehre von den Geweben 1572 S. $i 52 \mathrm{ff}$. 
hirn werden dagegen besser bei den autochthonen Bildungen belassen, denn ihre Elemente sind beim Übergang ans den inmern in die äußern Wandschichten gleichwohl in ihrem Ursprungsbezirke verblieben.

Die in das Mark einwachsenden Faserbündel lagern sich inı allgemeinen sehr oberflächlich, indem sie in die äußern Maschen des Markgerïstes eindringen. ${ }^{1}$ ) Diese oberflächliche Lagerung kann aber dadurch verloren gehen, daß Zellen- oder Fasermassen späterer Bildung die frïlier vorhandenen von anßen her ïberdecken. So rückt infolge solcher Überlagerungen z. B. der Tractus solitarius von der Oberfläche des rerlängerten Markes allmählich immer mehr in die Tiefe. Bei peripherisch auswachsenden Nervenstämmen gestalten sich die Verhältnisse des Auswachsens im allgemeinen für dünne Stämmehen einfacher als für dicke. Solange die zu einem Bündel sich sammelnden Nerven unter geringen Winkeln konvergierend zusammentreten, pflegen sie mehr oder minder parallel zueinander sich anzuordnen, bei größerem Konvergenzwinkel durehkreuzen sich die Fasern, und es ergibt sich damit die Bedingung einer Stammesteilung. So gehen bei Spinalnerven dic am meisten ventral hervortretenden Fasern in den Ramus dorsalis ïber, die dorsal hervortretenden in den Ramus ventralis, und in letzterem sind es die zu hinterst hervorgetretenen, die in den R. splanchnicus gelangen. Die Entdeckung von GASKELL, daß die Rr. splanchnici ans den Seitenhornkernen des Rückemmarks und der Med. obl. hervorgehen, findet in der Art des Auswachsens der Fasern ihre volle Begründung. Aus größeren Ganglien treten die Fasern nieht parallel hervor und es liegt zum Teil schon darin die Bedingung zur Sonderung getremnter Stämme.

Das Auswachsen der Nervenfasern geht langsam vor sich und anch die Dendritenfortsätze der Nerrenzellen entwickeln sieh, wie wir dureh CAJAL wissen, nur allmählich. Beim gegenwärtigen Stand unseres Wissens ist es schwer zn bestimm.en, wam das Auswachsen der zentralen Faserbahmen und insbesondere das ron Kollateralen sein Ende erreicht. Wahrscheinlich wohl erst jenseits des Kindesalters. Dagegen läßt sich die naheliegende Vermutung, daß die in spätern Jahren vor sich gehende Weiterbildung. körperlicher und geistiger Fähigkeiten mit einer Weiterbildung vorhandener Nerrenbahnen Hand in Hand gehe, nicht leicht aufrecht erhalten. Die Gehirnwägungen ergeben bekanutlieh, daß dies Organ den Höhepunkt seiner Nassenzunahme verhältnismäßig früh erreicht, und für ein anch ïber reifere

1) So zeigt sich das Verhalten ron Anfang ab beim Hinterstrang ron Embryo Br 3 (Fig. 12), wogegen es beim Tractus solitarins, beim Tractus spinalis N. trigemini und bei den Acnsticnsbündeh desselben Embryo den Anschein hat, als lägen die einwachsenden Nervenbündel anfangs frei anßerhalb des Narkes. Ich mnß, im Anschluß an die ron HeLd iiber das allgemeine Vorkommen der M. limitans externa gegebenen Erörterungen annehmen, daß es sich bei den angegebenen Stellen meiner Präparate (man vgl. Fig. 25 и. 30) $1 \mathrm{~m}$ Oberflächenverletzungen und $u \mathrm{~m}$ ein Losreißen der M. limitans externa handelt. 
Jahre sich ansdehnendes stetiges Weiterwachsen des Gehirns gibt demnach die Beobachtung keine Anhaltspunkte. ${ }^{1}$ )

Fassen wir nochmals die Motive zur Differenzierung der verschiedenen Abschnitte von Gehirn und Rïekenmark znsammen, so können wir daron ansgehen, daß in frïheren Perioden die Eigensehaften der Wand, was Dieke und inneren Bau betrifft, nur innerhalb enger Grenzen variieren. Die Gliederung des Rohres ist in der Zeit wesentlich nur eine morphologisehe, im Vorbandensein bestimmter Achsenkrümmungen und der ihnen entsprechenden Faltungen sieh änßernd. Die ursprïngliche morphologisehe Gliederung. kamn in der Folge dureh Veränderung der Achsenkriimmungen und durch ungleichmäßiges Hervortreten der Einzelnglieder sich modifizieren. $\mathrm{Zu}$ den morphologischen Umbildungen treten aber jetzt die inneren Umbildungen der Wand hinzu, und für die endguiltige Ausbildung eines jeden einzelnen Hirn- und Riickenmarkteiles erseheinen demnach folgende Prnkte mafgebend:

1) die Größe und Gestalt der primären Anlage;

2) die Daner der in ihr ablaufenden Neubildnngsvorgänge;

3) die Menge der von anßen her in den Teil einwandernden Zellenmassen und

4) die der in ihn einwachsenden Fasermassen.

\section{Ir ritische Bemerkungen.}

Vor zwei Jahren ist Bethe in einem in Baden-Baden gehaltenen Vortrage für die Lehre von der Bildung von Nervenfasern ans längsgeordneten Zellen eingetreten, den "Nervenzellen", wie er sie im Gegensatz zu den Nenroblasten und Ganglienzellen nennt. In einem soeben erschienenen Buch (Allgem. Anatomie und Physiologie des Nervensystems 1903) teilt er nun Beobachtungen an Hühnehenembryonen mit, die diese Lehre stiitzen sollen. Ich erhalte das Bueh genan gleichzeitig mit der Korrektur des rorliegenden Bogens und kann daher nur mit wenigen Worten darauf eingehen.

BETHE glaubt beobachtet zu haben, daß bei der Bildung motoriseher Wurzeln beim Hühnerembryo eine Straße von Spindelzellen dem Auftreten von Fasern vorausgeht. Die Zellen denkt er sich von Anfang ab untereinander und mit den Riiekemmarkszellen syneytial rerbunden. Weiterhin sollen innerhalb dieser Zellen Nervenfasern anftreten, die entweder mit Neuroblastenfortsätzen zusammenlängen, oder unabhängig ron diesen ins Rïekenmark eindringen. Die Beobachtungen bedïrfen einer sorgfältigen

1) Marchand kommt in seiner griindlichen Arbeit ïber das Hirngewicht des Menschen zum Ergebnis, daß schon bei Kindern von vier bis fünf Jahren ein starker Prozentsatz das mittlere Gehirngewicht erreicht oder ïberschritten hat. Als oberste Wachstumsgrenze erklärt er beim Mann das zwanzigste, beim Weib das sechzehnte bis achtzehnte Lebensjahr (IARchaxo, Abh. d. k. s. Ges. d. W., math.-phỵs. Kl. 1902 Bd. XXVII S. 403 ff.). 
Nachprüunng, da das Vorhandensein von Täuschungsquellen nicht ausgeschlossen ist. Allein, wemn auch deren Richtigkeit, das Umschlossensein von Nervenfasern durch das Plasma spindelförmiger Zellen festgestellt sein sollte, so ist damit der Beweis nicht geliefert, daß die Fasern imerhalb der Zellen entstanden sind. Sie können, wie mir bei einer mündlichen Besprechung Herr HELD andeutet, in die Zellen hineingewachsen, oder, was mir noch wahrscheinlicher erscheint, von dem Zellplasma umwachsen worden sein. Beтне läßt aus seinen „Nervenzellen" die Schwann schen Scheiden und deren Kerne hervorgehen, es ist also kein Zweifel, daß er dieselben Elemente im Auge hat, die wir bis dahin für mesenchymatöse Scheidenzellen angesehen hatten. Diese treten bei den niedrigeren Wirbeltierklassen sehr viel früher auf, als bei den Sängern. Bei den letzteren und speziell beim Menschen heben sich die kernlosen Nervenbündel und deren frei auslaufende Stümpfe so auffällig von ihrer Umgebung ab, daß ein jeglicher Irrtum ansgeschlossen ist (Figg. 12 u. 13, S. 20 u. 21).

Völlig undurchführbar erweist sich die Lehre einer Bildung von Nervenfasern durch Längsverwachsung von Zellen bei den nervösen Zentralorganen, denn in deren weißer Substanz fehlt es rundweg an einem Material, das dazı verwendbar wäre. Wir konstatieren das Hereinwachsen der aus den Spinalganglien kommenden sensibeln Fasern in die Außenfläche von Gehirn und Rïckenmark und das schrittweises Vordringen innerhalb völlig zellenfreier Bezirke des Markgerüstes. Ebenso verfolgen wir das Auftreten von Kommissuren- und von Strangfasern in zellenfreien Gebieten, und wo ïberbaupt die Schnitte entsprechend orientiert sind, da vermögen wir die Fasern uiber weite Strecken zuriick bis zu ihren Ursprnngsneuroblasten zu rerfolgen. Den 1886 am Schluß meiner Ruickenmarksarbeit aufgestellte Satz, daß eine jede Nervenfaser ans einer einzigen Zelle als Ausläufer hervorgeht, halte ich auch heute noch für tatsächlich begründet. Schon damals habe ich übrigens die Möglichkeit sekundärer Verbindmgen von auswachsenden Nervenfasern mit Zellen nicht in Abrede gestellt. ${ }^{1}$ )

Auch NIssL nimmt neuerdings Anlaß auf meine Arbeiten uiber Nervenentwicklung einzugehen (Fr. Nisst, Die Neuronenlehre und ihre Anhänger, Jena 1903). Dem entwicklungsgeschichtlichen Standpunkt steht NIssL sehr fern und er erklärt ansdrïcklich (S. 15): „Für unsere Frage ist es völlig nebensächlich, wie sich das Nervensystem entwickelt." Auch ist er allem Anschein nach erst durch mein bei der Naturforscherversammlung in Aachen (1900) abgegebenes Votum auf die entwicklungsgeschichtliche Begriundung' der Neuronenlehre anfmerksam geworden. In dem früher geschriebenen ersten Teil seines Buches erklärt er noch (S. 11), es sei „die Neuronenlehre erst nach dem Bekamntwerden der Silberbilder denkbar gewesen und selbstverständlich erst danach aufgestellt worden". Nachdem 
Nisst eimmal auf meine Arbeiten aufmerksam geworden ist, lat er sie, wie ich ausdriicklich betonen muß, mit großer Gewissenhaftigkeit his zum Jahr 1874 hinauf durehstudiert, und so konstatiert er anch mit großer Bestimmtheit, daß ich 1856 den Grundgedanken der Neuronenlehre zuerst mit den Worten ansgesprochen hahe, „daß eine jede Nervenfaser ans einer cinzigen Zelle als Ausläıfer hervorgeht, die deren genetisches, nutritives und funktionelles Zentrum sei. Alle andern Verbindungen der Fasem seien mur mittelbare, oder sie seien sekundär entstanden" (Abl. d. k. s. Ges. d. Wissensch., math.-phys. K’l. 1886 Bd. XIII S. 513). NISsL überzengt sieh anch dureh Vergleichung meiner älteren Aufsätze, daß ich seit langem auf den Sat\% hingearbeitet und nach dessen tatsächlicher Begründung gesucht habe. Er sieht darin das Vorhandensein einer vorgefaßten Meinung (NIssL, S. 312, es ist dies indessen ein Vorwurf, den ich nicht allzuselıwer empfinde, denn die Gesehichte der Wissensehaften zeigt, daß noch größere Forscher wissensehaftliche Wahrheiten aus dem Gesamtergebuis ihrer Erfahrungen intuitir ersehlossen und erst nach längeren Bemuihungen die eigentliehen Beweise dafür gefunden haben.

Um nun die gegen mich gerichtete Polemik NissLs zu verstehen, ist es notwendig seine Vorstellungen von den Beziehungen zwisehen Nerrenzellen, Nervenfasern und graner Substanz zu kemnen. In betreff des Achsenzylinders erklärt NISsL (1. c. S. 299): „Es ist eine exakt festgestellte Tatsache, daß der Achsenzylinder von Markfasern, die direkt mit den Achsen einer Nervenzelle zusammenhängen, nieht die Verlängerung des Nerrenfortsatzes einer Nervenzelle, also kein Zelleibsbestandteil derselben ist, sondern ein Gebilde sui generis, in das die wenigen Zelleibsfibrillen hineinwaehsen. An andern Stellen erklärt er den Nervenfortsatz der Ganglienzellen für einen Spieß, dessen Spitze der Stelle entspricht, wo die Zelleibssubstanz des Nerrenfortsatzes aufhört. Der Zwischenraum zwischen diesem Fortsatz und der von der Zelleibssubstanz völlig rersehiedenen Achsenzylindersubstanz wird nur ron einem Draht eng aneinander gepreßter Neurofibrillen iibersehritten (S. 458). Über die grane Substanz sagt NIssL: „Die grane Substanz ist der morphologisehen Analyse noch nieht zug:änglich. Der Punkt, wo die markhaltige Faser das Mark abwirft, ist die Barriere, die uns ein gebieterisehes Halt zuruft." In Gehirngrau befinden wir uns in einem ,fremden Land“. Auch wenn wir Achsenzylinder erkemnen, so sind sie uns fremd geworden, wir verstehen sie nieht mehr, weil wir ihren Zusammenhang verloren haben. Im Sehema (Taf. II Fig. 5 rechts) wird die graue Substanz als ein aus Zerteilung der Achsenzylinder gebildetes feines Netzwerk dargestellt. Das so frühzeitig auftretende Markgerïst, mein Mrelospongium, oder HeLds Gliageriist findet bei NIssL keine Beriicksichtigung, obschon es klar ist, daß dieser Bestandteil bei der Raumerfïllung innerhalb der grauen Substanz eine herrorragende Rolle spielt. Da ich in die Diskussion in betreff der granen Substanz nicht ummittelbar verwickelt 
bin und ïberdies im Text des Aufsatzes anf das Markgerüst vielfach zurïickzukommen habe, kann ich es hier unterlassen, den Gegenstand zu berühren, und ich komme auf die Einwendungen zuriek, die mir NISSL in betreff der Nervenentwicklung entgegenstellt.

Im wesentlichen gehen diese Einwendungen darauf zuriick, daß ich Zellenfortsätze und Nervenfasern verwechselt habe. Das Auswachsen der embryonalen Nervenfasern als kontinuierliche Fortsätze der embryonalen nervösen Zellen bleibt nach NissL erst zu beweisen, da die ron mir in Verbindung mit den Neuroblasten aufgefundenen feinen Fäden histologiseh nicht als unbestreitbare Nerrenfasern legitimiert sind (S. 305). Wir miissen mit der Möglichkeit rechmen, daß sie gar keine einheitlichen Gebilde sind, und vor allem haben wir nach NISsL daran festzuhalten, daß in der späteren Entwicklung andere Zellen an der Bildung des Achsenzylinders mit teilnelmen als die Neuroblasten. Wie man sich das denken mag, ist gleichgültig, es genïgt für NIssL, daß ich die Unmögliehkeit eines solehen Vorkommnisses nicht bewiesen habe. NISsL seinerseits deutet anf die die hervortretenden Stämmehen begleitenden Bindegewebszellen hin. Er erklärt überhaupt, daß bei Prüfung meiner Angaben nur die birnförmigen Neuroblasten der vorderen Markhälfte und die spindelförmigen Zellen der embryonalen Spinalganglienanlage in Betracht kommen (S. 302). Nun ist doch in meinen Arbeiten nicht ron diesen allein die Rede, sondern aueh von den intramedullar auswachsenden Zellenfortsätzen, unter denen die in die vordere Kommissur eintretenden zu den am frïhesten auftretenden gehören. Gerade bei den intramedullar auswachsenden Faserbündeln läßt sieh aber das sehrittweise Vorrüeken olme Beteiligung irgendweleher fremder Zellen mit großer Bestimmtheit verfolgen.

Bei den so völlig verschiedenen Ausgangspunkten von NIssL und von mir ist es schwer, einen gemeinsamen Diskussionsboden zu finden. Für ihn sind gewisse färberiseh gewonnene Ansehaumgen die Grundlage, anf die alles zurüekzuführen ist; entwiekhungsgesehichtliche Betraehtungsweisen lassen ilın kalt, oder sie gewälıren ihm höehstens ein Feld zur Betätigung. seines vorzïglichen Scharfsinnes. Ieh meinerseits anerkenne nicht unbedingt die zwingende Macht farbtechnisch gewonnener Anschaumngen, dagegen halte ieh eine anatomische Einriehtung erst dann für verstanden, wemn ich deren Entwicklungsgeschichte zu iibersehen vermag. Und so bin ieh anch der Ansicht, daß die Forscher, die sich die Ausbildung der Neurofibrillenlehre zur Aufgabe gemacht haben, uns u. a. den Nachweis von der Bildungsgeschichte der Fibrillen schuldig sind. Die Behauptung, dab diese Gebilde unabhängig von den Zellen entstanden seien, ist meines Erachtens sehr willkürlich. Das, was wir von den Neuroblasten und deren Ausläufern wissen, mag im Widerspruch mit gewissen Axiomen der jetzigen Neurofibrillenlehre stehen, einen Widersprtuch mit nachgewiesenen Tatsachen vermag ieh nicht zu erkennen. 
Nachdem das Manuskript dieser Arbeit längst abgeschlossen war, habe ich von V. Hensen die Sehrift zugesandt erhalten: „Die Entwicklungsmechanik der Nervenbahnen in Embryo der Sängetiere." In gar manchen Punkten wissenschaftlichen Strebens harmoniere ich mit meinem langjälırigen Freunde, und ich hege die größte Hochschätzung vor dessen feiner Beobachtungsgabe und ïberlegener Einsicht, aber hinsichtlich der Nervenbildung gehen unsere Vorstellungen diametral auseinander. Hein gesamter, seit Jahrzehnten gesammelter Erfahrungskreis führt mich, in Übereinstimmung mit einer Reihe der vorziiglichsten Forscher, mit zwingender Notwendigkeit zur Lehre rom Auswachsen der Nerven ans Zellen. Dies gilt anch von den in dieser Schrift mitgeteilten Beobachtungen, und ich sehe keine vermittelnde Brücke, die mich zu der von Hexses vertretenen Auffassung hinüber zu leiten rermöchte, wonach „proximaler und distaler Endapparat rom Begimn ihrer Sonderung an bis zur abschließenden Festlegung der Nervenbahnen in Znsammenhang bleiben". Unter den Unständen ist eine ins einzelne gehende Diskussion wenig ersprießlich, und es mag genïgen, wenn ein jeder von uns seinen Standpunkt klar zum Ausdruck bringt.

\section{Das erste Auftreten von Neuroblasten und von Nervenfasern.}

Die Entwicklung des Markgeriistes geht allenthalben derjenigen der Nervenzellen und Nervenfasern mehr oder minder lang vorans. Bei den jüngsten ron mir untersuchten menschlichen Embryonen von 2.15 bis $3.2 \mathrm{~mm}$ (Lg, Rf, EB) ist das Geriist der Markplatte bereits angelegt, nach imen und nach außen von einer M. limitans eingefaßt. Die Kerne treten, wie schon oben bemerkt wurde, noch beiderseits nahe an die Grenzschichten heran, Sänlensehicht und Randschleier existieren noch nieht als gesonderte Lagen. Keimzellen sind nur sparsam vorhanden.

Über das erste Auftreten von Nervenfasern bei menschlichen Embryonen habe ich in einem meiner älteren Aufsätze berichtet. ${ }^{1}$ ) Bei einem Embryo ron $4 \mathrm{~mm} \mathrm{Nl.}(\boldsymbol{\alpha})$ hatte ich noch keinerlei Nerrenfasern, wohl aber die Anlagen der vier Kopfganglien zu erkennen vermoeht. Bei dem 5 nmm langen Embryo R sind motorische Wurzelfasern bereits sehr scharf unterseheidbar. Als schmale Fortsätze birnförmig gestalteter Zellen sammelı sie sich zu kleinen Bündeln, deren drei oder vier nebeneinander das Riickenmark in dessen ventraler Hälfte verlassen und in die Körperwand eintreten (Fig. 16, S. 34). Hier ziehen die Fasern frei zwischen den Mesenchymzellen hindurch bis zum nächstliegenden Urwirbel, an dessen Grenze sie teils rentral-, teils dorsalwärts mmbiegen. Noch ist es in dorsalen Teil des Ruickemmarks nicht zur Bildung ron Bogenfascrn gekommen, und dementsprechend ist noch keine Andeutung einer rorderen Kommissur vorhanden. Die Spinal-

1) His u. Braunes Archir 1Ss3 S. $153 \mathrm{ff}$.

His, Die Entwicklung d. mensehl. Gehirns. 
ganglien sind bei dem betreffenden Embryo vorhanden und zeigen bereits streifigen Ban, aber sie geben weder an ihrem dorsalen, noch an ihrem ventralen Pol Wurzelfasern ab.

Ich habe seit jener Zeit noch einen brauchbaren Embryo von $4.4 \mathrm{~mm}$ (Oc) geschnitten, dessen Entwicklung der von $\mathrm{R}$ ziemlich gleich kommt. Die

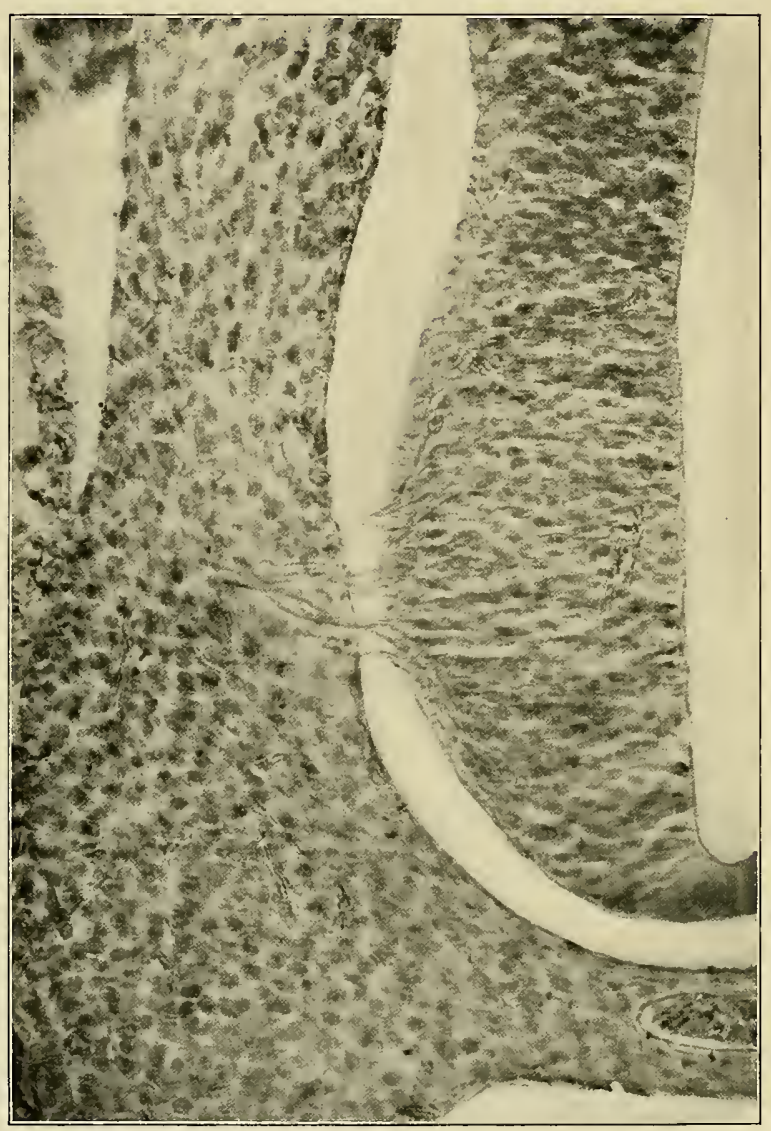

Fig. 16. Austritt motorischer Wurzelbündel aus dem Rückenmark von Embryo R (Nl. 5 mm). Die Fasern lassen sich in der Richtung nach dem Myotom hin verfolgen. (Zu Seite 33.) in dieser Reihe erheblich dümneren Schnitte von $6.6 \mu$ lassen die Einzelheiten noch deutlicher verfolgen. So tritt an manchen Schuitten der bipolare Charakter der Spinalganglienzellen sehr deutlich hervor. Die stärksten Zellen ind abgehenden Fasern zeigt das G. acusticofaciale. Ein Übertritt von sensibeln Fasern in das Markrohr läßt sich indessen anch hier nicht mit voller Sicherheit nachweisen. Stellenweise berühren sich Ganglion und Markrohr, und an solchen Stellen ist die Möglichkeit eines Faseriibertrittes nicht ohne weiteres auszuschließen. Als iibergetretene sensible Fasern lassen sich auch einige sparsame Bündelchen von Längsfasern deuten, die an Frontalschnitten der hinteren Rückenmarkshälfte erkemnbar sind. Es kann sich aber höchstens um die allerersten Anfänge sensibler Wurzelbildung handeln. Neuroblasten mit bogenförmigem Faserverlauf finde ich in der dorsalen Markhälfte noch nicht vor. Anch fehlt jede Andeutung einer vorderen Kommissur. An Frontalschnitten, die den vorderen Markrand streifen, sieht man nur das faserfreie Geriist. Unerwarteterweise fehlen beim Embryo Oc motorische, aus dem Rautenhirn hervortretende Wurzeln. Ich wïrde nicht wagen, diesen negativen Ausspruch durch die bloße Abwesenheit aus dem Mark austretender Fasern 
zu begriinden. Solche Fasern könnten ja bei der Präparation zerrissen sein. Für entscheidend halte ich aber das Fehlen von Fasersträngen in Gewebe jenseits von der M. limitans meningea. Die später so charakteristisch dem Ganglion Gasseri sich anlagernde Portio minor Trigemini vermisse ich vollständig, ebenso den N. facialis, die motorischen Fasern zum Glossopharyngens und Vagus und den N. hypoglossus. Es ist dies um so befremdender, als die motorischen Wruzeln der Rückenmarksnerven bis weit herab angeleg't und zı den zugehörig'en Myotomen verfolgbar sind. Nach anderen Richtungen ist das Rautenhirn hinter dem Riickemmark nicht im Riickstand. Es hat, wie dieses, noch keine vordere Kommissur, aber in seiner ventralen Hälfte findet sich eine wohlansgeprägte Mantelschicht mit charakteristischen Neuroblasten.

Fassen wir die Verhältnisse der beiden Embryonen Oc und R zusammen, so ergibt sich als Hauptresultat 1) daß der Austritt motorischer Wurzeln ans dem Mark dem Eintritt von sensibeln vorausgeht und 2) daß die das Riickenmark als motorische Wurzeln verlassenden Fasern zu den allerfrïbesten Bild ungen gehören.

Die Zeit, während der motorische Wurzeln das Mark verlassen, mag beim menschlichen Embryo auf amnähernd eine Woche zn veranschlagen sein, beim vierwöchentlichen Embryo ist die Zahl der anstretenden Fasern noch gering, beim fünfwöchentlichen dagegen scheint sie, soweit sich dies schätzen läßt, ilıre volle Höhe erreicht zu haben.

Auch das Hereinwachsen sensibler Fasern in das Mark beschränkt sich auf eine kurze Zeitperiode, und noch schärfer als bei den motorischen Wurzeln macht sich hier das sukzessive Hereinwachsen der Fasern geltend. Ton den Sinnesnerven entwickeln sich die Fasern des Acusticus grleichzeitig mit den sensibeln Wurzeln, die des Olfactorins erreichen das Gehirn ein wenig später, und am spätesten finden die ans der Retina hervorwachsenden Fasern ihren Anschluß. Ein nnzweifelhaftes Chiasma ist erst bei Embryonen ron ca. sieben Wochen nachweisbar (Embryo Zw), und es scheint zu der Zeit noch nicht seinen rollen Faserbestand zu haben. Voll ansgebildet sind Chiasma und Tractns am Ende der achten Woche (Mr). Dies späte Auftreten des N. opticus läßt sich damit in Zusammenhang bringen, daß der Nerr im Grund als eine intracerebrale Bahn des Vorderhirns anfzufassen ist.

\section{Das Markrohr beim vierwöchentlichen Embryo.}

Die belehrendsten Bilder für die frühere Geschichte des Gehirns und des Riickemmarks geben Embryonen ron etwa vier Wochen. Die morphologische und die bistologische Gliederung des Medullarrohres sind durchweg: eingeleitet, motorische und sensible Wurzeln sind angelegt, anch die ersten Längsstränge in Bildnng begriffen, und dabei stimmen Gehirn mo Riickenmark noch soweit mntereinander überein, daß sich die Verhältnisse leicht anfeinander beziehen lassen. 
Als Ansgang'spunkt wähle ich den trefflich erhaltenen Embryo Br 3 (von $6.9 \mathrm{~mm} \mathrm{Nl}$.), den ich schon bei früheren Arbeiten mehr oder minder eingehend besprochen habe. ${ }^{1}$ ) Das Rautenhirn ist vorriegend quer geschnitten, das im Bogen verlaufende Rückemmark teils quer oder schräg, teils g'eradezu frontal. Die verschiedenen Schnittbilder ergänzen sich somit in erwünschter Weise. Das Markrohr ist bei Br 3 im Rückenmarksteil stellenweise aufgerissen, im übrigen aber, und so auch im gesamten Gehirnteil geschlossen. Im candalen Stumpf hat es den Charakter eines einfachen Epithelrobres von annähernd zylindrischem Querschnitt. Abgesehen hiervon und von bestimmten Strecken der Deck- und der Bodenplatte hat sich schon iiberall ein durchbrochenes Markgerïst mit schmalem Randschleier ausgebildet. Auch ist in den neuralen Abschnitten des Rohres mit Ausnahme des Vorderhirns und des candalen Endstumpfes die Sonderung der Mantelschicht und ihrer motorischen Kerne schon überall eingeleitet. Letztere bedingen da, wo sie auftreten, lokale in die Imnenplatte einschneidende Verdickungen der Mantelschicht. Als Überblick iiber die absolute und die relative Dicke der Schichten teile ich im nachfolgenden einige Maße mit. Allzugenan sind solche Messumgen ja nicht ausführbar, doch lassen sich bei angemessener Kritik Zahlen erhalten, die untereinander wohl rergleichbar sind. Im allgemeinen habe ich die mittleren Dickenwerte bestimmt, und da, wo die Röhrenwand sich verjüngte, wie bei Annäherung an die Deckplatte und die Bodenplatte, die Messung unterlassen.

\begin{tabular}{|c|c|c|c|c|c|c|c|}
\hline \multirow{2}{*}{$\begin{array}{l}\text { Sehnitt- } \\
\text { nummer }\end{array}$} & \multirow[b]{2}{*}{ Maße in $\mu$} & \multicolumn{3}{|c|}{ Dorsale Hälfte } & \multicolumn{3}{|c|}{ Ventrale Hälfte } \\
\hline & & $\begin{array}{c}\text { Gesamt- } \\
\text { dicke }\end{array}$ & $\mid \begin{array}{l}\text { Mantel- } \\
\text { schicht }\end{array}$ & $\begin{array}{c}\text { Rand- } \\
\text { schleier }\end{array}$ & $\begin{array}{c}\text { Gesamt- } \\
\text { dicke }\end{array}$ & $\begin{array}{l}\text { Mantel- } \\
\text { schicht }\end{array}$ & $\begin{array}{l}\text { Rand- } \\
\text { schleier }\end{array}$ \\
\hline 103 & muteres Thoracalmark & 125 & 16 & 11 & 140 & 70 & 18 \\
\hline $1 \delta_{0}$ & verl. Mark, unteres Ende (Hypogl.) & 165 & 20 & 12 & 190 & 60 & 20 \\
\hline 160 & $" \quad, \quad$ Höhe des Vaguseintritts & 175 & 22 & 10 & 200 & 70 & 22 \\
\hline $14 \mathrm{~s}$ & ", ,Glossopharyng. & 175 & 25 & 15 & 185 & 60 & 20 \\
\hline 136 & " der Gehörblase. & 140 & 20 & 10 & 175 & 62 & 16 \\
\hline 120 & $"$ des Acusticofac. . & 160 & 20 & 10 & 170 & 60 & 18 \\
\hline $9 \mathrm{~s}$ & Rautenhirn, Trigeminuseintritt & 115 & 8 & 9 & 160 & 48 & $1 \mathrm{~s}$ \\
\hline 62 & . . . . . . . . & 130 & 25 & 14 & 130 & 25 & 15 \\
\hline 40 & Nittelhirn . & 122 & 10 & 20 & 140 & 25 & 20 \\
\hline 40 & Thalamus, seitlich . . . . . . & 130 & - & 20 & - & - & - \\
\hline 65 & Hypothalamus . . . . . & - & - & - & 115 & - & 15 \\
\hline 40 & Hemisphärenmantel, seitlich & 110 & - & 10 & - & - & - \\
\hline
\end{tabular}

1) Das Nervensystem rom Embryo Br 3 findet sich besprochen und teilweise abgebildet in den beiden Aufsätzen: 1S\$6 Zur Geschichte des menschlichen Riickenmarks und der Nervenwurzeln. Abh. der k. s. Ges. d. Wiss., math.-phys. Klasse Bd. XIII 1886. No. VI S. 482 ff. und Taf. Fig. 1 11. Zur Geschichte des Gehirns, sowie der zentralen . und peripherischen Nervenbahnen beim menschlichen Embryo ebendas. Bd. XIV 15s8. No. VII Taf. II Fig. 4. 


\begin{tabular}{|c|c|c|c|c|c|c|c|}
\hline \multirow{2}{*}{$\begin{array}{l}\text { Schnitt- } \\
\text { nummer }\end{array}$} & \multirow{2}{*}{ Maße in $\mu$} & \multicolumn{3}{|c|}{ Dorsale Ilalfte } & \multicolumn{3}{|c|}{ Ventrale Hälfte } \\
\hline & & $\begin{array}{c}\text { Gesamt- } \\
\text { dicke }\end{array}$ & $\begin{array}{l}\text { Mantel- } \\
\text { sehicht }\end{array}$ & $\begin{array}{c}\text { Pand- } \\
\text { sehleier }\end{array}$ & $\begin{array}{l}\text { Gesamt- } \\
\text { dicke }\end{array}$ & $\begin{array}{l}\text { Mantel- } \\
\text { schicht }\end{array}$ & $\begin{array}{l}\text { Rand- } \\
\text { schicht }\end{array}$ \\
\hline & $\begin{array}{l}\text { Mittel der sechs Schnitte durch das } \\
\text { Rautenhirn, obne den Isthmus } \\
\text { Gesamtmittel, wobei der Mittelwert } \\
\text { des Rautenhirms einfach ein- } \\
\text { gesetzt ist. . . . . . . . . . }\end{array}$ & 165 & 19 & 11 & 150 & 60 & 19 \\
\hline
\end{tabular}

Die wesentlichsten Ergebnisse der Vergleichnng sind folgende: Die Gesamtdicke der neuralen Markwand schwankt zurzeit noch in verhältuismäßig engen Grenzen. Die maximalen Dickenwerte $(200 \mu)$ fallen in den unteren Abschnitt des verlängerten Markes, die minimalen $(110 \mu)$ in die Großhirnhemisphären. Im Rückenmark, im Rauten- und im Mittelhirn ist die ventrale Hälfte des Rohres der dorsalen voraus, es äußert sich dies nicht nur in der Gesantdicke, sonderu auch in der Dicke des Randschleiers ${ }^{1}$ ) und besonders in der der Mantelschicht. Letztere erreicht ihre stärkste Entwicklung überall da, wo es zur Sonderung motorischer Kerne gekommen ist. Mit dem Aufhören der motorischen Kerne im Mittelhirn hört anch die Ablösung einer ausgiebigen Mantelschicht auf. Nur unbedeutende Fortsetzungen sind längs der unteren Grenze des Thalamushirus zu verfolgen. Das Rautenhirn ist iiberhaupt am weitesten fortgeschritten, daher seine Mittelwerte nicht nur das Gesamtmittel des Markrohrs, sondern auch die Einzelwerte der ïbrigen Gehirnteile und großenteils auch die des Rückenmarks ïberschreiten. Eigentiumlich ist die Stellung des Isthmus; in diesem, seine motorischen Nerven dorsalwärts entsendenden Abschnitt des Hirnrohres ist der Gegensatz zwischen dorsaler und ventraler Hälfte so gut wie gar nicht ausgesprochen, es finden sich selbst Stellen, wo die dorsale Mantelschicht etwas breiter ist, als die ventrale. Das Vorderhirn ist noch in allen seinen Teilen im Rückstand, am meisten das Hemisphäirenhirn. Eine rerhältnismäßig starke Verdickung zeigt die Wand schon jetzt beim Übergang rom Zwischenhirn zur Hemisphäre. Auf diese, sowie auf die iibrigen Dickenschwankungen im Bereich des Vorderhirns werde ich nachher zurickkommen.

Rückenmark. Abgesehen von den motorischen, in der rentralen Hälfte des Markrohres gelegenen Kernen, besteht die Mantelschicht in dieser friihen Periode überwiegend aus bogenförmig angeordneten Neuroblasten und deren Fortsätzen. Bogenzellen und Bogenfasern bilden anfang's eine dïmme, nur

1) Es ist möglich, daß die absoluten Werte für den Randschleier in obiger Tabelle fiir Br 3 etwas zu gering sind, da sich die Narkoberfläche meistenteils von der Limitans meningea abgelöst hat. Bei Embryo $\mathrm{T}$ ist der Zusammenhang noch durchweg erhalten (Fig. 7 11. Fig. 12). 
wenige Zellen breite Schicht, eine Formatio arcuata, die nach einwärts vom zellenfreien Randschleier liegend, das Rückenmark umgreift. Die Bogensehicht entstammt vorzugsweise den Neuroblasten der dorsalen Markhälfte. Ihre Fasern verlanfen ventralwärts und sie durehsetzen und umgreifen die motorisehen Kerne. Ein Teil derselben erreicht die Mittelebene und krenzt sich hier mit den Fasern der andern Seite. Die also zustande kommende vordere Kommissur tritt auch an Frontalschnitten sehr ausgeprägt hervor, und an solchen Schnitten sieht man die parallel gestellten Faserzüge seitlich ans Bündehn hervorgehen, die

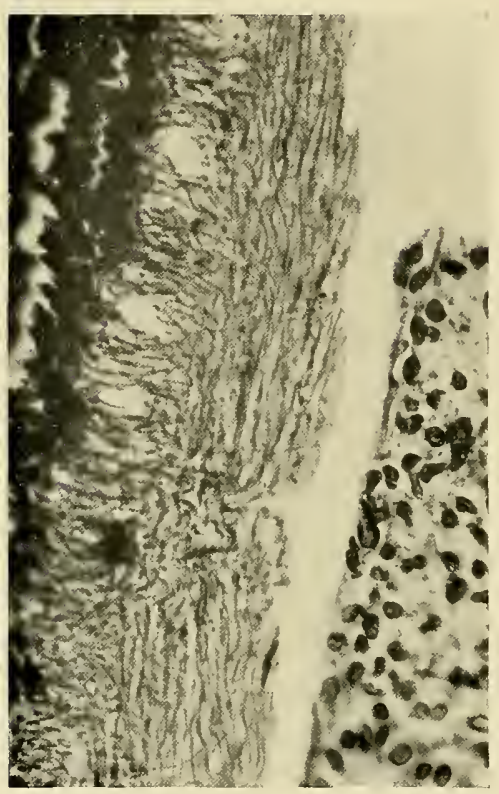

Fig. 17. Frontalschnitt durch das Riickenmark vou Embryo Br 3. Vorderstrang und vordere Kommissur. Die Fasern der letzteren endigen zum Teil abgeschnitten, zum Teil gehen sie in die Längsbïndel des Vorderstranges ïber. dureh Gefäße in einzelne Streifen zerlegt, neben der Kernsäule quer oder schräg* abgeschnitten endigen (Fig. 17). Die Frontalschnitte geben auch gute Anschaumgen von den bereits ziemlich kräftigen Faserbündeln der Vorderstränge und ron der teilweisen Umbiegung ron Kommissurenfasern in dieselben. Die Commissura anterior bildet die eine Quelle der Vorderstrangbündel, eine andere Quelle ist in ungekreuzt bleibenden Bogenfasern zu suchen sowie in Fasem, die ans schräg- oder längsgestellten Neuroblasten herrorgehen. Die Menge der letzteren ist jedenfalls noch unbeträehtlich. An Frontalsehnitten finden sie sich vereinzelt hinter den motorisehen Kernen.

Die motorischen Kerne zeigen sowohl im Quersehnitt als im Frontalschnitt ein sehr eharakteristisches Aussehen. Wie dies sehon meine älteren Zeichnungen (1886) wiedergeben, so sieht man an Quersehnitten Faserbïndel ans der gesamten vordern Markhälfte konvergierend

der Oberfläche zustreben, die sie, in Büindel gesammelt, durehbrechen. An Frontalschnitten (Fig. 18, S. 39) drängen sich die Fasern im immern Mantelgebiet in parallelem Verlauf zwisehen den zahlreichen langgestreekten Kernen dureh, dann sammeln sie sich wiederum zu kleinen Bündeln, deren jedes an die 10-15 Fasern umfassen mag, und die in Abständen von etwa $20 \mu$ das Mark verlassen. Solange die Faserziige parallel zueinander verlanfen, stehen anch die Kerne, sowohl der Spongio- als der Neuroblasten unter sich parallel, d. h. senkrecht zur Oberfläche; da, wo die Bündel sich zu sammeln begimnen, finden sich querdurehschnittene (kreisrunde) Kerne, d. h. Kerne von Bogenfasern. Weiter nach einwärts finden sich 
aneh Neuroblasten, deren Fasern bogenförmig in den benachlbarten Längsstrang ïbergehen.

Die Hauptmasse der Längsbündel liegt als Anlage des Vorderstranges vor dem vorderen. Wurzeln, im Winkel zwischen dem rentralen Ende der motorischen Kerne und dem Beginn der Bodenplatte. Andere Längsfasernbündel durehkrenzen sich mit den den Randschleier durchsetzen-

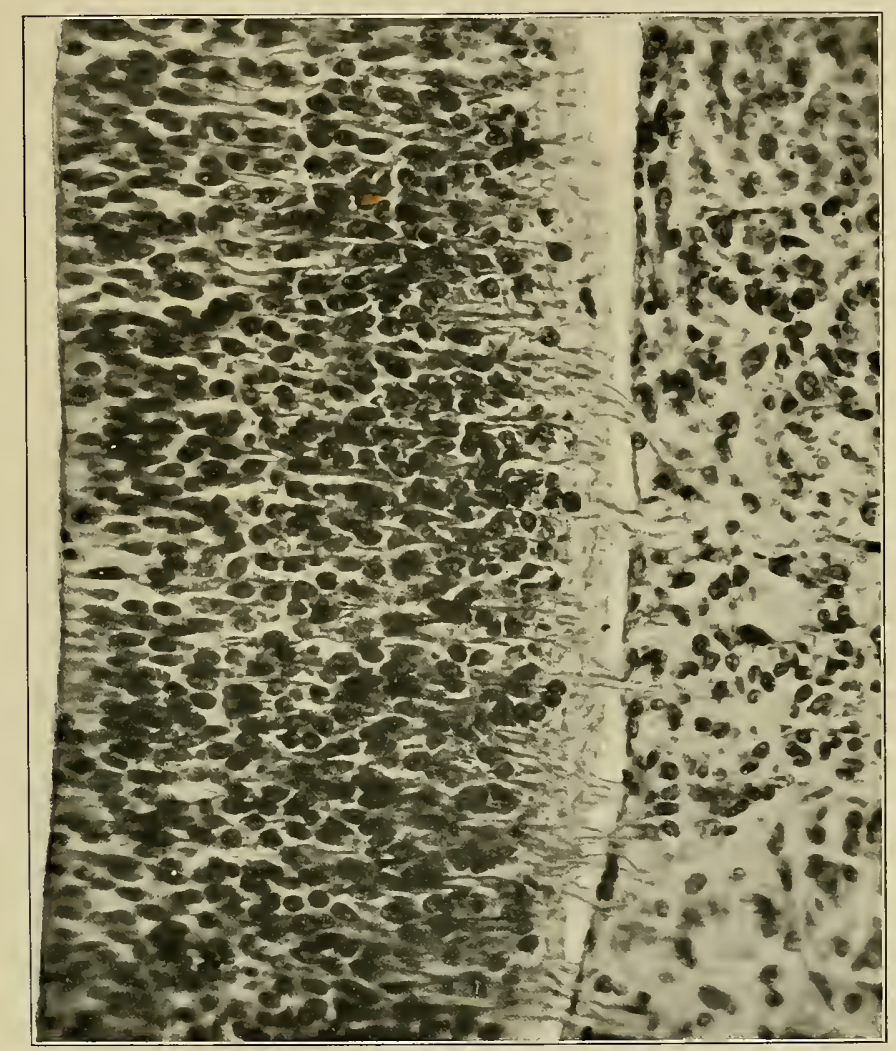

Fig. 18. Frontalschnitt des Ritckenmarkes ron Embryo Br 3. Motorisehe Wurzelbuindel innerhalb und auferlaalb des Markes. (Zu Seite 38.)

den motorischen Wuzehn, und endlich liegt ein Teil noch hinter den Wurzeln im Gebiet des rordern Seitenstranges. Von da ab folgt eine breite Strecke, deren Randsehleier keine Fasern enthält. Dicse Strecke wird nur unterbrochen dureh das zurzeit noeh sehr dünne, aus den eintretenden sensibeln Wurzeln gebildete Hinterstrangbundel. Dieses liegt dicht unter der Oberfläehe aber noch im Randsehleier, dessen Bälkchen hier anseinandergetrieben erscheinen.

Ich habe rersucht, dureh Messungen und durch Fasernzälılung ïber das Hinterstrangbündel etwas bestimmtere Unterlagen zu gewinnen. Zn dem 


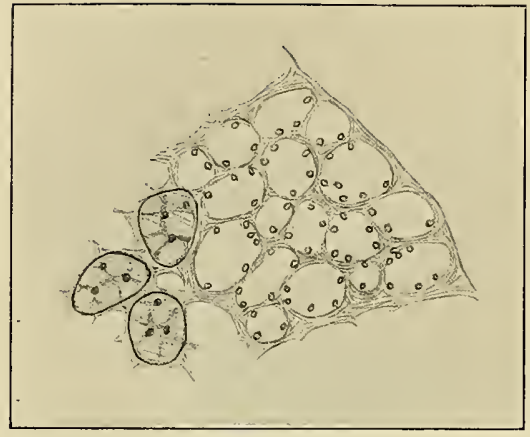

Fig. 19. Prismenzeichnung des Hinterstrangquerschnittes an Embryo $\mathrm{Br}$ 3. Geriist mit den eingelagerten Faserquerschnitten, links drei zım Gerïst gehörige Kerne.
Zweck habe ich bei starker (1000 facher) Vergrößerung Prismenzeichnungen aufgenommen (Fig: 19). Am Rückenmark von $\mathrm{Br} 3$ zeichnet sich der Hinterstrang als helles Feld $a b$, innerhalb dessen die Faserquerschnitte als dunkle Punkte zerstrent liegen. Die letzteren sind dentlich genug, um gezeichnet und in der Zeichnung gezählt werden zn kömnen.

Im Bereiche des untern Thoracalmarkes beträgt an den senkrecht zur Achse geführten Schnitten:

Der Flächeninhalt eines Hinterstranges mit dem Planimeter gemessen rund $500 \square \mu$, die Zahl der unter scheidbaren Faserquerschnitte 80 bis 90 . Kleine Fehler sind möglich, ich glaube aber nicht, daß sie $10 \%$ überschreiten.

Bei Embryo N von $10.9 \mathrm{~mm}$ Nl ergibt sich im untern Thoracalmark:

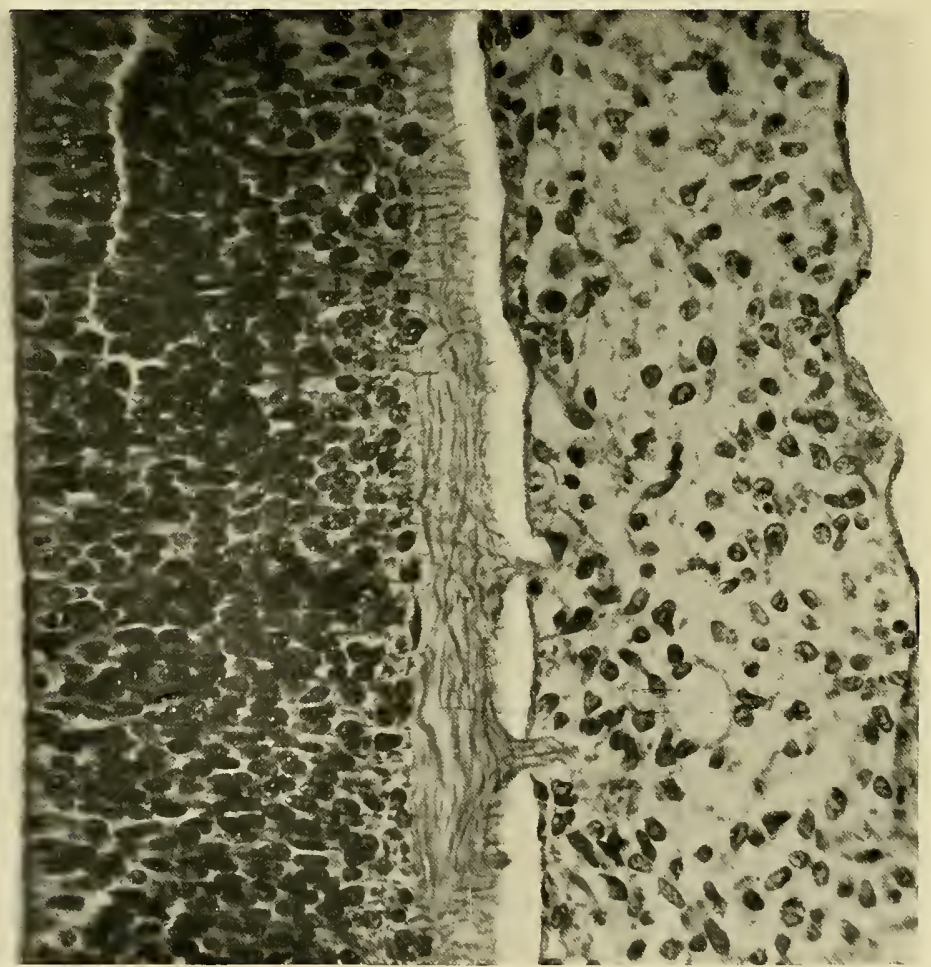

Fig. 20. Frontalschnitt aus dem Rïckenmark von Embryo Br 3.

Hinterstrang und Eintritt hinterer Wurzelfasern, Auseinanderweichen der letzteren. (Zu Seite 41.) 
Der Flïcheninhalt eines Hinterstranges rund $12000 \square \mu$, im oberen Thoracalmark bestimme ich denselben Wert auf $22500 \square \mu$.

In gleicher Höhe ist also von B 3 zu N, d. h. im Verlauf der fünften Woehe, der Querschnitt auf das 24 fache gestiegen. Dabei zeigt sich bereits sehr ansgesprochen die Zunahme der Hinterstränge ron unten nach aufwärts. Die Zahl der Fasern läßt sich bei $N$ anuähernd schätzen. Diese liegen nämlich hier mindestens so dicht, eher noch dichter als bei $\mathrm{Br} 3$. Ihre Zahl muß somit beim unteren der beiden gemessenen Schnitte mindestens 200n, beim oberen geg'en 4000 betrag'en.

An frontal getroffenen Schnitten von $\mathrm{Br} 3$ ist direkt zu beobachten, wie die sensibeln Wurzelfasern bei ilıem Eintritt ins Mark nach oben und nach abwärts nmbieg'en und den Hinterstrangbiindeln sich anlagern (Fig. 20, S. 40). Noch sind die Wurzelfasern im Auswachsen begriffen, und nach den anderweitigen Erfahrungen iiber diesen Vorgang ist anzunehmen, daß sie erst auf verhältnismäßig kurze Strecken angelegt sind.

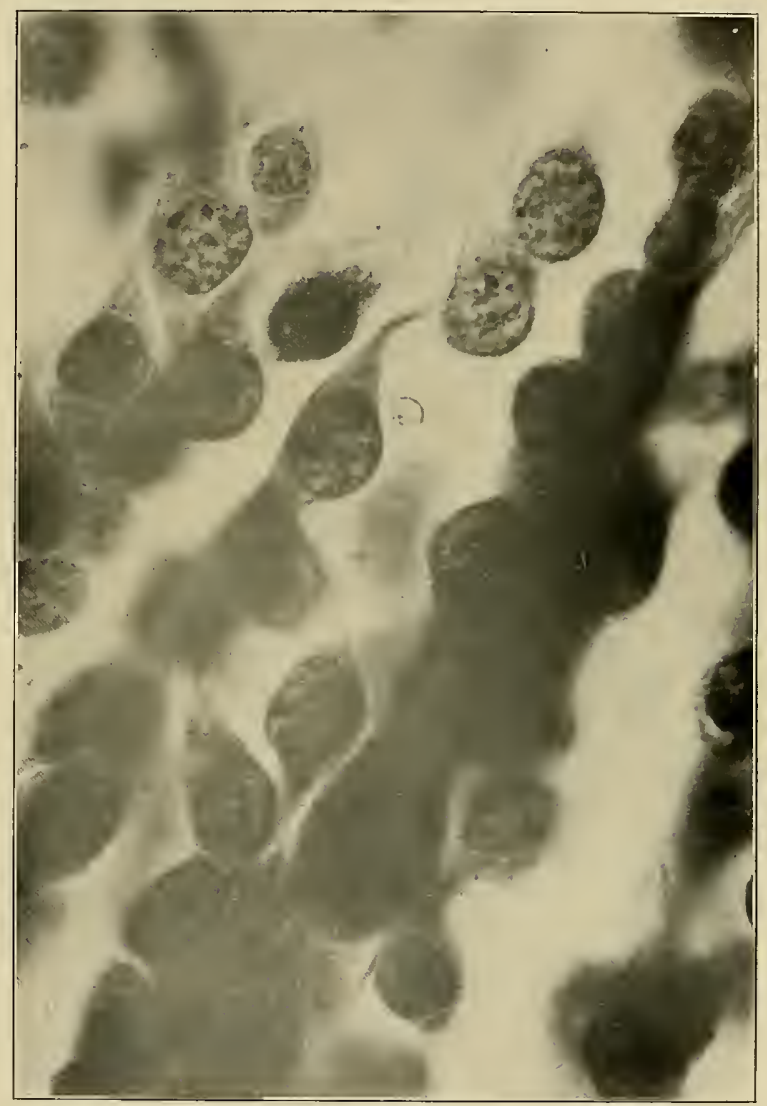

Fig. 21. Aus einem Spinalganglion am Embryo $x$. Die freiliegende Zelle zeigt in ihrem oberen Ansatzkegel die im Imern rorhandenen fibrillären Streifen. (Photogramm ohne jegliche Retouche.)

(Zu Seite 42.)

Es ist demmach anzu-

nehmen, daß sieh das Hinterstrangbündel in jeder gegebenen Höhe erst aus wenigen benachbarten Wurzelbüudeln zusammensetzt.

Firr die Beobachtung der Spinalganglien erweist sich der rorhin erwähnte Embryo $N$ als besonders giinstig (Fig. 15, S. 31). Die Zellen bilden langgezogene Gruppen, deren jede einem kleinen Faserbuindel entspricht, und die weite Spalträume zwischen sich frei lassen. Die Faserbündel sammeln sich einerseits zu zentralen, anderseits zu peripheren Stämmchen. Erstere erreichen den rentralen Rand des nunmehr ansehnlich gewordenen 
Hinterstranges und strahlen unter pinselförmiger Ausbreitung in ihn ein. Die ventral gelegenen Wurzelbündel stoßen am ventralen Ende des Ganglions auf die motorisehen Faserzinge, mit denen sie'sich vermengen. Gleieh jenseits von der Vereinigungsstelle spaltet sieh der Ramus dorsalis vom Ramus ventralis ab. Da, wo die Spinalganglienzellen isoliert hervortreten, zeigen sie die bekannte Spindelform mit seitlieh gelagertem Kern. Vermittels eines breit begimmenden Konus gehen sie in die sehmalen Endfasern über, die man in gestreektem oder leieht wellenförmigem Verlauf oft weithin verfolgen kamn. Der Ansatzkonus läßt in

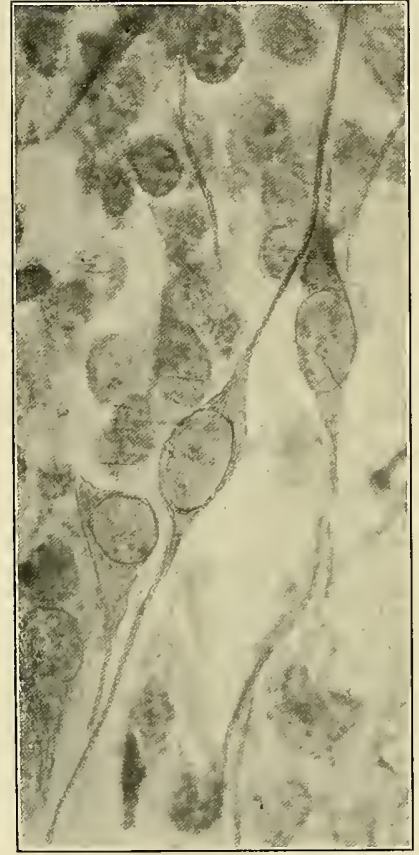

Fig. 22.

Spinalganglienzelle mit zwei langen Nervenfortsätzen (äberzeichnet). seinem Innern eine Anzahl fibrillärer Streifen erkemen, die eine Streeke weit noeh in die Faser hinein verfolgbar sind. Mit der Annäherung an den Kern weiehen sie auseinander, indem sie ihn umfassen. Bei dem zur Illustration dieses Verhaltens mitgeteilten Photogramme (Fig. 21, S. 41) ist absichtlieh jegliehe Retonehe vermieden worden. Fig. 22 zeigt eine isoliert liegende Zelle nit zwei langen Nerrenfortsätzen.

Die Nenroblasten und Faserbahnen des Gehirns bei $\mathrm{Br}$ 3. Das allgemeine Sehema des Rüekenmarkbanes kehrt beim Rau'tenhirn wieder, insofern aneh hier die ventrale Hälfte motorische Keme liefert und die dorsale Hälfte seusible Wurzeln aufnimmt, und als aneh hier ein System ron Bogenfasern ans der dorsalen in die ventrale Markhälfte übertritt. Immerhin finden sich eine Reihe vou Besonderheiten: die motorisehen Kerne bilden keine fortlaufenden Reihen mehr, und sie zerfallen in zwei nebeneinander herlanfende Gruppen, die der Seitenhorn- und der Vorderhornkerne, deren Wurzelfasern in zwei weit auseinanderliegenden Zeilen das Mark rerlassen. Spezifisehe Eigentïmlichkeiten bieten der Verlauf des N. faeialis und der des $\mathrm{N}$. troehlearis, von denen jener auf einem winkligen Umweg. die Obcrfläehe erreicht, während dieser als einziger von allen Körpernerven zur Deeke des Markrohres emporsteigt und hier mit dem der andern Seite sich krewzt. Die sensibeln Wurzelfasem lagern sich aneli dem Rantenhirn anfangs nur oberfläehlieh an, aber sie sammeh sieh nieht zu einem einheitliehen Strang, wie im Rückemmark. Es bildet sieh einesteils der Traetus solitarius, in den, außer Fasern des Vagus und Glossopharyngeus, noeh solehe des $\mathrm{N}$. intermedius und des restibularis eintreten, andernteils entsteht als gesondertes Hinterstrangluindel die Wurzel des N. trigeminus. 
Alle in das Rautenhirn eintretenden Faserzüge sind auf der Stufe vom $\mathrm{Br}^{\circ} 3$ noch sehr kurz. ${ }^{1}$ )

In Fig. 23 habe ich versucht, die Verteilung und Anordnung der Neuroblasten im Gehirn von $\mathrm{Br}^{\circ} 3$ übersiehtlich zusammenzustellen. Gleich wie das Rückenmark, so enthält auch das Rautenhirn in sciner dorsalen Hälfte ventralwärts gekehrte Neuroblasten, die im allgemeinen in kurze Bogenfasern auslaufen. Thre Nenge ist noch unbeträchtlich, und sie rerlieren sich am Übergang vom Isthmus zum Nittelhirn. In der ventralen Markhälfte sind die Neuroblasten viel reichlicher angehäuft, und in untunter-

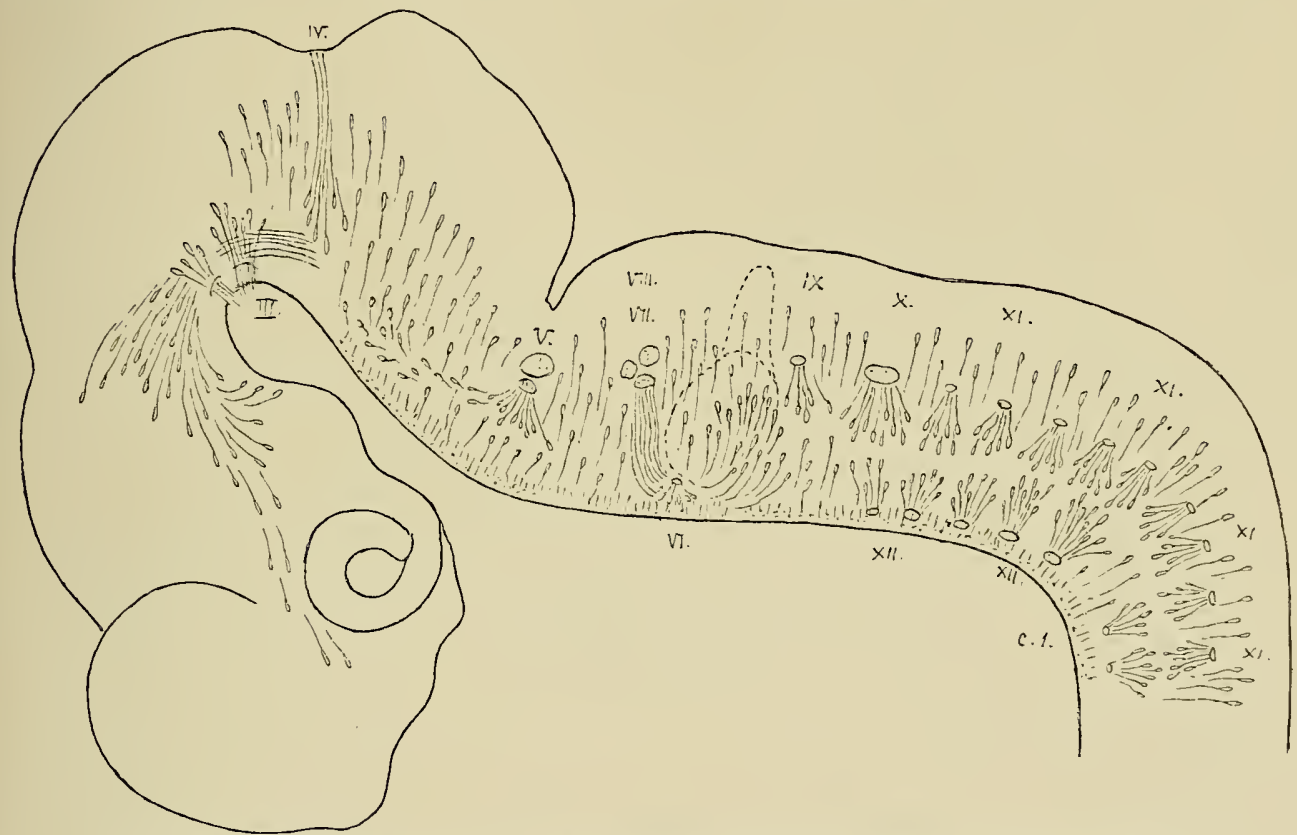

Fig. 23. Gehirnprofil ron Embryo Br 3 mit eingezeichneten Neuroblasten. Konstruktionsbild.

brochener Reihenfolge erstrecken sie sich bis zum Hypothalamus. Für ihre Anordnung läßt sich keine durchgreifende Regel aufstellen, wem sieh auch nicht verkemnen läßt, daß ein dorsal- oder ventralwärts gerichteter bogenförmigen Verlauf der Fortsätze das vorwaltende Vorkommuis ist. Eine Commissura basalis findet sich ron der Nackenbeuge ab bis in die Höhe des Trigeminusanstrittes. Sie ist nirgeuds sehr stark und rechselt etwas in ihrer Mächtigkeit. In obern, der Sattelspalte zugekehrten Teil des Rautenhirns ist die Kommissur durch wenige Querfasern rertreten und auch diese Spuren rerlieren sich noch ror Erreichung des Isthmus.

1) Ich verweise hier anf meinen Aufsatz rom Jahre 1sss: ..Znr Geschichte des Gehirns" und auf die darin mitgeteilten Zeichnungen. 
In letzterem, sowie in der Mittelhirnbasis finden sich keinerlei Kommissurenfasern. Ein großer Teil der Neuroblasten des ventralen Rantenhirns sind Wurzelzellen. Von der Rückenmarksgrenze ab.bis in die Nähe der Gehörblase folgen sich die Wurzelbiundel der ventral austretenden Hypoglossusreihe und der dorsolateral gelegenen Reihe vom Aceessorins, motorischen Vagus und Glossopharyngeus. Ihnen entspreehen die zugehörigen Nervenkerne, von denen der des Hypoglossus stellenweise sehon reeht ansehnlich

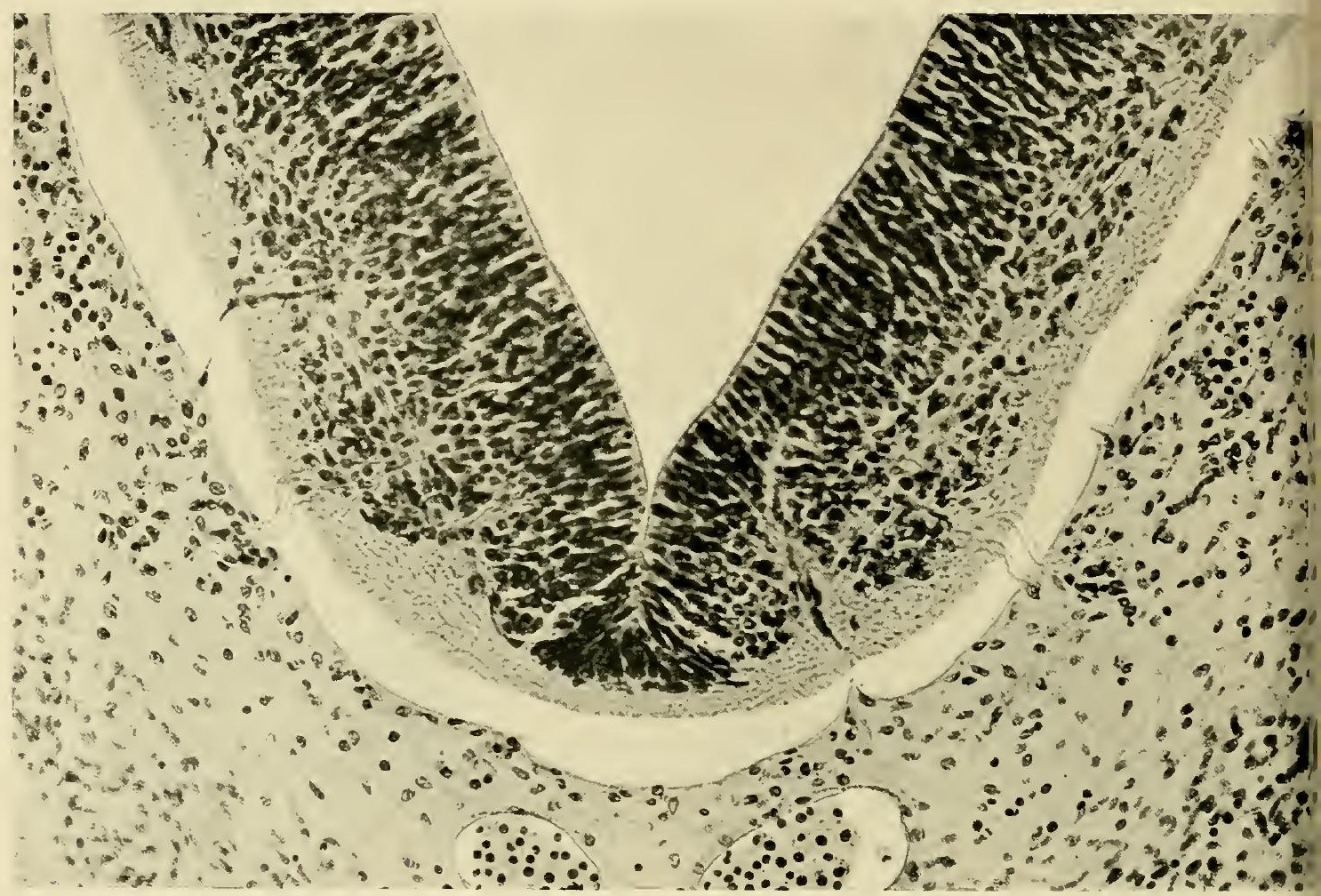

Fig. 24. Medulla oblongata vom Embryo Br 3. Man sieht daran die beiden Hypoglossuskerne mit den abgehenden Wurzelfasern. Rechts sind auch einige Fasern vom Accessorius, sowie der Accessoriuskern zu erkemnen. Die an mehreren Stellen sichtbaren dunkeln Spitzen gehören Gefäßanlagen an.

erseheint (Fig. 24). Der Hypoglossuskern wird von kräftigen Zïgen von Bogenfasern durchsetzt und umgriffen, die medialwärts in die vordere Kommissur eintreten. Sie entstammen Nemroblasten der ventralen Markhälfte, die zum Teil verschränkt mit den Hypoglossuszellen liegen. Dorsalwärts vom Hypoglossuskern folgen Zellen, die ilıre Fasern an die Aecessoriusreihe abgeben. Anch diese haben, bevor sie zur Oberfläehe umbiegen, den Charakter von Bogenfasern.

Über der Austrittsstelle der Aceessoriusfasern liegt der Markoberfläehe ein Längsbiundel an, in das der $N$. vagus und N. glossopharyngeus mit 
ihren sensibeln Fasern eintreten. Es ist dies der zu der Zeit noch völlig oberflächlich gelagerte Traetus solitarius. Fig. 26, S. 46, zeigrt den Tractus solitarius mit den cintretenden Vagusfasern vom Embryo $\mathrm{Br} 3$; anch anstretende Accessoriusbïndel sind an dem Schnitt sichtbar. Ich schicke der Figur ein Durchsehnittsbild rom Embryo Ko $(10.2 \mathrm{~mm})$ vorans, an dem außer den Vagus- und Aceessoriusbiundeln und dem großen Vagusganglion aneh austretende Hypoglossuswurzeln zu sehen sind (Fig. 25).

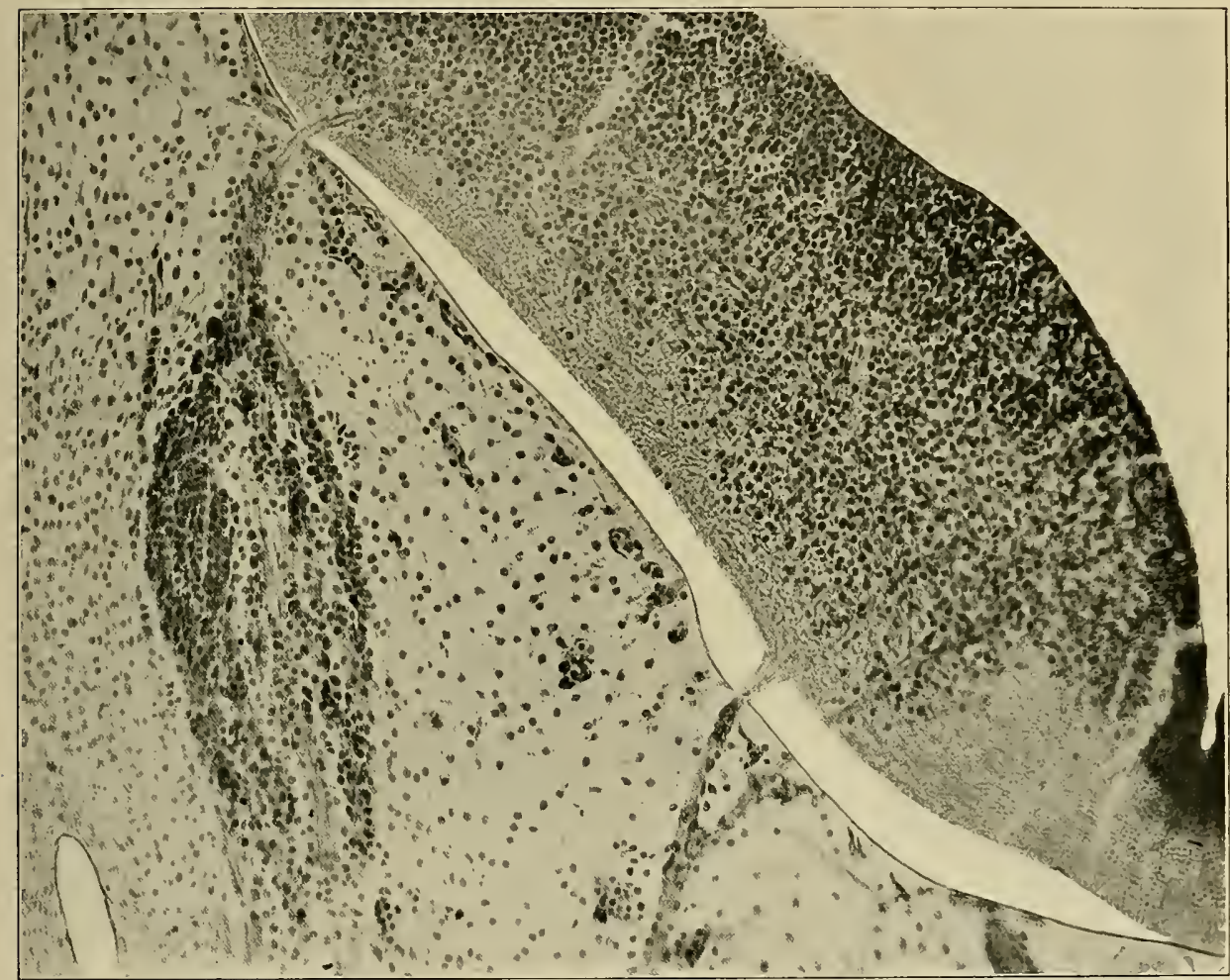

Fig. 25. Ganglion und sensible Wurzehn des N. Vagus. Tractus solitarius, Accessoriuskern und Wurzeln, Hypoglossuswurzeln. Embryo Ko.

Mit der Annäherung an die Gehörblase wird das Bild ein andres. In der ventralen Markhälfte erscheinen nun reichliche, ventralwärts sich $\mathrm{zu-}$ spitzende Neuroblasten. Ihre Faseru treten großenteils in die inneren Lagen der Mantelsehicht und charakterisieren sich als Wurzel des $\mathrm{X}$. facialis. Der Facialiskern reicht bis uiber den rostralen Rand der Gehörblase hinaus, dam folgt dicht unter der Oberfläche der ziemlich kompakte Abdncenskern und jenseits davon das breite Bündel des anstretenden $\mathrm{N}$. facialis.

Ton den mitgeteilten Schnitten zeigt Fig. 27, \$. 47, die Gelı̈rblase, Fig. 28, S. 48, das dreigeteilte Ganglion acnsticofaciale und den anstretenden 
N. facialis. Ein kleiner Einriß trennt die Übergangsstelle der Facialisund Acusticuswurzeln vom übrigen Markrohr. Bei Fig. 27 ist auch der

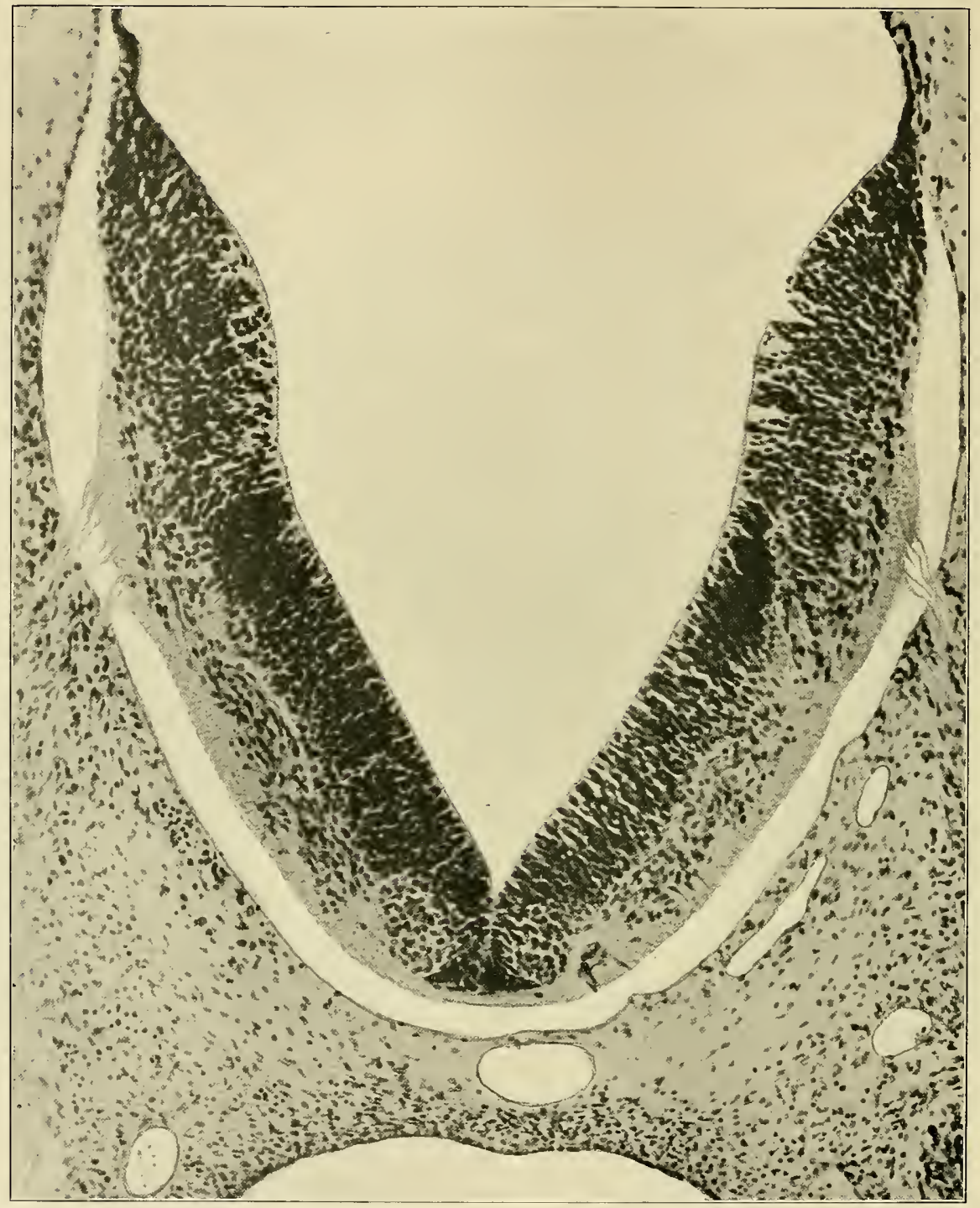

Fig. 26. Eintritt sensibler Glossopharyngeusfasern in den Traetus solitarins, links Austritt motorischer Fasern der Accessoriusreihe aus dem Mark, Embryo Br 3. Der Hypoglossuskern ist jederseits als gesonderte Masse der Mantelschieht erkennbar, aber es liegen keine austretenden Wurzelfasern im Schnitte. (Zu seite 45.)

kleine dreieckige Nervenkern zu sehen, den mein Sohn ${ }^{1}$ ) an diesem Präparat aufgefunden hat, und dessen Fasern er in den Facialisstanm verfolgen

1) W. His jun., Entwicklungsgeschichte des Acustico-Facialisgebietes in His und Braunes Archiv. 1589 Suppl. S. 7. 
kounte. Das Verhalten dieses kleinen Kernes auf spätern Stufen bedarf noch der Aufklärung.

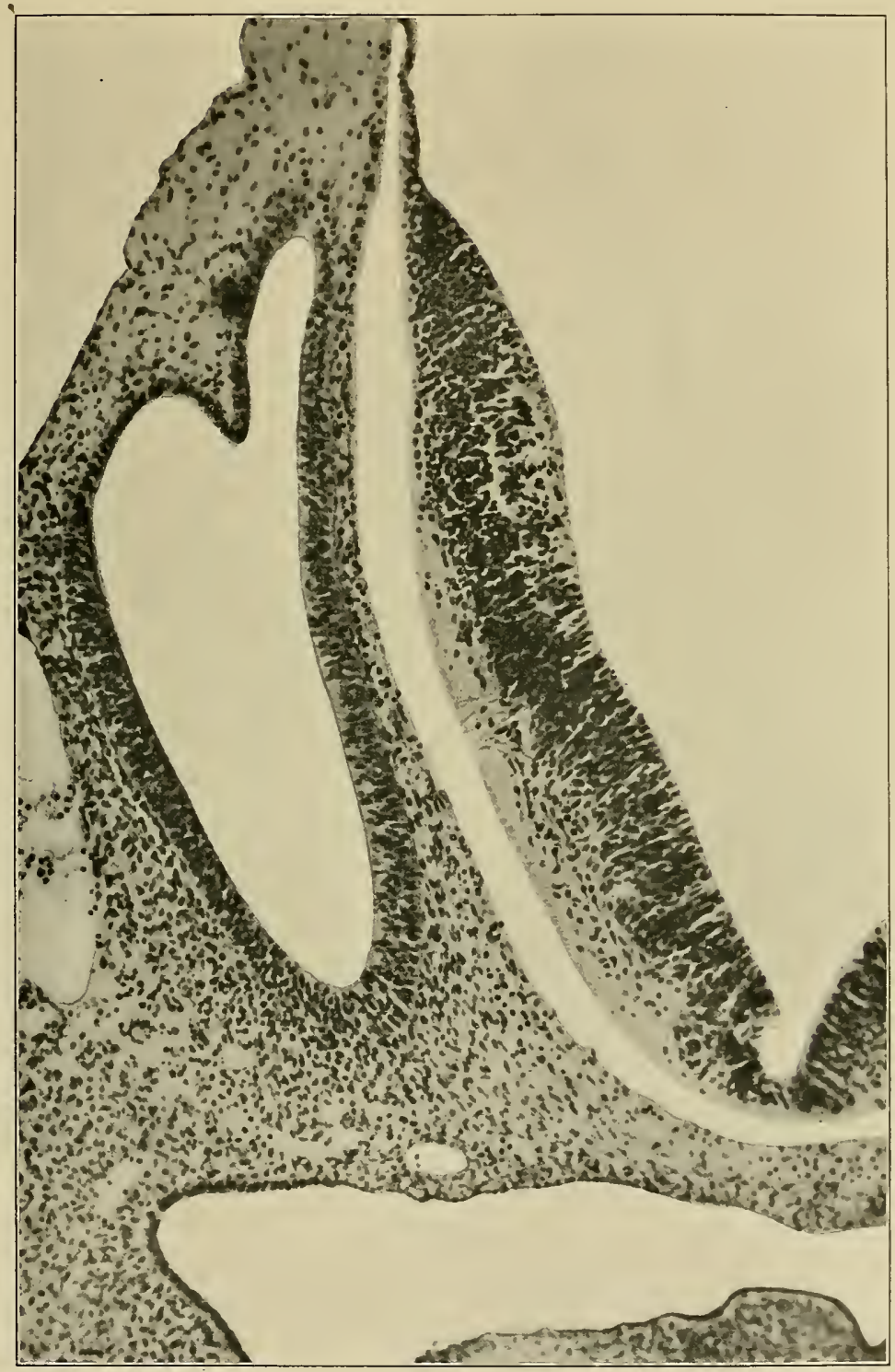

Fig. 27. Gehörblasen und Rautenhirn rom Embrỵo Br 3. Die Fasern des Facialiskernes verlaufen in der Mehrzahl medialwärts. Ein accessorischer kleiner Fern entsendet seine Fasern in der Richtung nach der Oberfläche. (Zu Seite 45 u. 46.)

In diesem frïhen Stadium bietet der Facialiskern noch wenig spezifische Eigentimlichkeiten. Medial gerichtete, der rentralen Markhälfte angehörige Neuroblasten finden sich anch in höher und in tiefer gelegenen Distrikten des Rautenhirns, mit dem Lnterschied allerdings, daß sie nirgends 
sonst zu einem gesonderten, das Mark verlassenden Bündel zusammentreten. Anch die Strecke zwischen dem Facialisaustritt und dem motorischen Hauptkern des Trigeninus enthält Neuroblasten mit Bogenfasern. Ein Teil der letzteren ist bis zuir basalen Kommissur zu rerfolgen, andere scheinen in Längsbïndel umzubiegen. Dazwischen finden sich auch einzelne rïckläufige Neuroblasten.

Der motorische Hauptkern des Trigeminus tritt dadurch sehr dentlich in Erscheinung, daß seine Zellen gegen die Narkoberfläche andrängen und

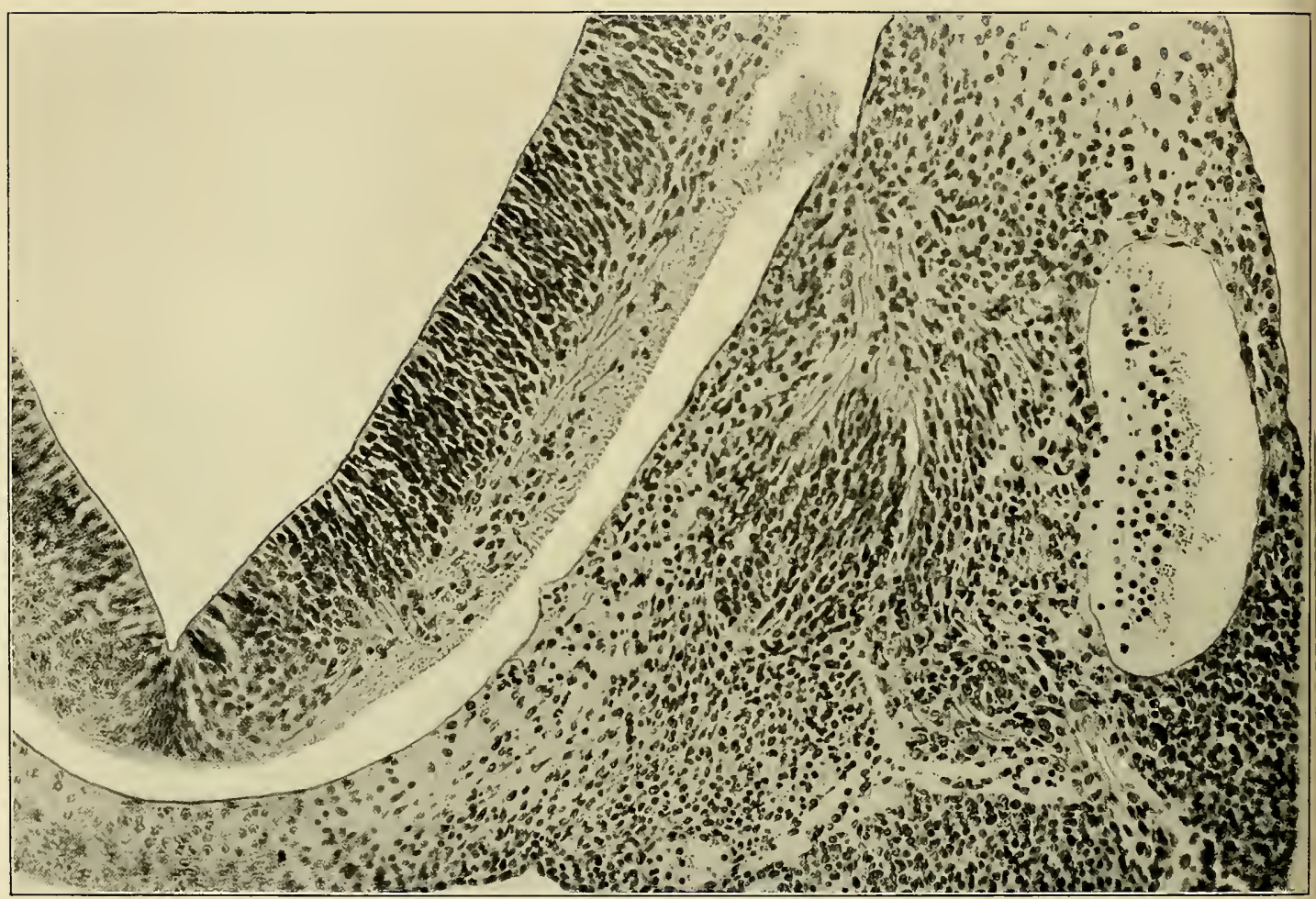

Fig. 28. Rautenhirn und Ganglion acustico-faciale von Embryo $\mathrm{Br}$ 3. Im Rantenhirn sieht man stellenweise die zur Austrittsstelle emporsteigenden Facialisfasern, anßerdem aber auch medialwärts gerichtete Fasern. Die nnweit von der Mittelebene gelegenen, radiär gerichteten Fasern gehören dem N. abdncens an. Im Ganglienkomplex liegt das großzellige G. geniculi an meisten ventralwärts, und es schiebt sich eine Streeke weit zwisehen das G. cochleae nnd G. vestibuli ein. Die Anschlußstelle der Nervenwurzeln an das Mark ist etwas eingerissen. (Zu Seite 45.)

diese nach Art eines Keiles gegen das GASSER sche Ganglion vorschieben (Fig. 29, S. 49). Ans der Kante des Keiles tritt das dichte Büschel ron Wurzelfasern hervor, das sich weiterhin als Portio minor Trigenini der medialen Ganglienfläche dicht anschmiegt. Der motorische Trigeminnıskern erweist sich als ein Seitenhornkern, die große Mehrzahl seiner Zellen liegen indessen medialwärts ron der Anstrittsstelle. Die Zellen der Vorderhorn- 
zone entsenden ihre Fasern teilweise medialwärts. Tielc derselben sind schräğ angeschnitten nud daher nicht weiter rerfolgbar. Lateralwärts rom motorischen Trigeminuskern liegt als flaches, querdurchschnittenes Bündel der Tractus Trigemini, in den man vom Ganglion Gasseri aus Faserziige eintreten sieht (Fig. 30, S. 50).

Die Strecke zwischen dem Trigeminnsanstritt und dem Beginn des Isthmus bietet keine einfachen, eindentigen Bilder. Eine basale Kommissur

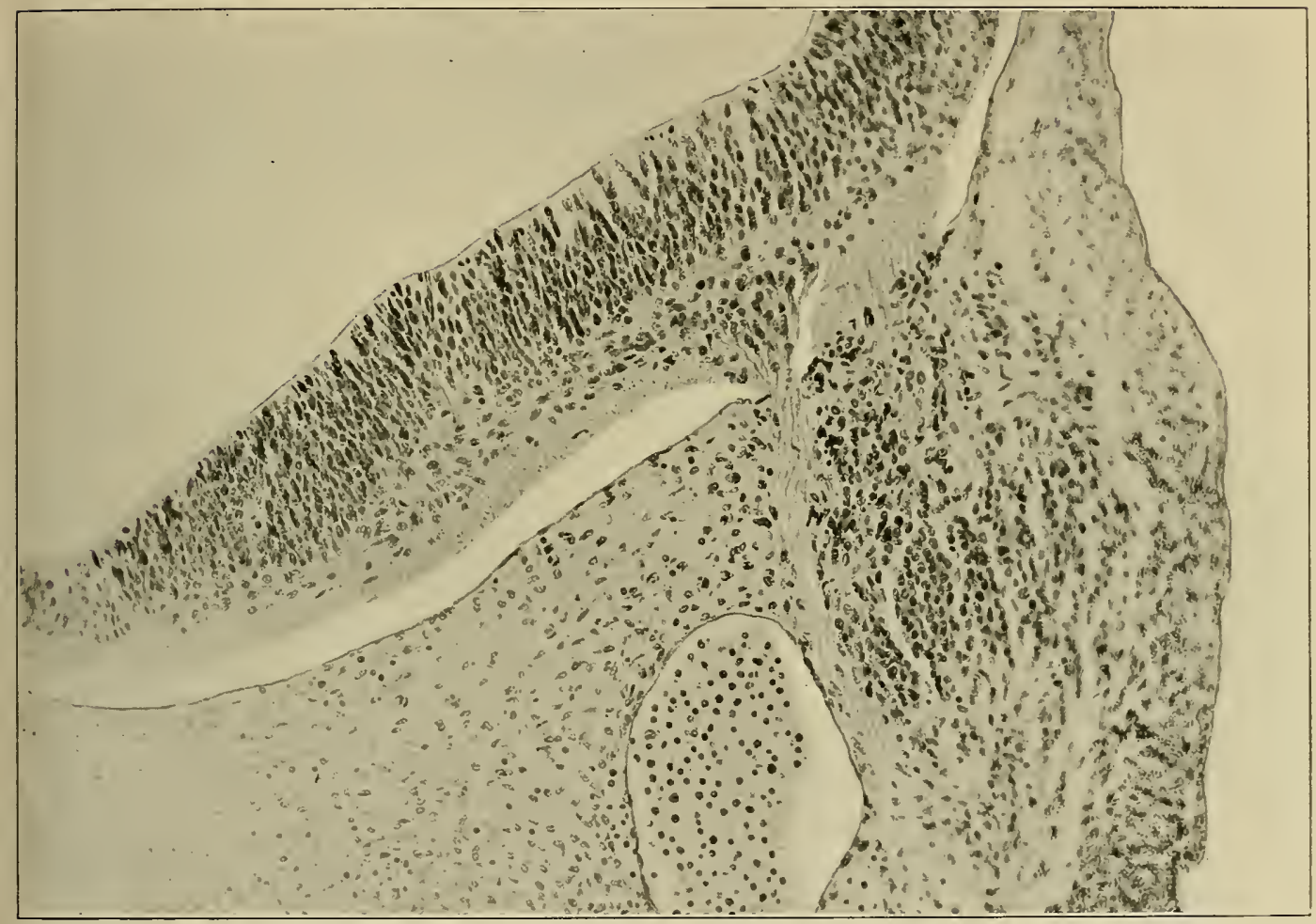

-Fig. 29. Embrro Br 3. Motoriseher Hauptkern des N. trigeminus mit der Portio minor, dem Ganglion Gaßeri und den aus diesem ins Mark eintretenden sensiblen Wurzelfasern. (Zu Seite 48 .)

findet sich kanm andeutungsweise. Die rentrale Mantelschicht ist im allgemeinen ziemlich breit, aber ihre Kerne und Zellen liegen anscheinend regellos durcheinander. Es ist mir wahrscheinlich, daß ein Teil der Zellen der absteigenden Trigeminuswurzel angehört, aber eine scharfe Sonderung: dieser Anlage rermag ich nicht durchzuführen. Mit der Annähermug an den Isthmus wird das Querschnittbild wieder regelmïBiger, dorsale und ventrale Hälfte zeigen wieder basalwärts gerichtete Neuroblasten und Bogenfasern.

Der Isthmus charakterisiert sich, abgesehen ron seiner geringen Teite und seiner Abplattung, durch seine Beziehungen zun $\mathrm{N}$. trochlearis (Fig. 31. 
S. 51). Die Bündel dieses Nerven verlaufen nach einwärts vom Randschleier und teilweise nach einwärts von der dorsalen Mantelschicht. Die Zellen der letzteren zeigen, insoweit sie nicht schräg getroffen sind, ventrale Fortsätze. Auf die Frage, ob der N. trochlearis aus einem Seitenhorn- oder einem Vorderhornkern komme, möchte ich nicht zuviel Gewicht legen. Die Zellengruppen, denen seine Fasern entstanmen, liegen zum Teil in den Seitenabschnitten, zum Teil in den basalen Strecken der Mantelschicht. ${ }^{1}$ )

Beim Übergang zum Mittellim verbreitert sich das Markrohr, besonders an seiner Basis und nun sammeln sich aus der ziemlich breiten Querzone

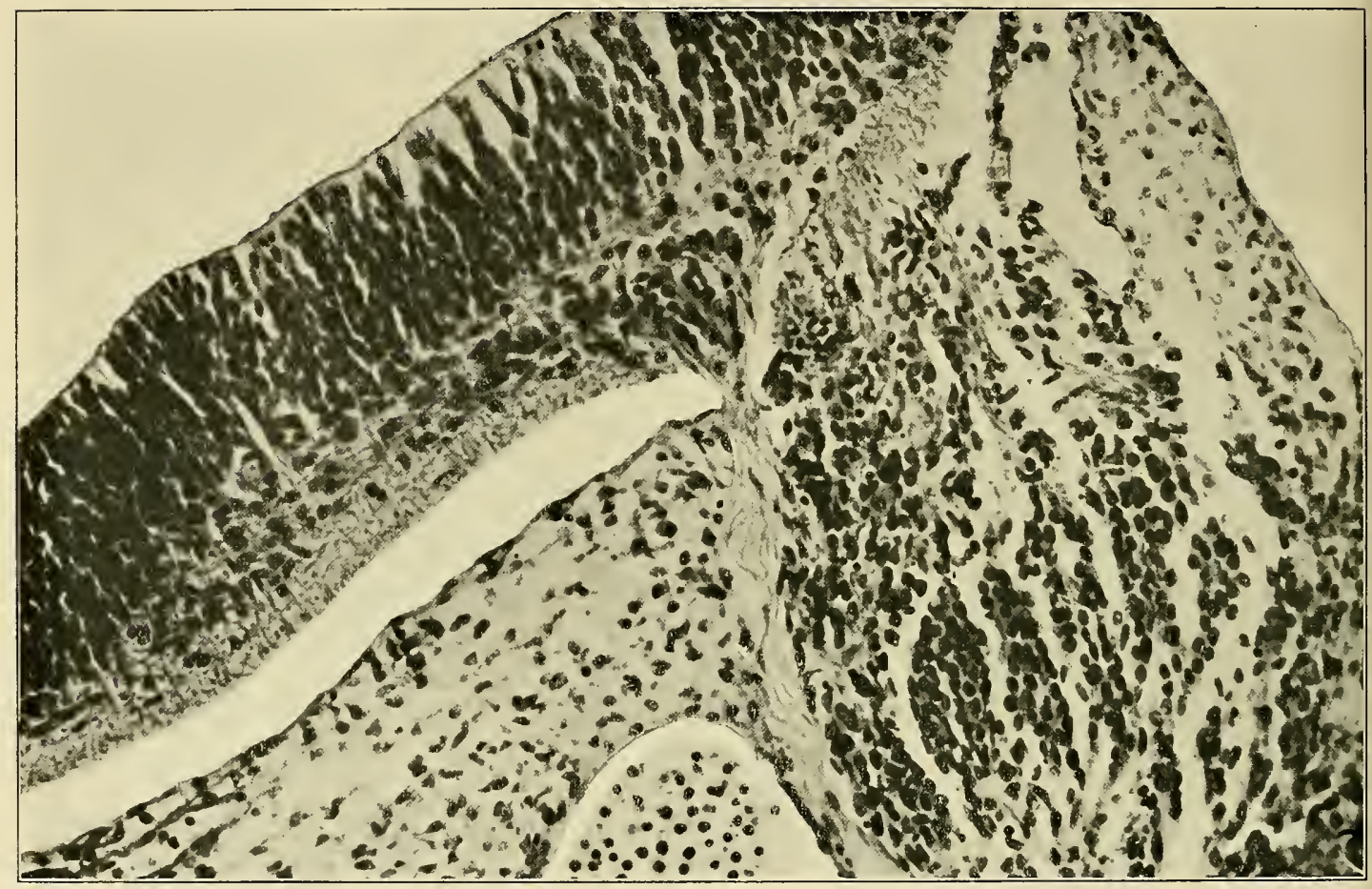

Fig. 30. Anderer Schnitt aus derselben Gegend, etwas stärker vergrößert. (Zu Seite 49.)

nebeneinander liegende Oculomotoriusbïndel. Der N. oculomotorius ist ein ausgesprochener Vorderhornkern (Fig. 32, S. 52). Der Seitenhornanteil der Mantelschicht beteiligt sich an der Bildung von ventralwärts gerichteten Bogenfasern. Die Decke des Mittelhirus ist in ihrer Entwicklung wenig

1) Max Fürbringer, Morphologische Streitfragen Morphol. Jahrb. XXX 1902 S. 105, spricht denselben Gedanken aus, daß in Bezirk des Trochlearis- nnd des Oeulomotorinskernes die medial-motorische und die lateral-motorische Nervenreihe nicht so scharf ansgesprochen sei, wie im iibrigen Hanptteile des Kopfes und im Rumpfe. In diesem Punkte nähern sich unsre Auffassungen, in andrer Hinsicht stehen wir auf völlig verschiedenem Boden. 
fortgeschritten. Einige zerstrent liegrende Bogenfasern finden sich in rer an den Isthmus stoßenden Strecke.

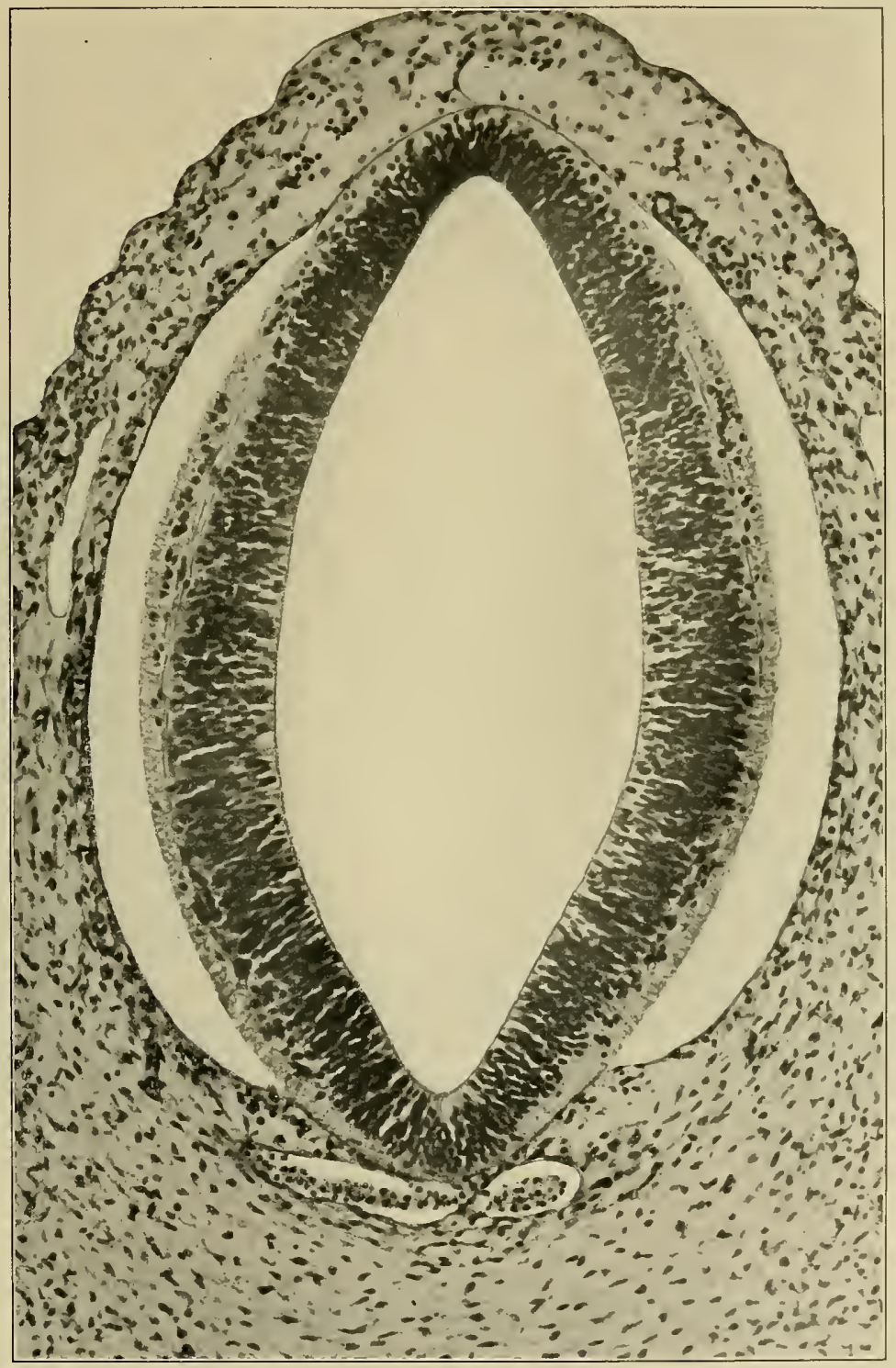

Fig. 31. Embryo Br 3, Isthmus, bciderseits sieht man eine Strecke weit dem Trochleariskern und die dorsalwärts emporsteigenden Trochleariswurzeln. (Zu Seite 49.)

Auch in der Decke des Zwischenhirns sind kaum spuren einer neuroblastenführenden Mantelschicht vorhanden. Die Hemisphären sind daron völlig frei. Dagegen erstreckt sich eine fortlaufende Kette ron Neuroblasten 
mit medullarwärts geriehteten Fortsätzen längs der Grenzen des Hypothalamus von der Gegend des Augenblasenstieles ab bis zum Beginn des Nittelhirns. Einige Zellen kommen aus dem Eingang zum Recessus mamillaris und einige zerstrent liegende Bogenfasern kommen vom hinteren Rande des Thalamus herab. Im allgemeinen konvergieren die aus diesen versehiedenen Bezirken kommenden Fasern gegen die Basis des Mittelhirns. Querschnitte

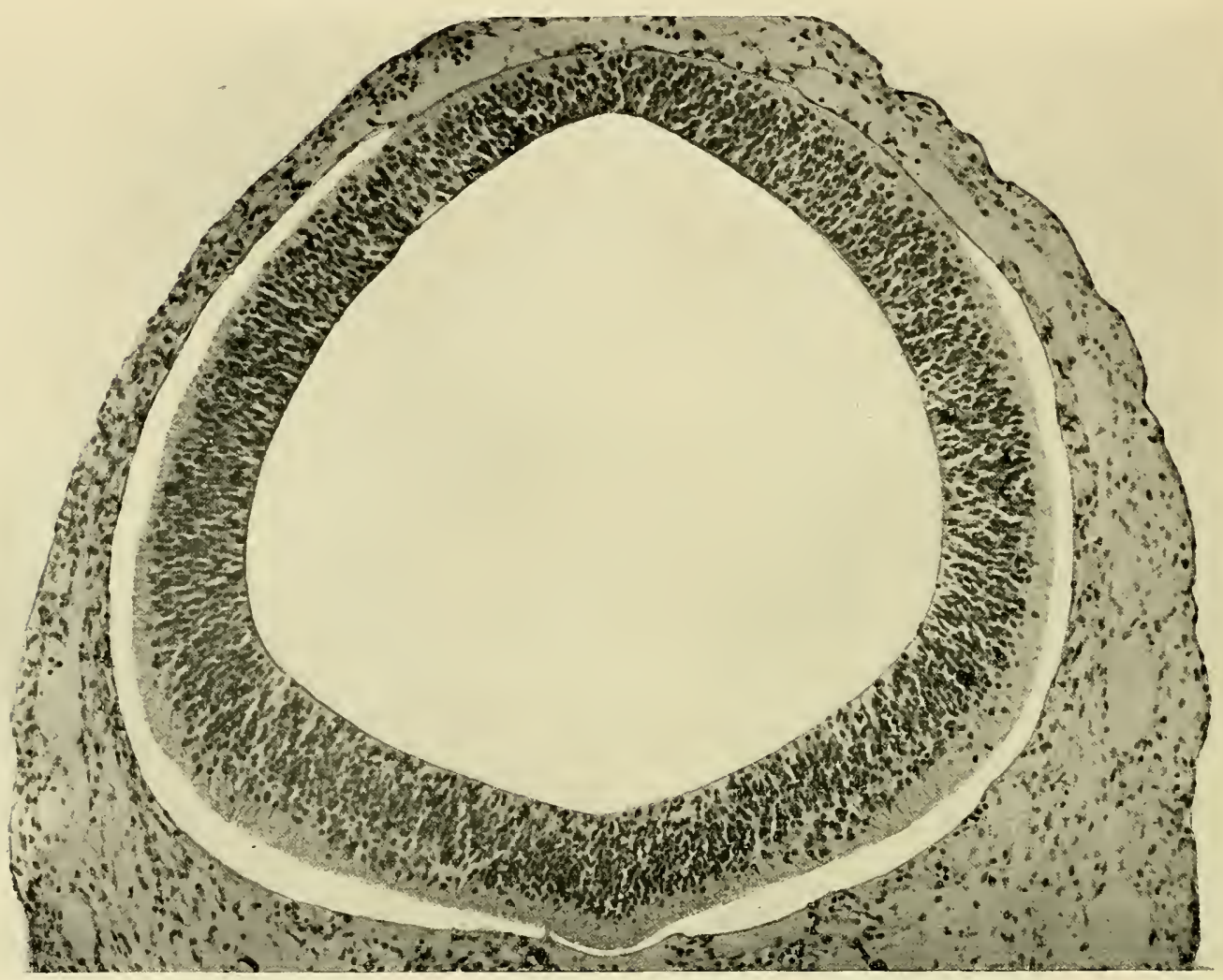

Fig. 32. Querschnitt durch das Mittelhirn vom Embryo Br 3. Man sieht die Neuroblasten des Oculomotoriuskerns als feine birnförmige Körperchen beiderseits mit zur Oberfläche strebenden Spitzen. (Zu Seite 50.)

durch das letztere zeigen anfangs melı zerstreut liegende Faserdurchschnitte. Weiterhin aber treten im Seitenteil des Mittelhirnbodens einige seharf umschriebene rundliche Bündelchen anf. Sie liegen anfangs sehr oberfläehlich dem Randschleier eingefügt, beim Übergang auf den Isthmus rücken sie mehr seitwärts und drängen sich dichter an die zellenfülırende Sehicht heran, zwischen deren Elementen sie sich schließlich verlieren. Diese Bündelchen sind die ersten im Gehirn etwas gesehlossen anftretenden Bildungen, ihrer Lage nach sind sie dem System der sogenannten hinteren Längsbiindel (Fase. longitudinales mediales BNA) zuzuteilen. Im ïbrigen 
finden sieh im Randschleier und nach einwärts davon dureh den gesanten ventralen Markbezirk hindurch bis zum Rückenmark hinab zerstrente Längsfasern. Hier sehließen sie sieh den Faserzuigen des Vorderstranges und des Vorderseitenstranges an. Ihre Menge weehselt in den versehiedenen Höhen, was darauf hinweist, daß es sieh un Komplexe von kurzen Bahnen handelt. ${ }^{1}$ )

Fassen wir die Entwicklungsvorgänge bis zum Schluß des ersten Monats nochmals zusammen, so ergibt sich, daß die Differenzierung der versehiedenen Streeken des Markrohres sich eingeleitet hat, aber noeh in ihren ersten Anfängen sieh befindet. Der maßgebende Grundvorgang ist die Sonderung einer neuroblastenhaltigen Mantelschicht. Diese tritt zuerst in der ventralen Hälfte der Röhrenwand auf, und hier kommt es zur Bildung der motorischen Kerne mit ihren mehr oder minder ansgeprägten Eigentümlichkeiten. Die Mantelschicht der dorsalen Markhälfte des Rïekenmarkes, des Rautenhirns und teilweise die des Mittelhirns ist anfangs noch dünn, und sie liefert Bogenfasern, die in ventralwärts gerichteten Verlanf teilweise die Mittellinien iiberschreiten, teils in die Vorder- und Seitenstranggebiete derselben Seite umbiegen. An der Bildung von Bogenfasern ist uibrigens die ventrale Röhrenwand mit beteiligt, deren Neuroblasten nur zum Teil Wurzelfasern liefern. Im dorsalen Teil des Vorderhirns ist es noch nicht zur Bildung von Bogenfaseru gekommen, dagegen beginnen in dessen basaler Streeke Längsfaserzüge mit spinalwärts gerichtetem Verlaufe aufzutreten.

1) Nach Flechsig entwickeln sich die Markscheiden unter allen Faserzïgen des Gehirns zuerst an den hintern Längsbündeln (gegen die Mitte des Fötallebens). Er bezeichnet die hintern Längsbiindel als kurze Bahnen, die mit den Vorderstranggrundbündeln in Verbindung stehen und legt besonderes Gewicht anf ihre Beziehungen zu den Augenmuskelkernen. (P. Flechsig, Plan des menschl. Gehirns 1853 S. 27 n. 2S.) 


\section{Die Entwicklung der Großhirnhemisphären.}

\section{Die erste morphologische Entwicklung des Hemisphärenhirns.}

Obwohl ich die Formentwicklung des menschlichen Vorderhirns während der Zeit des zweiten Monats schon in meinem Aufsatz vom Jahre 1889 ansführlich besprochen habe, komme ich hier auf den Gegenstand zuriuck. Ich habe das schwierige Kapitel nochmals von Grund aus durchgearbeitet und auch mein Naterial nach ror- und nach riickwärts zu erweitern rermocht. So hoffe ich denn, daß die nummehrige Darstellung, trotz unvermeidlicher Wiederholungen von früher Gesagtem, zur Klïrung der Verhältnisse Neutes beitragen wird.

\section{Die Abgliederung und früheste Gestaltung der Hemisphären.}

Die Hemisphärenanlage scheidet sich vom iibrigen Vorderhirn so frül, als dieses nebst den Augenblasen iiberhaupt angelegt ist und noch vor Vollendung des Gehirnschlusses (Fig. 2, S. 10). Sie bildet jederseits eine konrexe. Vorwölbung, die die Augenblase rostral- und scheitelwärts iiberragt, und sie setzt sich von dieser durch eine seicht einspringende Furche ab. Diese Furche, die Stielfurehe, geht scheitelwärts auf die Decke des Gehirmrohres iiber und trifft in der Mittellinie mit der der anderen Seite zusammen. Ihr unteres Ende verliert sich breit auslaufend in der rostralen Schlubwand des Gehirnrohres; der Augenblasenstiel, vor dem sie ausläuft, gehört noch zum Telencephalon. Ich finde die Stielfurche schon bei den jüngsten ron mir geschnittenen menschlichen Gehirnen, bei $\mathrm{Lg}$ (2.95 mm) bei $\mathrm{Rf}^{2}$ ) und bei dem 14 Tage alten, vorzïglich erhaltenen Embryo EB $\left.(3.2 \mathrm{~mm})^{\circ}{ }^{2}\right)$ Gemäß der Schräigstellung der Augenblasen, beginnt die Hemi-

1) Abhandl. der k. s. Ges. d. Wiss., math.-phys. Kl. 1859 Bd. XV S. 675 ff.

-) Anat. menschl. Embr. III Taf. IX und Aufsatz iiber die Formentwicklnng des menschl. Vorderhirns. Ich verweise iiberdies anf meinen Aufsatz: Zur allg. Morphologie des Gehirns, His' Arehiv 1592 S. $346 \mathrm{ff}$. und speziell anch auf meine, durch Herrn F. ZIEGLer in Freiburg i. B. herausgegebenen Gehirnmodelle. 
sphärenanlage in ihrem basalen Abschnitt schmal, nud sie rerbreitert sich nach der Decke zu. Sie hat demnach eine etwas retortenfürnigge Gestalt, der Hals der Retorte entspricht dem späteren Riechhirn.

An der Innenfläche des Vorderhirnrohres erscheint das Gegrenbild der Anßenfläehe: Der außen vorgewölbten Stelle entspricht innen eine grerundete Ansbuchtung, der äuBeren Furche eine innere flach vorgewölbte Leiste von dreieckiger Grundform. Es sind dies noch einfache Formen, aber sie sind für die nachfolgende Gliederung von entscheidender Bedeutung. Die dreieckige, vor dem Zugang zur Augenblase liegende Leiste ist die erste Anlage des Streifenhiigels, die dariiber befindliche Ausbuchtung bezeichnet den Ort des Palli u m s (Fig. 33). Die Streifenhiigelleiste läuft im Gebiet des Riechhirns ans. Der noch nnversehlossene Teil des Neuroporus lieg't ziemlich hoch, auf der Grenze der Gebiete von Rhinencephalon und Pallinm.

Vom Boden des Recessus opticus ab bis zur Zwischenhirngrenze hängen die zwei Hemisphärenhälften ummittelbar zusammen ohne Andentungen einer Zweiteilung. Die hintere Grenze der Hemisphären zerfällt in einen oberen und einen miteren Abschnitt. Ersterer trennt das Pallium

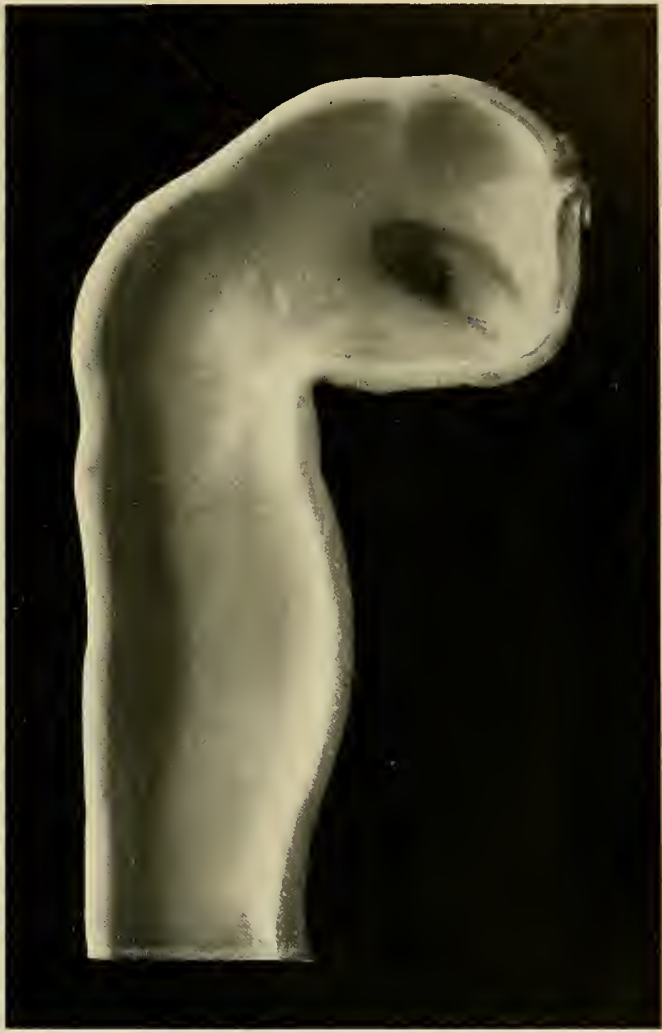

Fig. 33. Plattemmodell des Gehirns rom Embryo EB, innere Oberfläehe. Man erkennt die Haehe, der Hemisphärenhöhlung entspreehende Vertiefung und die Anlage des Streifenhïgels. Letzterer erseheint an der Figur als dreieckiges helles Feld, das nach rïckwärts den Rand des noch weit klaffenden Augenblasenzuganges bildet. Naeh oben setzt es 'sieh ron der Höhlung des Pallium ab, und es erreieht mit seiner vordern obern Kante den Neuroporus. rom späteren Sehhiigel, die

untere Grenzhälfte liegt hinter der Anlage des Streifenhïg'els und fällt in dieser frühen Zeit noch in die Vorderwand der Augenblase. Später, wenn die Abschniirung der Augenblase weiter fortgeschritten ist, hängt der Streifenhiigel anch seinerseits eine Strecke weit mit dem Sehhiigel zulsammen, und weiter basalwärts liegt er ror dem Hypothalamns, bez. ror dem Recessus opticus. Wir haben somit ron friiliester Zeit ab und durch 
alle folgenden Perioden folgende vier Grenzsäume des Hemisphärenhirns (Fig. 34 11. 35):

1) Rhinencephalon mit Rhinencephalon

und Pallium nit Pallium

2) Pallium mit Thalamus

3) Corpus striatum mit Thalamus

4) Corpus striatum mit Hypothalamus

Die vier Ränder zeigen in der Folge sehr verschiedene Schicksale: 1 und 2 gelangen nach dem Auftreten der medianen Sichelspalte und nach

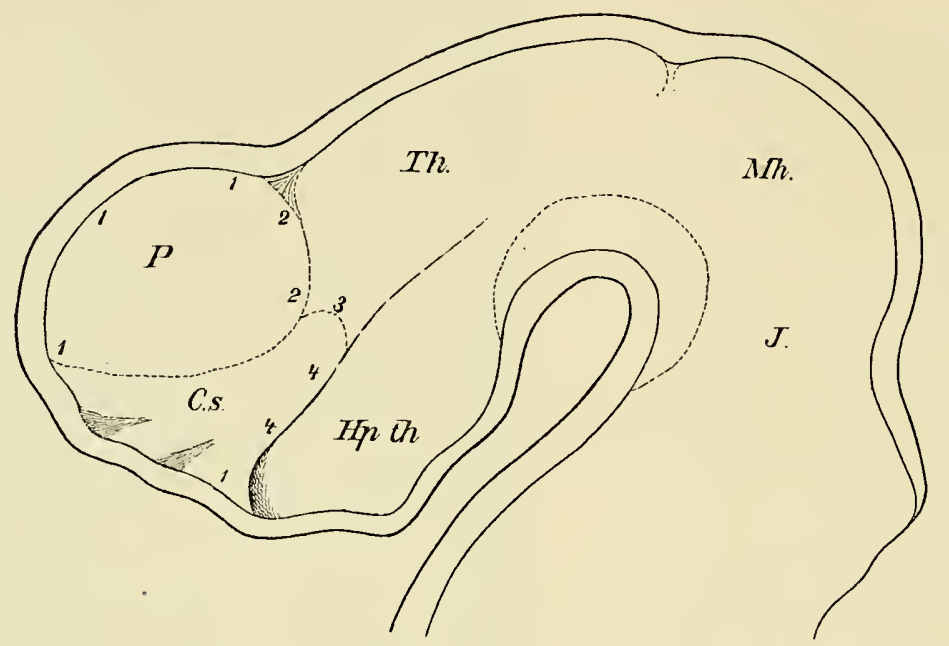

Fig. 34. Innenfläche des Vorderhirns von Embryo Br 3. Die Figur ist linear gehalten und soll die Verbindungen der Hemisphären exläutern. P. Pallium, C.s. Corpus striatum, Th. Thalamus, Hpth. Hypothalamus, Mh. Mittelhirn, I. Isthmus.

1) Margo reuniens (Rhinencephalon mit Rhinencephalon und Pallium mit Pallium)

2) , thalamicus (Pallium mit Thalamus)

3) , peduncularis (Corpus striatum mit Thalamus)

4) ,, hypothalamicus (Corpus striatum mit Hypothalamus).

der dadurch bedingten Scheidung der beiden medialen Henisphärenwandungen an den Grund dieser Spalte, und sie bewahren einen ependymalen Charakter. Ans Nr. 1 geht die vordere Schlnßplatte des dritten Ventrikels hervor, ans Nr. 2 die Lamina chorioidea und infrachorioidea. Nr. 3, das Verbindungsstiick zwisehen Corpus striatum und Sehhügel, bildet die Pforte, durch die das Hemisphärenhirn mit den übrigen Hirnteilen und mit dem Rückenmark in Verbindmng tritt. Nr. 4 kann sich mit seinem oberen Abschnitt noch an der Bildung dieser Pforte beteiligen, sein basaler Abschnitt bleibt von untergeordneter Bedentung.

Die einfachen Verhältnisse dieser frühen Stufen erhalten sich bis gegen Ende des ersten Monats. Noch ist bei Embryo Br $3(6.9 \mathrm{~mm})$. keine Längsfissur angelegt, und anch die Überlagerung des Zwischenhirns durch die 
Hemisphären ist noch nicht eingeleitet (Fig. 36, S. 58). Die einzige Andentung einer Zweiteilung findet sich in einer zwisehen den beiden Palliumhälften sich erhebenden niedrigen Längsleiste. Sie läuft im Scheitelgebiet ans, olne das Riechhirn zn erreichen. Anch die imnere Gestaltung der Hemisphärenwand bietet zu der Zeit keine bemerkenswerten Nenerungen. Der



Fig. 35. Modell des Gehirus vom Embryo Br 3, innere Oberfläche. Es sind daran die drei Schenkel des Streifenhïgels zum Ausdruck gebracht. (Zu seite 56.)

Zugang zur Augenblase ist niedriger geworden, die Anlage des Streifenhiïgels tritt etwas bestimmter hervor, und die Grube des Hirmmantels ist vertieft. Vom Thalanıs setzt sie sich mit einer rostralwärts konkaren Kante ab.

Vom Beginn des zweiten Monats ab ändert sich das Bild rasch, sowohl für die äußere, als für die innere Betrachtung. Noch hatten bei $\mathrm{Br} 3$ die beiden Hemisphären eine einheitliche Vorwölbung ron kugliger Gestalt gebildet. Diese wird nummehr durch Auftreten einer medianen Fissur halbiert. 
Die am Pallium vorhandene Längsleiste sinkt nämlich in die Tiefe und sie wird, ohne zunächst zu schwinden, von zwei Rimnen, den Anfängen der Sichelfurche, seitlich eingefaßt. Diese gehen nach riickwïrts in die Stielfurchen iiber. Gleichzeitig beginnen die anseinander tretenden Hemisphären in der Richtung nach dem Zwischenhirn sich auszudehnen und das

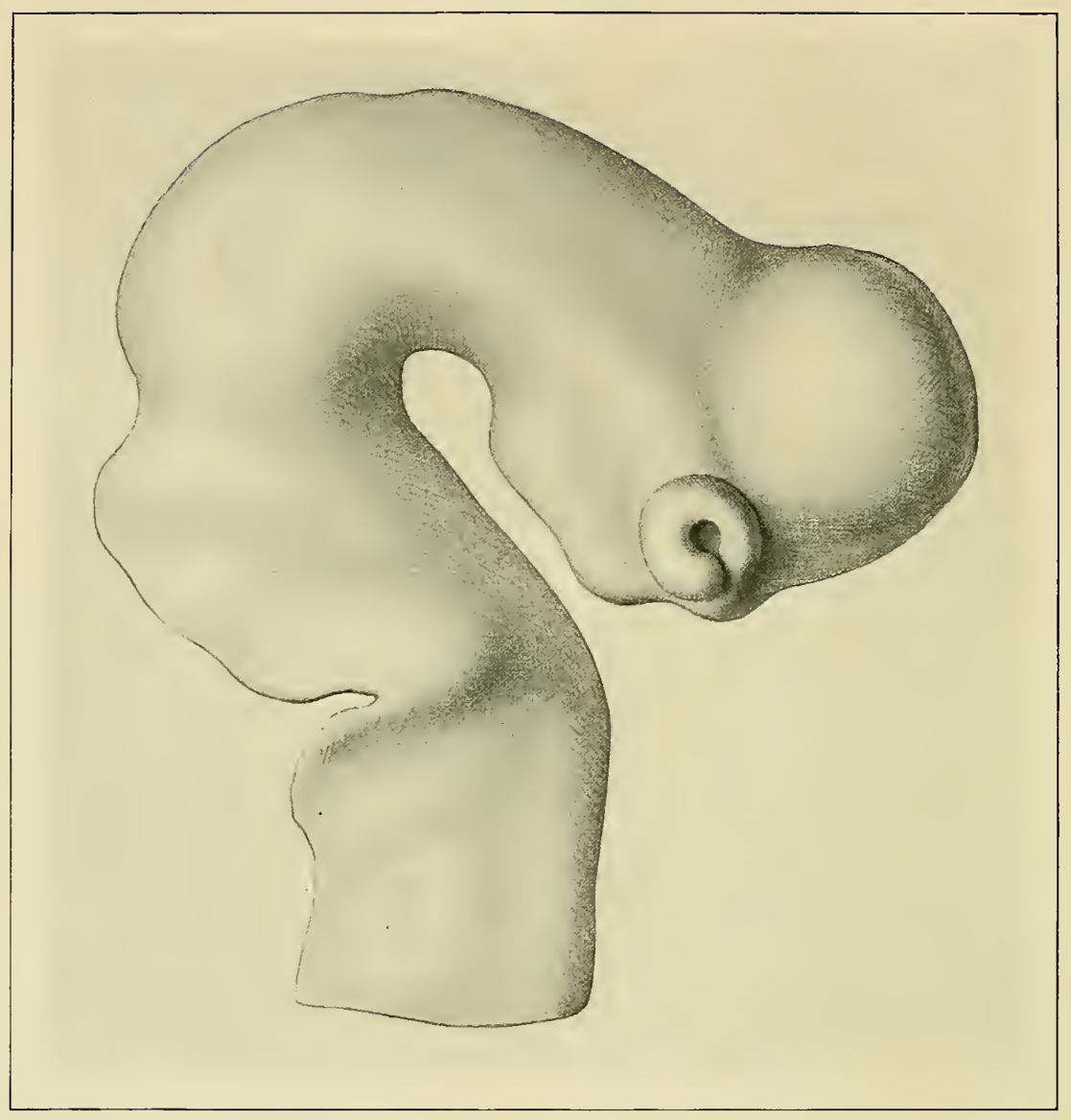

Fig. 36. Modell des Gehirus vom Embryo Br 3 von der Seite her gesehen. Die Hemisphären sind noch ungeteilt, zwischen ihnen liegt eine mediane Längsleiste, die nicht bis ins Riechhirn herabreicht. Eine Überwachsung des Zwischenhirns durch die Hemisphären ist noch nicht eingetreten. (Zn Seite 57.)

vordere Ende des Thalamus za ïberlagern. Die Sichelfurche rertieft sich in eben dem Maße, als dieser Prozeß fortschreitet. Durch ihre Vertiefung kommt es zur Scheidung des ursprünglichen Ventriculns impar in die beiden Lateralventrikel, sowie zur Ansbildung einer medialen Hemisphärenwand. Diese geht aus den an den Margo reuniens und thalamicus anstoßenden Randstrecken hervor. 


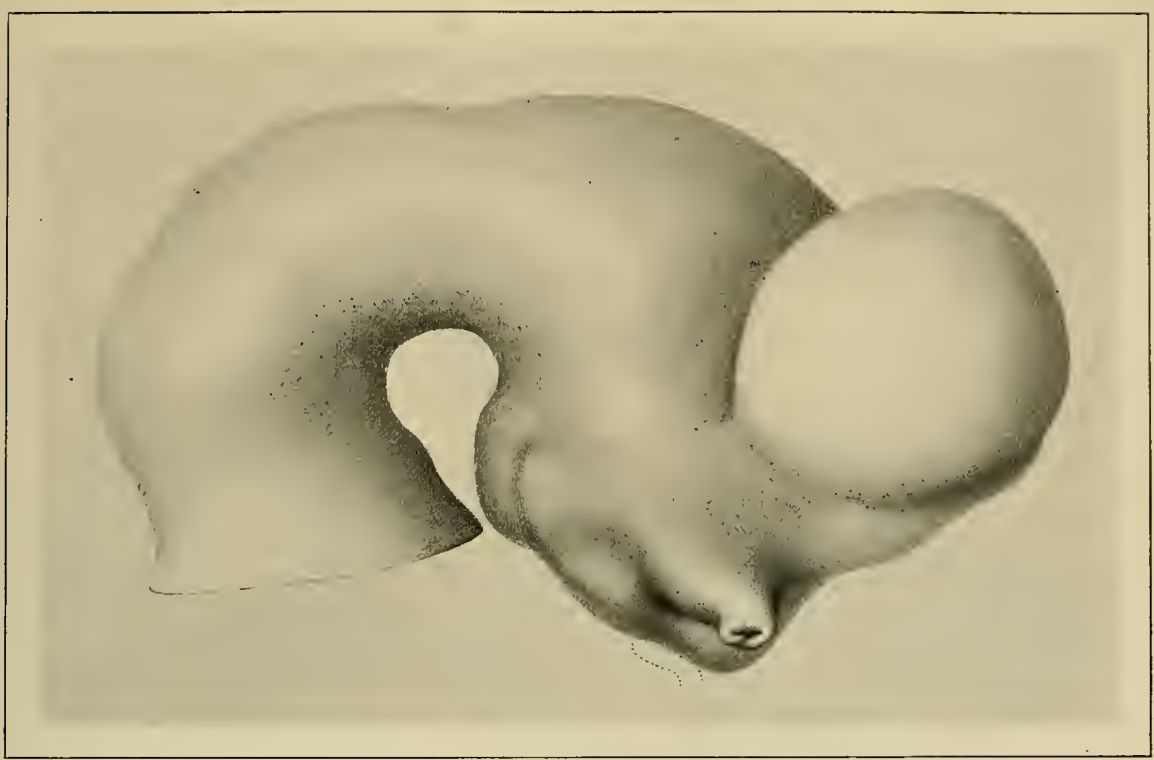

Fig. 37. Außenfläche des Vorderhirns vom Embryo Ko, nach dem Modell. Beginnende Überlagerung des Zwischenhirns durch die Henisphäre. Umgrenzung des Riechhirns. (Zu Seite 60.)

Beim Übergang vom ersten zum zweiten Monat beginnt die Sonderung des Riechhirns rom Pallium bemerkbar zu werden. In schwachen Andentungen ist die Ungrenzung schon am Plattenmodell von Br 3 erkemubar

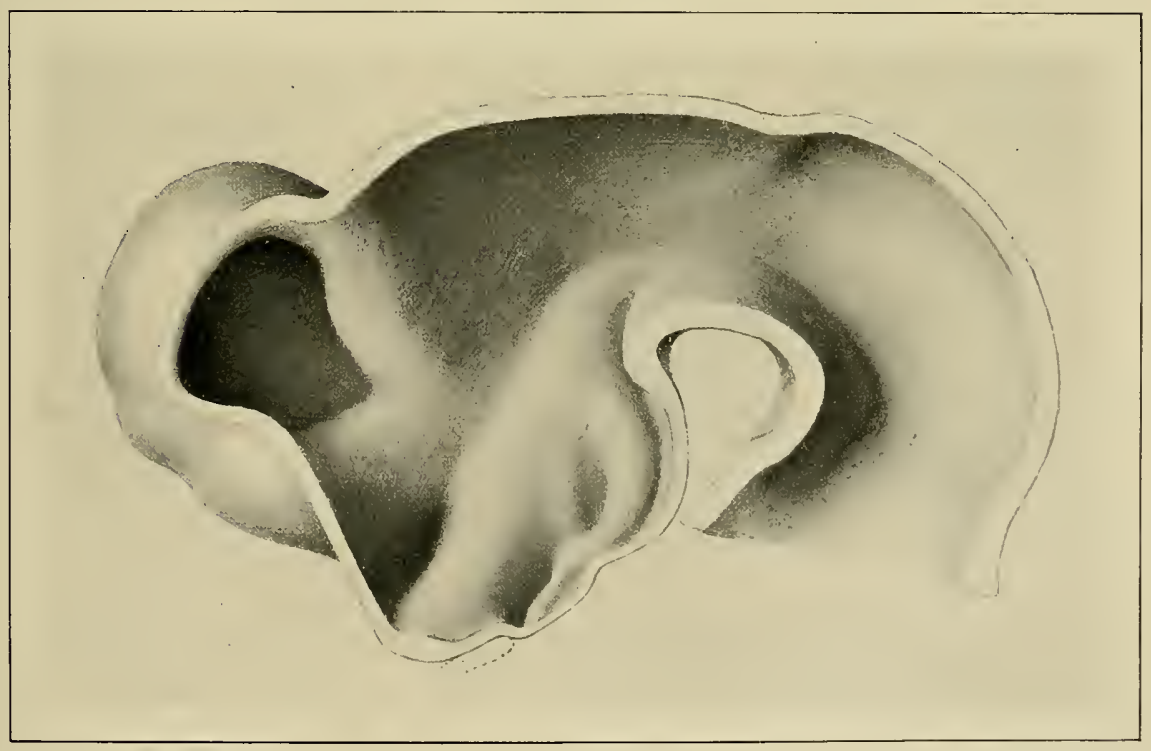

Fig. 38. Innere Oberfliche des Vorderhirus rom Lmbryo Ko, nach dem ILodell gezeichnet. Weites Foramen Monroi, vorderes und hinteres Ricchhim. (Zu seite 60.) 
(S. 58 Fig. 36), aber in bestimmter Weise tritt sie erst bei Embryonen von $10 \mathrm{~mm}$ und dariiber auf (Fig. 37, S. 59). Das Riechhirn zeigt sich an Plattenmodellen aus der Zeit als flache, ringsherum von einer seichten Furche umgebene Erhebung von gestreckter Bohnenform. Vordere und hintere Hälfte werden durch eine an der medialen Seite beginnende Einbuchtung, die Fissura mesorhin ica (Fig. 38, S. 59), voneinander abgegrenzt. Die das Riechhirn lateralwärts begrenzende Furche, TurNers Fissura rhinica, trifft nach rückwärts mit dem basalen Ende der Stielfurche zusammen (Fig. 39). Im Gegensatz zu der die Hemisphären scheidenden tiefen Sichel-

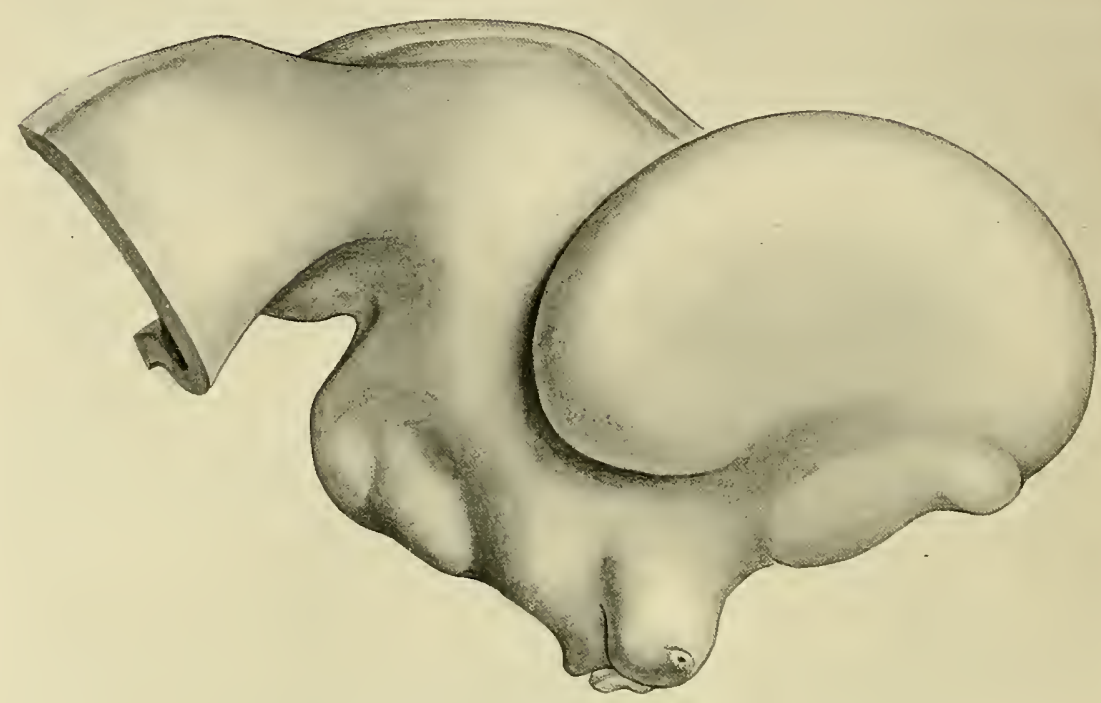

Fig. 39. Seitenansicht des Gehims vom Embryo CR, nach dem Modell gezeichnet. Das Riechhirn mit seincn beiden Abteilungen, die Fissura peduncularis, F. rhinica und mesorhinica, zeigen sich. Ihnen entsprechen an der Innenflüche die drei Schenkel des Streifenhügels.

furche bewahrt der basale, zwischen dem Angenblasenstiel und dem Riechhirn hindurchtretende Teil der Stielfurche den Charakter einer seichten Rinne.

Sobald die Ungrenzung des Riechhirns kennbar geworden ist, lassen sich auch die Hauptabteilungen des Palliums mit Sicherheit bestimmen. Der das vordere Riechhirn berührende Teil wird in der Folge zum Stirnl a p p en, der über dem hinteren Riechhirn liegende zum Schlä f e nl a p pen. Von der zweiten Hälfte des zweiten Monats ab überholt der Hemisphärenmantel das Riechhirn mehr und mehr im Wachstnm und iiberragt es nach vorn und nach rïckwärts mit freien Ausladungen. Die Verschiebung des Schläfenlappens iiber seiner befestigten Basis nach vorn führt in der Folge (im vierten Monat) zur Bildung des rücklänfigen Une us. 


\section{Streifenhïgel und Riechhirn in ihren gegenseitigen Beziehmngen.}

Es wurde oben (S. 55) hervorgehoben, daß die als dreieckige Leiste schon früh erkemnbare Anlage des Streifenhïgels rostralwärts in die Wand des Riechhirns ausläuft. Nachdem die Sondermng der beiden Riechhirnlälften voneinander, sowie rom Hemisphärenmantel und rom Zwischenhi'n schärfer sich ansgeprägt hat, tritt anch am Streifenhügel eine bestimmtere Gliederung hervor. Dem Sristem der äußeren Furchen (dem Sulcus peduncularis, der Fissura rhinica nnd Fissura mesorhinica, entsprechend, scheiden sich am rostralen Ende des Streifenhïgels drei Schenkel, deren einer ror dem vorderen Riechlirn anslänft, der zweite zwischen vorderem und mittlerem Riechlhirn und der dritte zwischen dem hinteren Riechlhirn und-dem Sehhiigel und Recessus opticus (Crus epirhinicum, mesorhinicum und metarhinicumi). In ihren ersten Andeutungen ist diese Dreigliederung des Streifenhügels schon bei Embryo Br 3 erkennbar (Fig. 34 u. 35, S. 56 11. 57).

Der Schweif des Streifenhïgels bildet sich später als die drei vorderen Schenkel und seine Ausbildung hält Schritt mit der des Lobus occipitalis und temporalis. Indem sich nämlich die hintere Hemisphärenhälfte iiber den Thalamus wegschiebt und

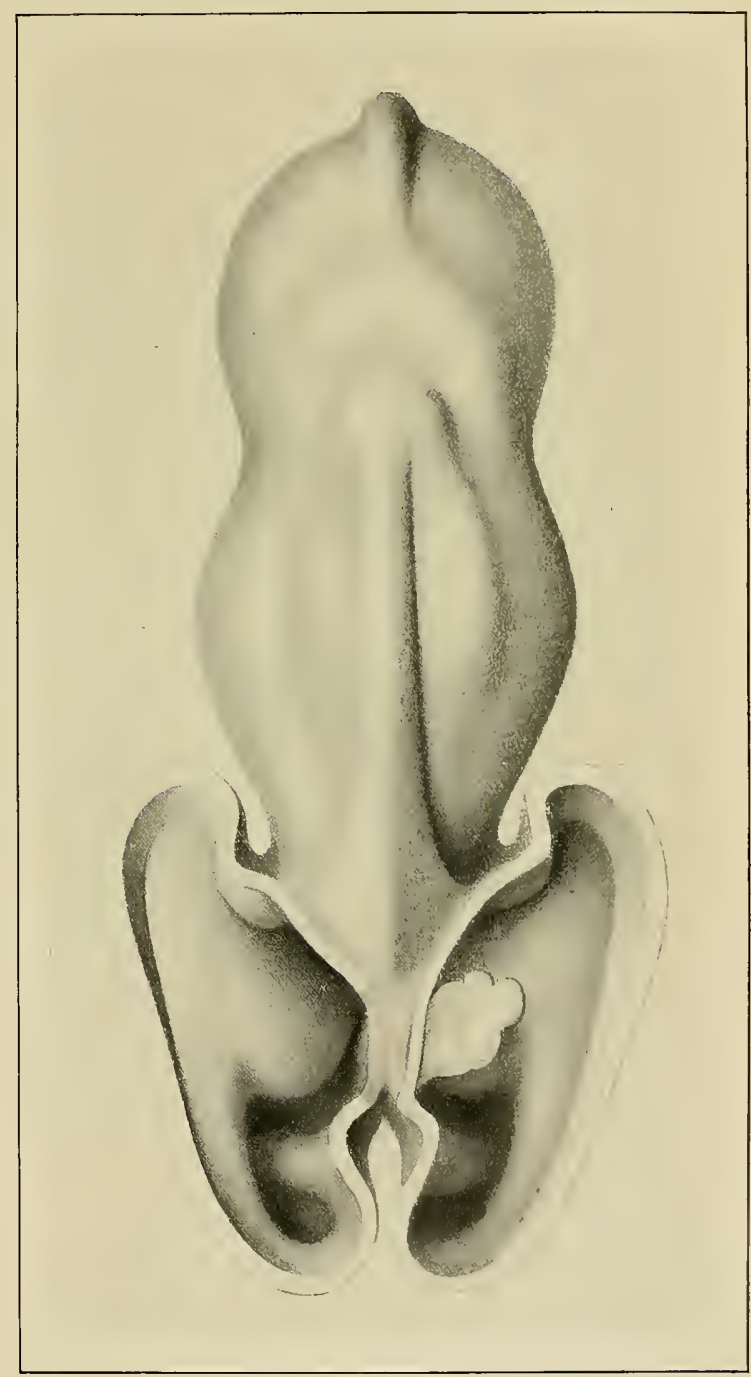

Fig. 40. Vorderhirn desselben Embryos (Modell), die Hemisphälen sind ron oben her eröfnet, rechts rom Beschaner ist das noch relativ renig umfangreiehe Corpus chorioileum dargestellt, links ist es weggelassen. Man sieht ron oben her denstreifenhiigel und den Eingang der Höhlungen des vorderen und des hinteren Riechhirus; die ron dex medialen Wand aus einspriugencle Falte entspricht der Fissura prima. (Zu seite 64. ) 
zugleich basalwärts senkt, verschiebt sich anch das schmale Ende des Streifenhügels nach rüickwärts und basalwärts. Es behält dieser caudale Abschnitt des Streifenhügels seine Lage über dem Beginn der Stielfurche

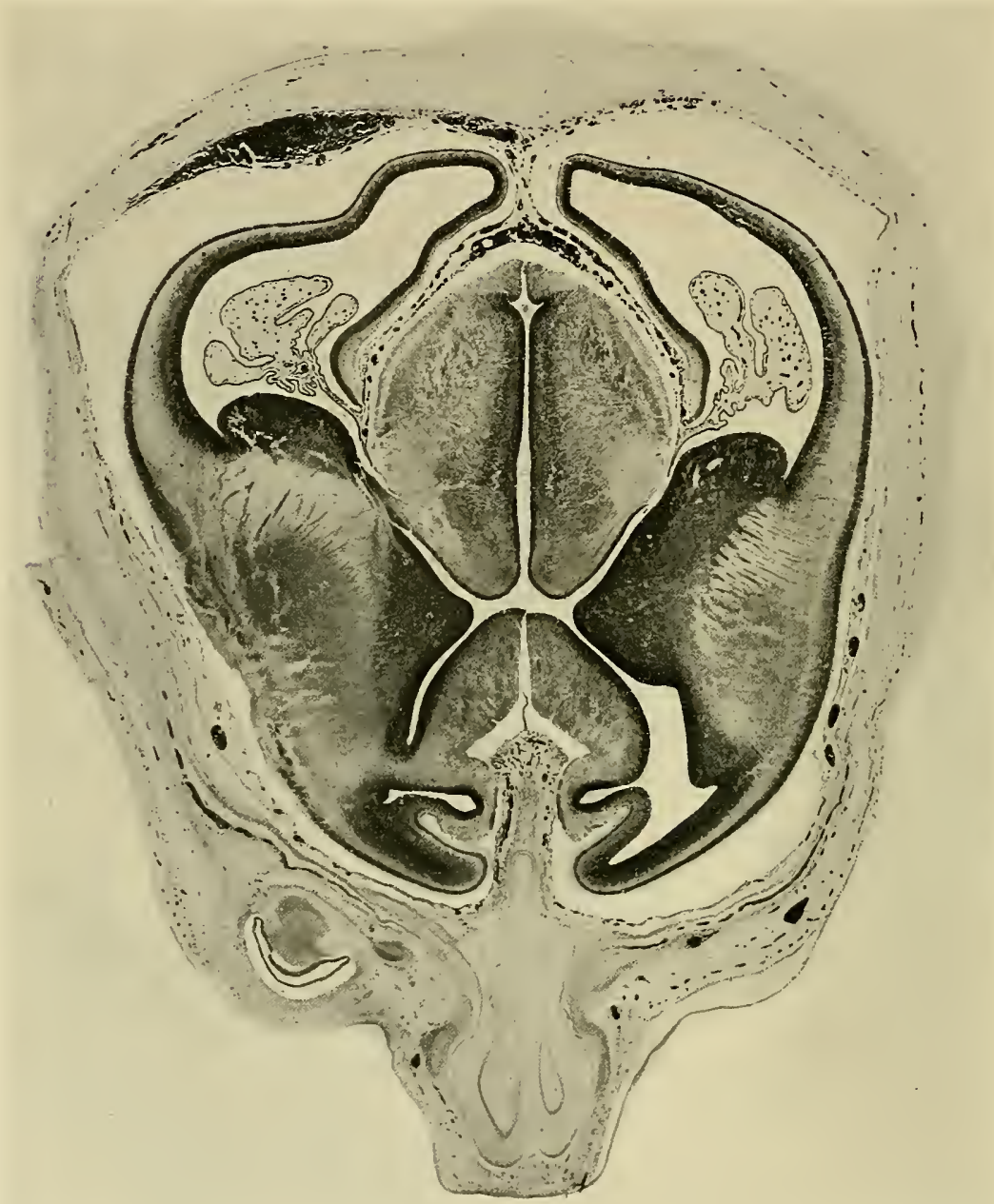

Fig. 41. Durclıschnitt durch das Vorderhirn rom Embryo Oe. Die rechte Seite zeigt, dem Hinterhorn des Ventrikels zugekehrt, den Schweif des Streifenhügels, vorn dagegen die drei schenkel, ron denen der hintere mit scharfer Kante gegen das Foramen MIonroi vortritt. Auf der linken Seite sieht man die Verwachsung des mittleren Schenkels mit dex der Fiss. prima entsprechenden Falte der medialen Wand. Die hintere Riechhöhle hängt nach rïckwärts mit dem iibrigen Seitenventrikel zusammen. Von der vorderen Riechhöhle sieht man links nur die quergestellte Höhle des Trigonum, rechts auch die des Bulbus. (Zu Seite 64.)

und erscheint als verdickte, den seitlichen Boden des Schläfenlappens bildende Leiste. Je weiter die Verschiebung des Hemisphärenrandes fortschreitet, 1 m so mehr rïckt das Schweifende des Streifenhiigels basalwärts, und nach 
vollendeter Ausbildung erscheint der Streifenhügel als eine grebogene, den rom Zwischenhirn kommenden Hemisphärenstiel umgreifende Spange, deren vorderes Ende in der Wand des Riechhirns anslänft, während das hintere im Unterhorn des Schläfenlappens endigt. Der vordere Teil des Streifenhiugels zeigt, wie dies sehon von TIEDEuAnN abgebildet worden ist, ${ }^{1}$ ) im

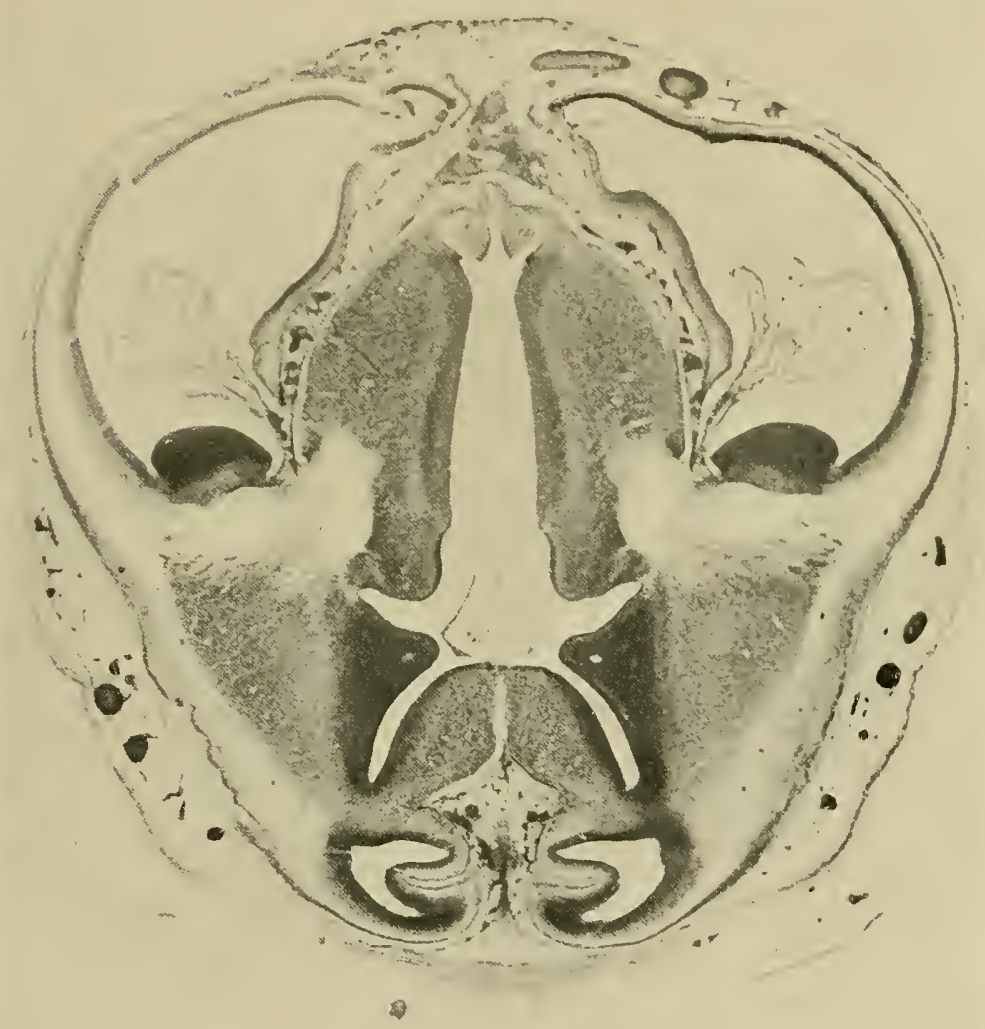

Fig. 42. Aus derselben Schnittreihe etwas tiefer. Die Verwachsung des mittleren Streifenhügelschenkels mit dem vorderen Rand der Trapezplatte ist beiderseits vom Schnitt getroffen. (Zu seite 64.)

Verlanfe des zweiten und dritten Ionats eine Teilung in einen medialen und einen lateralen Abschnitt. Ersterer beschreibt den rollen Bogen rom Riechhirn bis ins Unterhorn, nnd seine Breite wechselt in den rerschiedenen Strecken nur unerheblich. Dagegen nimmt sich der mediale Abschnitt, ron

1) Trevemaxi, Anatomie und Bildungsgeschichte des Gehirns. Nümberg 1816. Taf. II Fig. ว. 
oben her gesehen, wie ein dreieckiger Anhang des lateralen aus (Fig. 40, S. 61). Er bildet eine scharfe, dem Foramen interventriculare zugekehrte Kante, deren unteres Ende in der Folge mit der medialen Wand der Hemisphären verwächst. Eine seichte, von oben nach abwärts an Breite zulnehmende Furche trennt diese hintere Kante von einer stumpfen vorderen. Letztere senkt sich von der Seite her zwischen die vordere und die hintere Riechhirnhöhle ein und durch ihre Verwachsung mit der medialen Wand liefert sie die Rückwand der vorderen Höhle (Fig. 41, S. 62 11. Fig. 42, S. 63). Von den beiden Kanten des medialen Streifenhïgels ist die lintere aus dem primären Crus metarhinicum, die vordere aus dem Crus mesorhinicum hervorgegangen. Das aus dem Crus epirhinicum entstandene vordere Ende des lateralen Streifenhügels geht in die Seitenwand des vorderen Riechlappens iiber.

\section{Die Bildung der medialen Hemisphärenwand.}

Es lassen sich, wie oben (S. 56) gezeigt wurde, an der Umgrenzung: der Hemisphären von früh ab vier Abschnitte unterscheiden: der mediale Rand, der Thalamusrand, der Stielrand und der Hypothalamusrand. Von den an diese Ränder stoßenden Strecken liefern in der Folge die beiden ersteren das Material zur Bildung der medialen Hemisphärenwand. Während des zweiten und dritten Monats hängen die beiden Hemisphären in der Nittelebene durch eine schräg ansteigende dïnne Ependymplatte, die vordere SchluBplatte oder Lamina renniensi) zusammen. Diese Platte riickt nit zunehmender Vertiefung der medialen Hirnspalte dicht an den hinteren Schenkel des Streifenhügels heran nnd schließlich an diesem rorbei bis an den Rand des Sehhiigels und den Eingang zum Recessus opticns. Der davor liegende Teil der medialen Hemisphärenwand gehört mit seinem basalen Abschnitt dem Riechhirn an, mit dem darïber befindlichen dem Stirnhirı.

Die tiefgreifendsten Veränderungen erfährt der vordere Teil der medialen Hemisphärenwand im Bereich des Riechhirns. Schon rom Beginn des zweiten Monats ab wird dieses durch eine seichte, von der medialen

1) Die Ausdriicke „Schlnfsplatte“ und „Lamina terminalis" branche ich nicht in gleicher Bedentung. Das Wort Schlnßplat te, Laminareuniens ist ein embryologischer Ausdruck, der die Vereinigungshaut der beiden Seitenwandungen des Hirnrohres bezeichnet. Dagegen ist das Wort Lamina terminalis, Endplatte, der althergebrachte anatomische Ausdruck für die dünne, den dritten Ventrikel nach vorn abschließende Membran; sie geht aus dem untern Abschnitt der Schlußplatte hervor und ist gleich dieser ein ansschließlich ependymales Gebilde.

Als Area terminalis bezeichnet G. Retzius (Menschenhirn S. 1) die etwas vorgewölbte Vorderwand des Recessus opticus und als Fenestra lamina termi$\mathrm{n}$ a. lis den verdünnten medianen Streifen derselben. 
Seite ausgehende Furche, die Fissura mesorhiniea, in einen vorteren und einen hinteren Lappen geschieden. Die Scheidung ist keine durch-

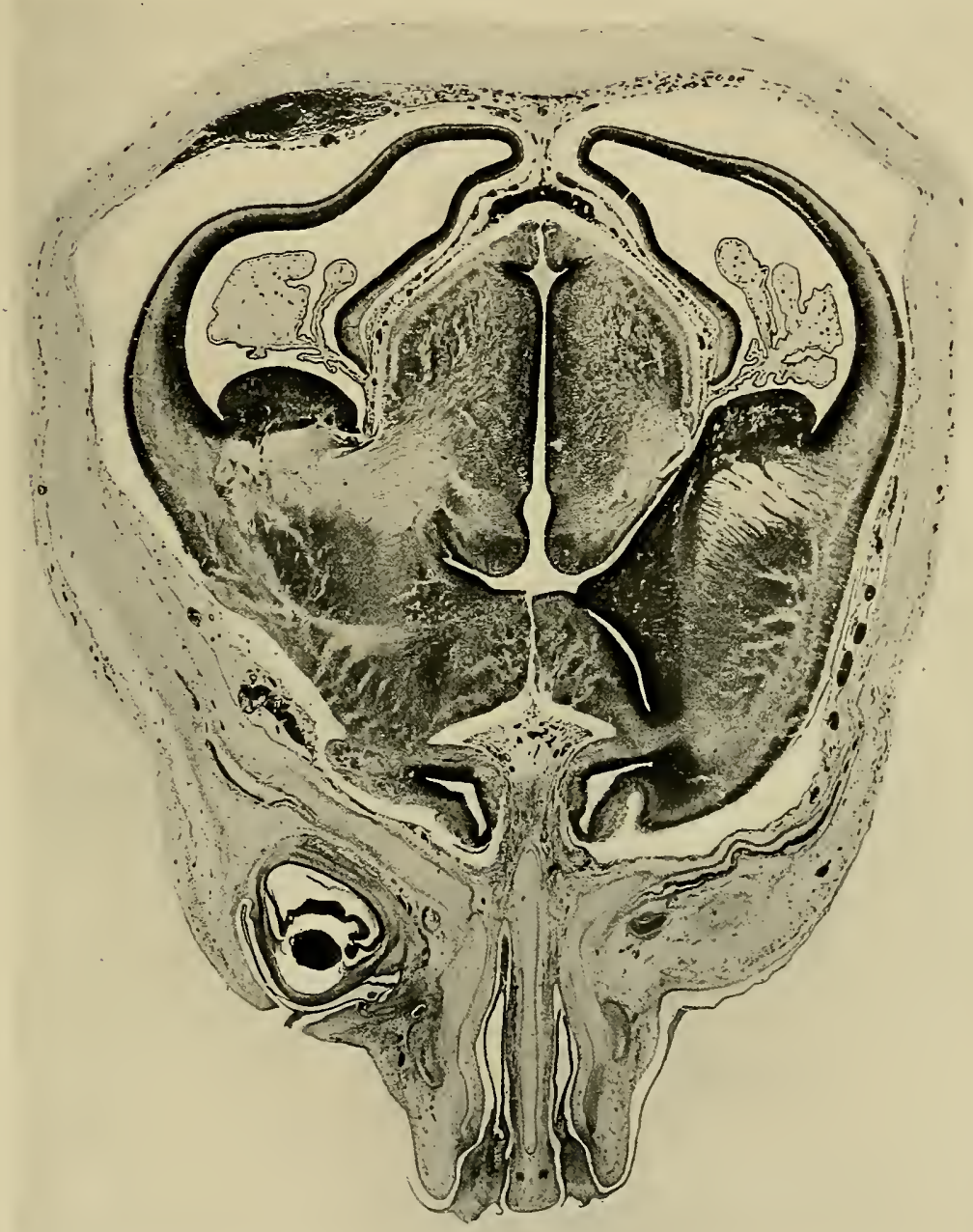

Fig. 43. Durchsehnitt dureh das Vorderhirn ron Embrto Stg, desselben, ron dem auch Fig. 41 stammt.') Der Schnitt zeigt die geknickte Form der vorderen Riechhöhle. Durch die laterale Falte werden die Höhlen des Bulbus und des Trigonum voneinander geschieden. Die hintere Riechhöhle ist nur noch reehts zu sehen. als enger Spalt, der im Begriff steht, rom iibrigen seitenventrikel sich zu trennen. Links ist die hintere Ricchhöhle nicht mehr in schnitt, dagegen erscheint hier der Seitenabschnitt der bei stg noch unverbundenen Commissura anterior. (Zn Seite 66.)

1) Durch ein Terselen steht bei Fig. 41 , dass der Schnitt rom Embryo Oe stamme, er stammt ron Stg. Dagegen gibt Fig. 12 einen Sehnitt ron Oe.

greifende, und so stellt sich das Riechhirn, ron der Basis her gesehen, als ein lateralwärts ausgebogener Wulst da. Diese Grundform ist noch lange His, Die Entwicklung d. menschl. Gehirns. 
erkembar und sie prägrt sich in der Folge noch schärfer aus. Während des zweiten und dritten Ionats schneidet die Fissura mesorhinica tiefer in das Ricehlim ein, anfangs ohne die laterale Verbindung der beiden Lappen zu unterbrechen. Eine Fortsetzung des Fissura mesorhinica greift als Fissura prima eine strecke weit auf die mediale Himwand iiber, von ilsr wird nachlıer die Rede sein.

Durch Vertiefung der ungrenzenden Furche sondert sich das Endstiick des vorderen Riechlappens oder dessen loulbusteil in zunchmendem Maße ron dem ïberliegenden stimhirn. Der loulbusteil bewahrt eine sagittale Pichtung und er chlierlert sich dureh eine von der Seite her

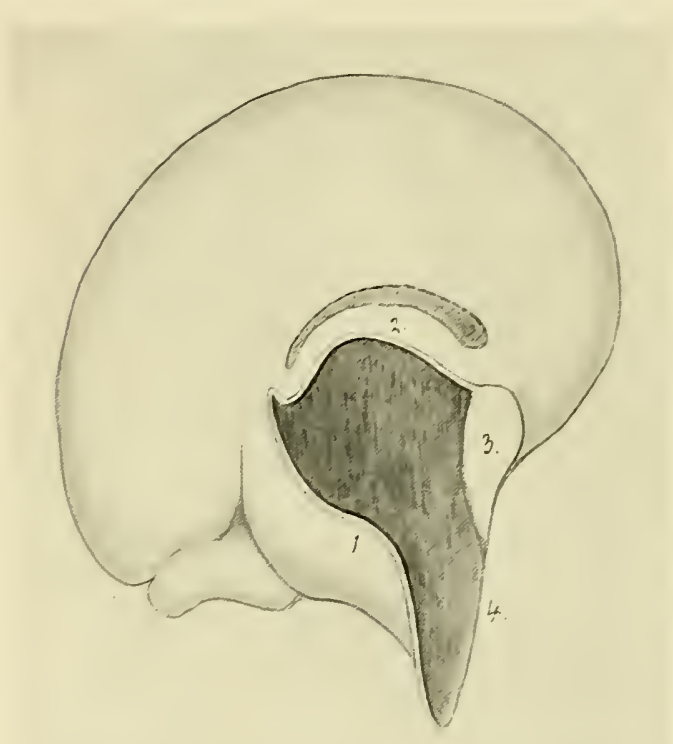

Tig. 41. Konstruktionsbild der incrlialron Ifromicphärenwand won Embryo Se (16 Inm N1.). 1. Hargo, reuriens, 2. Wargo thalamicus, 3. Margo perfurieularis, 4. Margo hygothalamicus. ber Ort der Fissura chorioirlea ist sobraffiert, das noch selur write Foramen Morroi ist durkel gehalten. erfolgesude Finknickung von einem quer gelagerten Abselmitt des vorderen Riechlims ab (Fig. 43, S. 65). Letzterer ist die Anlage des Trigonu m. Wenn sich in Verlaufe des vierten Monats der Bulhus rom Stirnlimn abgelöst liat, vermittelt rlas quergestellte Trigonum seine Terbindung mit dem iibrigen Gehirn. Noch bis in den vierten Monat hinein steht die sagrittal verlaufende Bulbusspalte in offener Verbindung mit dem Seitenventrikel. In Terlaufe des fiinften Yronats (16 cm SSSI.) finde ich die Bulbushöhle verklebt, die Trigonmmhöhle noch als kurzen, vertikalen, nach oben sich öffnenden Gang.

Der vordere Abschnitt des medialeı Hemispliärenwand zerfällt durch die nachliev zu besprechende Fissura prina in einen dem vorteren Rand zagekehrten, im bogen zum Scheitel emporsteigenden Streifen nud in ein an dic Schlufplatts anstopendes, nach unten und nach oben hin sicls verjingeudes Feld, das Trajezfeld. Die Śchlupplatte der medialen Henisplärenwand geht mit scharfer Knickung in die mediale Schlufplatte der 'Thalanuswand ïher (Fjo. 44 u. Fig. 45, S. 67). Wah kann diese stelle als vorderen Thalamuswinkel, Angulus puetlo a a m icus, hezeichnen, mel,en ilı beginnt des Cuschlagstand der Wand des Thalamus in die mediale Hemisphärenwand, der Marogo thalanicus der letzteren. Der Thalanousrand 
der Hemisphäre verläuft in einer nach vorn und abwärts konkaven Bogenlinie, die bis zur Berïhrungsstelle von Streifenhügel und Selıhïgel, dem Margo peduncularis reicht (Fig. 44 11. 45). Die Linie bildet die hintere Grenze des Foramen Monroi, von ihr aus erstreckt sich der dem Thalamus verbundene Lbschnitt der Hemisphärenwand seheitel- und occipitalwärts. Dieser Wandabschnitt erfährt eine weitergehende Gliederung, auf die ich unten zurüick" kommen werde. Sein dem Thalamus angehefteter Randstreifen bleibt ependymal und in ihm bildet sich die Fissura chorioidea, von der aus die Epithelfaltungen des Corpus chorioideum in den Seitenventrikel sich einstülpen. Die Spalte ist anfangs nur kur angelegt ${ }^{1}$ ) und sie beginut dicht linter dem Angulus praethalamicus; weiterhin verlängert sie sich und erstreckt sich nach voller Ausbildung des Sehlïfenlappens bis in die Nähe des Uneus herab. Der zwischen der Fissura chorioidea und dem Thalamus liegende Teil der medialen Hemisphärenwand bewahrt anfangs seine Unabhängigkeit, später legt er sich dem Thalamus dicht an und wird zur La mina af fịxa der BNA. ${ }^{2}$ )

Die uiber die Seitenwand des Thalamus zulriickgeschlagene mediale Hemisphärenwand um-

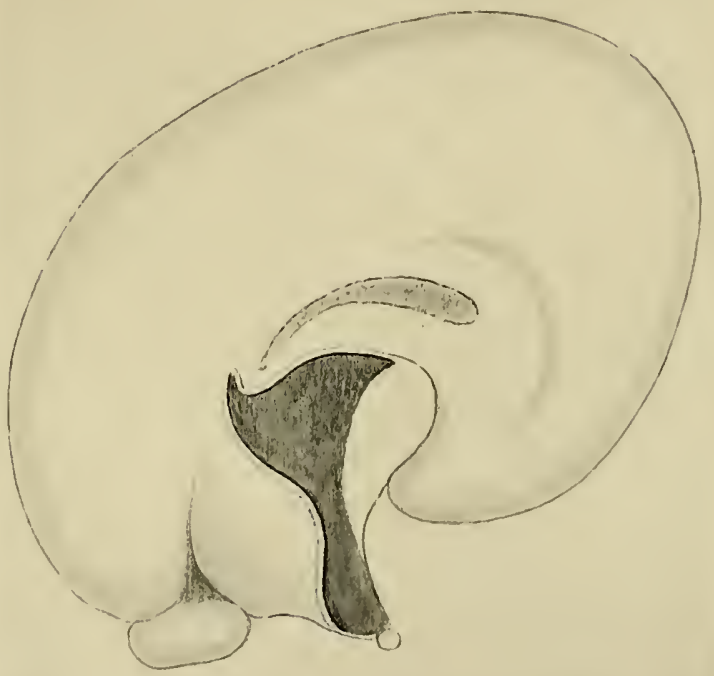

Fig. 45. Gleiche Darstellung von der Hemisphärenwand von Embryo Mr (22 mm Nl.). (Zu Seite 66.) Diese, sowie Fig. 41 sind etwas stark vorniibsx geneigt, daher der konkave land nach abwïrtigekehrt erseheint. Man vgl. oben Fig. 35 S. 57 und Fig. 38 ร.. 59. greift das Stielgebiet, in dem Thalamus und Streifenhiigel zusammentreffen, und bei voller Ausbildung iiberragt sie dies Gebiet nach rïckwäirts. Basalwärts hängt sie mit der lateralen Wand, d. h. mit dem streifenhïgel zusammen. Man findet daher an Schnitten, je nach Richtung und Lage, die mediale Henisphärenwand verbunden mit der Thalamuswand allein, oder mit dem Streifenhïgel allein, oder anscheinend mit Streifenhiigel und Thalamus

1) So bei Embryo Ha $(10.5 \mathrm{~mm})$ und bei Cle $(13.6 \mathrm{~mm})$ Formentwicklung d. $\mathrm{m}$. Vorderhirns Fig. 19 S. 697 u. Fig. 7 Taf. I, sowie beim entsprechenden Mlurlell.

2) Diese Verwachsung lïßt sich nicht, wie Goldstens will, in Abrede stellen, sie ist jat zeitlebens noch erkeunbar. Der großgedruckte Satz Golostens : „Verwachsung von ursprünglich getremnten oberflïchlichen Hirnpartien findet nicht statt", ist völlig unhaltbar und steht im Widerspruch nit den positiven Befunden. 
(man vgl. oben Fig. 41 bis 43). Letzteres gilt für das Stielgebiet, der Anschluß an den Thalamns ist hier nur ein mittelbarer. Die Verbindnng mit dem Streifenhügel allein findet sich in dem frei nach riickwärts hervortretenden Schläfen- und Occipitalhirn.

Der Hemisphärenstiel. ${ }^{1}$ ) Solange die Angenblasen noch in breiter Verbindung mit dem Vorderhirn stehen, beschränkt sich die Verbindung des Streifenhïgels mit dem Sehhügel (der Margo peduncularis) anf einen schmalen, über dem Angenblaseneingang befindlichen Streifen, nnd die Terbindung erfolgt läng’s eines linearen Sarmes von nur mäßiger Dicke. Mit zmuehmender Abschnïrung des Augenblasenstieles wird die Berïhrung. zwischen Streifenhiigel und Thalamus ansgiebiger. Zugleich verdickt sich aber das Verbindungsstiick vom zweiten Nonat ab dadurch, daß im Bereich der Stielfurche das ätßere Gliageriist reichlicher sich anhäuft. Es entsteht so ein anfangs lockeres Gewebspolster, das die Basis des Stielgebietes und des Streifenhïgels bildet. Dureh dessen Anwachsen wird die änßere Furche seichter, und sie gibt ihren Parallelismus mit der nach innen stark sich vorwölbenden Oberfläche des Streifenhiigels mehr und mehr auf. In dieses basale Polster herein treten gegen Ende des zweiten und im Verlanfe des dritten Monats die Verbindungsfasern des Thalamus mit der Hemisphäre, sowie die Zellemmassen des Linsenkernes und des Claustrums. Die Beriihrungsfläche zwischen Thalamus und Streifenhügel nimmt infolge der Rückwärtsschiebung der Hemisphären mehr und mehr eine kreisförmig gerundete oder richtiger eine geschlossene Bogenform an. Vorn reicht das Stielgebiet beim zwei- bis dreimonatlichen Fötus bis zum hinteren Schenkel des Streifenhügels, sein occipitaler Rand wird vom Schweif des Streifenhïgels umgriffen. An der Anßenfläche des Gehirns bezeichnet die iiber dem Augenblasenstiel einsetzende Stielfurche den Ort des Anschlusses.

Der Anschluß des Streifenhïgels an den Hypothalamus. Während des zweiten Monats erscheint der hintere Schenkel des Streifenhiigels als ein mächtiger, medialwärts dem klaffenden Foramen Monroi zugekehrter Wulst, und sein unteres Ende erreicht den Boden der Hirnböhle unmittelbar vor dem Recessus opticus, zwischen diesem und der Höhlıng des hinteren Riechhirns, dem Ventriculus olfactorius posterior. So finden sich die Verhältnisse noch im Beginn des dritten Nonats; der medialwärts mbedeckte Teil des Streifenhiigels wird indessen schmaler, und weiterhin verschwindet er infolge der Überlagerung durch die mediale Hemisphärenwand. Eine Strecke weit rerwächst er mit dieser und es entsteht zwischen dem offen bleibenden Teil des Foramen Monroi und dem

1) Ich habe in meinem frïhern Aufsatz den Namen "Streifenhiigelstiel" benutzt. Da Marchand dies Wort in einem andern sinne gebrancht hat als ich, erscheint die nene Bezeichnung unverfänglicher. 
Recessus opticus eine Substanzbrücke, innerhalb deren die Säılen des Fornix ihren Weg zum Corpus mamillare finden. Jene entstanmen der medialen Henisphärenwand, dieses gehört dem Hypothalamus an, der Streifenlingel wird zum verbindenden Mittelglied zwischen beiden.

\section{Dickenwachstum der Vorderhirnwand.}

Bei meinen jüngsten menschlichen Emlbryonen (Lg, Rf usw.) zeigt die Vorderhirnwand in ihren verschiedenen Abschnitten nur geringe Dickenschwankungen. So messen bei Embryo Lg die Wand des Zwischenhirns, die der Angenblasen und die der Hemisphären gleichmäßig etwa $50 \mu$, bei dem um weniges älteren Embryo Rf rund $55 \mu$; bei $\mathrm{EB}(3.2 \mathrm{~mm})$ schwanken die Werte zwischen $65-75, \mu^{1}$ ) Die Anfänge einer ausgesprocheneren Differenzierung zeigen sich gegen Ende des ersten Monats. Laut den Messungen an Schnitten beträgt bei $\mathrm{Br} 3(6.9 \mathrm{~mm})$ die Wanddicke:

in der Seitenwand des Thalamus . . . 130-140

in Corpus striatum steigt sie auf . . . $150 "$

in der Seitenwand des Hemisphärenmantels 110-120 ",

Am Hemisphärenmantel finden sich die größten Wanddicken im basalen Abschnitte; scheitelwärts verjüngt sich die Wand, anfangs langsann, dann aber mit Annähernng an die Nittelebene ziemlich rasch, sie geht bis auf 80 und im Bereich der medianen Leiste bis auf $60 "$ herab.

Von diesem Zeitpunkt ab schreitet die Differenzierung in der Vorderhirnwand rasch rorwärts. Bei Ko. (10.2 mm) mißt.

die Seitenwand des Hemisphärenmantels . . 150-160

die mediale den Thalamus iiberlagernde Wand 110 "

längs der medianen Lüngsleiste nur noch . . 40-50",

dagegen steigt die Wanddicke im Gebiete des

Streifenhïgels und des Riechhirns auf . . 250-380 "

Im weiteren Verlauf des zweiten Monats iiberholt der Thalamus den Hemisphäremmantel im Dickenwachstum etwa um das Doppelte, so messe ich an den dicksten Stellen bei den Embryonen

$\begin{array}{llcc} & \mathrm{Zw}(18.5 \mathrm{~mm}) & \mathrm{Mr}(22 \mathrm{~mm} \\ \text { die Seitenwand des Thalamus . . . } 600 " \mu & 900 \mu \\ \text { die Seitenwand des Hemisphäremmantels } & \mathbf{3 0 0} ", & 400 "\end{array}$

Der Hemisphärenmantel ist in seinem an den Streifenhïgel stoßenden basalen Abschnitt am dicksten und sein Durchmesser rerjüngt sich stetig nach der Decke zu und von der Decke ans nach dem Grund der Median-

1) Die Messungen sind durchweg an Paraffinschnitten rorgenommen, sie geben somit zu geringe absolute Werte und beansprnchen nur relative Gültigkeit. 
furehe. Schließlich geht die Wand in die das Corpus ehorioidenm nmkleidende Lamina chorioidea über. So messe ich

die Dicke der seitliehen Mantelwand in halber

$$
\text { bei } \mathrm{Zw}
$$

bei $\mathrm{Mr}$

Höhe

$$
170 \mu
$$

die Dieke an der Decke . . . . . . 110 ",

$"$ " " , medialen Wand . . . . 100 ,

$" \quad "$ am Boden der Medianfurche . . 30 "

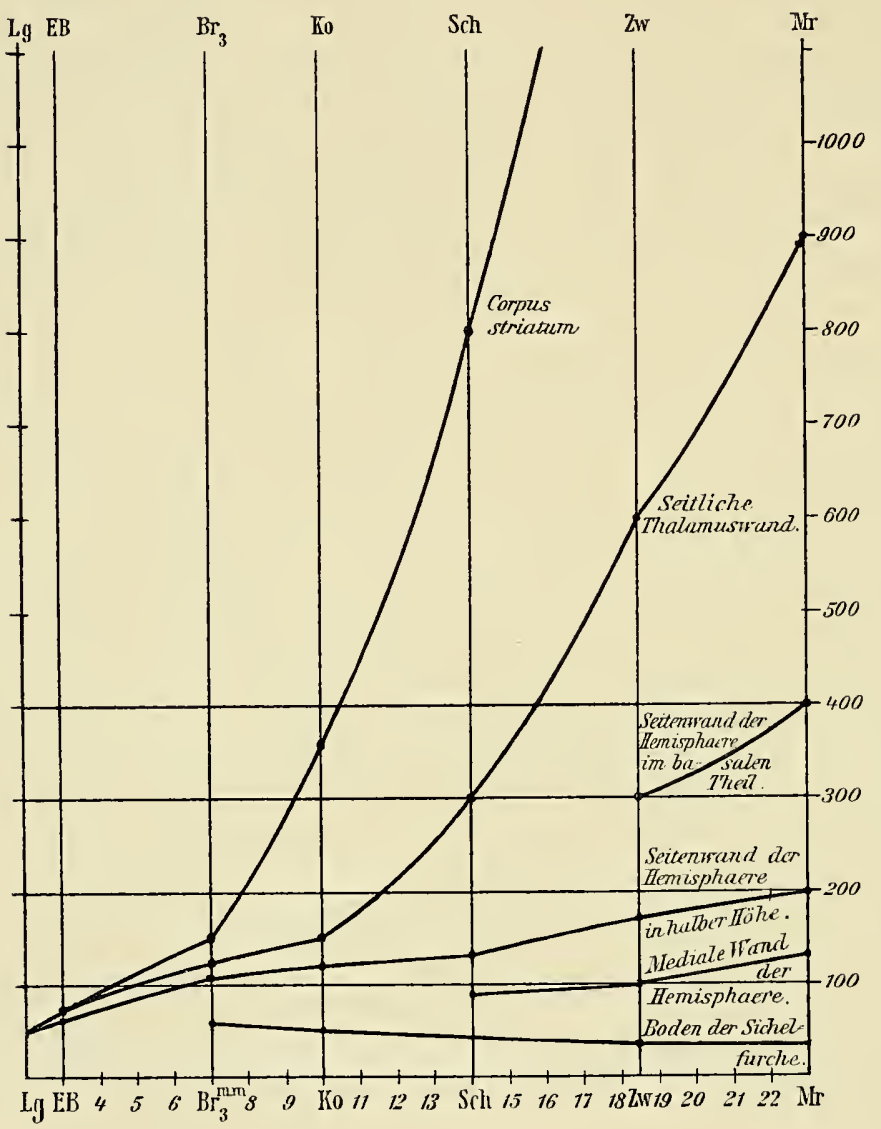

Das mäehtigste Diekenwachstum zeigt das Gebiet des Streifenhügels und des Übergangsteiles rom Sehhïgel zum Streifenhïgel (des sog. Stielgebietes). Hier messe ieh die maximale Dicke

bei Ko $\quad 350 \mu$ "Seh ca. 800 ", "Zw , 1300 " " $\mathrm{Mr}, 2000$,

In beistehendem Kurvenbild sind einige der erhaltenen Werte übersichtlich zusammengestellt. Bis zn $\mathrm{Br} 3$, d.h. bis gegen Ende des ersten Monats, selıreitet das Diekenwachstnm der verschiedenen Absehnitte langsam und annähernd gleiehmäßig voran. Von da ab aber eilen Thalamms und Corpus striatum der Mantelwand raseh voraus und gewimnen einen Vorsprung, den diese erst nach langer Zeit wieder einholt.

\section{Zur Kritik normaler und postmortaler Furchen der Hemisphären- oberflïche.}

Vor dem Eintreten auf fernere Besehreibungen von Fläehenreliefs ist prinzipiell festznstellen, inwieweit die den Beobaehtern entgegentretenden 
Formen embryonaler Gehirnoberflächen den Anspruch erheben können, für normal angesehen zu werden. Die älteren Beobachter hatten sog. „transitorische Furchen" der Gehirnoberfläche beschrieben, d. l. Furchen, von denen sie annahmen, daß sie sich im Lanfe der Entwicklung wieder zuriickbilden. Gegen diese Annahme wurde dann eingewendet, daß die sog. transitorischen Furchen Kunstprodukte seien, bedingt durch die Einwirkung ron Alkohol oder ron andern Aufbewahrungsmitteln. Es war dies ein Einwand, den man mit der Berufung auf frisch eingelieferte Präparate glaubte beseitigen zu können. Die Diskussion über transitorische Furchen ist neuerdings wieder lebhafter in Gang geraten, dabei ist eine Verschiebung des Standpunktes insofern eingetreten, als nummehr das Hauptgewicht auf den Einfluß postmortaler Quellungsvorgänge gelegt wird. Nur dann wemn uns ein Foetus noch durchsichtig übergeben und wenn er sofort in passende Fixationsfliissigkeit gebracht wird, haben wir Anssicht, die Form der Hemisphären naturgemä $\beta$ zu erhalten. In andern Fall geniigen, selbst wenn der Foetus lebend, und nicht seit einiger Zeit abgestorben, ausgestoßen worden war, wenige Stunden, um postmortale mit den natiirlichen sich kombinierende Faltensysteme hervorzurufen, deren Sonderung. nur einer sorgfältigen Kritik gelingt. Solche Falten treten um so rascher und ausgiebiger ein, je dünner die Hemisphärenwand ist, und sie bereiten daher in der Zeit ron der Nitte des zweiten bis zum Beginn des vierten Nonats die grösste Not. Manche ron uns haben wohl diese Quellungserscheinungen gekannt und bei ihrer Beurteilung ron Präparaten in Betracht gezogen, immerhin ist es als ein Verdienst ron HochstetTER anzuerkennen, daß er strenger, als andere ror ihm, auf eine Ausscheidung postmortaler Veränderungen als Irrtumsquelle hingearbeitet hat. ${ }^{1}$ ) $\mathrm{Ob}$ er dabei nicht iibers Ziel hinansgeschossen hat, werde ich im Nachfolgenden zu prïfen haben, ich glaube, daß gerade in seiner gegen mich gerichteten Polemik störende Mißrerständnisse mit untergelaufen sind.

Über eine Reihe von Punkten werden wir uns, glaube ich, leicht einigen können. Auch ich betrachte seit langem die an der Außenfläche der Hemisphären ron 2-4 monatlichen Foetus auftretenden Furchen, insbesondere die an unfrischen Präparaten sehr häufig auftretenden Radiärfurchen für postmortale Erscheinungen, und ich habe dementsprechend schou in meinem Aufsatz rom Jahre 1889 erklärt, daß die laterale Fläche der Hemisphärenwand auf längere Zeit hinaus eine glatte gleichmäßig gerundete Wölbung besitzt. ${ }^{2}$ ) Zwei Foetus mit rorziiglich erhaltenem Gehirn sind mir sodann im Jahr 1891 eingegangen. Der eine maß 5, der andere $5.3 \mathrm{~cm}$ SSl. Das Gehirn des ersteren habe ich in der dureh Herrn Zieglen in den

1) F. Hochstetter, Beiträge zur Entwicklungssgeschichte des Gehirns. 1595. In Bibliotheca medica. Stuttgart.

$\Rightarrow$ l. c. S. 694 . 


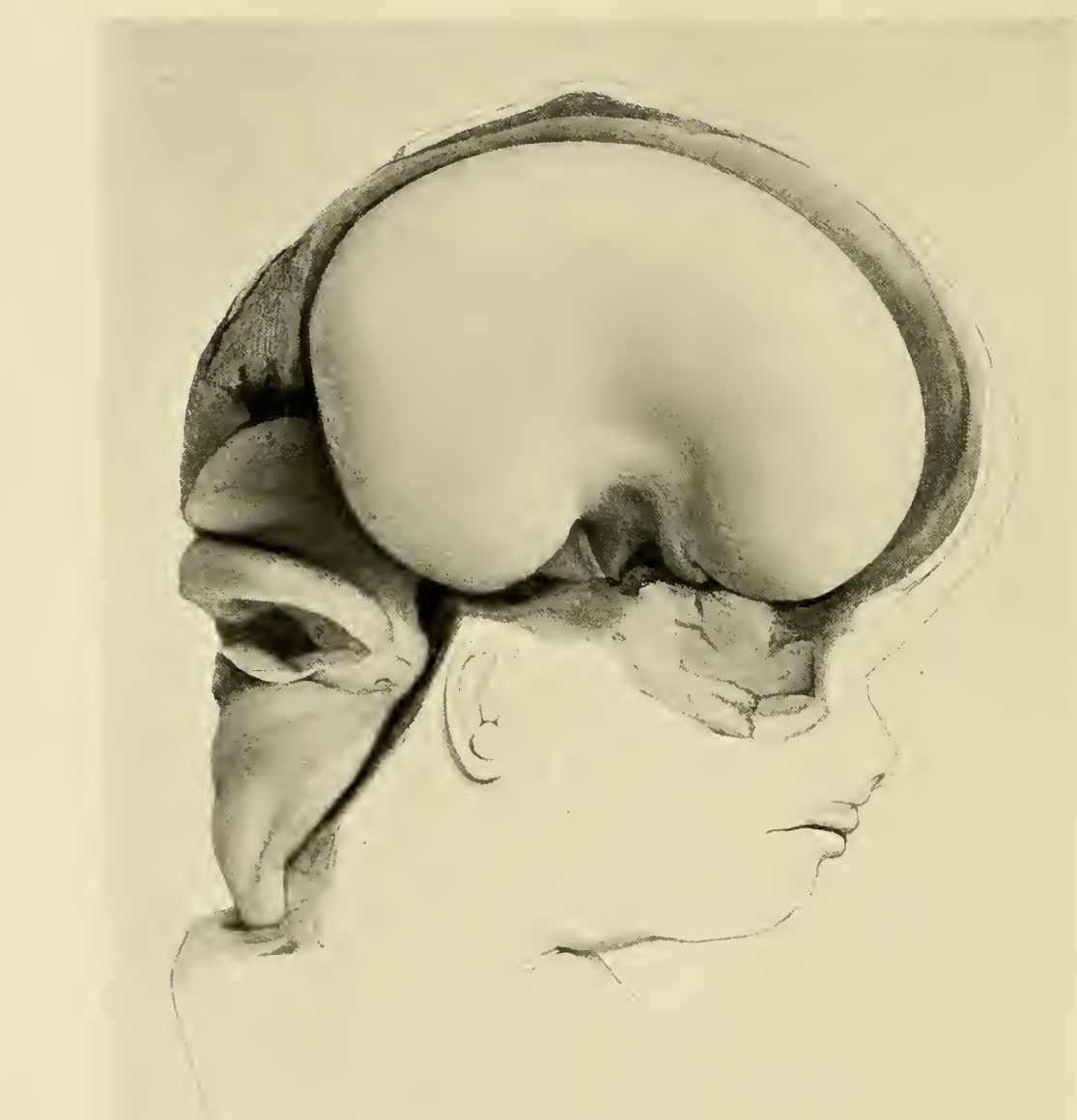

Fis. 46. Seitenansicht rom Gehim des Foetus Bi von $5.3 \mathrm{~cm}$ ssl. Glatte laterale Hemisphärenfäehe. Das hintere Riechhim, bez. der Gyrus olfactorius hateralis von G. Retzius erscheint durch eine seiehte Furehe rom iiberliegenden Gebiete der Fossa Sylvii abgesetzt.

Handel gebrachten Hodellreile reproduziert, von dem Gehirn des anderen habe ich damals eine genane Beschreibung anfgenommen und sechs Zeichnungen anfertigen lassen, die ich in den Figg. 46, 48, 53, 54, 62 ш. 63 dieses Aufsatzes mitteile. ${ }^{1}$ ) Bei beiden Präparaten zeigt die mediale Hemisphärenwand nichts von Radiärfalten und so hat sieh damals die jedenfalls schon

1) Ich verdanke den oben erwähnten Fötus Bi dem seither verstorbenen Prof. J. J BischoғF in Basel, vou dem ich s. Z. anch andere wichtige Zusendungen, die in der Anat. menschl. Embryonen beschriebenen Embryonen B, B B u. a. m. erhalten hatte: der Fötus von $5.3 \mathrm{~cm}$ SSl. und $2.2 \mathrm{~cm}$ Kopftiefe war in MÜLLERscher Lösung fixiert worden. Die laterale Fläche des bloßgelegten Hemisphärenmantels zeigte eine ziemlich regelmäßige bohnenförmige Gestalt, und war glatt, ibre Länge betrng $1.65 \mathrm{~cm}$, die größte Höhe $1.15 \mathrm{~cm}$. Ein Hintenïberlıängen des Occipitalbirns war mir andentungsweise er- 


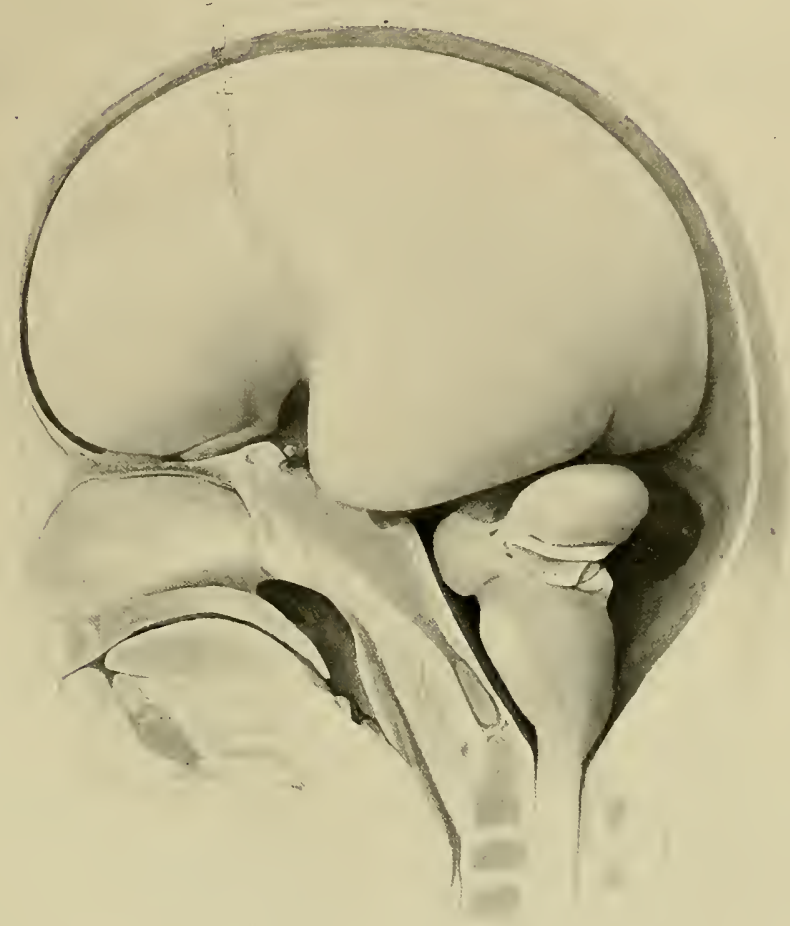

Fig. 47. Blongelegtes Gehim eines Foetus von $9 \mathrm{~cm}$ nit glatter lateraler Hemisphärenoberfläche. Am oecipitalen Rande zeigt sich das hintere Ende der Fissura calearina.

frïher gehabte Überzeng'ung bei mir befestigt, daß Radiärfalten auch hier als Quellungserscheinungen zu denten sind, wie ich denn anch an dem publizierten Modell solche Falten nicht zur Darstellung gebracht habe.

Nun finden sich aber solehe Furchen unglücklicherweise in einigen meiner Zeichnungen vom Jahre 1889 wiedergegeben (l. e. Figg. 26, 34, 37 und 38). HochstetTen, der sich gerade mit diesen Figuren riel zu schaffen macht, wirft mir vor, daß ich auf die Dentung der Furchen im Text nicht eingegangen sei. Der Grund ist ein sehr naheliegender und ist ans der

kennbar. Die Fossa Sylvii zerfiel in einen oberen, alhmählich ins Pallinm anslanfenden und in einen unteren dem Riechhirn angehörigen Abschnitt. Eine seichte, die Grenze bezeichnende Furche entsprach Tunsens Fissura rhinica. Der letzteren entlang verlief die laterale Olfactoriuswurzel als ein gebogener heller Streifen rom rorderen zum hinteren Riechlim (Fig. 46 1. Fig. 47). In betreff der medialen Oberflïche, der Fissura prima und der Fissura arcnata accessoria rerweise ich anf die nachfolgenden Textseiten. 
Stellung der Figuren im Text und ans der dabei stehenden Erklärung ohne weiteres zı erkennen. Alle vier genannten Figuren sollten Verhältnisse des Streifenhïgels und des Thalamus erläntern, ${ }^{1}$ ) und dabei war es völlig gleichgiiltig, ob die Wand des Pallium faltig war, oder nicht. Aus den Figuren durfte eben nur das herausgelesen wer-



Fig. 48. Vorderansicht des Gehirns ron Foetus Bi. den, wofür sie sich ansgaben.

Die Furchen, auf die ich in meiner Arbeit Gewicht gelegt habe, sind die Fissura prima oder vordere Bogenfurche und die Fissura hippocampi oder lintere Bogenfurche. Beide Furchen werden von HochstetTER und nenerdings von Goldstein in Abrede gestellt und als postmortale Bildungen gedentet. AuBerdem zeigt mein Modell von der Hemisphäre eines 3 monatlichen Foetus eine oberhalb der Fissura prima den Stirnlappen sagittal durchsetzende Längsfurche, die ich bei allen meinen Pr:̈pa-

raten wiedergefunden habe, und die anch in den Zeichnungen anderer Beobachter wiederkehrt. Diese verschiedenen Furchen, sowie das noch zu beschreibende Mittelstiick der Bogenfurche, sind einzeln zn erörtern. Zuvor

1) Fig. 26 steht im Abschnitt „Seitenfläche des Zwischenhirns" und sie soll lant Erklärung die Ausdelmung des frei bleibenden Thalamusfeldes demonstrieren. Fig. 34 steht im Kapitel „Streifenhïgel und Seitenventrikel“ und sie zeigt die Bogenform des Streifenhïgels und dessen Beziehungen zur Fossa Sylvii, während die im Kapitel der "Regio thalamica" stehenden Fig. 37 u. 35 die Stellung und den Verschlufs des Recessus geniculi erläıtern. 
aber habe ieh noeh einen wichtigen Punkt hervorzuheben, hinsichtlich dessen ieh mit HochstetTER iibereinstimme. Überall da, wo an lebenden Gehirn Furehen in die Tiefe treten, pflegen blattartige Fortsetzungen, oder bei noeh seichten Furehen Verdiekungen der gefäßführenden Hirnhaut in den

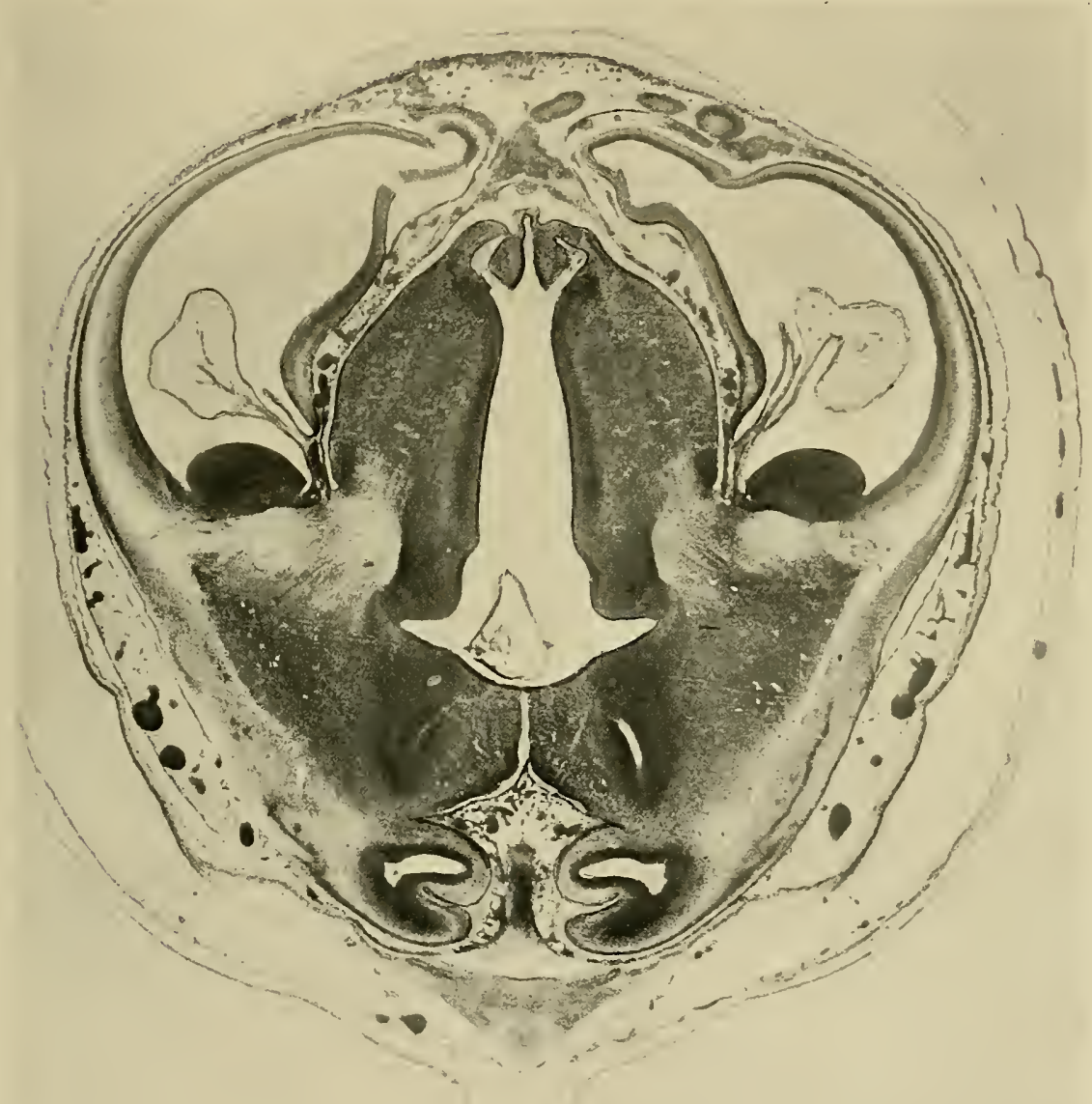

Fig. 49. Durchschnitt dureh das Vorderhirn von Embryo Oe (s. o. Figg. $\mathbf{1 1}$ bis $\mathbf{4 3}$ ), die Höhle des hinteren Riechhirns ist nur noch rechts ein Stiick weit offen. Die Hirnsichel entsendet jederseits einen zugesch ̈̈rii:1 Fortsaty in die Fissura prima. Der zwisehen die Trapezplatten eintretende Fortsatz ist kurz und ausnehmend diinn.

offen bleibenden Raum sieh vorzuschieben. Eine jede Furche der Gehirnoberfläehe, in die sieh Verdiekungen oder Fortsätze der Gefässhaut eindrängen, ist dadnch als ursprüg glieh vorhandene, echte Bildung gekennzeichnet. 


\section{Die Fissura prima.}

In meiner älteren Arbeit habe ich die Fissura prima oder vordere Bogenfurche von Embryonen des zweiten Monats als eine vom Riechhirn scheitelwärts emporsteigende, allmählich seichter werdende Furche beschrieben. ${ }^{1}$ ) Ilır unteres Ende beginnt als breiter Einschnitt zwischen den beiden Abteilungen des Riechhirnes, lier nimmt sie einen dicken zum System des Riechnerven gehörigen Faserstamm auf. Ihr oberes Ende rerliert sich vor der Adergeflechtfurche. Diese Beschreibung halte ich noch jetzt für zutreffend. Sie paßt auch für Embryonen des nachfolgenden dritten Monats. Zu der Zeit hat sich der Riechlappen oder das vordere Riechhirn an seiner medialen Seite durch eine ans der lateral gelegenen Fissura rhinica hervorgehende Furche, die Fissura rhinica medialis vom iberliegenden Stirnlappen abgegrenzt. ${ }^{2}$ ) Diese Furche trifft mit der hinter dem Riechlappen einschneidenden Fissura prima zusammen, es entsteht so eine tiefe dreieckige Grube, in deren Vorderwand der mediale Tractus olfactorius emporsteigt. Die vorhin besprochenen Figg. 26, 37 n. 38 meiner älteren Arbeit erläutern dies Verhalten in völlig charakteristischer Weise, die an ihnen hervortretenden postmortalen Furchen gehören dem oberen Hemisphärengebiete an. Fig. 37 läßt auch den ans dem Grund der Furche hervortretenden Tractus olfactorius erkennen. Auch das obere Ende der Fissura prima und die Abgrenzung des Trapezfeldes sind bei den drei Figuren gut verfolgbar.

Hinsichtlich des oberen Endes der Fissura prima bei vorgeriickteren Stufen enthält dagegen meine Arbeit einige Unklarheiten: es heißt nämlich an eincr Stelle, $\left.{ }^{3}\right)$ daß sich dic Furche in der Nähe des oberen Hemisphärenrandes verliert. Das beruht anf einer mißverständlichen Deutung und dasselbe gilt von der Darstellung der Konstruktionsfigur 36, die einen breiten Übergang der Fissura prima in eine die Adergeflechtzone ungreifende Furche zeichnet. Die Fissura prima geht zu keiner Zeit über das obere Ende der Schlußplatte hinans. Thr bleibender Rest ist die Fissura parolfactoria posterior der BNA.

Schon bei Embryonen des zweiten Monats erscheint der untere Teil der gefässführenden Hirnsichel in dem an die Fissura prima anstoßenden Teil sehr verbreitert und er läuft hier in drei zugeschärfte Blätter ans, ein mittleres und zwei seitliche, letztere dringen in die Tiefe der beiderseitigen Fissurae primae, das mittlere geht nach dem Grund der Sichelfurche bis in die Nähe der Schlußplatte. Ich verweise auf die obigen Figg. 42 11. 43, sowie auf Fig; 49 (S. 75). Da wo die Fissura prima in

1) 1. c. S. 69 \%

2) Fissura serotina meiner älteren Beschreibung 1. c. S. 724 , ich lasse den Namen fallen.

$\left.{ }^{3}\right)$ 1. c. S. 713 . 
ihrem obern Abschnitte seiehter wird, verkiirzen sich die blattartigen Fortsätze der Hirnsichel (s. o. Fig. 41), der Querschnitt der letzteren bewahrt dabei eine Form, die ZuCKERKANDL, mit einem zweckmäßigen Vergleich als "Lanzenform" bezeichnet hat. ${ }^{1}$ ) Bei noch weitergehender Abschwächıng der Form zeigt die Sichelfalte anf den Durchschnitt eine spindelförmige Verdickung. Soweit ïberhanpt solehe Verdickungen der Sichelfalte naehweisbar sind, entsprechen sie stets einer Einbiegung der Hemisphärenwand.

Unter den Abbildungen meines älteren Aufsatzes finden sich (Fig. 16 bis 18 ${ }^{2}$ ) die eines menschlichen Embryos $\mathrm{Ha}$, die bei noch wenig entwickelten Hemisphären bereits angelegte Bogen- und Adergeflechtsfalten zeigen. Diese drei Abbildungen sind von HochstetTER besonders lebhaft beanstandet und die dargestellten Falten als postmortale Bildungen bezeichnet worden. Ieh gebe meinem Opponenten zu, daß er in dem einen Punkte recht haben mag, wenn er den breiten Zwischenraum zwischen der Hirnsichel und der Hemisphärenwand als postmortale Erscheinung deutet. Dabei kann eine Retraktion des schrumpfenden Bindegewebes der Sichel ebensogut im Spiel gewesen sein, als eine durch Quellung bedingte Faltenbildung der Hemisphärenwand. Dagegen bestreite ich, daß die gezeichneten Bogen- und Adergeflechtsfalten rein postmortale Produkte gewesen sind, und ich stütze mieh dabei auf die ron HochsteTTER unbeachtet gelassene Form des Sichelqnersehnittes, die bei allen drei Figuren die den Furchen entsprechenden Ausladungen zeigt.

Ich finde die rentrikelwärts gerichteten Ausbiegungen der vorderen Bogenfalte und die entsprechende Verdickung der Hirnsichel anch an den eben erst selbständig abgelösten Hemisphären eines Katzenembrỵos ron $14 \mathrm{~mm}$ Nl. (Fig. 50, S. 78), wie sie denn anch ZUCKERKANDL in seinem vortrefflichen Aufsatz uiber Balkenbildung von der Ratte wiederholt abbildet. Über die in späteren Stufen anftretende Verdickung der Hemisphürenwand im Bereich der Trapezplatte werde ich mich weiter unten anssprechen.

Bei ilurer Opposition gegen das Vorhandensein einer vorderen Bogenfurche berufen sich sowohl Hochstetter als Goldstein:3) anf ihre $\mathrm{Ab}$ bildungen von angeblich besonders g'ut erhaltenen menschlichen Foetus. Die vom ersteren Forscher als durchaus beweisend angesehene Fig. S, Taf. II muß ich indessen als für den Zweck unbrauchbar ablehnen. Sie zeigt nicht nur auffallend flane Formen, sondern sowohl in ihrem hinter dem Thalamus liegenden, als in ihrem Hemisphärenteil so fremdartige Faltenzügge, daß ich vermuten muß, es habe das Präparat durch irgendwelche

1) E. Zuckerkande, Znr Entwicklung des Balkens und des Gewölbes 1901. Sitzungsber. d. K. Ak. d. Wissensch. in Wien, mathem.-naturw. Klasse Bd. CX Abt. III S. $5 T$ (289).

2) 1. c. S. 696 .

3) Golusteix, Beiträge zur Entwicklungsgeschichte des menschl. Gehirns. His Archiv 1903 S. 2 fff. 
Druckwirkung gelitten. Glücklicherweise teilen sowohl HochstetTer als Goldstern anch Photogramme ihrer Präparate mit. Als Dilettantenleistungen sind diese zwar nicht allzuhoch einzuschätzen, auch ist der Maßstab der HochstetTERschen Figuren ein sehr kleiner. Gleichwohl kann man aus denselben genügende Klarheit gewinnen. Taf. IV, Fig. 14, nnd noch besser Fig. 16 von HochstetTer zeigen sehr dentlich den basalen Anfang der

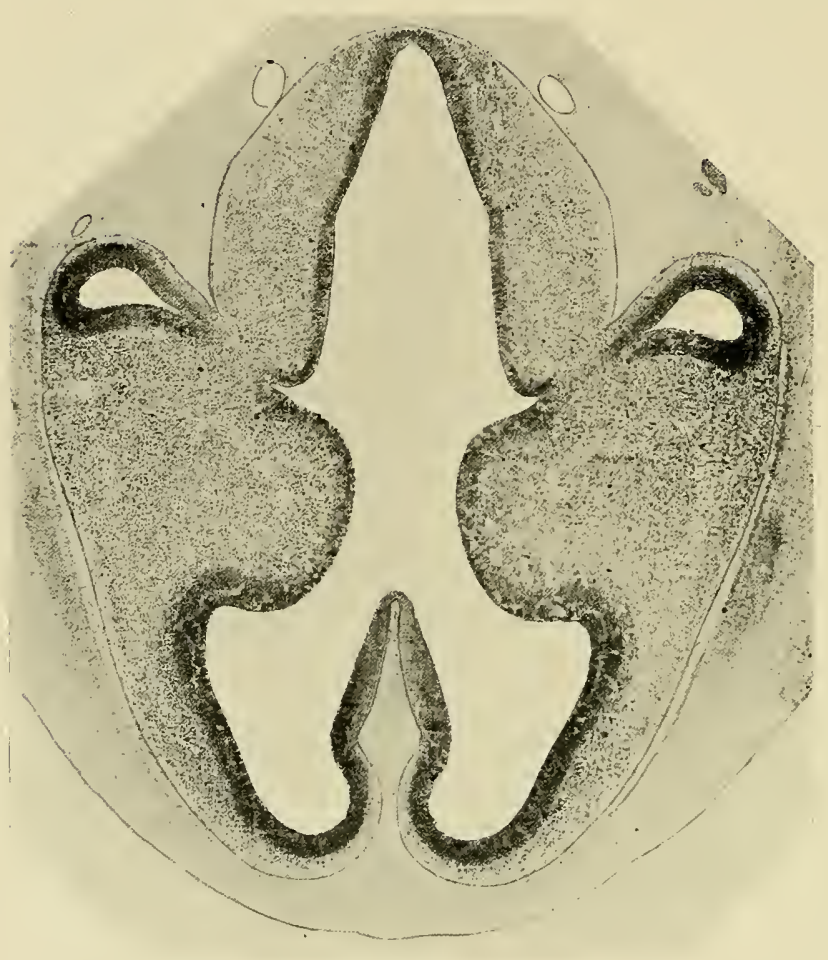

Fig. 50. Durchschnitt durch das Vorderhirn eines Katzenembryos von $14 \mathrm{~mm}$ Nl. An der medialen Seite beider Hemisphären erscheint die Fissura prima durch einen lanzenförmigen Fortsatz der Hirnsichel ausgefiillt. ( $\mathrm{Zu}$ Seite 77.$)$

Fissura prima ${ }^{1}$, und noch bestimmter tritt dieser bei GOLDSTEIN (Fig. 2) hervor. Hier spricht GOLDSTEIN auch ansdrücklich von einer „Rinne die rom Trigonum olfactorium wach oben zieht." Die nach einem gleichfalls sehr frisch eingelegten Präparate entworfene Zeichnung von G. ReTzius ${ }^{2}$ ) zeichnet die Furche bis zu ihrem oberen Ende, und es tritt an ihr die Abgränzung des Trapezfeldes sehr deutlich hervor. Die basalen Anfänge der Furche vor und hinter demRiechlappen lässt Retzius eine Strecke weit getrennt rerlaufen, der zwischen beiden dargestellte Strang ist unverkembar der mediale Tractus olfactorius. Auch unter den älteren Abbildıngen von RetziUs ${ }^{3}$ ) zeigen verschiedene die Fissura prima und das Trapezfeld. Unter den Zeichnungen von MARCHAND ${ }^{4}$ ) kann die von dem relativ gut erhaltenen Gehirn eines Foetus von $4^{1} / 2$ Monat

1) Gleichwohl sagt Hochstetter l. c. S. 10 er habe keine Furche gesehen, „die auch nur annähernd der vorderen Bogenfurche von His entspricht".

?) G. Retzius, Biolog. Untersuchungen. Nene Folge. Bd. X. 1902. Taf. XIX Fig. $3-4$.

3) G.Retzius, Das Menschenhirn. Stockholm 1896. Taf. IV-V.

1) F. Marchand, Arehiv f. mikrosk. Anat. 1891 Bd. 37 Taf. XV Fig. 2. 
zitiert werden und endlich verweise ich noeh anf die verschiedenen Konstruktionsfiguren der vorliegenden Arbeit (Figg. 44 u. 45 S. 66 u. 67).

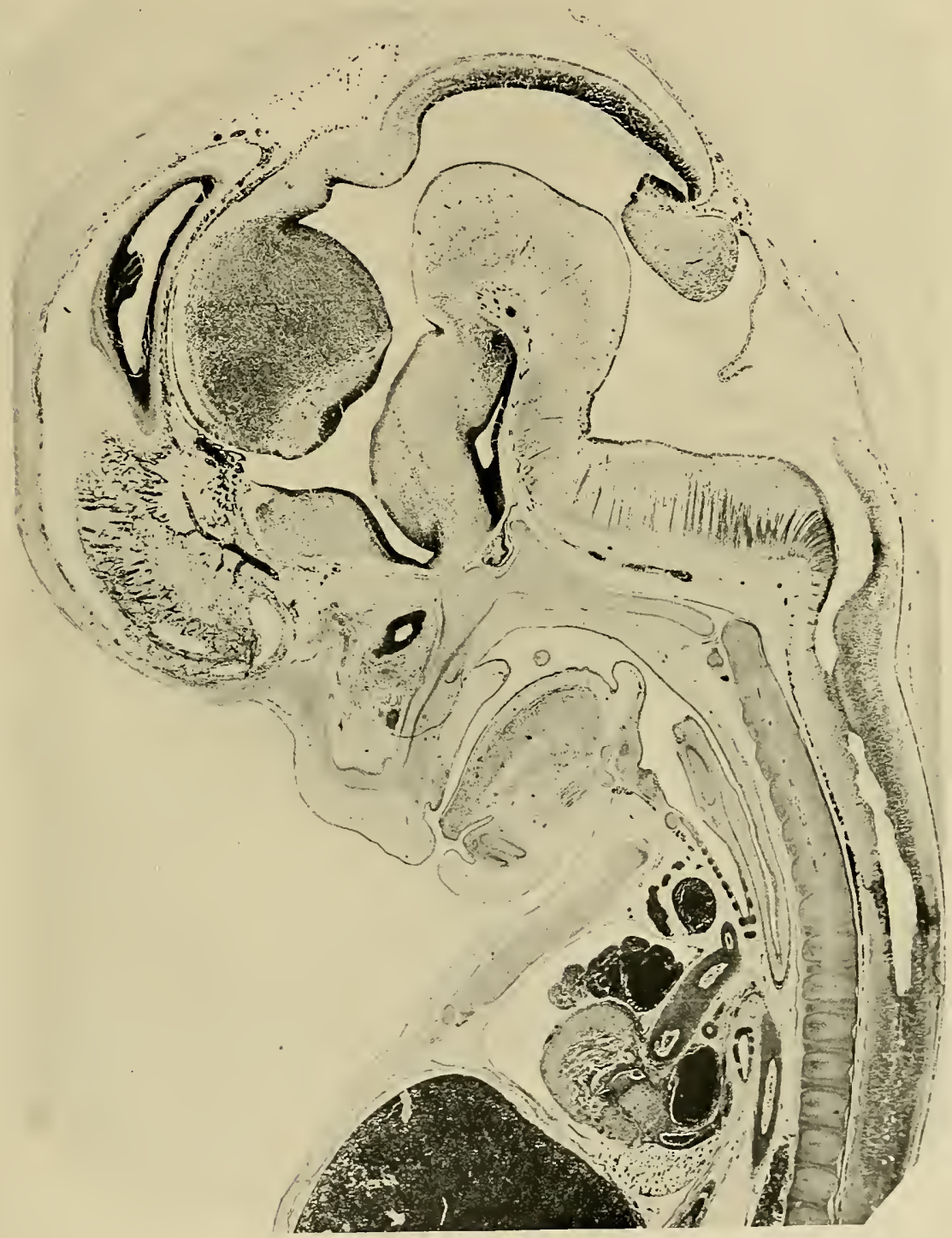

Fig. 51. Sagittalschnitt etwas seitwärts von der Jittelebene, Foetus Cl. Die Hemispläre ist nur leicht gestreift. Vor dem Thalamus liegt die primäre Hirnsiehel mit der vorderen Bogenvene; dahinter die Trapezplatte und als dunkler schmaler Streifen, die Sehlußplatte. Zwischen der Hemisphäre und dem Thalamus zielıt sich eine doppeIte Gefäßsehicht dureh, die der Tela chorioidea angehört. (Zu Seite 80.)

Das von der Fissura prima abgegrenzte Trapezfeld tritt in seiner charakteristisehen Form und Umgrenzung anch an guten Sagittalschnitten herror. 
Bei der relativ bedentenden Dieke der Trapezplatten kann das fragliche Bild an mehreren nebeneinander gelegenen Sehnitten wiederkehren. Als Beispiel gebe ich in Fig. 51, S. 79 einen Sagittalsehnitt dureh das Gehirn eines Foetus ans dem Begimn des dritten Monats. Der Sehnitt hat die eine Trapezplatte etwas seitwärts von der Mittelebene gestreift und zeigt deren beiderseitige Zusehärfung, einerseits nach dem Recessus opticus, andererseits naeh dem Angulus praethalamieus hin. Vor der Trapezplatte liegt die gefäßreiche Hirnsichel, auf deren Verhalten ich nachher zurïckkommen werde.

Das Vorkommen eines wohlumgrenzten Trapezfeldes besehränkt sich keineswegs auf das Gehirn des mensehliehen Foetus. Ein entspreehend ungrenztes Feld kommt am Süugetierhirn in weitester Verbreitung vor. Abbildungen hiervon geben P. MARTIN vom Gehirn der Katze ${ }^{1}$ ), ZuckerKANDL von dem der Ratte ${ }^{2}$ ), Elliot Suith von dem von Phascolaretos und von Eehidna. ${ }^{3}$ ) Letzterer Autor nennt das Feld die „Area praecommissuralis" oder nenerding"s "Area praeterminalis".

\section{Das Trapezfeld, die Bogenzone und der Limbus hemisphaericus.}

Das zwisehen der Fissura prima und der Schlufplatte liegende, den vorderen Absehnitt des medialen Hemisphärensaumes bildende Feld ist das Trapezfeld (die Trapezzone meines älteren Aufsatzes). ${ }^{4}$ ) Es gehört zum hinteren Riechhirn, dessen mediale Wand es liefert. Der jenseits rom Thalamnswinkel folgende und von da bis in den Sehläfenlappen reichende Absehnitt kann als Bogenzone (Zona arenata) bezeichnet werden. Trapez- und Bogenzone lassen sieh im Anschluß an die BRoca sehe Terminologie, als Zona limbica, oder kurzweg als Limbus hemisphaerieus zusammenfassen. Die Trapezzone liegt vor dem Vereinigungsrand der medialen Hemisphärenwand, die Bogenzone über dem Thalamus- und Stielrand. In der Trapezzone und im vorderen Teil der Bogenzone sind sich die beiden Hemisphären zugekehrt und nur dureh die Hirnsiehel von einander geschieden. Zwischen die hinteren Teile der beiderseitigen Bogenzonen schiebt sich das Zwischenhirn ein, und dureh diese Einsehiebung bekommt die Hemisphärenfläche eine konkave Wölbung, die HochstetTer mit einem nieht unzweekmässigen Namen als Thalamusmulde bezeichnet").

1) Paul Mantix, Bogenfurche und Balkennetze bei der Katze. 1894. Diss.-Inang. Jena. Fig. 3,4 u. 8.

?) Zuckerkandi, l. c. S. 16 .

3) Elliot Suith, Anatomy of the brain in the Monotremata Journal of Anat. and Physiol. vol. XXXIII 1899 Taf. XI. Ders., Relation of the fornix to the margin of the cerebral cortex ibid. rol. XXXII S. 30.

) l. c. S. 714 .

") „Bogenmulde“ bei Martin. 
Die von der lateralen zur medialen Hemisplärenwand fortschreitende Bildung einer Rindenselicht riiekt im Beginn des dritten Monats in der Richtung nach dem Grund der Siehelfurehe vor, ohme ihn jedoch zu erreichen. Es bleibt sowohl im Trapezfeld als in der Zona arcuata cin Streifen iibrig, der zwar in der Folge von Nerrenfasern durchwachsen wird, der aber keine Rinde besitzt. Jenseits davon folgt, durch einen zugeschärften Saum rermittelt, eine düme, rein ependymale Platte. Von der Zeit ab, da die Flächenansbreitung der Rindenschicht abgeschlossen ist, sind somit am Limbus zn nuterscheiden:

1) ein Bezirk mit Rindenbelag, der Rindensaum oder Limbus corticalis, ${ }^{1}$ ).

2) ein rindenfreier, markhaltig werdender Bezirk, der Marksanm oder Limbus medullaris,

3) der medullare Übergangssaum, die Taenia,

4) die ependymale Wandplatte. Diese gliedert sich in die $S$ c l 1 u $B$ platte und in die Lamina chorioidea und infrachori o idea. Die Schlußplatte bildet den schmalen Verbindungsstreifen zwischen den beiden Trapezplatten, während die ependymale Wandplatte der Bogenzone breit angelegt wird nnd anßer dem Überzng des Corpus ehorioideum, die nach abwärts von der Fissura ehorioidea sich erstreckende La-

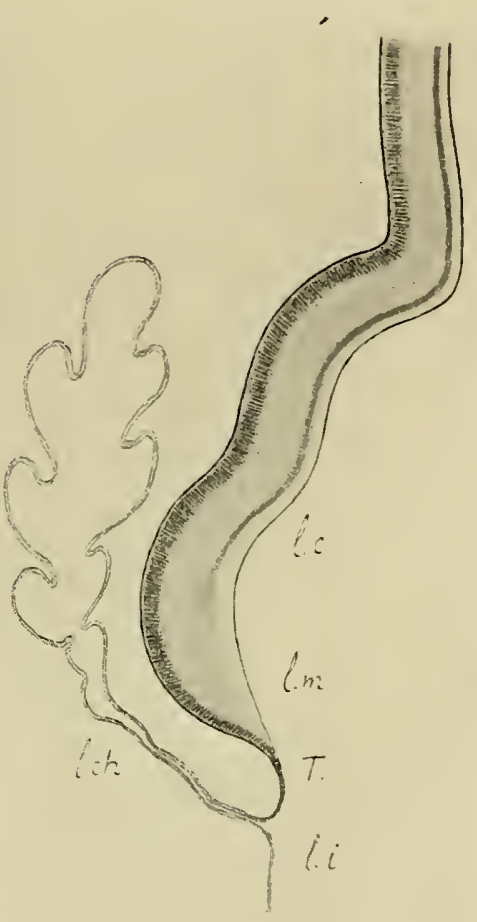

Fig. 52. Limbus der Hemisphäre im Bereich der Zona arcuata beim Foetus des dritten Monats. 1. c. limbus corticalis, 1. m. limbus medullaris T. Taenia, 1. eh. lamina chorioidea, 1. i. lamina infrachorioidea. Die nach links gekehrte Fläche ist die Ventrikelfläche, die nach rechts sehende die freie. Der rerdickte Abschnitt der Hemisphärenwand ist rentrikelwärts flach eingehogen. zeigt aber dabei eine wellenförunige krïmmung: dadurch sondern sich eine obere und eine untere flache Rinne, letztere ist die Anlage der mittleren. erstere die der aecessorischen Bogenfurche. mina infrachorioidea liefert.

Der rindenfreie Marksaum erstreckt sich längs der gesanten Zone des Limbus vom Riechhirn ab bis zum Schläfenpol.

1) Den Limbus hemisphaericus, bez. den Limbus corticalis kamn man enger oder weiter fassen. Rechnet man dazu die Lippe iiber der nachher zu beschreibenden Bogenfurche, so entspricht der Begriff dem "lobe limbique“ von Broca, d. h. sie umfaft 
Hintere und mittlere Bogenfurche.

Die hintere Bogenfurche oder Fissura hippocampi des foetalen Gehirns ist anch ihrerseits angezweifelt worden, nach meiner Überzeugung aber mit

\footnotetext{
Fig. 53. Gehirn des Foetus Bi, 5.3 ssl. (s. o. Figg. 46 11. 48) nach Wegnahme der rechten Hemisphäre. An der medialen Wand der linken Hewisphäre zeichnet sich die accessorische Bogenfurche. Außerdem sieht man den Bogen des Streifeuhïgelschweifes. (Zu Seite 85.)
}

vollem Unrecht. Sie sowohl, als die in ihrer oberen Verlängerung liegende mittlere Bogenfurche sind sehr wohl charakterisierte Bildungen, und mit postmortalen Produkten in keiner Weise zu verwechseln. Es wird, wie mir

auch den Gyrus fornicatus. Faßt man den Begriff enger und rechnet zum Limbus corticalis nur den Boden der Bogenfurche, so entspricht er, abgesehen von seinem Trapezanteil, der Ammonsformation, oder dem Gyrus dentatus der Antoren (Edinger, Vorlesungen 6. Anfl. 1900, S. 197 ff.); bei Elliot Sмiтh gehört dahin die bei Monotremen bis ïber die Area praecommissuralis sich erstreckende Fascia dentata. 
scheint, genügen, wenn ich, unter Zuriickdrängung polenischer Erörterungen, einfach beschreibend vorgehe, wobei ich die Verhältnisse vom Foetus des dritten Monats zu Grunde lege.

Der Limbus der Zona arcuata entstammt dem Thalamussaum der medialen Hemisphärenwand, er legt sich der freien Oberfläche des Thalamus von oben und von der Seite her an, und sein Anschluß an den letzteren erfolgt im Grunde der seitlichen Sichelfurche mit rascher Umbiegung. An Querschnitten durch das Vorderlirm tritt dieser AnschIuß, je nach Ort und Schnittrichtung, entweder als scharfer Rand frei hervor, oder cr zeigt sich

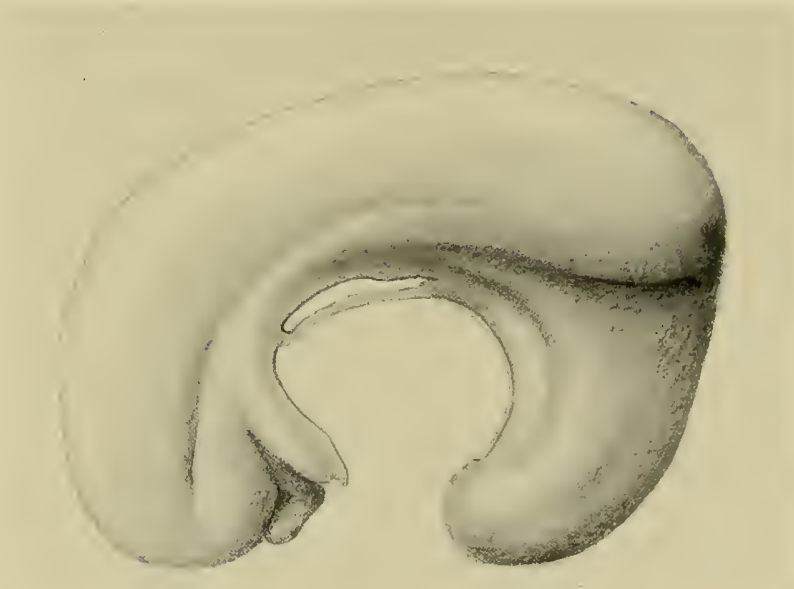

Fig. 54. Mediale Fläche der abgelösten reehten Hemisphäre desselben Foetus. Man sieht daran die Fissura prima und das Trapezfeld, die mittlere und die hintere Bogenfurche, die Fissura ehorioidea und darunter den schmalen Streifen der Lamina infrachorioidea. Die aceessorisehe Bogenfurehe sehneidet vorn ins Stimhirn ein, nach rüekwärts verliert sie sich ïber der mittleren Bogenfurche. Sehr seharf tritt an dem Präparate die Fissura ealearina hervor. ( $\mathrm{Zu}$ Seite 85.)

zwischen den Thalamus und den mit diesem rerbundenen Streifenhïgel eingeklemmt (Figg. 41 - 43 u. 49). Mag das eine oder das andere zutreffen, so zeigt der Limbus dieselben Eigentïmlichkeiten (Fig. 52, S. S1). Am tiefsten liegt die ependymale Lamina infrachorioidea, ron deren oberem Rand die Adergeflechtfalte mit sehr schmaler Basis abgeht. Damn folgt die zugeschärfte Taenia und über ihr ein Streifen, der von der übrigen medialen Wand durch etwas größere Dicke sich unterscheidet. Dieser Streifen ist stets ventrikelwärts eingebogen. Seine freie Fläche zeigt daher ron früh ab eine Furche, oder genauer gesprochen, eine Doppelfurche. Der verdickte Limbusstreifen ist nämlich leicht wellenförmig gekrïmmt und ein mittlerer Faltenzug scheidet an ihm eine obere und eine untere seichte Rimne. Letztere ist die Bogenfurche. 
Die Rindensehicht tritt in den obern Teil der Furchenwand ein, rerliert sich aber vor Erreichung des unteren Randes. Die Grenze zwischen dem Limbus corticalis und medullaris obiger Aufzählung fällt somit in den



Fig. 55. Selnitt dureh das Vorderhirn am Foetus Ma (SS1. $5.6 \mathrm{~cm})$. Der Schnitt fählt etwas vor den Thalamus und zeigt noch die an den Hemisphärensanm anstoßende Ependymdecke des dritten Ventrikels. Die Hemisphärendecke ist etwas eingedriickt. Der Hemispärensaum zeigt die im Text besehriebenen, ventrikelwäris konvexe Ausbiegung, zwischen ihn und die Ventrikeldecke schiebt sich als dünne Gefäßplatte die Tela chorioidea. Die dicke den Ventrikel basalwärts absehließende, durch eine mediane Furche halbierte Platte gehört dem oberen Ende der Trapezplatte an. Seitlich davon sind die Streifenhügel, die innere Kapsel und der Linsenkern rom Schnitt getroffen. (Zu Seite 87.)

Bereich der Bogenfurehe, und sie liegt deren unterem Rande näher als dem oberen. Die Gesamtbiegung der Wand ist, wie man sieht, eine S-förmige und sie bedingt das Hervortreten von zwei medialwärts gericliteten Lippen, 
deren obere anfangs nur schwach angedentet ist, während dic untere, dic Randlippe, im Übergangsteil von der Taenia zur Lamina chorioidea licgend, sehr scharf sich ansprägt.

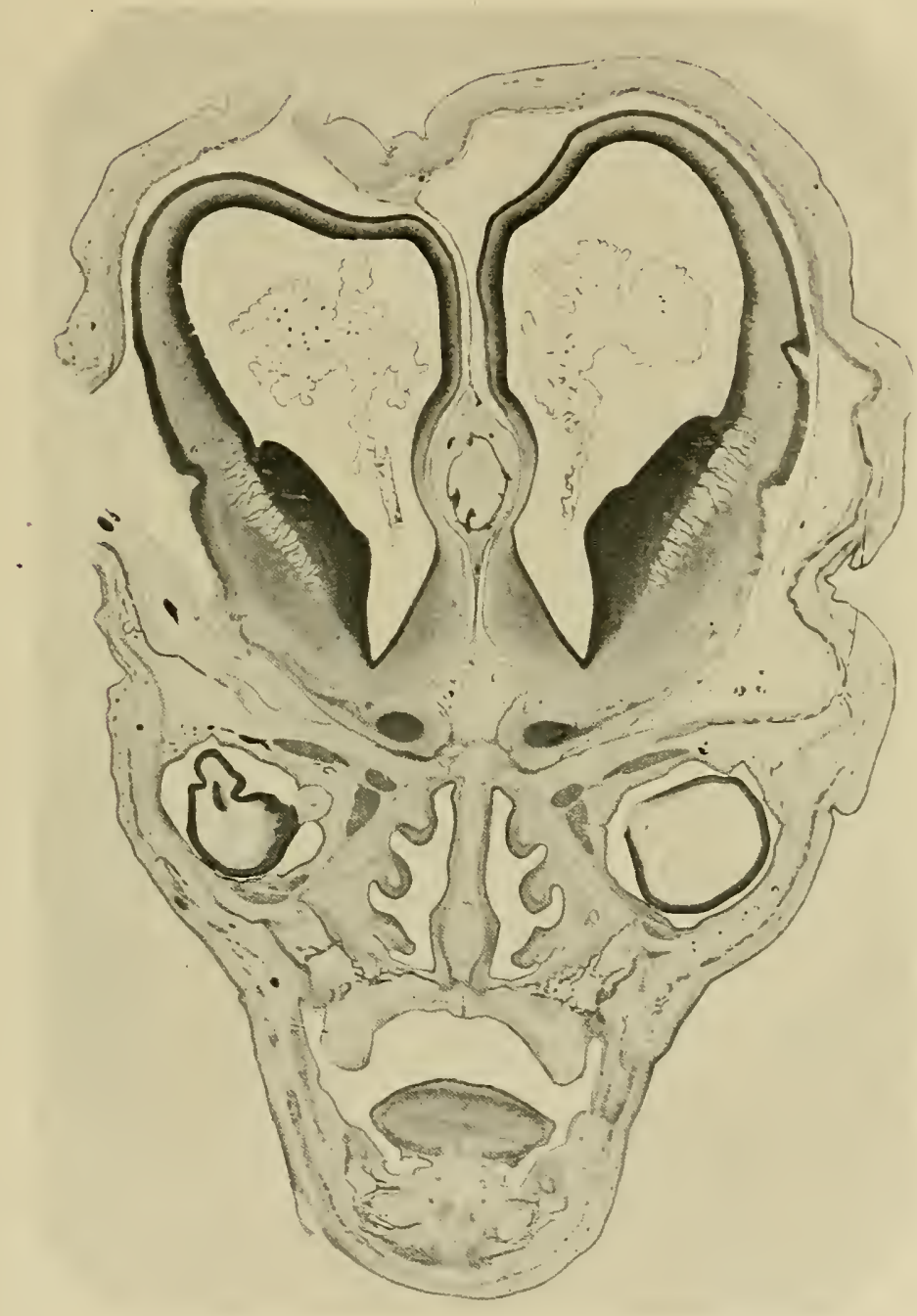

Fig. 56. Sehnitt durch dasselbe Gehirn etwas weiter vorn. Der Sehnitt streift noch das varderste Ende des dritten Ventrikels und zeigt nummehr die Deekschicht in sich zurüeklaufend und außen Verbindung mit der Hemisphärenwand. Die an der medialen Wand befindliehe flache Furehe ist die Fissura arcuata aceessoria. Der Sehnitt streift weiterhin die dieken Trapezplatten, die Fissura prima und das Riechhirn. Die innere Kapsel ist sehon erheblich dünner als beim vorigen Sehnittbild und ebenso der Linsenkern. (Zu Seite 88 .)

\section{Die accessorische Bogenfurche.}

Meine besten eigenen Zeichnnngen ron Foetus des dritten und rierten Monats (Fig. 53 u. 54, S. 82 u. 83), die Zeichnungen von MARCHaxd und 
von Retzius, ja sogar die Figur Taf. II, 8 von Hochstetter und seine Photographie Taf. IV, Fig. 14 zeigen eine iiber dem Trapezfeld vorbeiziehende, leicht gebogene Sagittalfurche, die am vorderen Rande des Stirn-

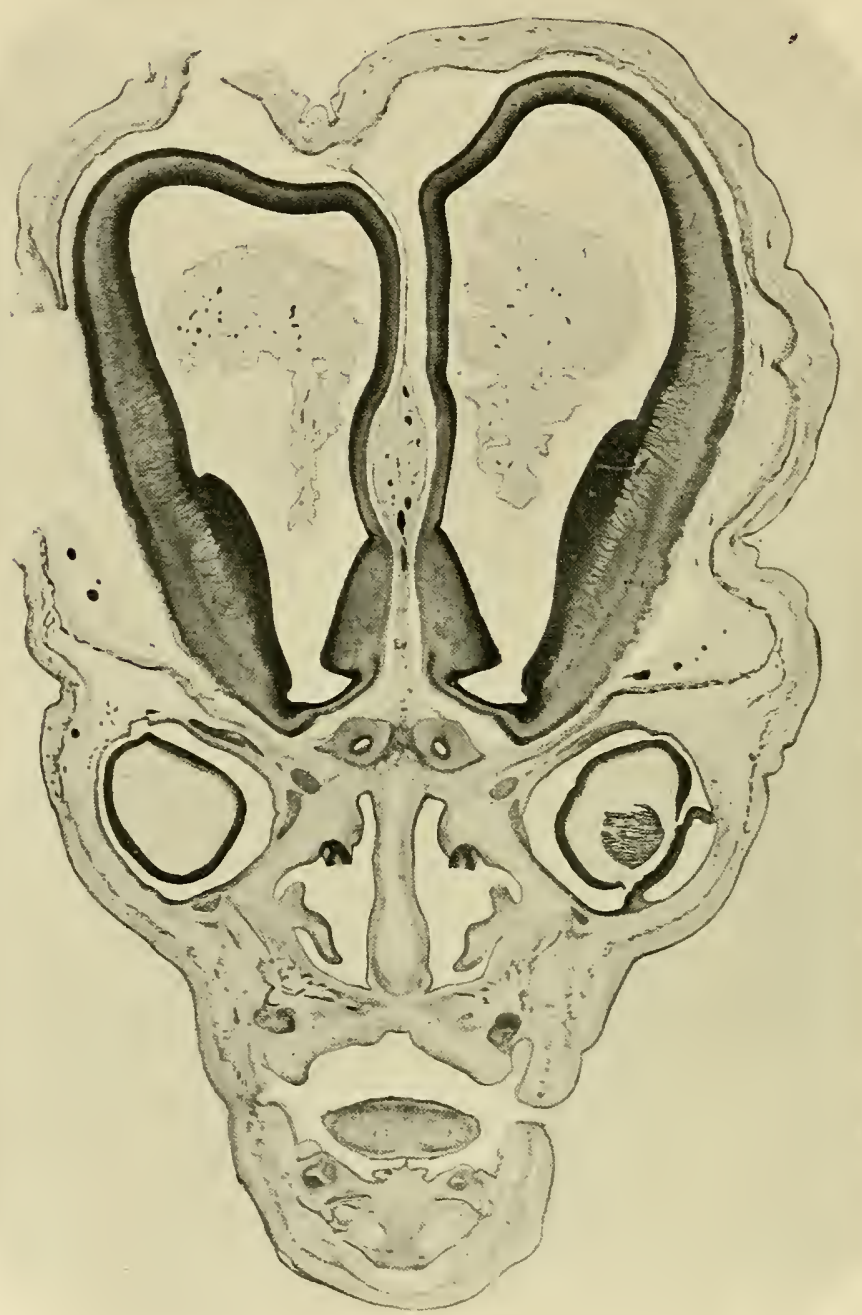

Fig. 57. Schnitt durch dasselbe Gehirn jenseits rom dritten Ventrikel. Die accessorische Bogenfurehe ist ahgeflacht, aber durch die spindelfömige Verdickung der Hirnsichel immer noch klar legitimiert. Vor derselben sieht man noch die oberen Ausłäufer der Trapezplatten. Auch erkennt man den in ihnen frei auslaufenden Pindenbelag. Der Schädelbasis aufliegend sind die noch hohlen Bulbi olfactorii quer getroffen. Streifenhügel, innere Kapsel und Linsenkern sind nummehr sehr schmale Bildungen. (Zu Seite 88.)

hirns, mehr oder minder weit rom Riechlappen entfernt, ansläıft. Die Furche findet sich anch an meinem publizierten Modell eines dreimonatlichen Foetıs wiedergegeben. Sie ist nach rückwärts in das Gebiet ïber der 
mittleren Bogenfurche verfolgbar, und ich bezeichne sie daher als $\mathrm{F}$ is s ur a arcuata a ecessoria.

Spricht sehon die konstante Wiederkehr dieser Furehe dafiur, daß es sich $u m$ eine natiurliche Bildung handelt, so sind die Schnittbilder gut erhaltener Präparate entscheidend, denn sie gewähren jenes Merkmal, dessen bei früherem Anlaß gedacht worden ist, eine der Furehe entspreehende Verdickung der ihr anlieg'enden Hirnsiehel. Ich teile zur Erläuteruı einige Schnittbilder des Foetus Ma (SSI. $5.6 \mathrm{~mm}$ ) mit, sowie dessen aus

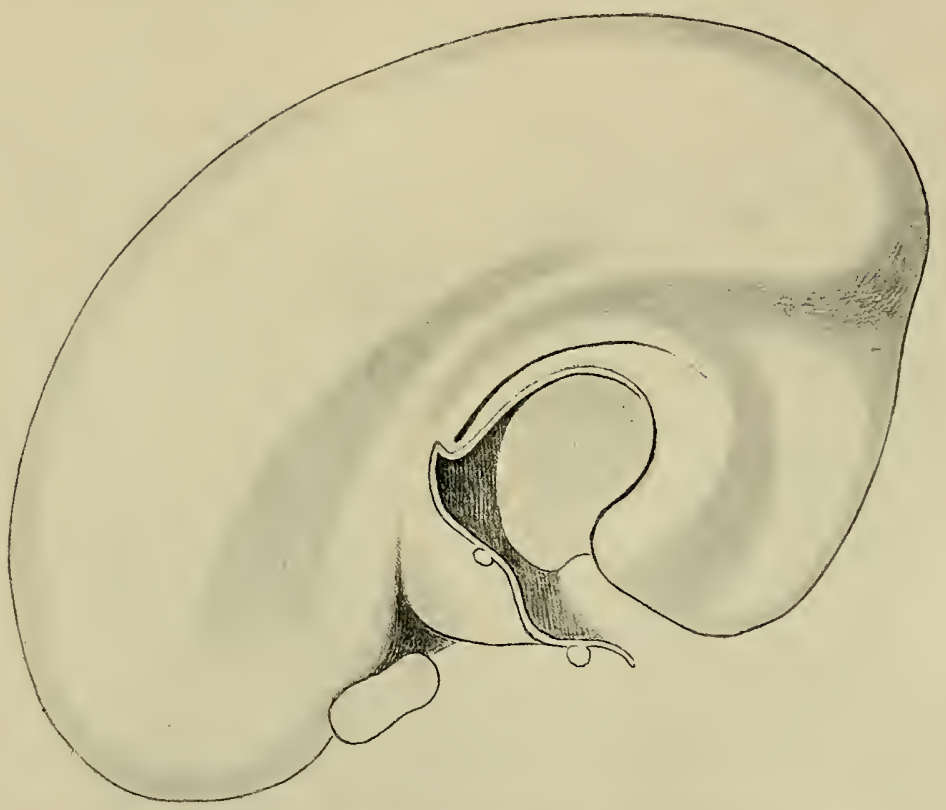

Fig. 58. Konstruktionsfigur der medialen Gehirnoberfläche rom Foetus Ma (SS1. 5.6 cm). Die Zeichnung zeigt über dem Riechhirn emporsteigend die Fissura prima bez. die Trapezplatte und an den Grenzen des Ventrikels die zuror durchschnittene diinne Verschlußplatte. Chiasma opticum und Commissura anterior liegen außerhalb der letzteren. Die Verschlußplatte endigt am Angulus praethalamicus. Hier schließt sich der Thalamusrand an, über dem die Fissura chorioidea als dunkler Streifen eingezeichnet ist. Unter der Fissura chorioidea liegt, hell ausgespart, die Lamina infrachorioidea, darüber die mittlere Bogenfurche, die sich nach abwärts in die noch seichte Fissura hippocampi, occipitalwärts in die Fissura calcarina fortsetzt. Über dem rorderen Abschnitt der mittleren Bogenfurche verläuft die accessorische Bogenfurche, die im Stirnhirn breit ausläuft. Die Schnittfläche des Hemisphärenstieles ist schräg schraffiert, darunter folgt scharf abgeschnitten der Hypothalamusrand der Hemisphäre. (Zu Seite 88.)

den Sehnitten konstruierte mediale Hemisphärenwand. Die Hemisphärendecke ist von außen her etwas eingedriiekt, im iibrigen ist das Präparat gerade in den uns interessierenden Teilen tadellos.

Der Sehnitt Fig. 55, S. 84, trifft den Hemisphärenlimbus eine kurze Streeke weit vor dem Thalamus. Die beiden medialen Hemisphären- 
wandungen umfassen mit ihrem Limbas zangenartig einen klaffenden, in der Verlängerung des Thalamus gelegenen Raum, in den noch die ependymale Decke des dritten Ventrikels hineinreicht. Beim Schnitt Fig. 56, S. 85, ist dieser Raum verschmälert, noch zeigt er sich aber innen von

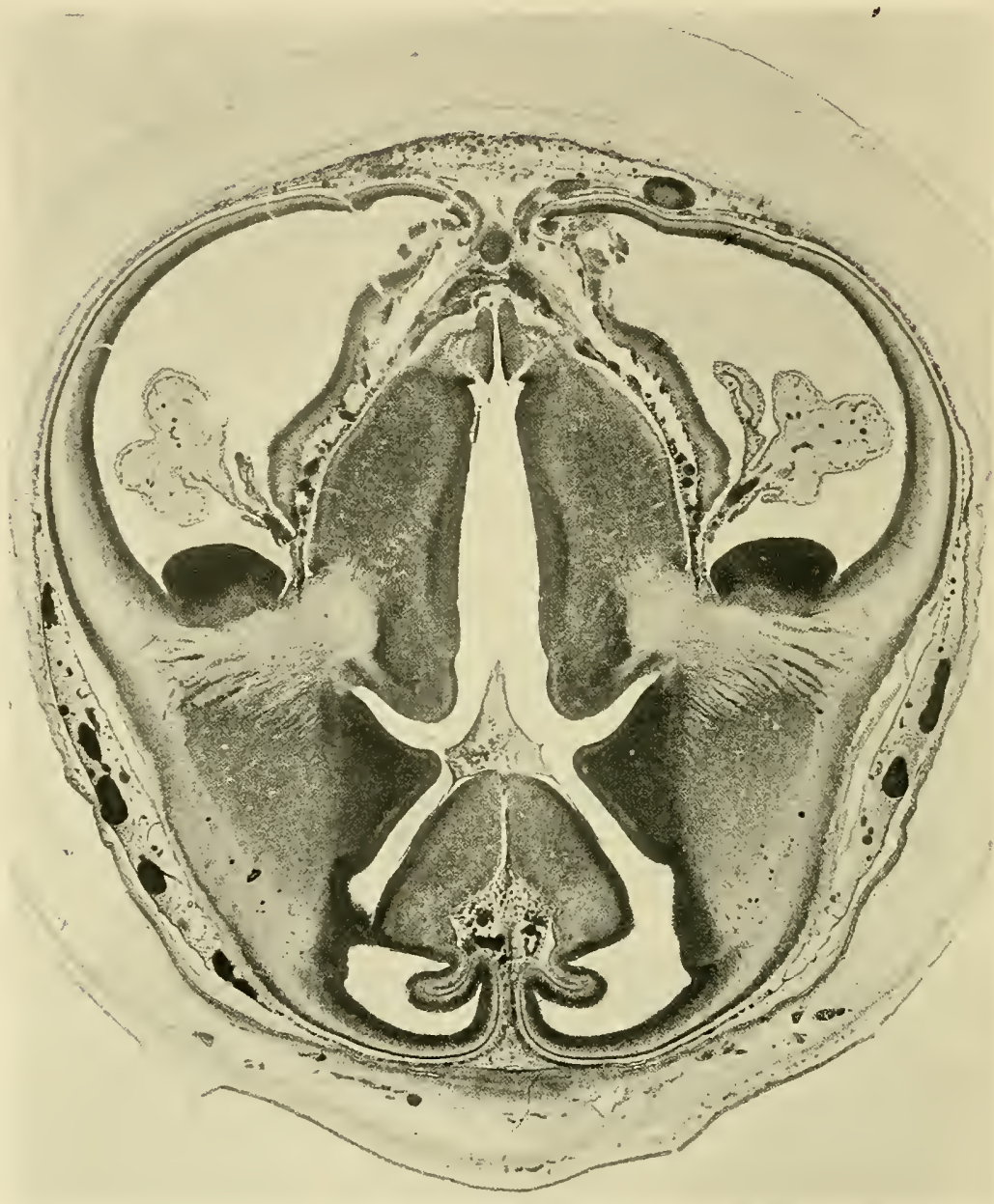

Fig. 59. Durchsehnitt durch das Vorderhirn des Embryos Oe, Der Schnitt zeigt die wellenförmige Bitgung des verdickten Limbns der Hemisphäre. (Zu Seite 91.)

der fraglichen Deckplatte ansgekleidet. Bei dem noch weiter nach vorn liegenden Sehnitt Fig. 57, S. 86, sind die beiderseitigen Wandfurehen erheblich abgeflacht, aber der von ihmen umschlossene Raum wird von einer spindelförmigen Auftreibung der Hirnsichel ausgefüllt, die sich durch die nachfolgenden Schnitte bis in die Nähe des Hemisplärenrandes verfolgen läßt. Im Konstruktionsbild Fig. 5S, S. 87, sind die accessorische Bogen- 
furche und ihre Beziehungen zur mittleren Bogenfurehe naeh den Schnitten eingetragen.

Eine oberflächliche Betrachtung der Schnittfolge von Ma gewährt den Eindruck, als ob die accessorische Bogenfurehe in die mittlere Bogenfurche

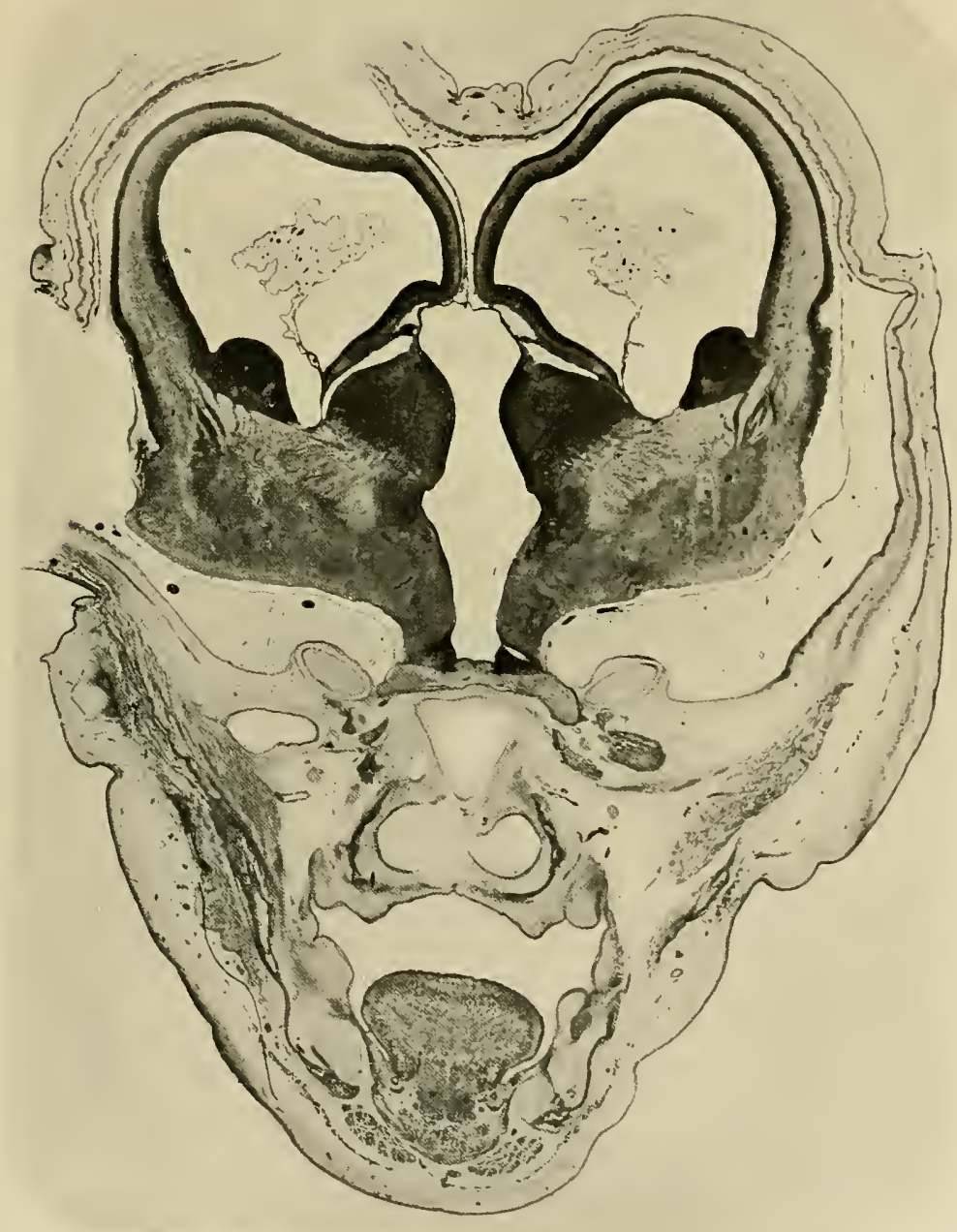

Fig. 60. Quersehnitt durch das Vorderhim von Foetus Ma (Ssl. 56 mm). Die Hemisphärendecke ist leicht eingedriickt, im ibrigen zeigt das Gehim keine Anzeichen postmortaler Quellung. Der Limbus biegt sich leiderseits in beinahe rechtem Winkel ron der übrigen medialen Wandfl̈̈che ab und zeigt die im Texte besprochene wellenförmige Biegung. Der Schuitt streift das Chiasma opticum und rechts den Recessus opticus. (Zu Seite 91.)

unmittelbar anslanfe. Dies wïrde in Widersprnch sein nit der direkten Wahrnehmung. An den in Fig. 53 u. 54 wiedergegebenen Prïjaraten läuft die accessorische Bogenfurche iiber der eigentlichen Bogenfurche aus und 
bleibt von dieser durch einen schmalen Faltenzug getrennt. Nun stellt sich aber bei genauerer Betrachtung, wie dies soeben hervorgehoben wurde, heraus, daß der verdickte, ventrikelwärts eingebogene Limbusstreifen schon im Beginn des dritten Monats an seiner medialen Oberfläche eine obere und eine untere Rinne zeigt, die allerdings anfangs beide nur seicht sind (Fig. 52). ${ }^{1}$ )

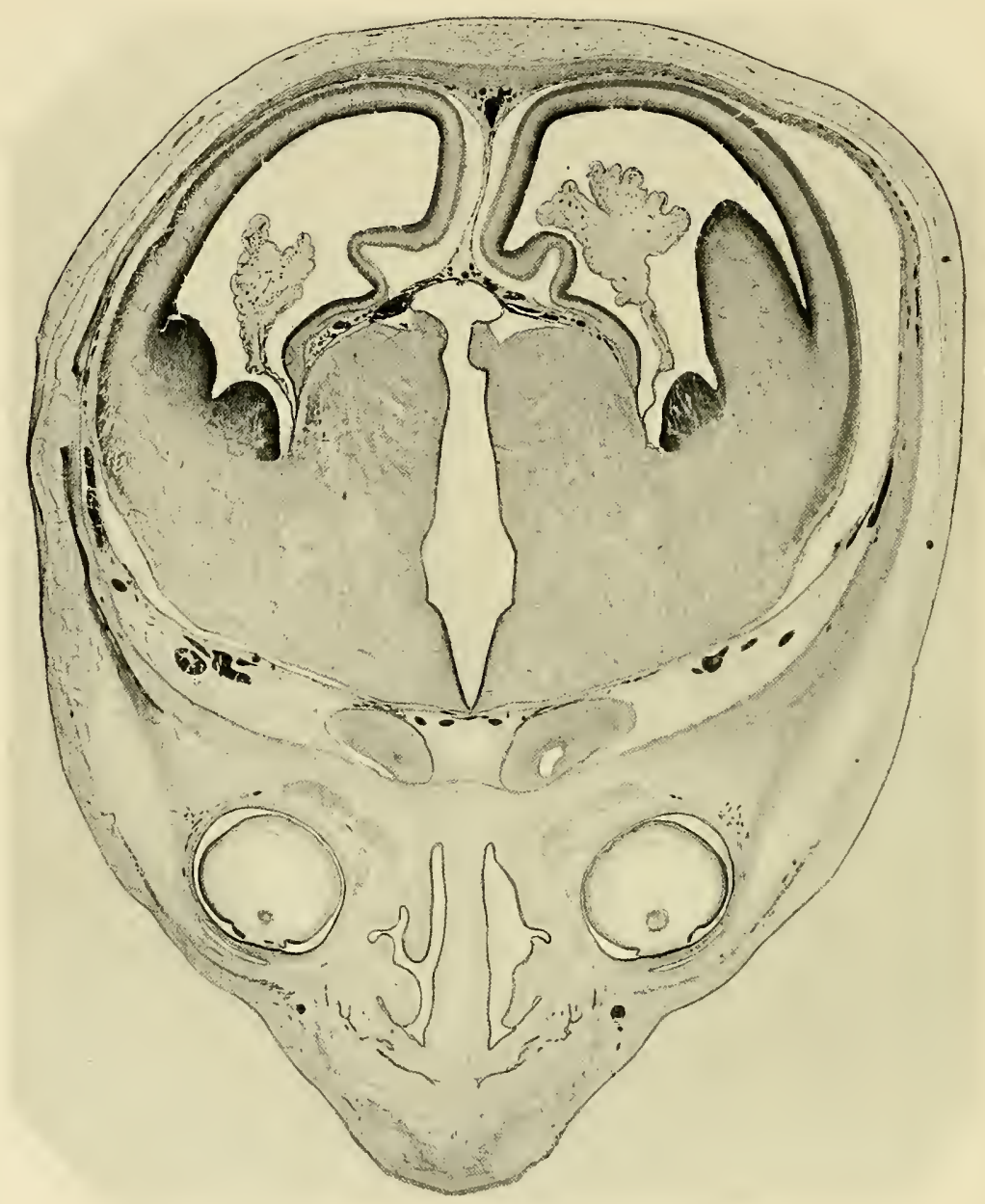

Fig. 61. Querschnitt dureh das Vorderhirn von Foeius Cr (SSl. 60 mm). Die wellenförmige Biegung des Hemisphärenlimbus ist stärker ausgebildet, als bei den jüngeren Stufen von Figg. 59 n. 60, nnd die die Bogenfurche von oben her einfassenden Falten treten nach der Mittelebene zu winklig hervor. (Zn Seite 90.)

Die obere dieser Rinnen gehört der accessorischen Bogenfurche an, die untere ist die eigentliche Bogenfurche. Man vergleiche die obenstehenden Schnitt-

1) Die Biegungen des Hemisplı̈̈renlimbus finden sich sogar in verschiedenen Schnittbildem ron Hochstetten unverkennbar dargestellt, so Taf. II, Fig. 2, 3 u. 4. Fig. 1 
bilder Figg. 59 u. 60 , S. 88 u. 89 , von denen das erstere, gleich der früher mitgeteilten Figg. 42 u. 49 , dem sehr wohl erhaltenen Foetus Oe entstammt. Bei dem etwas älteren Foetus Cr (Fig. 61, S. 91) ist die wellenförmige Biegung des Limbus bereits stärker ansgebildet und die iiber der Bogenfurche- liegenden Falten wölben sich beiderseits medialwärts stark hervor.

\section{Fissura calcarina.}

Von der Thalamusmulde ab nach riickwärts schneidet eine in der Verlängerung der mittleren Bogenfurche gelegene Einsenkung tief in die mediale Wand des Occipitalhimes ein. Es ist dies die Fissura calcarina. Sie zeichnet sich bei der Ansicht der Hemisphären von hinten her als eine ziemlich scharfe Einknickung (Fig. 62, S. 92) und ihr entspricht naturgemäß eine breite innere Vorwölbung der medialen Hemisphärenwand, der Calcar a vis (Fig. 63, S. 93). Unter den Photogrammen von HochsteTteis zeigen die Figg. 3, 14 n. 16 der Tafel IV die besprochene Furche. Die Bedingungen der Einknickung des Occipitalhirns sind leicht zu verstehen. Die unteren Abschnitte der Hemisphären sind durch das Vittelhirn roneinander geschieden, die oberen dagegen treten sich iiber dem Mittelhirn bis beinahe zur Beriihrung in der Mittelebene entgegen.

\section{Die Schichten der Hemisphärenwand und deren histologisches Verhalten.}

Die Großhirnhemisphären entwickeln sich erheblich später als die tiefer gelegenen Abschnitte des Gehirns. Bis gegen Ende des zweiten Monats bleibt die Wand des Hemisphäremmantels dümn. Der Hauptsache nach besteht sie ans der kernreichen Innenplatte oder Matrix, an die sich die II antel- oder $\mathrm{Z}$ wischens $\mathrm{chich} \mathrm{t}^{1}$ ) mit locker verteilten Zellkörpern anschlieBt. Eine kernfreie Randschicht (Randschleier) überragt letztere

der Tafel zeigt anch ähnlich meiner obigen Fig. 5$\rceil$ die querdurchschnittene accessorische Bogenfurche mit der spindelförmigen Verdickung der Hirnsichel. Eine gute, mit meiner eigenen Darstelhung übereinstimmende Zeichnnng der accessorischen Bogenfurche gibt ReTzics in seinen Biologischen Untersuchungen Bd. X, Taf. XIX, Fig. 3. Das Gehirn stammte von einem Foetus ron $52 \mathrm{~mm}$.

1) Ich habe die Bezeichmungen „Innenplatte“ und „Mantelschicht" in meinen älteren Abhandlungen (zuerst 1586 im Anfsatz zur Geschichte des Riickenmarks S. 4S2) gebrancht, und ich sehe keinen Grund, im allgemeinen davon abzugehen. Mit Rücksicht anf die Hemisphärenwand besteht indessen die Unbequemlichkeit, daf die Bezeichnung „Mantel" oder Pallinm schon als anatomischer Ansdruck in festem Gebranch ist. Hier" kann bis anf weiteres der Ausdruck ,Zwischenplatte" als Synonym von, ,Mantelschicht"* eingefiihrt werden. Das Wort Matrix als Synonym für Imnenplatte empfiehlt sich durch seine kurze und bequeme Handhabung. 
nach außen hin. Am frühesten erfolgt das Dickenwachstum der Hemisphärenwand in den basalen, an den Streifenhïgel anstoßenden Strecken, am langsamsten in der medialen Hemisphärenwand. Daher erscheint schon frühzeitig die Hemisphärenwand von der Basis zul Decke und von da nach dem Grund der Medianfurche zu stetig verjüngt. Im gleichen Sinn erfolgt die Bildung der Rindenschicht, sie beginnt über dem Gebît der Fossa Sylvii und schreitet von hier scheitelwärts vor.

Fig. 62. Ansicht des Gehirns von Bi von der Rïekseite her gesehen. Die beiden Hemisphären zeigen die Thalamusmulde und die tief einsehneidende Fissura ealearina. Auf die Verhältnisse von Mittelhim mnd Rautenhim dieses Präparates soll bei späterer Gelegenheit eingegangen werden.

(Zu Seite 91.)

Ich wähle als Ausgangspunkt der Beschreibung einige Embryonen aus dem Ende des zweiten Monats Se, $\mathrm{IJ}_{\mathrm{y}}, \mathrm{Zw}_{\mathrm{w}}$ und $\mathrm{Dd}$. Der jiingste derselben Se hat eine $\mathrm{Nl}$. von $16 \mathrm{~mm}, \mathrm{Zw}$ eine solche von $18^{1} / 2 \mathrm{~mm}$ (SSl $22 \mathrm{~mm}$ ) und das Alter des letztern habe ich seinerzeit auf $71 / 2$ Wochen veranschlagt, ${ }^{1}$ ) mngefähr gleich alt war My. Der Embryo Dd war etwas älter als die beiden. Seine Nl. mag $1 \mathrm{~m} 20 \mathrm{~mm}$ betragen haben. 
In der Nähe der Basis beträgt bei Se bei $7 w$ bei $D d$ die Gesamtdicke . . . . . $145 \mu \quad 150 \mu \quad 210 \mu$

$\begin{array}{rrrrr}" \text { Dicke der Matrix . . . } & 85, & 100, & 120 ", \\ " \text { " " Zwischenschicht . } & 35, & 50, & 60 ",\end{array}$

" " " Randschicht . . 25,

Fig. 63. Dasselbe Gehirn, es zeigt die mediale Wand der rechten Hemisphäre mit den einspringenden Falten der accessorischen Bogenfurche des Hippocampus, des Calear avis in der Eminentia collateralis. (Zu Seite 91 .)

Die Matrix charakterisiert sich durch die dicht gedrängte Lagerung: und die radiäre Anordnung ihrer Kerne; in der Zwischenschicht erscheinen anch tangential gelagerte Kerne. Ihr Kernreichtum ist in der an die Natrix stoßenden Innenzone sehr viel größer als in der Außenzone. Von den oben angeführten Embryonen zeichnet sich Se durch seine gute Konservierung aus ${ }^{1}$ )

1) Der Embryo Se stammt ron einer Selbstmörderin, deren Körper noch warm. also wenig Stunden nach dem Tode der Anstalt eingeliefert wurde. Ich legte das 
und er eignet sich daher an besten zur Feststellung der feineren Verlältnisse. Unter der scharf gezeichneten inneren Grenzhant findet sich eine 3-4 $\mu$ breit durchscheinende Zone und in dieser zallreiche in Mitose begriffene Keimzellen. Das übrige Matrixgebiet ist von gedrängt liegenden ovalen Kernen (von 7-8 $\mu$ Länge, 4,5-5 $\mu$ Breite) erfüllt. Diese sind zu radiär gestellten Zeilen anfgereiht, deren im basalen Gebiet eine jede 12 bis 15 Kerne enthält. Kapillare Blutgefäße dringen dazwischen bis nahe zur immeren Grenzhant hindurch. Bei der dichten Lagerung der Kerne sind deren Beziehungen zu Zellenleibern nur stellenweise zu entwirren. Ein größerer Teil derselben gehört den Spongioblasten an, die auf jüngeren Stufen als getrennte Säulen in die innere Grenzhant auslaufen. Diese Säulenzellen schließen sich nunmehr dichter aneinander an und ihre kernfreien Enden bilden die oben erwähnte durchscheinende und streifige, vielfach von Keimzellen durchsetzte Schicht; die Sänlenzellen sind der Wandbestandteil, der in der Folge als Epithel bezeichnet wird. Außer ihnen muß die Matrix alle jene Zellen enthalten, die bestimmt sind, in die äußeren Wandschichten vorzudringen. In erster Linie kommen dabei die Geriist-oder Gliazellen in Betracht, in zweiter Linie erst die Neuroblasten. Die Zwischenschicht ist sowohl in ihrer kernreicheren Innenzone, als in der durchsichtigeren Außenzone von einem Gerisst durchsetzt, das naturgemäß in der letzteren besonders dentlich hervortritt (Fig. 64, S. 95). Seine Maschen sind auf der Stufe von Se von Nervenfasern und von Nervenzellen frei, was man von Zellen sieht, gehört daher zu den Geriistzellen. Deren Kerne liegen größtenteils flach, sie sind in allgemeinen von feinen Chromatinnetzen umsponnen, und die Schnitte zeigen sie teils längs teils quer getroffen.

Im Außenteile der Hemisphärenwand ordnet sich eine einfache Lage von Gliazellen parallel zur Oberfläche und bildet eine scharf sich abhebende Schicht, die ich als Siebschicht (Stratum cribrosum) bezeichnen werde. Diese Schicht beginnt neben dem Streifenhiigel, greift von da anf den basalen Abschnitt der Hemisphärenwand über, und sie delnt sich in späteren Stufen mehr und mehr auf die übrige Hemisphärenwand aus. An weniger gut erhaltenen Präparaten schließt das Markgerïst anscheinend mit dieser Schicht ab, und man ist versucht, sie als die von der Limitans meningea abgehobene Limitans externa zu denten. Dies trifft indessen nicht z11: die Siebschicht findet sich an gut erhaltenen Schnitten von einem nahezu kernfreien Gerüst überragt, das den Raum bis zur Limitans meningea er-

Chorion durch schichtenweises Abtragen der Uteruswand frei, brachte das Präparat auf einige Stunden in Formalinlösming, und nahm dam den wundervoll injizierten Embryo heraus. Dieser wurde in $10 \%$ Salpetersäure nachfixiert und dam in Alkohol verbracht. Die Schnittdicke der Reihe betrug $10 \mu$. Ein Teil der Sclnitte wurde mit Eisenlämatoxylin gefärbt, andere mit Hämatoxylin und Erythrosin. 
fiillt. Seine imneren Fäden gehen aus den Zellen der Siebschicht hervor, die äuBern verbinden sich zı einer feinen, die Oberfläche umsäumenden Grenzschicht.

Bei dem nachfolgenden, mit Keruvermehrung verkniipften Wachstum des Gliagerüstes sind die nen hinzutretenden Zellen der Zwisehenschicht aus der Matrix abzuleiten, und es frag't sich, ob sie aus dieser frei hervorwandern und sich weiterhin dem bereits vorhandenen Geriist einfïgen, oder ob die äußeren Lag'en der Matrix sich answeiten uud durch schichtenweisen Anschluß an die Zwischenschicht deren Ausdelınung herbeiführen. Für letztere Annahme ließe sich anfuihren, daß die äußere, ältere Zone der Intermediärsehicht weit kernämer ist, als die innere, und daß auch in der Folge die gregenseitigen Abstände der Gliakerne sich verg'rößern. Vom iibrigen Gerüst gilt aber das Umgekehrte; es ist in späteren Entwicklung'sstufen engmaschiger als anfaugs, was zum mindesten eine einfache mechanische Ausweitung der Maschen ausschlieBt. Für die Annahme frei wandernder Gliazellen läßt sich geltend machen, daß die urspriinglich bei-

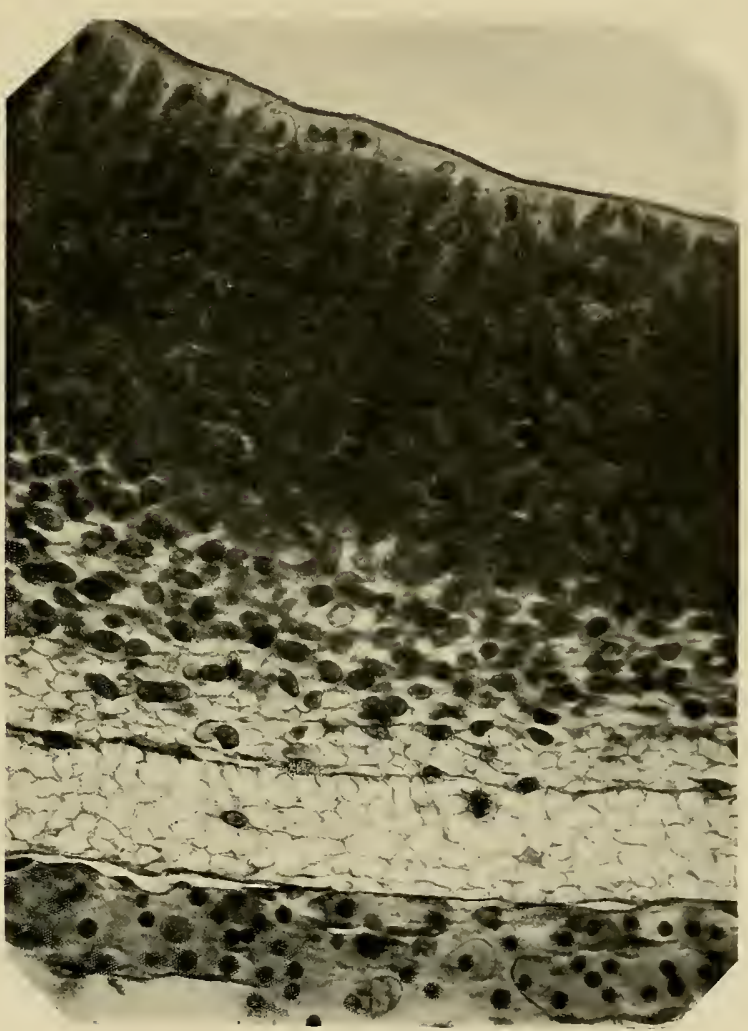

Fig. 64. Durchsehnitt durch die Hemisphïrenwaud rom Lmbryo se. Die Mantelschicht beginnt, sich rou der Immenplatte $/$ lïsen. Xoch ist aber keine Rindenschicht angelegt. Dagegen tritt sehr aulfullig die im Text als Siebschieht bezeichnete Bildnng hervor. Eine der Oberfläche parallel laufende Lage unter sich verbundener kernhaltiger Zellen schiebt sich zwischen einen äußsern und einen inneren Bezirk des engmaschigen Markgerïstes. Der äußere Bezirk wird zur Schleiersehicht, der imere nimmt später die Pyranidenzellen auf. Die Schleiersehicht ist ron sehr sparsamen Gliazellen durchsetzt. Nach außen von der Limitans externa folgt die Limitans meningea mit ibrem reichen Kapillarbelag. ( $\mathrm{Zu}$ Seite 94.) nalue kernfreie, außerhalb der Siebplatte lieg'ende Randschicht später mehr Gliazellen euthält. Jedeufalls ist bei Beurteilung dieser Verhältnisse festzuhalten, daß die Gerüstbalken, falls nicht zeitlebens, so doch jedenfalls wälırend der Zeit der Entwicklung lebende Substanz, bez. lebendes Protoplasma und somit mannigfachen Umlagerungen fälig sind. 
Es ist bei Embryo Se nicht leicht, widerspruchslos zu entseheiden, ob die basalen Abschnitte des Hemisphärenmantels von Neuroblasten völlig frei sind. Es zeigen sich in der Matrix vereinzelte dunkle Körper von Spindelgestalt, die als Neuroblasten gedentet werden könnten; entscheidend sind die Bilder keineswegs, und jedenfalls spielen diese Elemente nach eine untergeordnete Rolle. Wenn auf nachfolgenden Stufen die Neuroblastenund die Faserbildung in Basalgebiete der Hemisphären in vollem Gange ist, so befinden sich die mehr scheitel- und medialwärts liegenden Zonen der Wand noch auf den früheren Stufen leeren Markgerüstes. Das eine ist sicher, daß die Neuroblasten durchweg eine spätere Bildung sind. Wie im Riickenmark, so wird auch in dermehr denneinen Monat später sich ausbildenden Hemisphärenwand das Markgeriist angelegt, bevor Nervenzellen und Nervenfasern auftreten. Und zwar wird das Gerist sofort mit Einzelneinrichtungen ausgestattet, die für das Zustandekommen der nachfolgenden Organisation von durehgreifender Bedeutung sind.

Die Anfänge einer mit Pyramidenzellen ausgestatteten Rindenschicht finde ich bei dem acht Wochen alten Embryo Mr (NI. $22 \mathrm{~mm}$, SSI. $29 \mathrm{~mm}$ ). Die Schicht beginnt als ein schmaler Streifen an der Außenseite des Streifenhiigels, den sie eine Strecke weit umfaßt. Sie reicht hier so weit, als bei Se die Siebschicht und erreicht weiterhin den basalen Abschnitt des Hemisphärenmantels. Scheitelwärts fließt sie mit der Zwischenschicht zusammen und verliert sich als selbständige Bildung. Nach anßen von ihr erhält sich eine schmale durchsichtige Randschicht, in der nur vereinzelte Kerne liegen.

Zur Beurteilung der nunmelırigen Wanddicke teile ich einige Messungen mit. Unter I, II, III finden sich Werte, die nahe iiber dem Orte des Freiwerdens des Hemisphärenmantels, aber ungleich weit rom Stirnpol genommen sind, die Zahlen von I fallen in die Nitte der späteren Stammstrahlung, die unter IV mitgeteilten Werte sind einer melı scheitelwärts gelegenen Strecke entnommen. Zur Vergleichung füge ich noch in Kolonne Lo die Zahlen mit, dic ich von Schnitten eines ungefähr gleichalten Embryos bekommen habe (Lo S Sl. $29 \mathrm{~mm}$ ). -

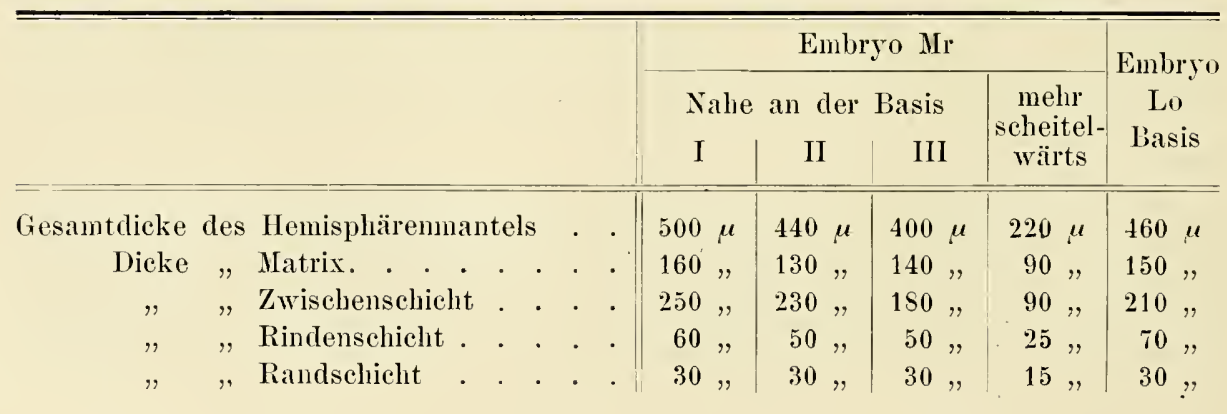


Die Vergleiehung dieser Zahlen mit den früher fïr $\mathrm{Zw}$ und $\mathrm{Dd}$ mitgeteilten crgibt, daß das Dickenwaehstum vorzngsweise in der nach außen von der Matrix liegenden Sehieht, im Bereich der primären Zwischenschicht erfolgt ist, ron der sich nun die Rindenschicht abgegliedert hat.

Die Rindenschieht hebt sich von der angrenzenden Zwischenschicht durch die dichter gedrängte Lagerung und die durchgreifend radiäre Anordumg ihrer Elemente ab. In ilı sammeln sieh die aus der Matrix stammenden Neuroblasten, die in Umbildung zu Pyramidenzellen begriffen sind. Sie liegen im Mittel zu 4-5, an den dicksten Stellen zu 6-8 hintereinander. Da wo sie der Länge nach getroffen sind, zeigen sie die Form dicker Spindeln (Fig. 65). Anfer dem nach eiuwärts gerichteten Nervenfortsat $\%$ besitzen sie einen naeh answärts abgehenden $S p$ itzc n fortsatz. Nach der Seite des Nerrenfortsatzes hin sind die Zellen dunkel gefärbt (Fig. 66, S. 98), es ist dies ein durchaus bezeichnendes Verhalten, das, wie ich bei friiheren Arbeiten gefunden habe, bei jugendlichen Neuroblasten der rersehiedenen Wirbeltierklassen wiederkehrt (s. o. S. 23). Der Übergang in den Nervenfortsatz erfolgt mit ziemlieh rascher Znspitzung, der Fortsatz selbst erseheint noeh kurz, aber fadenförmig

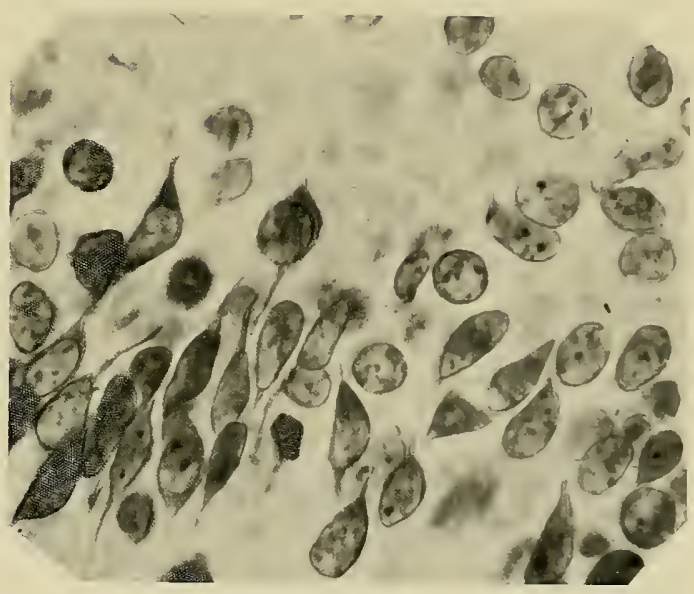

Fig. 65. Prramidenzellen aus der Henisphärenrinde von Foetus Mr. Einige zeigen beide, andere nur den inneren, oder nur den änßeren Fortsatz (Photogr. mit Immersion Zeiß 2 mm). und scharf umgrenzt. Die Kerne der Neuroblasten sind noeh rundlich oval, hänfig anch nach einer Seite hin eiförmig verjuingt $\left(7-8 \mu\right.$ auf $\left.5-5^{1} / 2 \mu\right)$.

Mehr Weehsel bieten die Spitzenfortsätze der beschriebenen Zellen. Neben solehen, die, ähnlich den Nervenfortsätzen, als schmale Fäden ans den Zellkörper hervortreten, finden sich breitere und diffus anslanfende Formen. Zahlreiehe Zellen zeigen nur den einen oder den andern der beiden Fortsätze, znweilen von zwei nebeneinander liegenden die eine den innern, die andere den äußern. Großenteils mögen es roul Sehnitt rerstümmelte Formen sein. Jedenfalls gilt dies ron den anscheinend nackten Kernen. Anch bei fehlendem Nerrenfortsatz pflegt sieh das ihm entsprechende Ende des Zellenleibes dureh seine dunkle Färbung anszuzeichnen. Alle Neuroblastenkerne dieser Stufe zeigen an Eisenhämatoxylinpräparaten einen oder meistens zwei dunkle punktförmige Fleeken. Ihrer Lage und ihrem sonstigen Terhalten nach kömen es ebensowohl His, Die Entwieklung d. menschl. Gehims. 
Kernkörper als Zentralkörperchen sein, jedenfalls liegen sie der Kernwand diclit an.

Radiär oder stellenweise auch etwas schräg gerichtete Zellen von den oben beschriebenen Eigenschaften finden sich in der äußern sowohl, als in der innern Zone der Zwischenschicht. Es sind Neuroblastent, die ans der Matrix stammen und anf dem Weg zur Rindenschicht begriffen sind (Fig. 66). Sie zeigen, wie die Pyramidenzellen, teils ein-, teils auswärts gerichtete

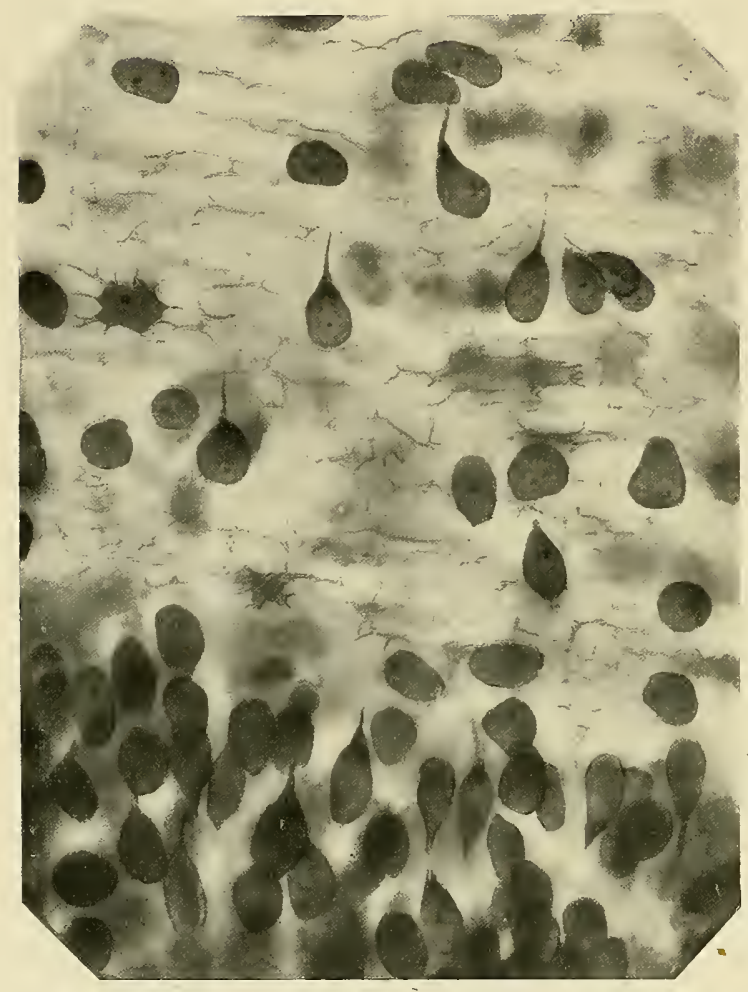

Fig. 66. Aus der Hemisphärenwand von Embryo $\mathrm{Mr}$, an der Grenze der äıßeren Zwischenschicht und der Rindenschicht. Die erstere zeigt das engmaschige Markgeriist mit vorwiegend tangential gerichteten Maschen, in der Rindenschicht tritt das Markgeriist zuriick. Die in der Zwischenschicht zerstreut liegenden radiärgerichteten Neuroblasten zeigen den nach einwärts in den Nervenfortsatz iibergehenden Cornus dunkel gefärbt. (Zu Seite 97.)
Fortsätze, erstere mit den Charakteren von Nervenfortsätzen. Anßerdem enthält die Schicht flach angeordnete Kerne und Zellenleiber; diese, sowie zahlreiche quergeschnittene (runde) Kerne gehören dem Gliageriist an, das mit rundlichen Maschen die Innen- und Außenzone der Schicht durchsetzt. Zweifellose Neuroblasten vermag ich unter den flach verlaufenden Zellen nicht zu erkennen.

Die laterale Hemisphärenwand enthält in ihrer'Zwischenschicht bogenförmig angeordnete Bïndel ron Nervenfasern. Sie kommen aus einem unter dem Streifenhïgeel liegenden Faserkomplex, der Anlage der innern Kapsel. Ihre Menge nimmt scheitelwärts rasch ab und sie verlieren sich etwa in halber Höhe.

Die Matrix zeigt in

ilrem innersten Abschnitt außer zahlreichen in Mitose begriffenen Keimzellen die bekannten, in die Limitans ausstrahlenden Säulenfasern. Die zugehörigen Kerne und Zellenleiber liegen teils nahe unter der Oberfläche, teils auch in größeren Abständen davon. Dementsprechend ist die Matrix in ihrer gesamten Tiefe von radiär laufenden Geriistbälkchen durchsetzt. Das von ihnen gebildete radiärmaschige Gerüst geht nach auswärts in das 
viel engere, rorwiegend rund- oder quemaschige der Zwischenschicht iiber; diese Schicht zeigt keine Radiärstrahlen. Neuroblasten mit einwärts rerichteter Spitze finden sieh zwischen den Kernen und Fasern der Matrix zerstrent. Dabei ist wohl zu beachten, daß die birnförmige Gestalt ron Zellen und ihr Übergang in einen nach einwärts gerichteten Faden zu einer sichern Diagnose nieht genügen, denn diese Form findet sich vielfach bei Zellen, deren Fortsatz nachweisbar bis zur Limitans vordringt. Fiir entscheidend halte ich auf dieser Stufe die dunkle Färbung des nenralen Zellenendes. Bei der Auswanderung ron Zellen aus der Matrix in die Rindenschicht bleibt die Richtung des Wanderns bemerkenswert. Wällrend die Nenroblasten des Riickenmarks und der Medulla oblongata bei ihren Verschiebungen mit dem Nervenende voranzugehen pflegen, rïeken die zu Pyramidenzellen werdenden Elemente der Hemisphärenwand mit dem Gegeupol voraus. Bei jugendlichen Neuroblasten anderer Gebietc pflegt dieser Gegenpol stımpf abgerundet und ron einer nur diinnen Plasmaschicht umbiillt zu sein. Man wird wohl nicht irre gehen, wenn man bei den Wanderungen der Pyramidenzellen dem Spitzenfortsatz eine wesentliche Rolle als Lokomotions-Apparat z11-

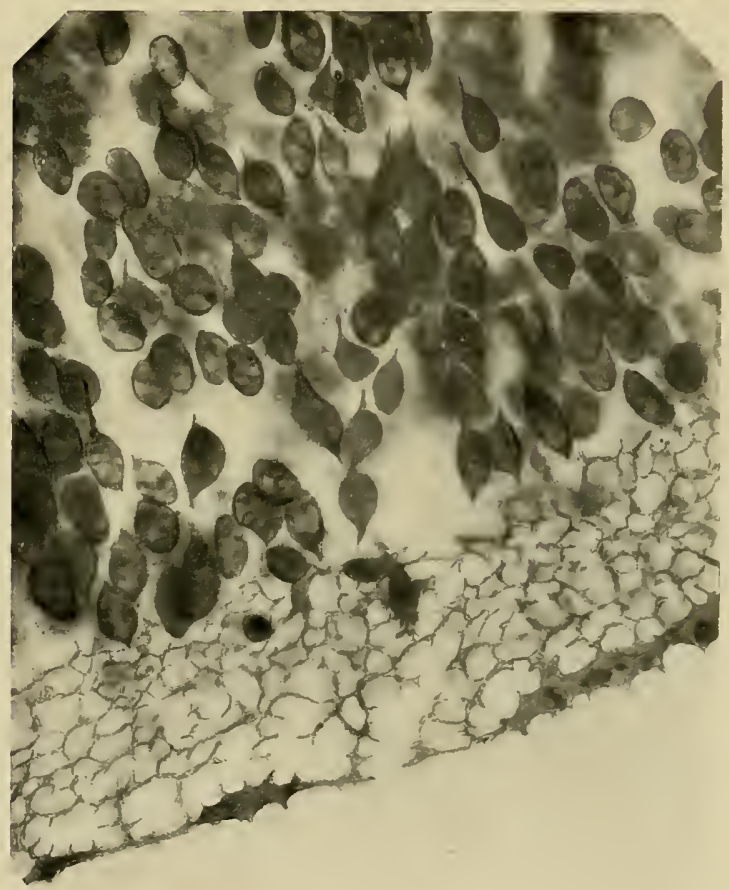

Hig. 67. Rindenschicht und Iiandschleier aus den Hemisphïren von Embryo Mr. (Inmersion Zeiß $2 \mathrm{~mm}$.) Das Geriist des Randschleiers enthält cinzelne Gliazellen, seine Maschenräime sind noch frei von Fasern und ron Nervenzellen. Innerhalb der Rindenschicht ist das Markgeriust nu* wenig entwickelt.

(Photogramm ïberzcichnet.) schreibt.

Nach answärts von der Rindenschicht folgt ein engmaschiger Randschleier, der zwar einzelne Gliakerne, aber noch keinerlei Nerrenfasern oder Nervenzellen enthält (Fig. 67).

\section{Mitte des dritten Monats.}

Ich unterlasse es, die Hemisphärenentwicklung einiger anderer Embryonen ron derselben oder von naheliegenden stufen wie Mr zu beschreiben 
(Lo, Re), da ich nur Wiederholungen bieten könnte, und ich wende mich zur Besprechung eines Foetus von $46 \mathrm{mmi}$ SSl. (Stg), der nach den iublichen Altersbestimmungen der Mitte des dritten Monats angehört. Das Präparat stammt aus dem Uterus einer Selbstmörderin. Die Dicke der Hemisphärenwand hat durchweg etwas zugenommen, und die Sonderung einer selbständigen Rindenschicht hat anch auf die mediale Seite übergegriffen, sie länft in deren Limbus in später zu erörternder Weise" frei aus.

Zur Benrteilung der Dickenverhältnisse kümen folgende Zahılen dienen:

$$
\begin{aligned}
& \text { Foetus Stg } \\
& \text { S.S. } 46 \mathrm{~mm}
\end{aligned}
$$

Dicke der Hemisphärenwand

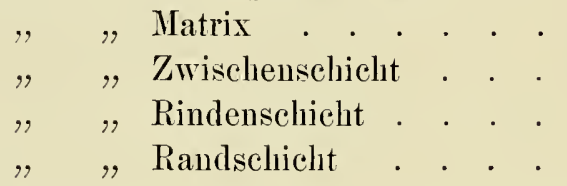

$$
\begin{gathered}
\text { Laterale Wand } \\
\text { nalıe an der Basis }
\end{gathered}
$$

$600 \mu$
$150 "$
$340 "$
$85 "$
$25 "$

Mediale Wand in halber Höhe

200,
100,
60,
20,
20,

Die Zahlen ergeben, gegenüber den jüngeren Stufen, geringe Veränderungen in der Dicke von Matrix und Randschicht, dagegen sehr ausgiebige in der von der Zwischen- und der Rindenschicht.

Das Bild, welches die Schnitte nunmehr gewilhren, ist viel reicher, allerdings aber auch verwickelter geworden. Zunächst handelt es sich wieder darum, die Bestandteile des Gliagerüstes und die nerrösen Elemente voneinander zu sondern. Das auf früheren Stufen bequeme Unterscheidungsmerkmal der dunkeln Spitzen der Neuroblasten läßt nummehr im Stich. Dafür kann man als feststehend annehmen, daß die Rindensehicht ansschließlich, oder doch nahezu aussehließlich Nerrenzellen enthält, und ebenso sind in der Zwischenschicht, besonders in deren durchscheinender Anßenzone die radiär gestellten Zellen unschwer als solehe zu erkennen. Weniger übersichtlich gestalten sich die Verhältnisse in der kernüberfiillten Matrix und in der daran anstoßenden Innenzone der Zwischenschicht. Die tangential gerichteten Zellenleiber der letzteren sind indessen durchweg als Gliazellen zu deuten.

In der Rindensehicht liegen die Pyramidenzellen in vielfachen Schichten ïbereinander, im basalen Bezirk bis zu 15-20 fach, weiter scheitelwärts stufenweise abnehmend, bis sie in der medialen Wand noch zu $3-5$ inbereinander liegen. In der Zwischensehicht treten sie vereinzelt oder in kleinen Gruppen auf, inden sie die Schicht in radiärer Riehtung durehsetzen. Am klarsten zeiehnen sie sieh in der relativ durehsichtigen Anßenzone der Zwisehenschicht. Die typische Form ist hier eine schlanke, bipolare (Fig. 68, S. 101). Anch die Kerne haben gestreckte Formen, ihre Länge maß ich z:11 $61 \%_{2}-9$, die Breite zu $3-4 \mu$. Manche zeigen birnförmige Gestalt und sind innen breiter als anßen. Von den beiden Fortsätzen tritt der spitzenfortsatz im allgemeinen auffälliger hervor, als der meistens dïmne 
und oftmals ïberhaupt nicht nachweisbare Nervenfortsat\%, er kann bis zur anderthalbfachen Kernlänge $(12-14 \mu)$ erreichen, und el zeight in seinem Verhalten einen gewissen Wechsel. Bald läuft er in einen schmalen Faden aus, bald in einen mehr bandartigen Streifen von lockerem, nicht streifigem Gefïge.

Die Pyramidenzellen der Rindenschicht unterseheiden sich in mehrfacher Hinsicht von denen der Zwischenschicht. Thre Kerne sind ninder schlank und von mehr gerundeten Formen, dabei auch etwas größer als die der Zwischenschicht (Breite $4-4^{1} \% \mu$ ). Die Spitzenfortsätze, wenigstens die in der änßeren Rindenschicht, sind nnbedentend; da wo ich sie am dentlichsten ansgeprägt finde, erreichen sie kaum mehr als die halbe Kernläng'e $\left(3^{1} / 2-4^{1} / 2, u\right)$. Sie treten noch nicht in die Randschicht ïber, diese zeigt noch ein von nerrösen Bestandteilen freies Gliageriist. Dagegen treten Nervenfortsätze ron Pyramidenzellen als mehr oder minder lange Fäden aus der Rinde in die Zwischenschicht ein. Durch den Schnitt verstiimmelte, fortsatzlose Kerne finden sich bei den breiten Formen der Rinde reichlicher als in der Zwischenschicht.

Der Gegensatz zwischen den schlanken Neuroblasten der Zwischenschieht und den mehr gerundeten und zugleich größem der Rindenschicht, sowie das rerschiedene Verhalten der beiderseitigen Fortsätze tritt anf etr as späteren Stufen noch anffallender zutage, und es ist

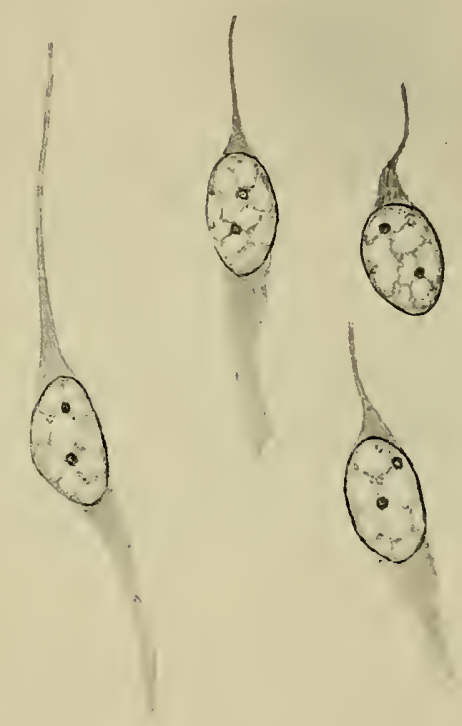
darans zu erschließen, daß die Pyra-

Fig. 68. Prismenzeichnung. Vergr. ea. 2000. In Wanderung begriftene Prramidenzellen auder Zwischenschicht (Foetus Stg). I)ie Nerrenfortsätze sind nach oben, die spitzenfortsätze nach abwärts gerichtet. (Zu Seite 100.) midenzellen während ihrer Wanderung aus der Matrix in die Rindenschicht ihre Formen stetig ändern. Ihr zurzeit noch wenig mächtiger Plasmaleib rermag sich bald mehr nach der einen, bald mehr nach der andern Seite auszuziehen. Während der Wanderung tritt der spitzenfortsatz am meisten hervor, nach erreichter Endstellung wird er zunachst bis auf greringe Reste eingezogen und dafür leitet sich ein ansgiebiges Wachstum des Nervenfortsatzes ein.

Unipolare und bipolare Neuroblasten lassen sich immitten der dicht geelagerten Kermmassen der Matrix stellenweise wohl erkennen. Sie haben im allgemeinen etwas kleinere Kerne als die Spongioblasten (Fig. 69, S. 102). 


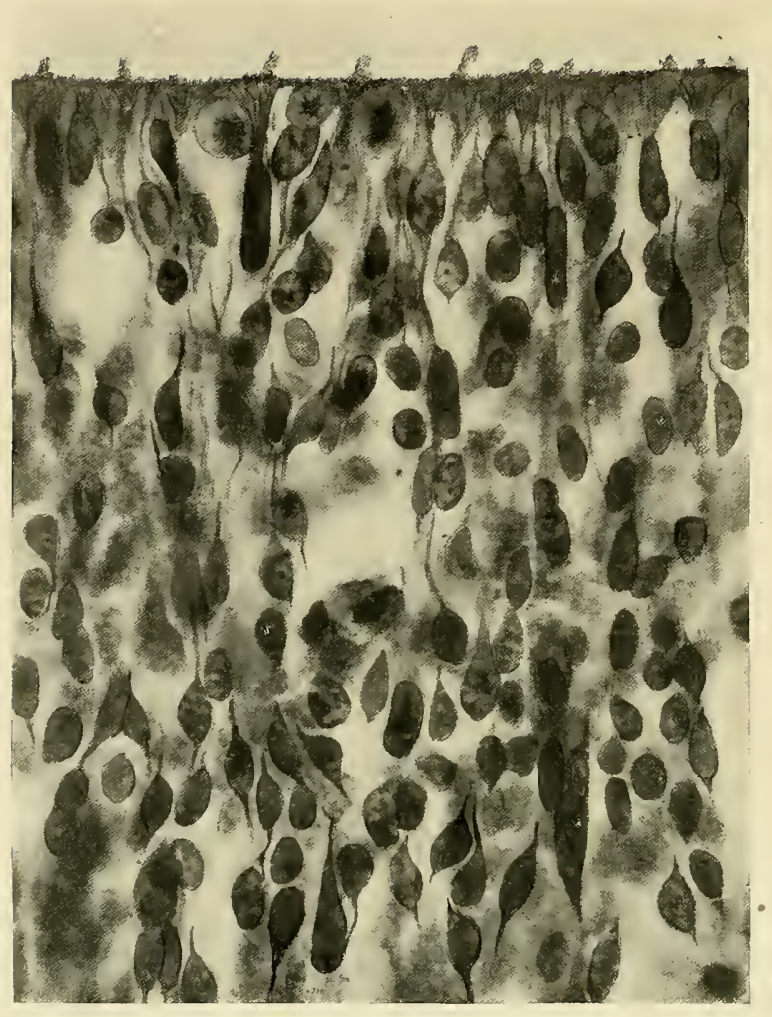

Fig. 69. Matrixschicht aus der Hemisphäre von Foetus Stg. (Inmersion Zeiß $2 \mathrm{~mm}$.) Die M. limitans interna erscheint etwas zackig abgegrenzt und sie ist von zerstrent liegenden kurzen Plasmafortsätzen überragt. Die Spongioblasten eharakterisieren sich durch ihre Verbindung mit der Limitans. Es scheint, daß sie nach auswärts meistenteils stumpf auslaufen, ein Anschluß an das Markgerüst der Intermediärsehicht tritt mirgends deutlich hervor. Da sich anf früheren Stufen durchweg rin ummittelbarer Zusammenhang der Spongioblastenleiber mit dem Außengerüst nachweisen läßt, so muß ich das anscheinende Fehlen dieser Verbindung am abgebildeten Präparat für eine Folge von Zerreißungen ansehen. Nach auswärts ïberwiegen die Neuroblasten, dic im allgemeinen etwas kleinere Kerne haben als die Spongioblasten und bipolar sind.
Ein großer Reichtum von kernhaltigen Zellenleibern lıäuft sich in der an die Matrix stoßenden Innenzone der Zwischenschichtan(Fig. 70, S.103). Die Kerne kreųzen sich hier in verschiedenen Richtungen, ein Teil derselben gehört den radiär gestellten Neuroblasten an, von denen oben die Rede war. Ein anderer großer Teil ist flach verlaufenden Zellen eingelagert, die auch ihrerseits nach verschiedenen Richtungen sich überkreuzen und an Durchschnitten bald längs, bald quer getroffen werden. Auch von ihnen gilt, was ich schon oben hinsichtlich der Zwischenschichtzellen von Mr bemerkt habe. Ich vermag unter ilunen keine zweifellosen Neuroblasten nachzuweisen und halte sie säntlich für Gliaelemente.

Die laterale Hemisphärenwand ist in einem Teil ihrer Ausdeh-

nung von Nervenfasern durchzogen (Fig. 71, S. 104). Diese sind relativ dick und bündelweise zusammengeordnet. Die Hauptmasse dieser Fasern tritt als dicke Platte unter dem Streifenhügel hervor in die anstoßende Hemisphärenwand. Die Fasern durchsetzen in schrägen Bogenlinien die innere und die äußere Zone der Zwischenschicht. Ihre Verlaufsrichtung führt sie scheitelwärts, die Faserbündel der immeren Zone treten dabei mehr und mehr in die AuBenzone über. Mit Annäherung an die Scheitelhöhe nimmt die Menge der Fasern rasch ab, und sie verlieren sich schließlich ganz und gar. 
Zu den Pyramidenzellen der Rinde stchen die beschriebenen Bogenfasern, wenigstens in den basalen Wandabschnitten, in keinen Beziehungen, und hier erhält sich zwischen den Faserbündeln und der Rinde ein ziemlich breiter faserfreicr Zwischenraum. Scheitelwärts verschmälert sich dieser Raum. Spätere Stufen zeigen einen Übergang ron Faserziigen in die mediale Hemisphärenwand, und hier scheint die Möglichkeit ihres Auslaufens zwischen den Pyramidenzellen der Rinde nicht ansgeschlossen. Mit den Flachzellen der Zwischenschicht lassen sich keine Verbindungen nachweisen. Am chesten wären solche in den kermreichen basalen $\mathrm{Ab}$ schnitten der innern Zwischenschicht zu erwarten. In gestreckten Scharen erscheinen hier die Kerne zwischen die Faserzüge eingeschoben. Allein, wenn auch,

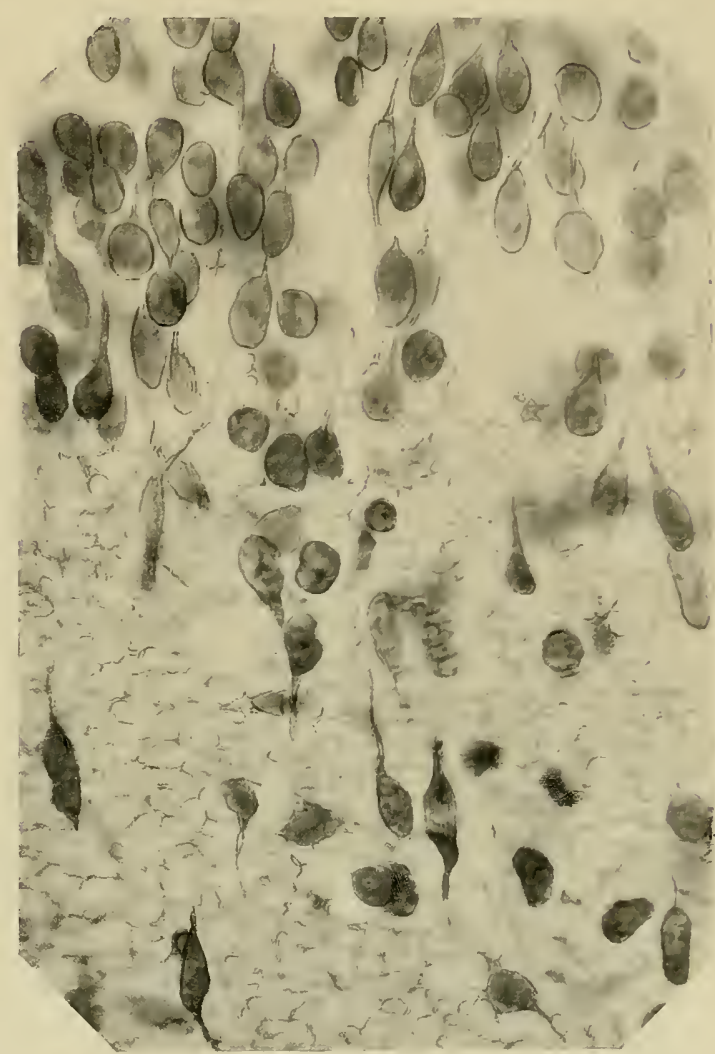

Fig. 70. Aus der Hemisphärenwand desselben Foetus Stg. Übergang von der Matrix in die $Z$ wischenschicht. Das engmaschige Gerüst der letzteren enthält an der photographierten Schnittstelle keine tangential verlaufenden Nervenfasern, dagegen einzelne rerzweigte Gliazellen und zahtreiche radiär durchtretende Neuroblasten. An diesen sind entweder beide oder nur einer der Fortsätze erhalten, je mach der schnittrichtung bald der immere, bald der äußere. In der Matrix ändert das Markgeriist seinen Charakter, es wird weitmaschig und rorwiegend radiär angeordnet. ( $\mathrm{Zu}$ Seite 102.) bei sorgfältigem Suchen, hie und da Zellkörper sich finden lassen, die anscheinend in Fäiden auslaufen, so entspricht dies Bild nicht entfernt demjenigen ron Stellen, in denen Faserzüge aus echten Neuroblasten herrorgehen. Die Fasermassen der Hemisphärenwand entstammen auf der vorliegenden Stufe ausschlieblich der bereits ausgiebigentwickelten inueren Kapsel, sie sind also secundär in die Hemisphärenwand hineinge wachsen.

Die Herkunft der ersten in die Hemisphärenwand einwachsenden Fasermassen ist auf ein kompaktes Faserbündel zu beziehen, das schon zu Ende des zwreiten Monats (My und Mrr) an der Außenfläche des Thalamus frei wird. Von hier aus erreicht das Bündel am Margo peduncularis den Streifen- 
hiigel und tritt, fächerförmigg sich ansbreitend, unter jhm hindureh in den basalen Abschnitt des lateralen Henisphärenmantels. Die zu dem Bündel gehörigen Neuroblasten befinden sich in der Dicke der Thalamuswand, die Eudausbreitung ihrer Fasern mus in dem Hemisphlärenunantel liegen, und zwar kann es siclı nach dem oben geselilderten Verhalten der Faserziige nur $11 \ldots$ ein Auslaufen in scheitelwärts und medial gelegenen Rindenbezirken handeln. ${ }^{1}$ ) Diese früh in die Hemisplä̈ren einwachsenden Fasermassen bilden den Stabkranz des Thalamus.



ligg. 71. Hemisphärenwand ron libelus stg in der Nailse des Strofenhïgels. Man sieht die versehiedenen

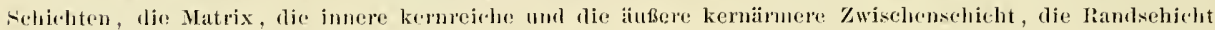

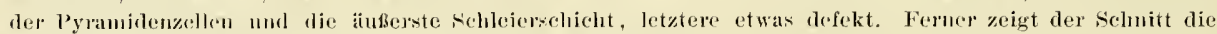
J'angentialfascrn der Zwischenschicht und, nit diesen in senkreehtor Richtung sich kreuz(nd, die Ziige von durchwanderulen bijolaren Nouroblasten. (Zu reite 102.)

Das Gliageriist der Hemispluärenwand zeigt nach Auftreten von Rindenschicht und Bogenfasern eine ansgeprägte, der Schichtenbildung sich anpassende Gliedermug. Nit der Limitans interna sind die Säulenfortsätze der ursprünglichen Spongioblasten in bekannter Weise verbunden. In versehiedene Tiefen herahreichend, Jassen sie zwischen sich ein System

1) Nach persönlichen Mitteilungen von Werm Kollegen Fucussis zeigt der Stahkranz des Thalamms innerhalb der Hemisphärenwand die ersten marklaaltigen Fasern, er enthiilt sensible Bahnen, die aus den Thalamus zum oberen Teil der Zentralwindung emporsteigen mol zum Teil an die mediale Wand ibertreten. 


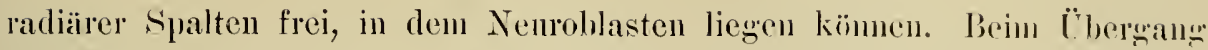
zur Zwischensehicht nimmt das Gerüst den Charakter eines kirrperlichen Netzes an, dessen Masehen, insofern von einer hevorngten Richtmng dic Rede sein kann, vorwiegend der Fläehe nach gerichtet sind. Die den Geriïst der Zwisehenschicht angehörigen Gliazellen sind flach oder schriag melagert, ron etwas gestreckten Formen und sie durehkrenzen sich nach rerschiedenen Richtnngen. An senkrechten Sehnitten ergibt sich dies schon darans, daß die Keme teils längs, teils aner getroffen sind. Noch besser tritt abu das Verhalten der gekreuzt liegenden Zellenleiber an Flachschnitten hervor.

Da sich in den Sehnitten die Bilder rerschiedener Geriistebenen iuberlagern, so 11n16 man Messungen der Maschenweiten in der Weise rornehmen, daß man mit einem nur anf geringe Tiefen scharf zeichmenden, starken System anf eine bestimmte Ebene einstellt, und diese entwerler mit dem Zeichnungsapparat zeichnet, oder bei bekannter Tergrößermng plotographiert. Ich finde so die Maschenweite inner-

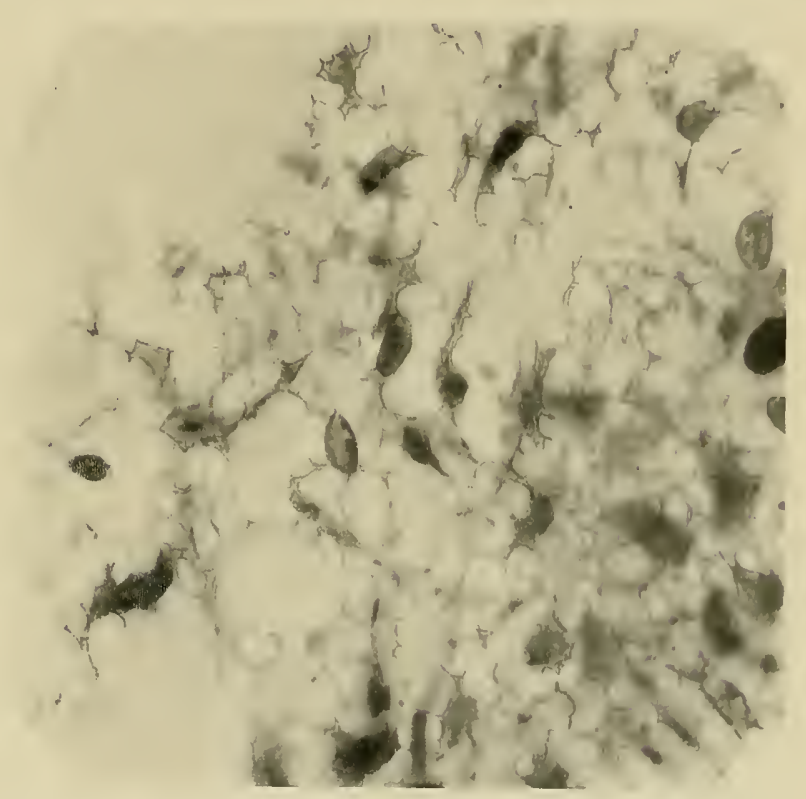

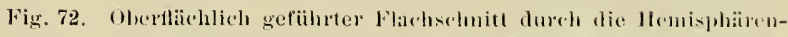
wand vou foetus stg. Iner selutilt \%eigt stïcke des Markgeriistes mit verzweigten (iliazellen. Jic efwas diclowe gelagerten, moseharet

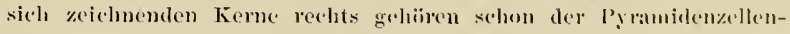
sclichlit :11.

\section{lalb der Zwischen-}

sehicht zwisehen 6-10 1 weehsehud, jedenfalls weit genug, un Nenroblisten den Durelitritt zu gestatten. Innerhalh der Rindensehicht liegen die Pyramidenzellen in gestreckten Geristmaschen, nud die sie trennenden Radiiirbälkehen scheinen nur wenig (Querverhindungen zu haben. Xach anken von den Pranidenzellen folgt das dichte Randgeriist (Fig. 72). Die Weite seiner Maschen lestimme ich nach ohiger Methode zin $3-5 \mu$, und zwal finden sich die engeren Maschen von 3 - $3{ }^{1} / 2$ " nach cinwiirts in den an die Pyaniden anstoßenden Strecken, die weiteren. bis $\%$ 5 ", in den der Limitans externa zugekehrten.

Das enge Maschenwerk der Randsehicht bildet die Wand, die die Pyranidenzellen an weiterem Vordringen lindert und ilıre Anhäufung in 
der Rindenschicht bedingt. Das Hindernis besteht nur für die kernhaltigen Zellenleiber, die Spitzenfortsätze dringen in der Folge reichlich in die Rindenschicht vor. Nur eine kleine Anzahl von Zellen durchbricht die Wand und ordnet sich der Randschicht ein. Es sind dies zurzeit wohl ausschlieBlich Gliazellen, sie lagern sich der Fläche nach, und die äußersten nehmen an der Bildung der M. limitans externa teil.

Etwas zweifelhaft bin ich iiber das Schicksal der bei Se so klar beobachteten Siebplatte. Da diese Platte sich an der Seitenfläche des Streifenhïgels soweit erstreckt, als späterhin die Pyramidenschicht, und da sie im voraus die Grenze angibt, bis zu der die Pyramidenzellen vordringen, so liegt der Gedanke am nächsten, ihr die Hemmung in der Weiterbeweg'ung dieser Zellen zuzuschreiben. Diese Annalme wäre ohne weiteres bewiesen, wenn die Siebplatte nach erfolgter Anlage der Pyramidenschicht, deren Außenfläche entlang, noch nachweisbar wäre. Ich vermag indessen weder bei $\mathrm{Mr}$, noch bei Stg, noch bei anderen diesen Stufen angehörigen Embryonen eine zusammenhängende Siebplatte aufzufinden. Flach gelagerte und unter sich zusammenhängende Gliazellen, die als Reste der Platte gedeutet werden können, sind nurstreckenweise nachweisbar. Die Schicht scheint im Laufe der Entwicklung. ihren geschlossenen Zusammen-

Fig. 73. Schema des Aufbaues der Hemisphärenwand beim Foetus des dritten Monats, links Neurogliageriist, rechts Neuroblasten und Nervenfasern. ( $\mathrm{Zu}$ Seite 107.)

hang eingcbüßt zu haben. Vielleicht ist dies dahin zu verstehen, daß das Vorhandensein der geselılossenen Siebschicht nur in Beginn der Rindenbildung: erforderlich ist, um das Vordringen der zuerst eintreffenden Pyramiden- 
zellen anfzuhalten. Später hemmen diese ersten Ankömmlinge das Vorriicken der nachfolgenden Generationen. Gliazellen finden dagegen kein IIindernis, und es zeigt die M. limitans externa einen immer reichlicher werdenden Besatz kernhaltiger Zellenleiber.

Ich fasse die Ergebnisse der mitgeteilten Untersuchung in einer schematischen Zeichnung (Fig. 73, S. 106) zusammen, in der links das Gliagerüst, rechts die Neuroblasten eingetragen sind. Die Differenzierung der Schiehten kommt, wie das Schema ergibt, wesentlich auf Rechnung des Gliagerïstes, das in jeder der vier Hauptzonen einen anderen Charakter amnimmt. Der in der Skizze angedentete schräge Verlauf der Bogenfasern und das Freibleiben der Rindenschicht von letzteren entsprechen der unmittelbaren Beobachtung. Die flachen Kerne im imneren Abschnitte der von Fasern durchzogenen Zwischenselicht halte ich für Gliabestandteile.

Hinsichtlich der Fasern tritt in dieser frühen Periode schärfer als später der Gegensatz zutage zwischen den ans der inneren Kapsel kommenden Fasern der Stammstrahlung und den ans den Pyramidenzellen der Rindenschicht stammenden zurzeit noch kurz angelegten Fasern, d. h. zwischen Fasern, die von außen her in die Hemisphärenwand eingedrungen und solchen, die in ihr entstanden sind (ectogen e und a ut ochthone Fasern).

\section{Zweite Hälfte des dritten Monats.}

In weiteren Verlauf des dritten Monats schreitet das Dickenwachstum der Hemisphärenwand langsam aber stetig roran. Am ansgibigsten nimmt die Zwischenschicht zu und nächst ihr die Rindensehicht, während Matrix und Randschicht viel merheblichere Zunahmen anfweisen. Ich teile als Beispiel die Maße mit, die ich an den Hemisphären des Foetus Doed (SSl. $50 \mathrm{~mm}$ and Kt. $20 \mathrm{~mm}$ ) and an den des Foetus Cr (SSl. $60 \mathrm{~mm}$ Kt. $25 \mathrm{~mm}$ ) bestimmt habe. Das Alter des ersteren ist anf die zweite Hälfte, das von $\mathrm{Cr}$ auf den Übergang zum vierten Monat anzusetzen.

Foetus Doed.

Zweite Hälfte des dritten Monats.

Basal. Abschnitt Mediale der lat. Wand.

Wand.

Foetus Cr.

Übergang zum vierten Monat.

Basal. Abschnitt Mediale der Jat. Wand. Wand.

Gesamtdicke der Hemisphärenwand $800 \mu$

\begin{tabular}{|c|c|c|}
\hline "ו" 390 & $1100 " u$ & $550 \mu$ \\
\hline 120, & 170. & 140 \\
\hline 170 & 650, & 250 \\
\hline 30, & 240, & 120 \\
\hline $40 "$ & 40, & 40 \\
\hline
\end{tabular}

Sowohl bei Foetus Doed als bei $\mathrm{Cr}$ ist die Zwischenschicht von radiär gesteliten Spindelzellen, den in Wanderung begriffenen Prramidenzellen, 


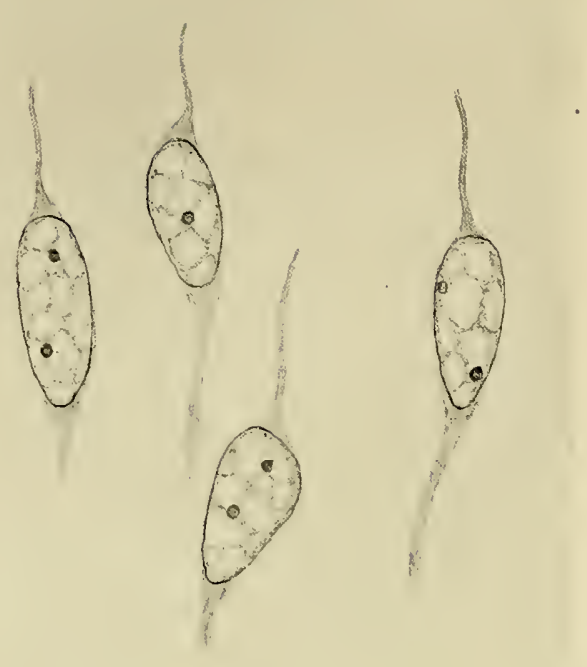

noch reichlich durchsetzt. Vielfach zeigen deren Kerne Birnformen, sie sind nach einwärts breiter als naeh auswärts (Fig. 74). Die Mögliehkeit, diese Formen mit der späten Pyramidenform der Zellen in Beziehung zu setzen, läßt sich nicht fésthalten, da beim Eintritt der Kerne in die Rindensehicht deren Birnformen wieder verloren gehen. Ich glaube vielmehr, daß die in der Zwisehenschicht so vielfach auftretenden einseitigen Verjüngungen der Kerne mit der Bewegungsrichtung der Zellen in Zusammenhang stehen. Der der Fortschiebungsrichtung zugekehrte Kernpol erscheint dabei als der verjüngte.

In der Rindenselicht sind die Kerne der Pyramidenzellen auffallend gerundet und entsehieden größer, als die der Zwischen-

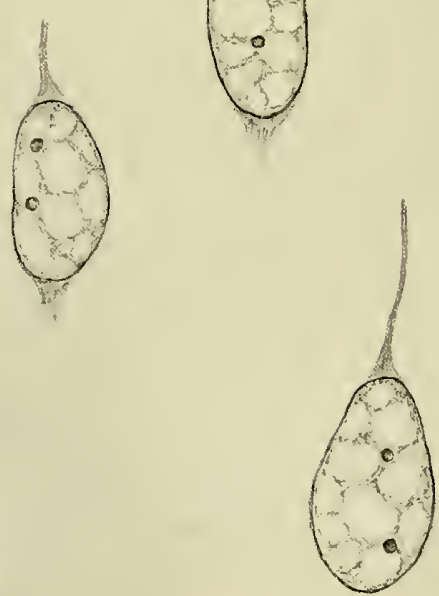

Fig. 74. Prismenzeichnung. Vergr. ea. 2000. Foetus Doed (SSl. $5 \mathrm{~cm}$ ). Zellen aus der Hemisphärenwand. Die oberen Zellen stammen ans der Zwischenschicht, die unteren aus der Rindensehieht. Erstere zeigen etwas kleinere und sehlankere Kerne als die letzteren. Vielfach finden sieh in den Zellen der Zwisehensehicht birnförnig gestaltete, nach auswärts sieh verjüngende Kerne.

sehieht. So messe ieh an Zeichnungen, die bei holıer Vergrößerung anfgenommen worden sind, in der Zwisehensehieht Kerne ron $3 \frac{1}{2}-4^{1} \% \mu$ Breite auf $8-9 \mu$ Länge, in der Rindenselicht solehe von $5-6 \mu$ Breite anf $8 \%$ bis $11^{1} / 2, \mu$ Länge, darunter viele kurzovale (ron $6^{1} \%$ auf $81 \%$, i).

Mit einer gewissen Yorsicht muß ich mich über die Spitzenfortsätze der Rindenzellen anssprechen. Ich finde sie bei Foetus Doed nur in Spuren vor, und es ist möglich, daß sie infolge ungenügender Konservierung zerfallen sind. Eine vorübergehende Verkïmmerung dieser Fortsätze bein Eintritt der Pyranidenzollen in die Rindensehieht hat 
sich indessen schon bei den Embryonen Stg und Ma nachweisen lassen. Ein massenhaftes Vorriicken von Spitzenfortsätzen in die Randschicht tritt erst in späteren Stufen ein. Im Gegensatz zu den Spitzenfortsätzen sind die Nervenfortsätze bei Doed und Cr schon reich entwickelt. Sie treten als dichter Wald ron feinen Fasern in die Zwischenschicht ein und durchsetzen diese bis in ilıre innere Zone. Dabei durehkreuzen sie die aus der inneren Kapsel stammenden Bündel von Bogenfasern. Die Menge dieser Bogenfasern hat gegen frïlıer nicht unerheblich zugenommen, ihre Ausläufer ungreifen die Scheitelhöhe der Hemisphären und greifen auf die mediale Wand ïber.

So ausgiebig nun während des dritten Monats die Auswanderungen ron Zellen ans der Matrix nach der Rinde hin vor sich gehen, so kömnen sich die Zellen doch nur mit einer gewissen Langsamkeit vorwärts bewegen. Der Prozeß der Rindenbildung nimmt ja nicht allein den ganzen dritten, sondern noch einen gruten Teil der naehfolgenden Monate in Anspruch. Nehmen wir, um zu annähernden Werten zu gelangen, an, daß die an den Streifenhiigel stoßende basale Hemisphärenwand zu Ende des zweiten Monats (bei $\mathrm{Mr}$ ) eine Rindenschicht von 8, in der Mitte des dritten (bei Stg) eine solche von 18 Kernhöhen besessen hat, so ergibt dies für den halben Monat den Zuwachs einer 10 fachen Zellenschicht, oder anders ansgedrückt: um die Rinde 1 m eine Zellensehicht zu vermehren, sind rund anderthalb Tage erforderlich. Bei dieser Berechnung ist die Flächenausdehnung der Hemisphärenwand nicht berïcksichtigt worden. Letztere muß dadureh zustande kommen, daß zwischen die bereits vorlandenen Zellen neu angekommene sich einschieben. Die wandernden Pyramidenzellen haben anch diesen Bedarf zu decken, eine Bereehnung der Geschwindigkeit ihres Fortsehreitens nach obigen Daten allein würde somit ein zu langsames Tempo ergeben. Indessen kommt man auch bei Berïcksichtigmng dieses Unstandes zur C̈berzengung, daß die Daner der Überwanderung eines Elementes aus der Matrix in die Rindenschicht zum mindesten nach halben Tagen zu rerauschlagen ist.

Solange die Überwanderung von Nenroblasten andanert, umschließt die Hemisphärenwand noch keine ron Nerrenzellen freie Markschicht. An das Lager von Höhlengra ${ }^{1}$ ) schließt sich die zwar faserreiche, aber

1) Th. Mervert gebrancht die ron ihm geschaffene Bezeichnung . Zentrales Ḧ̈hlengran " für die graue Auskleidung der Hirn- und Riickenmarkshöhlen nur rom dritten Ventrikel nach abwärts. Merxert s Definition „Röhrenförmiges Grau, der bleibende Ausdruck der genetischen Grundform des Gehirus" (STrickers Handb. der Lehre von den Geweben S. 697) paßt aher auch sehr wohl anf die rorhandene graue Auskleidung der Seitenventrikel, also zunächst auf den Nuclens candatus des streifenhïgels. Das ursprïnglich ringsherum vorhandene Höhlengran der seitenventrikel umfaßt die Matrix und die zellenreiche Innenzone der Zwischenschicht. Zutreffend ist die Bemerkung von RaUber: „Alles Grau ist ursprünglich Höhlengrau.” (Lehrbuch der Anat. 6. Aufl. Bd. II S. 4\$1.) 
von Neuroblastenketten durchzogene Zwischenschicht an, die bis zur Rindenschicht sich erstreckt. Im Hemisphärenmantel geht die Zellenauswanderung so lange vor sich, bis sich das Höhlengrau durch Abgabe seiner Elemente erschöpft hat. Als Rest bleibt das Ependym mit einem gewissen Anteil von Gliazellen zurïick.

Anders gestalten sich die Verhältuisse im Gebiete des Streifenh ï gels. Als mächtiger Klumpen von Höhlengran ragt dies Gebilde gegen den Seitenventrikel vor. Anch von ihm aus findet eine reiche Auswanderung. von Zellen nach den umgebenden Gewebslagen statt. Eine eigentliche Rindenbildıng tritt aber hier erst verzögert ein, dagegen sondert sich mit dem Hindurchbrechen der inneren Kapsel, im Beginn des dritten Monats, ein zellenreicher Distrikt als Linsenkern ab, und dieser scheidet sich damn weiterhin durch ihn umgebende weiße Substanzplatten vom Claustrum und vom angrenzenden Inselgebiet. Der Linsenkern ist also, entwicklungsgeschichtlich betrachtet, ein Stück abortir gebliebene Rindenanlage. Seine Elemente sind auf dem im Streifenhiigelgebiet besonders langen Weg zur Peripherie stehen geblieben und durch weiße Fasermassen ungrenzt worden.

Das Einriicken der Markschicht in das Innengebiet der Hemisphärenwand geht sehr allmählich vor sich. Schon im Verlauf des dritten Monats ragen, wie oben herrorgehoben wurde, Büschel ron Fasern ans der Pyramidenschicht in die anstoßende Zwischenschicht hinein, und weiterhin erscheint die gesamte Außenzone der letzteren von Radiärfasern durchzogen, die mit den Bogenfaserbündeln sich durchkrenzen. Diese Radiärfaserzüge sind bis in das Höhlengran hinein rerfolgbar und sie verlieren sich zwischen dessen dichten Kernmassen. Mit fortschreitender Entwicklung nimmt die Menge der Radiärfasern zul, und es ist ron deren reichlichem Torhandensein und von der entsprechenden Anordnung des Gliagerüstes abhängig, dass bei makroskopischer Präparation die anseinandergebrochene Hemisphärenwand eine ausgeprägt radiärstreifige Bruchfläche zı zeigen pflegt.

Die Radiärfasern einerseits und die Scharen radiärgestellter Zellen anderseits beginnen sich schichtenweise zu sondern. Zuerst erfolgt eine solche Sonderming ron rein faseriger und von zellenreicher Substanz im Innern des Streifenhïgels, und hier erhält sich zwischen Nucleus candatus und N. lentiformis zeitlebens eine ans granen und weißen Blättem geschichtete Zone. Vom Streifenhiigel ans greift die Schichtenbildmng auf das Basalgebiet des Hemisphärenmantels iiber und sie breitet sich ron hier aus scheitelwärts aus. So finde ich im Bereiche der Basis eine in der Innenzone der Zwischenschicht ansgeprägte, etwas schräg geordnete Schichtung schon bei den Foetus Doed und $\mathrm{Cr}$. Noch ist hier die Sondernng der Schichten keine scharfe, es handelt sich nur um einen Wechsel zwischen zellenreicheren und zellenärmeren Schichten. Während der nachfolgenden Perioden nimmt die streifige Sonderung innerhalb der imneren Wandzonen an Umfang und an scharfer Ansprägung zu, bis sie dam an Schlıß des 
vierten Monat, mit Ausnahme weniger, besonders sich verhaltender Bezirke, in der Umgebung des gesamten Ventrikelgebietes zur Ausbildung gelangt ist. Es ergibt sich darans, daß das Hemisphärenmark nicht von Anfang ab als geschlossene Faserschicht anftritt, sondern daß es sich sein fiebiet schrittweise erobern und noch während geraumer Zeit mit Straßen von durcliwandernden Neuroblasten teilen muß. Die Markschicht der Hemisphären bewahrt bekanntlich zeitlebens einen blättrigen Bau, der in einzelnen Bezirken, wie z. B. im Balken, besonders deutlich hervortritt. Dieser Bau leitet sich ans der Bildungsweise der ursprïnglichen Anlage ab, deren Spuren, in der Anordnung des Gliagerïstes und der Faserbündel erhalten bleiben.

\section{Die Hemisphärenwand im vierten Monat.}

Zn Ende des dritten Monats ist die Dicke der Hemisphärenwand noch gering und die Höhlung rerbältnismäßig weit. Die oben mitgeteilten Messungen zeigen für Foetus $\mathrm{Cr}$ noch eine Wanddieke ron 0.5 bis $1.1 \mathrm{~mm}$. Im Laufe des vierten Monats ändert sich dies Verhältnis und bei dem vier Monate alten Foetus PI (SSI. $12 \mathrm{~mm}$ ) mißt die W'anddicke an den meisten Stellen um $4 \mathrm{~mm}$, stellenweise sogar bis zu $5 \mathrm{~mm}$. Dementsprechend sind auch die Seitenventrikel erheblich verengert und in einem Teil ihrer Ausdehnung zu schmalen Spalten mingewandelt.

Die Entwicklung der Hemisphären ist zu der Zeit ziemlich weit fortgesehritten. Äußerlich ist die Grundform von der bleibenden nur wenig. nnterschieden. Stirn- und Schläfenlappen sind durch die breit klaffende Fossa Sylvii roneinander geschieden, die einzige an der Seitenfläche sichtbare Spalte. Der Hinterhauptslappen tritt mit stumpfer Spitze nach rïckwärts vor und iiberdeckt völlig das Kleinhirn. Der Balken und die rordere Kommissur sind vorhanden, das vordere Riechhirn zu einem langen Strang ausgezogen. An der medialen Wand machen sich vor allem die tiefe Fissura calearina und die F. parietooceipitalis bemerkbar, anßerdem die Fissura corporis callosi, die Fissura prima (parolfactoria BNA), und am Schliafenlappen die F. hippocampi. In den Seitenventrikeln scheiden sich Vorder-, Hinter- und Unterhorn. Aus der Seitenwand des Vorder- und des Unterhornes drängt sich der Streifenhügel als spangenartig gebogener, stark gewölbter Wulst hervor und er erfüllt die Lichtung großenteils bis auf eine enge Spalte. Im Hinterhorn bildet die mediale Wand eine gegen die Lichtung mächtig hervortretende Falte, die Anlage des Calear aris. Der Sänlenteil des Fornix sondert sich noch unscharf ron den dickwandigen Trapezplatten, seine Schenkel schließen sich als gleichfalls noch dicke Platten dem durchweg ansgebildeten Hippocampus an.

Die Gliederung der Wand erscheint zu Ende des rierten Monats reicher als zuvor. So lassen sich bei Foetus Pl $(12 \mathrm{~mm}$ SSl. $)$ in der lateralen Wand 
des Hinterlappens acht verschieden sich verhaltende Schichten unterscheiden, von denen die einen auf die früher vorhandenen Schichten zuriickführbar sind, wogegen andere als ncu hinzugekommene zu verstehen sind (Fig. 75).

1) Die Schicht des Höhlengraues oder Matrix;

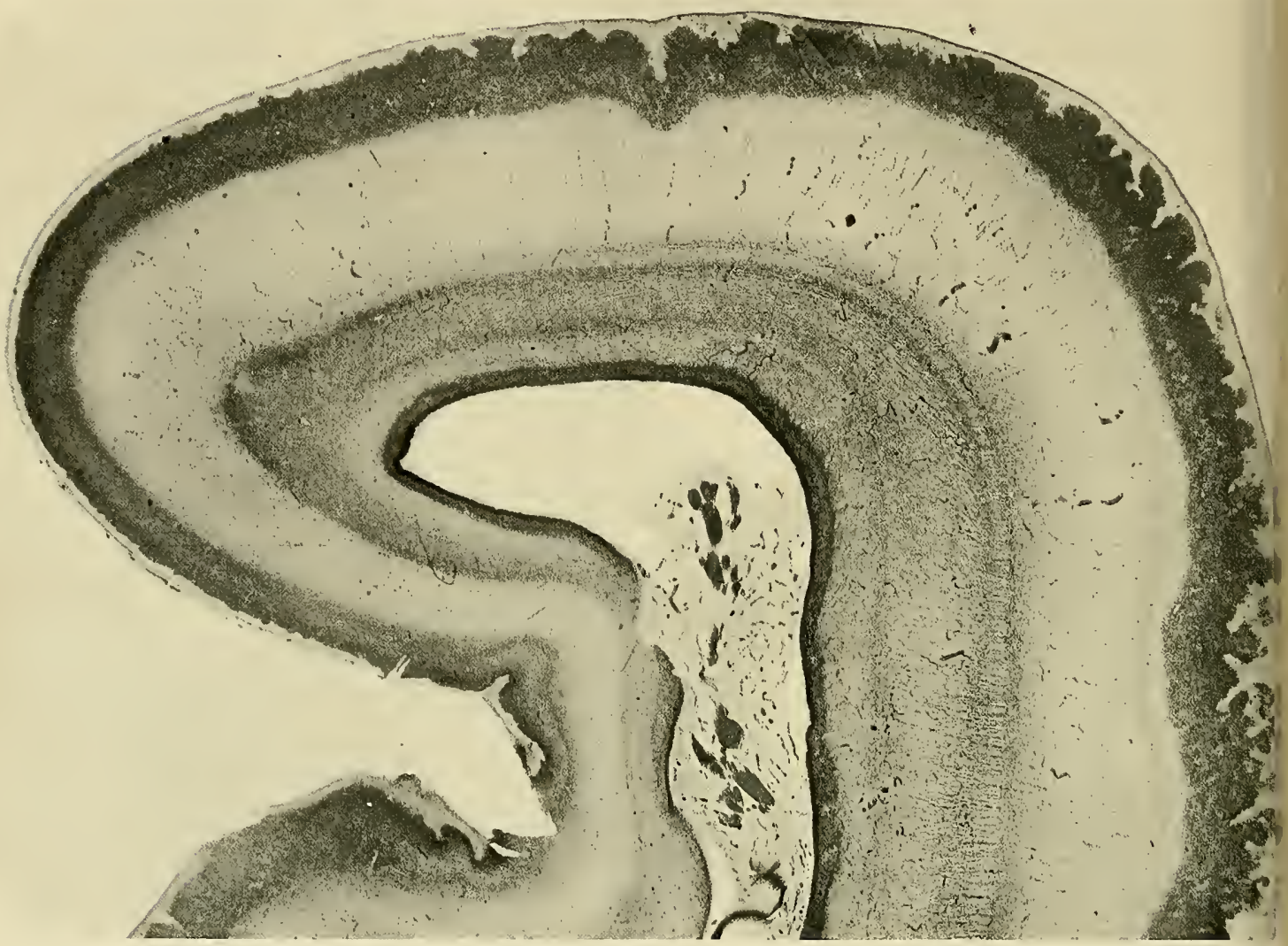

Fig. 75. Durehsehnitt dureh den Oecipitallappen des Gehirns von Foetus Pl (12 cm SSI.). Die laterale Wand zeigt die im Text angegebene Schichtung. Die Rindenschicht ist an ihrer peripherischen Oberfläche mit pilzartigen Auswiichsen besetzt, ïber denen die Randschicht glatt hinweggeht. Der nach links gekehrte Einschnitt ist die Fissura calcarina, der in den Ventrikel vorragende breite Wulst der Calcar avis, dessen freie Oberfläche mit einer sehr dünnen Schicht von Ḧ̈hlengrau bekleidet ist. Auch die Rindensehicht ist an Grund der Fissura calcarina erheblich dünner, als imı ïbrigen Umfang der Wand.

2) eine innere streifige Schicht;

3) eine innere Übergangsschicht;

4) eine äußere streifige Schicht;

5) eine äußere Übergangsschicht;

6) eine blasse, breite Zone, die $Z$ wischensehicht;

7) die Schicht der Rindenpyramiden;

8) die Randschicht (Randschleier). 
Ton diesen acht Schichten entsprechen 1, 6, 7 und 8 den gycichnanizen Schichten rorangegangener Stufen. Dagegen unfassen die streifigen und die Übergangsschichten 2, 3, 4 und 5 die allmählich nen hinzngekommenen Anlagen des Henisphärenmarkes, und wir kömnen sie mnter der geneinsanten Bezeichnung der Markschichten zusammenfassen.

Die Schicht des Höhlengranes enthält dicht gedränghte kernhaltige Zellenleiber, sie entsendet in die nächstfolgende Schicht blattartig' angeordnete zellenreiche Streifen, die mit flachen Lagen von Nervenfasern abwechseln (Fig: 76). Je nach der Schnittrichtung stchen die Blätter der streifigen Schicht senkrecht, sehräg oder parallel zur Ventrikelfläche, auch finden sich Umbieg'ung'en aus einer Richtung in die andere. Nach auswärts ron der inneren streifigen Schicht und nur durch einen schmalen Zwisclıenstreifen davon getrennt, folgt eine weitere streifige Schicht, der ersteren ähnliclı, aber mit anders gerichteter Streifung. Steht die Streifung in der immeren Schicht senkrecht zur Tentrikelfläche, so verläuft sie in der äuße-

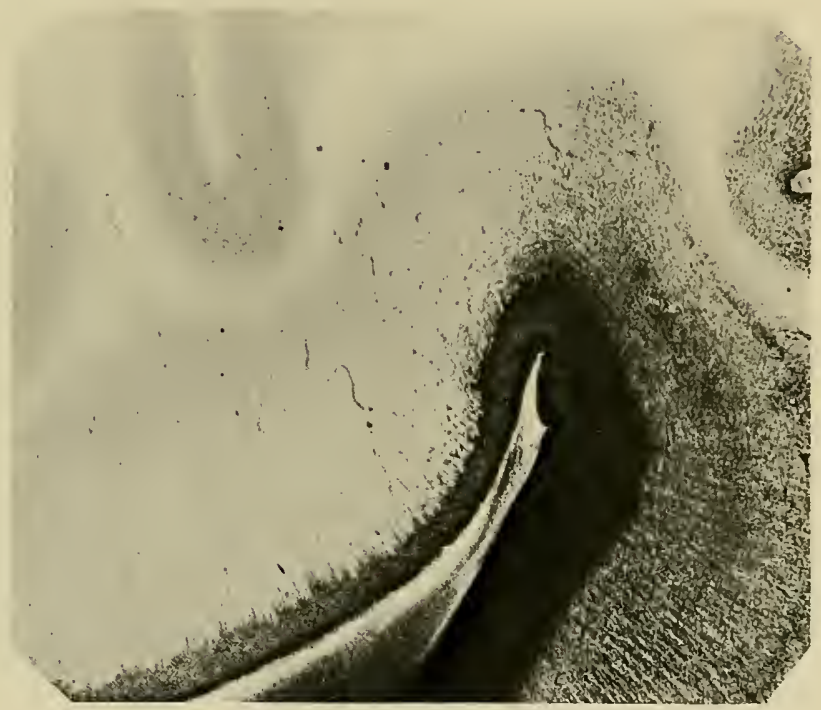

Fig. 76. Tentrikuläre Oberfläche der Hemisphärenwand ron Foetus Pl. Der Schnitt zeigt die noch ziemlich dicke Schicht von Höhlengrau und die von dieser nach auswärts ansstrahlenden dunkeln (zellenreiehen) Streifen. Zwischen den letzteren liegen in blattartiger Anordnung die Markfasem, die den Pyramidenzellen der Rinde entstammen. ren parallel oder doch

schräg zu dieser und umgekehrt. Die Richtung der Blätterschichtıng und die des Faserverlaufes immerhalb der Blätter fallen nicht notwendig zusammen. An Blättern, die senklecht zur Oberfläche stehen, erscheinen die Fasern durchweg querer geschnitten. In Blättern parallel zur Oberfläche fallen Faselrichtung . und Blattrichtmng im allgemeinen zusammen. Für beide Fälle ergibt sich sonach, daß die innersten Faserlagen in ihrer Verlanfsrichtung der Tentrikelfläche folgen, ein Verhalten, das für die Balkenfasern zeitlebens zutrifft. Die beiden Übergangsschichten heben sich durch ihren größeren Kernreichtum und dementsprechende dunklere Färbung von den Nachbarschichten ab, stellenweise treten sie anch als Doppelstreifen auf.

Die Schicht, die ich oben als breite, blasse bezeichnet habe, ist ans der Zwischenschicht frïherer Stadien abzuleiten. Thie diese ist sie ron II is, Die Entwicklung d. monschl, Gehirus. 
zahlreiehen Radiärfasern und radiär gestellten Zellenleibern durehsetzt, und sie schließt sich mit beiderlei Bestandteilen der Rindensehicht an (Fig. 77). Diese zeigt, da wo die Sehnitte senkrecht zur Oberfläehe geführt sind, in ihrer gesamten Dicke einen ansgeprägt radiärstreifigen Ban. Wird sie vom Schnitte schräg getroffen, so zeigt sie eine der Oberfläche parallele Streifung (Fig. 78).

Un von der relativen Mächtigkeit der versehiedenen Schichten eine Vorstellung zu geben, teile ich Dickenmaße mit, die ich bei Foetus Pl an der

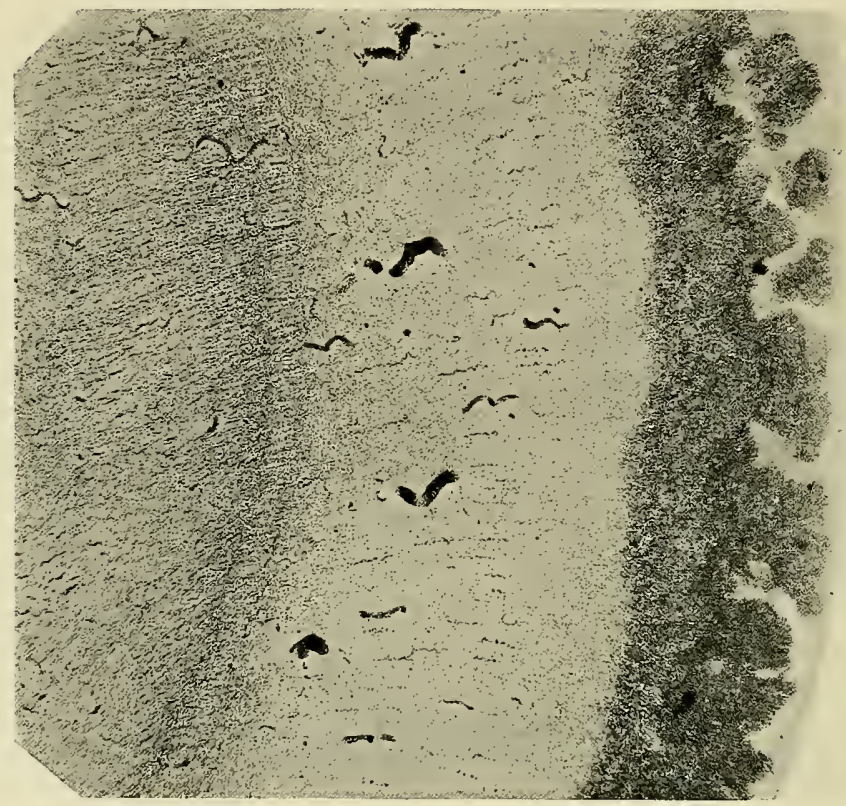

Fig. 77. 1)urchschnitt dureb den äußeren Wandabschnitt des Occipitalhirns von Foetus Pl. Der Schnitt zeigt die äußere streifige und die äußere Übergangsschicht, sowie die bloße Zwischenschicht und deren Anschluß an die Rindenschicht.

lateralen Wand des Hinterhorns anfgenommen habe: Die Gesamtdicke der Wand von der Ventrikel- bis zur Anßenfläehe beträgt $4 \mathrm{~mm}$. Davon kommen auf:

das Höhlengran . . . . 0.2 mun oder zusammengefaßt

die innere streifige Schieht 0.5,

die innere Übergangssehieht 0.2 ,

die äußere streifige Schicht $0.6 "$

die äußere Übergangssehieht 0.3 ,

das Höhlengrau . . $0.2 \mathrm{~mm}$

die Zwischensehicht . . . 1.4 , die Marksehichten . 1.6 , die Zwischenschicht 1.4 , Rinden- und Randschicht . . . 0.8,

die Rinden- mit Einsehluß der

Randsehicht . . . . . 0.8,

Die mächtigste Sehicht ist die ans der früheren Zwisehensehicht hervorgegangene blasse Schielit, sie nimmt ïber ein Drittel der gesanten Wanddicke ein. Sie ist es aber anch, die die ansgiebigsten Dicken- 
schwankungen zeigt. Überall da, wo die Rinde siclı einfaltet, greschieht die Einfaltung auf Kosten der Zwischenschicht, und deren Dicke kann unterhalb ron Rindenfalten bis unter die Hälfte ihres sonstigen Betrages herabgehen. An solchen eingefalteten Stellen pflegt sich iibrigens anch die Rindenschieht etwas zil verdümnen.

Der größere Teil der Hemisphärenwand ist nach den eben beschriebenen Typus gegliedert. Die absoluten und relativen Dickenmaße der Schichten weehseln zwar, aber in allen typiseh gebauten Strecken folgt auf

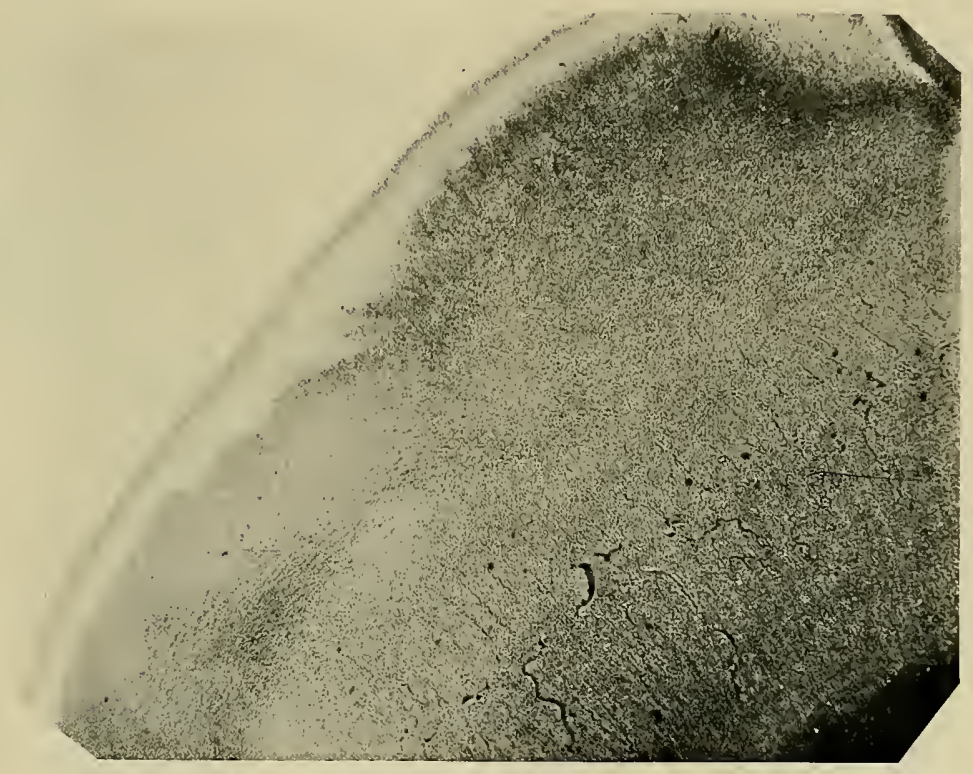

Fig. 78. Durehsehnitt durch die Henisphärenwand von Foetus Pl. In der Rindensehicht und teilweise sehon in der $Z$ wischenschicht ist eine der Oherfläche parallele Schichtung wahrzunehmen. Die bei Fig. 77 längsgetroffenen Blätter sind hier quer- oder schräggetroffen, wie dies auch aus dem Verhalten der Blutgefäße ersichtlich ist. Diese sind bei Fig. 77 radiär angeordnet, bei Fig. 78 ist eine solche Anorinung nur noch innerhalb der streifigen schicht und auch hier unvollkommen ausgesprochen. (Zu seite 114.)

das Höhlengran eine ein- oder mehrfaehe streifige Schieht, in der Blätter eines zellemreiehen Gewebes nit Faserplatten abweehseln. Nach außen davon kommen eine radiär streifige Zwischenschieht, sowie eine Prramidenzellen- und eine Randsehieht. Im Stimlappen vereinfacht sich die Anordnung, indem eine einzige streifige schicht von erheblicher Dicke auftritt. Die Zwischensehicht bleibt lier verhältnismäBig schmal. Ich messe z. B. an einem Schnitt durch die laterale Wand des Torderhorns:

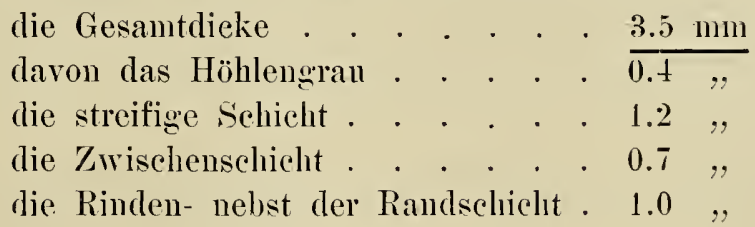




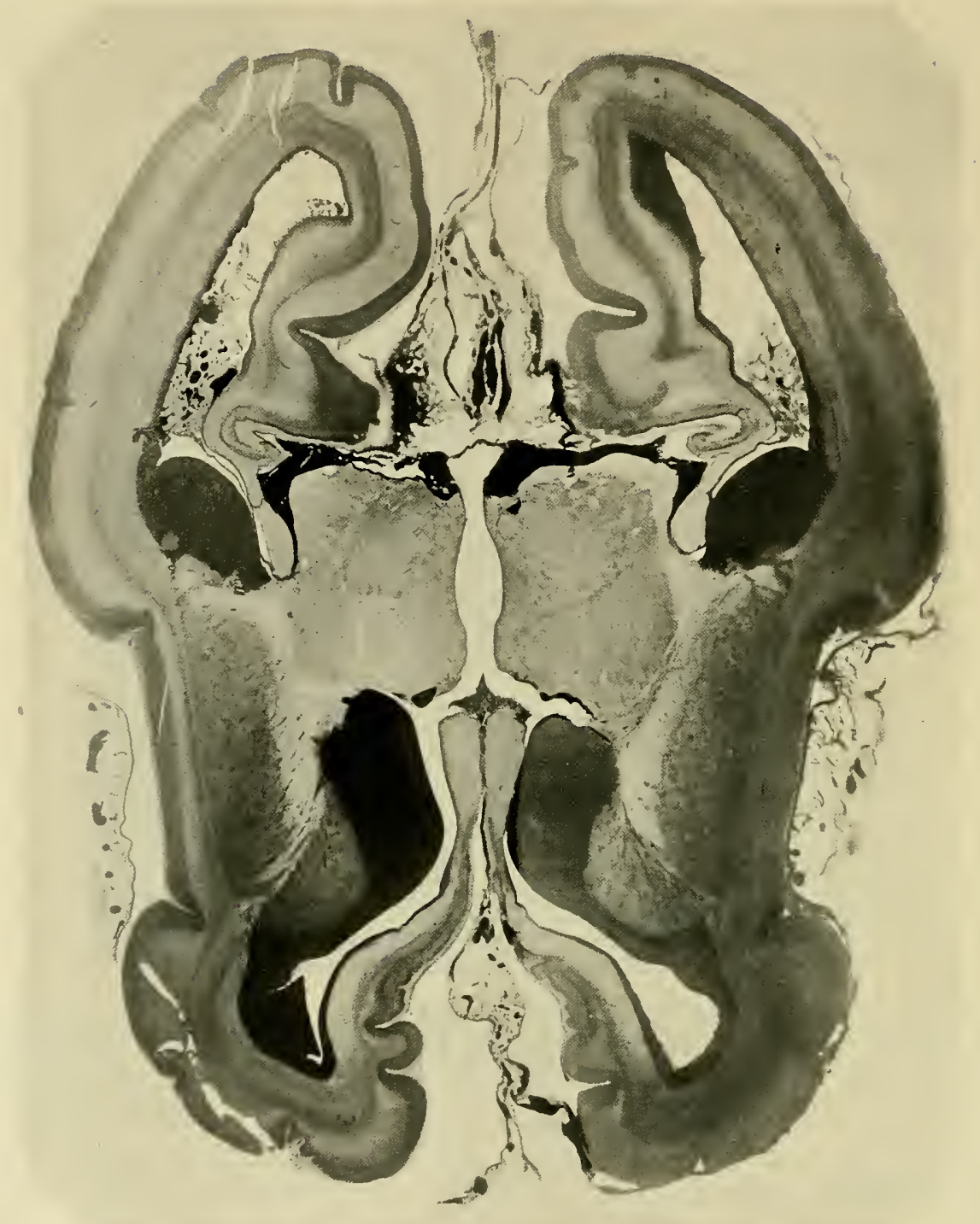

Fig. 79. Horizontalsehnitt dureh das Gehirn von Foetus CP (Ss]. $16 \mathrm{~cm}$ ). Es sind vom Sehnitt getroffen: Die Sehhïgel und die versehiedenen Glieder des Streifenhügels, N. caudatus, innere Kapsel, Linsenkern und Claustrum. Die Sehhïgel sind vom Anfangsteil des Hippoeanjpus und den Fornixsohenkeln eingefaßt. Nach vorn sind sie dureh die beiden Foramina Monroi von den Fornixsäulen geschieden. Die ans den früheren Trapezplatten hervorgegangenen Abschnitte der Hemisphärenwand sind im Bereiche der Fornixsäulen miteinander verwachsen (die Verwachsungslinie zeichnet sich als dunkler Streifen). Weiter nach vorn klaffen sie und nehmen eine diinne Fortsetzung der Pia zwisehen sich. Der klaffende Raum ist der nach vorn noeh nicht abgeschlossene Ventriculns septi pelheidi. In betreff der Schichtung der Hemisphärenwaud verweise ich auf den Text. Die Rindensehicht sicht man sowohl vor dem Septum pellueidum als am Fippocampus frei auslaufen.

Dieselbe Schichtung der Hemisphärenwand wie bei Foetus Pl finde ich bei dem 16 cm langen Foetus CP. Auf das Höhlengrau folğt eine doppelte 
Markfaserschieht, im Oecipitalhirn mit gekrenztem Verlanf der Faserbündel. Damn kommt eine kemmeichere Übergangsschicht, nach dieser die blasse Zwischenschicht und die Rindenschicht. An den horizontal gefïlıten Schunitten (Fig. 79, S. 116) sind die Beziehungen der Wandschieliten zu den Gliedern des Streifenhügelgebietes zu verfolgen. Das Iöhlengran geht in den Nucleus candatus iiber, der wie ein massiger Klumpen unverbrancliten Bildungsmateriales gegen die Ventrikellöhle sich vorwölbt. Die innere Kapsel schlieBt sich den Markfasersehichten der iibrigen Wand an, der Linsenkern, nach beiden Richtungen sich zuschärfend. wird durch die Endabschnitte der inneren Kapsel eingesäunt, und das Clanstrun setzt sich in die äußere Übergangsschicht fort. Letzteres erscheint somit als Rest einer Bildumg, die in frïlierer Zeit eine viel allgemeinere Ausbreitung besessen lat.

Eine weitere Verfolgung der Hemisphärenschichten auf spätere Gelegenheit versparend, wende ieh mieh zu den Entwicklungsvorgängen der medialen Wand zuriick. Zuvor sind noch gewisse Eigentiimlichkeiten der Rindenoberfläche zn besprechen.

\section{Die Retziusschen Wärzchen an der Oberfläche foetaler Großhirnhemisphären.}

Die Henisphärendurchschnitte der Figuren 75 und 77 , die von dem $12 \mathrm{~cm}$ langen Foetns Pl stammien, zeigen eigentiimliche warzen- und pilzförmige Auswüchse an der der Oberfläehe zugekehrten Seite der Rindenschieht. Ich hatte vor einigen Jahren Anlaß der histologischen Sektion des internationalen medizinischen Kongresses in Paris eine kurze Mitteilung über diese sonderbaren Gebilde zu machen. ${ }^{1}$ ) Später labe ieh bei der makroskopischen Präparation ron Foetus ans der Zeit des vierten Monats, die in Formalin aufgehoben waren, gefmnden, daß die oberflächliche Schieht der Hemisphären sich vielfach nit den Hirnhäuten ablöste und nun traten darmuter eigentümliche Wülste und Wärzchen hervor, deren Durchmesser zwischen $3 / 4$ und $1 \mathrm{~mm}$ betrug, und die in geringen Abständen roneinander lagen. Einzehne dieser Gebilde waren halbkuglig gestaltet, andere länglich und rerbogen (wurstförmig). Die Zusammengehörigkeit dieser Gebilde mit den auf Durchsehnitten gesehenen mußte ron vornherein sehr wahrscheinlich erscheinen. Die Schnitte durch solche Gehime zeigen in der Tat ähnliche Hervortreibungen der Rindenschicht. Diese Sehicht erscheint zu der Zeit ungemein zellenreich, ilıre Zellen sind regehmäßig radiär angeordnet, in den tieferen Zonen der Schicht liegen sie senkrecht zur Außenfliiele des Gehirns. beim Übergang in die Wärehen weichen sie fäeherförmig anseinander. Die innere Begrenzung des Zellenlagers folgt den Bewegungen der Außenfläehe

1) XIII Congrès international de Ilédecine. Paris 1900. Compte rendu. Section d'Histologie et d'Embryologie p. 36. 
nicht, sie verläuft glatt oder in breiten, flachen Wellenlinien. Auch die Randschicht zieht sich glatt iiber den Wärzchen hinweg und sie besitzt demnach eine wechselnde Dicke, eine geringe über den Erhebungen, eine größere in den Zwischenränmen. Es hat sich weiterhin herausgestellt, daß ähnliche Gebilde bei Foetus des vierten Monats schon vor mir gesehen worden sind. In seinem großartig angelegten, an tatsächlichen Befunden so reichem Werk „Über das Menschenhirn" hat Gustav Retzius") u. a. Beobachtungen mitgeteilt, die sich auf die von mir gesehenen Dinge zu beziehen scheinen. ReTzıUs sagt nämlich im angeführten Werke: „Außerdem habe ich am viermonatlichen menschlichen Gehirn noch eine andere Art eigentiimlicher Wncherung, die ich schon früher beschrieben, wahrgenommen. An der Außenfläche von Gehirnen, welche mit Chromosmiumessigsäure behandelt waren, sah ich eine feingranulierte Beschaffenheit durch die glatte Oberfläche durchschimmern; hier und da hatte sich die äußerste dünne Oberflächenschicht abgelöst, und dann erschienen diese Stcllen gleichsam gekörnt oder mit dichten, rundlichen Erhabenheiten besetzt. Bei der mikroskopischen Untersuchung senkrechter durch die Oberfläche gelegter Schnitte crgab es sich, daß die granulierte Beschaffenheit von einer ungleichen Wucherung der Pyramidenzellenschicht herriihrt, welche in rundlichen Erhabenheiten emporgeschossen war; die Zwischenräume dieser "Granulationen“ waren von der äuBersten sogen. molekularen Schicht ausgefüllt, so daß die eigentliche Oberfläche des Gehirns, wenn diese Schicht nicht abgelöst war, glatt erschien.“ „Diese eigentïmlichen ,Granulationen“ der Pyramidenzellen sah ich auffallend oft in Gehirnen aus dem vierten Monat, an Gehirnen aus dem fünften aber selten. Ich bin in der Tat geneigt, sie eher als eine natïrliche, denn als eine abnorme Erscheinung zu betrachten; sie scheinen mir anf eine vorübergehende sehr energische Entwicklung der Pyramidenzellenschicht hinzudenten, die jedoch bald wieder durch die Ausbildung der angrenzenden Schichten ausgeglichen wird. Man muß sich aber auch die Möglichkeit denken, daß diese Granulation eine krankhafte Erscheinung sein kann, was in Anbetracht des so zahlreichen Vorkommens pathologisch entwickelter (u. a. syphilitischer) Aborte nicht ohne weiteres auszuschließen ist." In der Tafelerklärung wird von RETzıUs die Möglichkeit pathologischer Bildumg gleichfalls hervorgehoben.

RETziUs beschreibt und zeichnet ïberdies (l. c. S. 76 and Tafeln L und LI) am Gyrus hippocampi des erwachsenen Gehirns als eine konstante Bildung dicht gedrängte Wärzchen als "Verrucae Gyri hippocampi“. Dic Zeichnung und noch mehr die vergrößerte Photographie, die RETZIUs von dieser Bildung mitteilt, erinnern auffallend an das Bild der an der foetalen Hirnoberfläche zu beobachtenden Wärzchen, auch hier treten, außer den

1) G. Retzius, Das Menschenhirn. Stockholm 1595. S. 17 u. Taf. II Figg. 18, 20 11. 21 . 
einfachen, rundlichen Hügeln, etwas gestreckte und verhogene Formen auf. ReTzIUs selber scheint eine Beziehung zwischen den von ihm aufgefundenen Wärzchen des Gyrus hippocampi und den "Granulationen" der foetalen Gehirnoberfläche nicht anzunehmen, wenigstens äuBert er sich nicht dariuber, und während er in dem einen Fall ron "feinen Granulationen" spricht, so beschreibt er in dem andern Fall „dicht gedrängte Wärzchen“.

Retzius gibt lant obigem Zitat an, daß er die „feingranulierte Beschaffenheit der Rindenschicht durch die glatte Obcrfläche hat durchschimmern" sehen. Ich Labe anch meinerseits Präparate in Händen gehab), an denen ein Hindurchschimmern kleiner Wärzchen durch die unverletzte Oberfäche hindurelı wahrnehmbar war. Am deutlichsten fand ich dies Verhalten an Gehirnen ansgeprägt, die zuerst in Formalin aufgehoben und dann auf einige Tage in MÜLLER sche Lösung gebracht worden waren. RETZıU's spricht sich ïber den normalen oder pathologischen Charakter der ron ihm bearbeiteten Foetus selı zuriuckhaltend ans und weist insbesondere auf die Möglichkeit luetischer Veränderungen hin. Meinerseits habe ich keinen Grund, so zurïckhaltend zu sein, demn mehrere meiner Präparate, an denen die Hemisphärenwärzchen trefflich zu sehen waren, stammen aus Leichen von gesunden Selbstmörderinnen, und die betreffenden Foetus haben sich durch ihr wohlgenährtes Aussehen als normal beurkundet. Eine andere Frage ist die, ob es sich auch hierbei um postmortale Quellungserscheinungen handelt, eine Annahme, die Hochstetter ${ }^{1}$ ) zu vertreten scheint. Es würde dies wohl ohne weiteres anzunehmen sein, wenn die äußere Randschicht an den Niveanbewegungen der unterliegenden Rindenschicht beteiligt wäre. Dies ist aber nicht der Fall. Wie die Figuren 73 und 75 zeigen, so zieht sich die Randschicht völlig glatt und gleichmäßig iiber die Unebenheiten der Rindenschicht hinweg. Die Frage über die Bedentung der fraglichen Wärzchen bedarf daher noch eingehender weiterer Priifung.

\section{Die Blutgefäße des Vorderhirns.}

Schon vom Beginn des zweiten Monats ab erschcint der gesamte Körper des Embryo sehr gefäßreich; dichte Netze ron weiten Kapillaren häufen șich insbesondere überall an den Grenzflächen ron Mesenchrum nnd ron ectodermalen Anlagen an. In der nächstfolgenden Zeit nimmt die Dichtigkeit der Gefäßgeriiste noch zul, und speziell das Gehirn wird in allen seinen Teilen von fast ununterbrochenen Lagen von relatir weiten, blutuiberfiillten Kanälen umgeben. Von der Dichtigkeit des Systemes kann Fig. So, S. 120, eine Vorstellung geben, die Reproduktion eines Sagittalschnittes, der die Gefäße des Mittelhirns und teilweise noch die des Thalamus streift, und

1) Hochstetter, 1. c. S. 5. 
an dern anch die Gefăfomkleidung der GroBhirnhemisphäre und des Cerebellums im Durchschnitt rerfolghar ist. Der Schnitt stammt ron dem

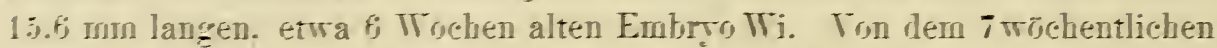
Embryer Lhs 17. 17 mm teile ich Fig. $81, \$ .121$, eine nach dem frischen Präparate anfęenonmene Flächenzeichntůg mit. Der Grundcharakter der Gefäfanordnung ist. wie man sielut. derselhe wie bei $W_{i}$, und er findet sich

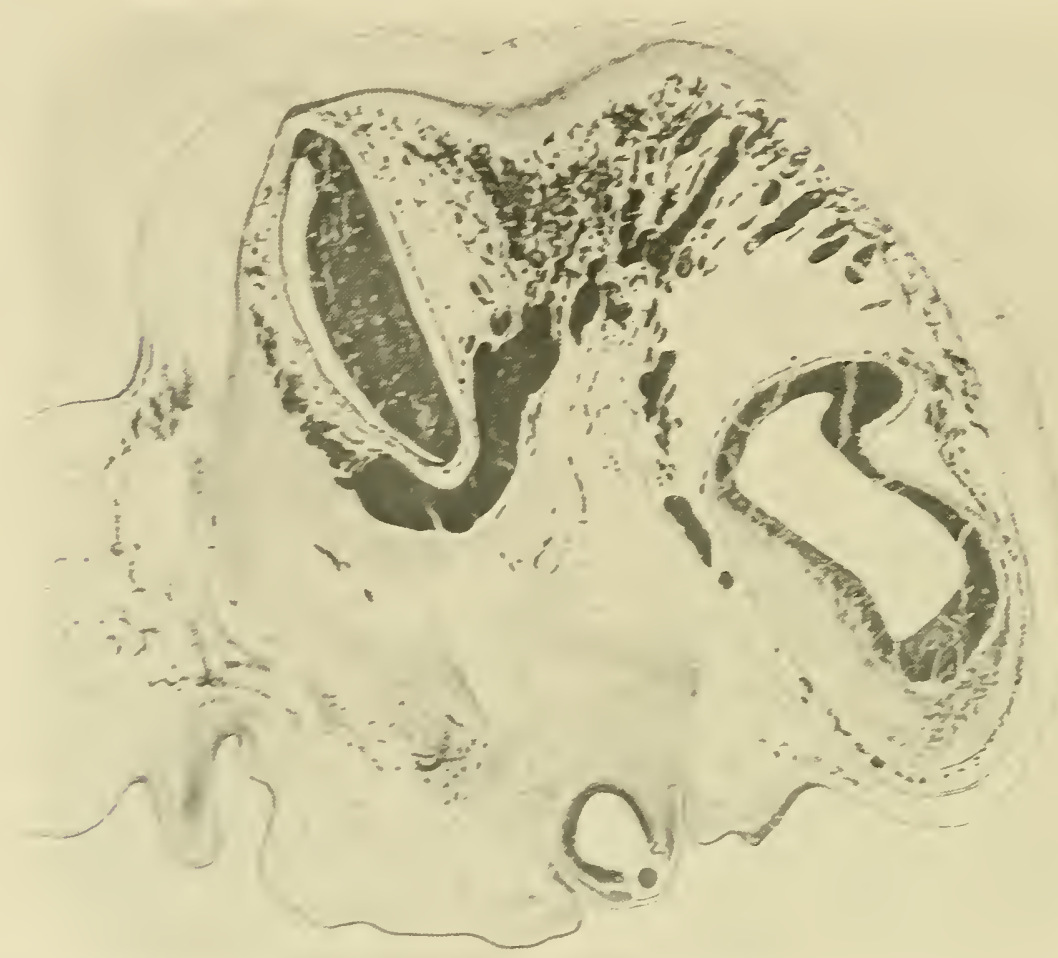

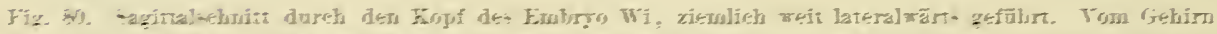

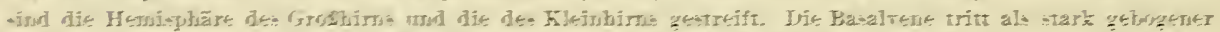


Zu -ejte 129.

bei allen zenüzend frisch zur Herbachtung gelangenden Embrronen des zweiten Yonats in ehen der Weise wieder. Starke, in kurzen Abständen aufeinander folgende sanumelnerven ungreifen die seitenflärhen des fiehims, und sie münden jeder:eits in einen starken zur Jugularrene hinführenden Starnu ein. den wir als basalrene bezeichnen können. In meinen

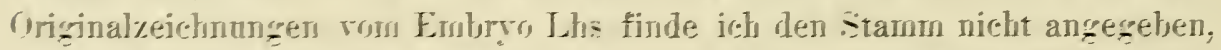
wrobl aber in anderen Zejchnuggen won zum Teil noch jüngeren Emabronen, und sehr märchtig tritt sie an den sacittalschnitten rom Enhlorn Wi zutage, wie sie denn auch in Figur $\oint_{0}$ eine strecke weit rerfolghtar ist. Ich habe 
daher kein Bedenken getragen, sie anch in Figur 81 einznzeichnen. Wie die Verfolgung an Sagittalschnitten ergibt, so mmgreift die Basalvene in einem starken Bogen die dorsale Wand der knorpeligen Gehörkapsel und erreicht nach Aufnahme starker, hinter dem Cerebellum herabsteigender Zufliisse, der Vorliufer des Sinus transversus, das Anfangsstiick der Vena jugularis. Der Schnitt Finm so streift noch das system des

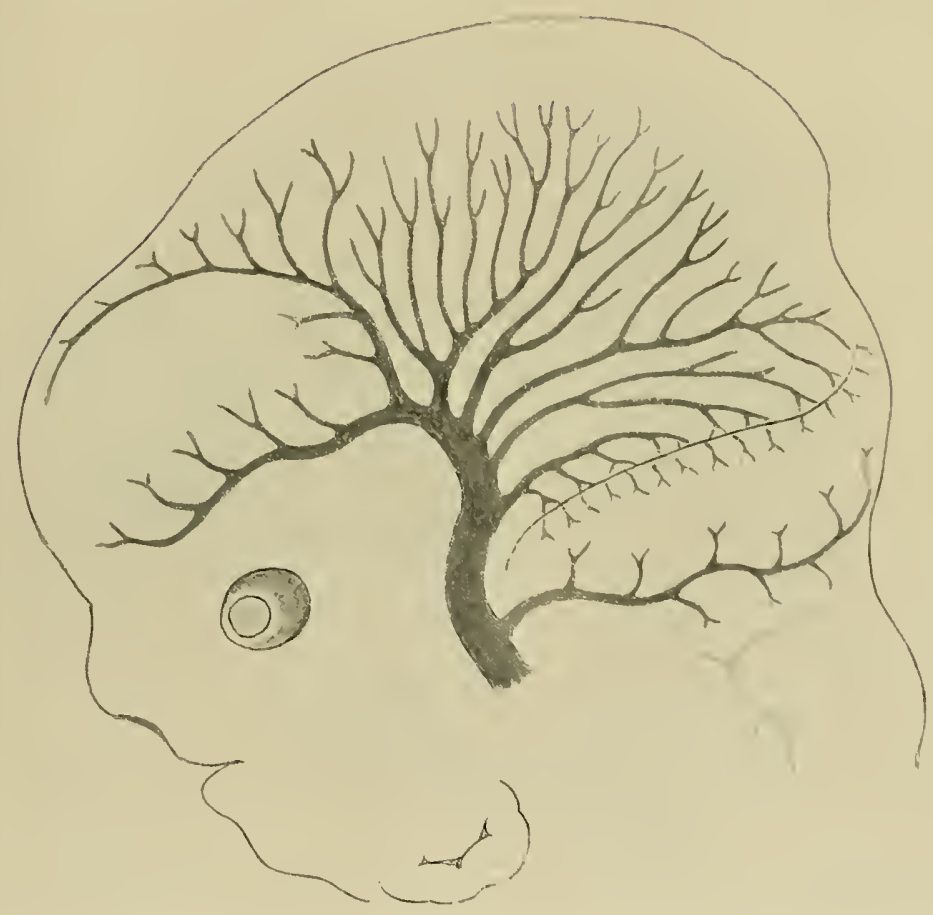

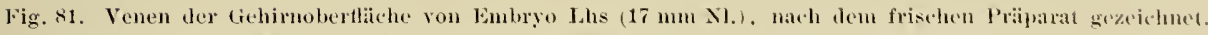
Zusammenlaufen der die verseliedenen Gehimabteilungen, bosonders abed das Zwischen- und Mittelhim nu-

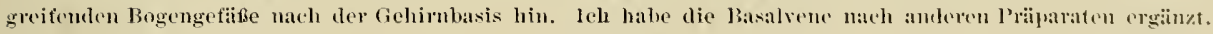
(Zi1 Scite 120.)

Sinus transversus, wogegen die Jugularvene in weiter medial gelegenen Sclinitte fällt.

Die oleren Ableitungsbahnen und inshesondere das Sisten des siuns sagittalis superior sind nur in ilıen vorderen Lnfängen vorhanden. Es ist dies anch verstimdlich, da ja die Hemisphä̈ren noch nicht eimmal den Thaalamus völlig äberdecken. Der Abflub des Bhutes alus diesen oboren Bezirken gesehieht gleichfalls nach der Basalvene hin durch Bogengefäie. die dem hinteren Henisphärenrand folgen. 
Mit zumehmender Entwicklung des Gehirns teilen sich in ausgeprägter Weise obere und untere Abflußbahnen des Großhirnblutes. Als Beispiel gebe ich die nach Photogrammen eines frischen Präparates angefertigte Zeichnung der oberflächlichen Hirngefäße eines Foetus von $16 \mathrm{~cm}$ SSl. (Fig. 82). Die Verzweigungen der A. meningea media treten darin als feine, von der Fossa Sylvii ausstrahlende Fäden herror, wogegen die Venen ein reiches Astwerk bilden, dessen Stämmchen und Zweige mit winkligen Biegungen teils basalwärts, teils scheitelwärts verlaufen, wobei sowohl im

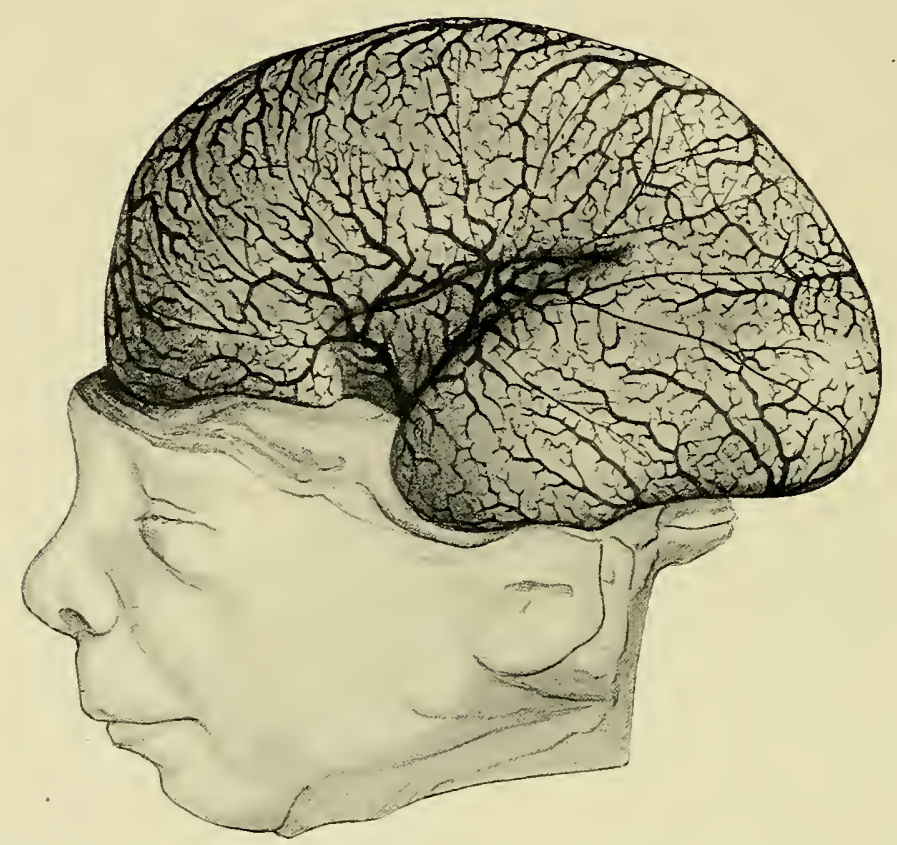

Fig. 82. Gefäßßnetz der Pia mater eines Foetus von $16 \mathrm{~mm}$ SSl. Die Verzweigungen der A. meningea media zeichnen sich als feine, nur wenig gebogene Stämmchen, die vom Gebiet der Fossa Sylvii aus nach den verschiedenen Richtungen hin ausstrahlen. Selhr viel reicher ist das Astwerk der Venenstämmchen, die in winkligem Verlauf, teils nach oben, teils nach der Basis hintreten. Die stärksten dieser Stämmchen treten zum Grund der Fossa Sylvii. Sowohl das obere als das untere Abflůgebiet zeigen zahlreiche Parallelstämmchen.

oberen, als im unteren Abflußgebiet die Stämmehen vorwiegend in parallel gestellten Bogenlinien angeordnet sind. Bei dieser weit vorgerückten Stufe von Figur 82 haben die Großhirnhemisphären bereits ihre endgültige Form und Ausdehnung angenommen. Thalamus, Mittelhirn und Cerebellum sind von ihnen iiberlagert und man darf wohl annehmen, daß nummehr auch die Abflußbahnen des Blutes durchweg ihre bleibende Stellung eingenommen haben.

Als primär e Hirnsich el können wir die Mesenchymplatte bezeichnen, die zwischen die beiden Hemisphären sich einschiebt. Sie ist an jeder ihrer beiden Berührungsflächen von einer selbständigen Gefäßschicht bekleidet, 
umfaßt also außer der Hirnsichel im Sinn der Anatomie, d. h. außer der Anlage der fibrösen Hirnsichel, die beiderseitigen Anlagen der Pia. Die Scheidung der fibrösen Hirnsichel von den Piaanlagen vollzieht sich ziemlich früh. Wie überall da, wo gefäßführendes Mesenchymgewebe die Oberfläche von Gehirn oder Rückenmark umkleidet, so bezeichnet auch hier eine glatte Grenzchicht, die M. limitans meningea, den freien Saum der Pia, und ihm legen sich die kapillaren Blutgefäße dicht an. Da wo die Mesenchymplatte beiderseits an die Gehirnoberfläche anstößt, wie dies für die primäre Hirnsichel und die nachher zn betrachtende Tela chorioidea der Fall ist, da erscheint sie beiderseits geglättet und von Gefäßen besetzt. Dazwischen bleibt ein gefäßarmer Zwischenraum, in dem sich weiterhin faseriges Bindegewebe entwickeln kann. Bei Embryo N (Nl. $10.9 \mathrm{~mm}$ ) ist eine faserige Falx duralis von den beiderseitigen Piabekleidungen bereits sicher unterscheidbar.

Tela chorioidea und Plexus chorioidei. Da wo die primäre Hirnsichel die Decke des Zwischenhirns erreicht, gabelt sie sich in zwei Schenkel, die in den Spaltraum zwischen der freien AuBenfläche des Thalamus und dem Hemisphärenlimbus vordringen. Diese ron dem Rande der Hirnsichel sich abzweigenden Gewebsplatten stellen zusammen die Anlage der Tela chorioidea dar (Figg. 41 und 43). Gleich anderen in Gehirnspalten eindringenden Bindegewebsplatten trägt anch die Tela chorioidea eine doppelte Gefäßschicht, eine mediale, dem Thalamus und eine laterale, der Hemisphäre zugekehrte. Von der lateralen Schicht zweigt sich die GefäBauskleidung der lateralen Chorioidealtasche ab. Die mediale Schicht gewinnt ihre stärkste Ausbildung iiber der Decke des dritten Ventrikels und von hier aus entwickehn sich in der Folge die Plexus chorioidei mediales. Hinter dem Stielgebiet tritt die Fortsetzung der Tela chorioidea bis zur Basis herab und schließt sich hier an die ubrige Piabekleidung der Gehirnoberfläche an, indem ihre beiden Gefäßlamellen in eine der Hemisphäre folgende und in eine dem Hypothalamus sich anlegende Schicht auseinanderweichen.

Die Fissura chorioidea der medialen Hemisphärenwand ist zur Zeit ihres ersten Auftretens sehr weit und sie gewährt ihrcr gesanten Länge nach einen geräumigen Zugang zur Tasche des Corpus chorioideum. Das GefäBsystem des Corpus chorioideum bildet noch einen Bestandteil des allgemeinen Gefäßnetzes der medialen Hemisphärenwand, und es hängt mit diesem durch zahlreiche Zweige zusammen. Entsprechend seiner Bildungsweise besteht es ans einer oberen und einer unteren Platte (Fig. 83, S. 124). Die weite Öffnung erhält sich aber nicht auf die Daner, sie rereng.t sich sehr erheblich. Durch dichte Aneinanderlagerung ihrer Wandungen wird die Abgangsstelle des C. chorioidenm zu einer kapillaren spalte reduziert. Dabei schwinden auch die reichlichen Gefäßrerbindungen des inneren und des änßeren Netzes, die Kommunication der Tela mit den Plexus wird nur 
noch durch wenige Stämmchen unterhalten, die durch die vorderen Abschnitte der Figur hindurchdringen. Anch der innere Gefäßgehalt des Corpus chorioideum nimmt im Verlauf des dritten Monats ab. Der voluminöse Körper besteht in der Folge vorwiegend ans lockerem Mesenchymgewebe mit verhältnismäßig engen Gefäßen. Anf früherer Stufe, an den

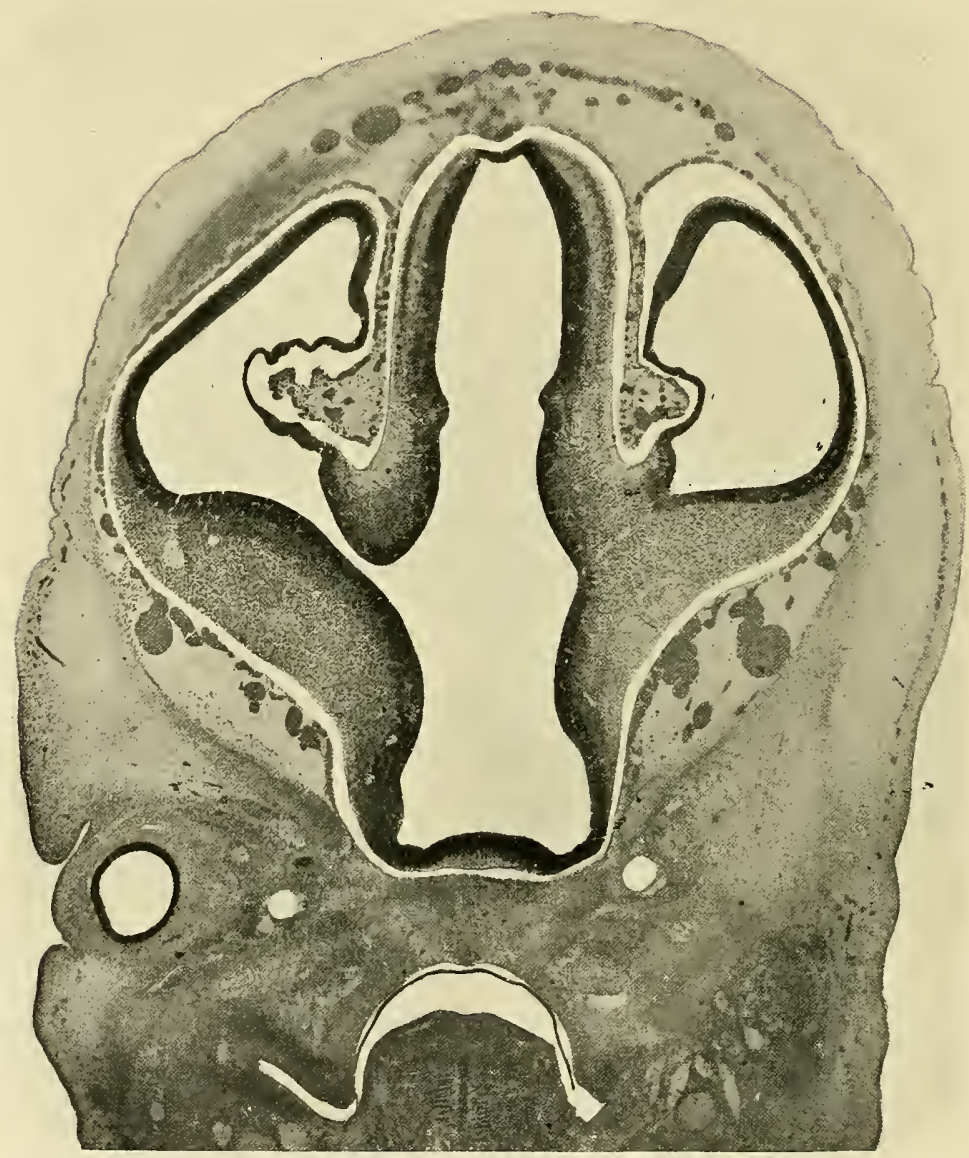

Fig. 83. Querschnitt durch das Vorderhiru von Embryo Se (N). 16 mm). Thalamus und Streifenhïgel sind links getremnt, reehts leginnt die Verbindung beider. An der medialen Hemisphärenwand äfnet sich mit sehr weitem Zugang die Fissura chorioidea, in die eine doppelte Gefäßschicht eintritt. (Zu Seite 123.)

Sagittalschnitten des oben besprochenen Embryo Wi, ist die zu dem Plexus eliorioidens fülrende Arterie als ein ans der Carotis interna emporsteigendes Stämmchen nachweisbar. Der Blutabfluß geschieht durch ein schräg nach riickwärts ansteigendes dichtes Geflecht, das in das dorsale GefäBnetz des Thalamus iibergelıt und als Vorläufer der Vena Galeni zul deuten ist. 
Als ein ljesonders bemerkenswertes, dem frontalen AJschnitt der Hirnsichel angehöriges Gefäß ist von dritten Nonat ab die rordere liogenvene hervorzuheben. Sie ist paarig angelegt und verläuft, wie Fig. 51, S. 79 zeigt, nahe vor der Fissura prima basalwärts, indem sie das Blut aus dem vordern Abschnitte der Henisphärenwand sammelt.

Die mediale. Hemisphärenwand ist im allgemeinen ebenso dicht mit Gefäßen bekleidet, wie die laterale. Von dieser Regel machen indessen zwei dem Limbus angehörige Streifen eine Ansmahme, die Spalte zwischen den Trapezplatten und die Rime zwischen der Lamina infrachorioidea und dem Thalamus. In die Spalte zwischen den Trapezplatten sieht man bei Foetus des dritten Monats eine sehr dünne Fortsetzung der Hirnsichel eindringen mit feinen Kapillaren (Figo. 41 u. 43, S. 62). Diese Platte läuft aber aus, bevor sie den Grund der Spalte erreicht hat, und es findet sich unmittelbar vor der Terschlußplatte des dritten Ventrikels ein Bezirk, der frei ist ron Bindegewebe und Gefäßen. Hier begegnen sich in frïher besprochencr Weise die Kontaktflächen der beiden Trapezplatten, zwischen denen es zu teilweiser Verwachsung kommt. Das zweite gefäßfreie, bez. sehr gefäßarme Feld liegt längs der Anheftung der medialen Hemisphürenwand an den Thalamus, im Bereiche der Lamina infrachorioidea. Das Feld umgreift den Hemisphärenstiel und reicht bis in den basalen Teil des Schläfenlappens.

\section{Commissura anterior und Balken.}

\section{Commissura anterior.}

Bis zur Mitte des dritten Monats wird der vordere Abschlub des Ventrikelsystems längs der Mittellinie ausschließlich von der Schlußplatte gebildet (Figg. 44 u. 45, S. 66 u. 67). Diese steigt vom Recessus opticus aus in einer geschwungenen Bogenlinie zum Angulus praethalanicus empor, und sie besitzt zu der Zeit eine Dicke ron $50-150 \mu$. Ihre Kerne liegen in 12-15 facher Schichtung. Der basale, als Lamina terminalis persistierende Alsschnitt der Schlußplatte ist nach rorn hin frei, und seine seitlichen Verlängerungen schließen den trichterförmig sich rerjüngenden Recessus opticns ab. Weiter oben geht die Schlußplatte beiderseits unter scharfer Lmbiegung: und gleichzeitiger starker Verdickung in die Trapezplatten der medialen Hemisphärenwand über. Von da ab liegt die Schlußplatte an Grund einer tiefen Spalte, deren Ränder sich stellenweise beinah bcrühren (Figg. 41 n. 42. S. 62 1r. 63). Der Durehmesser der Trapezplatten beträgt das Drei- bis Vierfache der ïbrigen Wand des Stimhirns.

Die Rindensehicht der Hemisphäremwand erstreckt sich his zur Fissura prima, und sie überschreitet diese als eine dünne, von einem blassen Rand- 
schleier eingefaßte Lage. Beim Übergang auf die Trapezplatte hört sie unter Auflockerung ihres Gefïges und ohne scharfe Grenze auf. Vom vorderen Rande der medianen Furche her tritt die gefäßreiche Hirusichel zwischen die beiden Hemisphären ein. Sie wird, wie dies oben erörtert wurde, vor Erreichung der Trapezzone dicker und entsendet quere Verlängerungen in die beiderseitigen Fissurae primae. Der in der Mittelebene zwischen die Trapezplatten eintretende Fortsatz verjüngt sich schon erheblich und endigt vor Erreichnng der SchlnBplatte. Mit ihren tiefen Abschnitten legen sich die beiderseitigen Trapezplatten dicht aneinander an, und die sich begegnenden Kontaktflächen sind nur durch eine verkümmerte Bindegewebsplatte geschieden. Hier kommt es weiterhin zur Verwachsung der beiderseitigen Gliageriiste, und durch die entstehende Gewebsbricke hindurch wachsen weiterhin die Fasern der Commissura a n t erior. ${ }^{1}$ )

Die Commissura anterior findet sich beiderseits angelegt, bevor ein Übertritt von Fasern erfolgt. Bei zwei unter sich völlig übereinstimmenden Schnittreihen von Foetus von $46 \mathrm{~mm}$ SSl. (Stg und Oe) finde ich kräftige, scharf abgesetzte Faserbündel, die unter dem Linsenkern durch, in gebogenem Verlanf medialwärts treten, damn aber vor Erreichnng der Mittellinie sich verjüngen und schließlich verlieren (Fig. 43, S. 65 links). ${ }^{2}$ ) Bei dem 5 cm langen Foetus Doed ist die Verbindung beider Seitenhälften voll ansgebildet, und das Verbindungsbündel der Kommissur liegt nun unmittelbar vor der Schlußplatte, d. h. extraventrikulär. Wir können also die zweite Hälfte des dritten Monats als die Zeit ansehen, in der die Bildung der vorderen Kommissur sich vollendet, nachdem deren seitliche Anfänge schon frïher angelegt waren. Um übrigens ans dem Streifenhïgelgebiete, d. h. ans der lateralen Hemisphärenwand in die mediale Wand ïberzutreten, bedurften die Kommissurenbündel einer ferneren Brücke. Diese Briicke ist durch Verwachsung des mittleren Streifenlïgelschenkels mit dem Rand der Trapezplatte hergestellt worden (Fig. 41 links, Fig. 42 beiderseits S. 62 u. 63). Die Kommissurenbïndel durchwachsen die Gewebsleiste, die sich so zwischen die vordere und die hintere Riechhirnhöhle eingeschoben hat, und sie liegen anfangs in deren oberem Rand.

1) Nach E. Zuckerkando wird die gefüßführende Hirnsichel bei der Ratte von einzelnen Zellenwülsten durchwachsen und damit zur Atrophie gebracht. Das, was oben Trapezplatte genamnt worden ist, bezeichnet Zuckerkandu als „Massa commissuralis" oder als primäres Septum, ELLiot Suith als Area praecommissuralis.

$\left.{ }^{2}\right)$ In einem soeben erschienenen Aufsatz „Über Balkenmangel im menschlichen Gehirn" beschreiben M. Ansdt und F. SkLARek einen Fall, in dem die vordere Kommissur ein dem oben beschriebenen sehr :̈hnliches Verhalten gezeigt hat Beiderseits existierte der Seitenabschnitt der vorderen Kommissur vom Schläfenlappen aus bis unter den Linsenkern. Hier verlor er sich und das Verbindungsstiick beider Seitenhälften war nicht zur Ansbildung gelangt (Archiv für Psychiatrie Bd. 37 Heft 3). 
Die beiderseitigen Trapezplatten zeigen nach dem Ventrikel zu eine kernreiche Innenplatte (Ependymplatte) mit radiär gestellten Zellenleibern und Kernen. An diese schließt sich ohne scharfe Grenze ein feinfasriges dichtes Gliageriist an, dessen Zellenleiber nach verschiedenen Richtungen sich durchkreuzen. Bei den Embryonen vou 2\%, Monat (Stg) finde ich außer den oben erwähnten Bündelı der vorderen Kommissur in dem Geriist keine Faserziige. Sein Maschenwerk erscheint noch frei von Einlagerungen, insbesondere vermisse ich zı der Zeit noch die später hier auftretenden Bündel der Fornixsäule.

\section{Die weitere Ausbildung von Kontaktflächen. Auftreten der Fornix- biindel und des Balkens.}

Die oben beschriebenen, die Bildung der vorderen Kommissur einleitenden Vorgänge sind Teilerscheinumgen eines ïber den gesanten Limbus sich erstreckenden Prozesses, als dessen Endergebnis die Bildung des Fornix nnd des Balkens sich darstellen. Balken- und Fornixbildmg sind vielfach ron vortrefflichen Forschern bearbeitet worden, allerdings nicht mit iibereinstimmenden Ergebnissen, und ich werde nachher auf einige der wichtigen literarischen Daten einzugehen lıaben. Vorerst scheint es mir zweckmäßig, mit meiner eigenen Beschreibung fortzufahren.

Im Bogengebiet des Limbus bildet die Hemisphärenwand, wie dies in einen frïheren Abschnitt gezeigt wurde, eine rentrikelwäirts einspringende, anfangs flache, im Verlaufe des vierten Monats schärfer sich ansprägende Falte, die Bogenfalte (Plica areuata). (Fig. 52, S. 81.) Ihr entspricht an der medialen Oberfläche die Schnidt s che B oge n furche. Unterhalb dieser Furche und vor dem Übergang in die Lamina chorioidea bildet die S-förmig gebogene Wand eine zweite, medialwärts konvexe Falte, die Randfalte oder Randlippe. Schon bei Foetus des dritten Monats zeigt sich der die Bogenfalte bildende Teil der Hemisphärenwand gegenüber dem außerhalb des Limbus liegenden verdickt. Unter dem Scheitel der Randlippe erfolgt damn rasch die Verjüngung zur Ependymplatte. Die auslaufende Rindenschicht verhält sich etwas anders als im Trapezfeld. Sie bildet anch hier eine schmale, von einer blassen Randschicht iiber\%ogene Platte, zieht sich aber beim Übergang zur Bogenfalte etwas von der Oberfläche zurück und endigt in dem untern Faltenschenkel aufgelockert und mit einer leichten Anschwellung.

Danit stellen sich num aber die Teile so, daß die an das Höhlengran stoßende innere Wandschieht bis in den Scheitel der Randlippe rordringt. Es ist dies die Schicht, in der sich in der Folge die ans den Pyramidenzellen stammenden Markfasern ansammeln, der Limbus medullaris obiger Aufzälung. Es wird somit am Scheitel der Randlippe eiu Bezirk geschaffen, längs dessen Markfasern Gelegenheit 
finden, die freie Oberfläche der Hemisphärenwand zu erreichen. Von dem Bogenstiick des Limbus kommt der vordere Teil iiber den Thalamus, der lintere Teil neben dessen Seitenfläche zu liegen. Über dem Thalamus sind sich die beiden Randlippen zugekehrt, durch einen mehr oder minder breiten Abstand roneinander getrennt.

Die medialwärts gekehrten Randlippen entwickeln sich mit zunehmender Anhäufnng von Markfasern zu kräftigen Platten. Anfangs durch eine Gefäßschicht voneinander geschieden, riicken sie sich in der Folge näher, und es bilden sich an ihnen ebene Kontaktflächen. SchlieBlich kommt es, unter Reduktion und Verkümmerung der dazwischen liegenden Gefäße, zu einer Versehmelzung der beiderseitigen Lippen und danit zur Herstellung einer Brücke, die den Übertritt von Balkenfasern ermöglicht. Auch die rindenführenden Streifen der beiden Randlippen nehmen an der Bildnng: der Qnerbrïcke teil und man findet den frisch entstandenen Balken an seiner oberen Fläche mit einer dümnen Rindenlage bekleidet. Auf Stufe Pl (12 cm SSI.) endigt diese Rindenlage (der Limbus corticalis) mit aufwärts gebogenem Rande, ohne die Mittelebcne zu erreichen. Die nutere, ansschließlich dem Limbus medullaris angehörige Lamelle der Randlippe liefert das Lager zur Fornixbildung und ans den dureh das Zwischenhirn getremnten Strecken des Limbns entwickelt sich der Hippocampus, dessen Bestandteile durchweg denen der Balken und Fornixanlage entsprechen. In iilocrsichtlicher Znsammenstellung bekommen wir folgende Verwendung der einzelnen Strecken des Limbns:

\begin{tabular}{|c|c|c|c|}
\hline & Oberes B: & kengebiet. & Hippocampus. \\
\hline & $\begin{array}{c}\text { Obere Lippe } \\
\text { der Bogenfurche }\end{array}$ & Gyrus cinguli & Gyrus hippocampi \\
\hline $\begin{array}{l}\text { Limbus } \\
\text { corticalis }\end{array}$ & Bogenfurche & $\begin{array}{l}\text { Fissura corpori } \\
\text { callosi }\end{array}$ & Fissura hippocampi \\
\hline $\begin{array}{c}\text { im weitereu } \\
\text { Sinne (s. o. S. 81) }\end{array}$ & $\begin{array}{l}\text { Rindenschicht } \\
\text { der Randlippe }\end{array}$ & $\begin{array}{l}\text { Rindenbelag des } \\
\text { Balkens (Indusium } \\
\text { grisenm und Striae } \\
\text { Lancisi) }\end{array}$ & Gyrus dentatus \\
\hline $\begin{array}{l}\text { Limbus } \\
\text { medullaris }\end{array}$ & $\begin{array}{c}\text { Markteil } \\
\text { der Randlippe }\end{array}$ & Balken und Fornix & Fimbria \\
\hline Taenia & & Taenia fornicis & \\
\hline $\begin{array}{l}\text { Lamina } \\
\text { chorioidea }\end{array}$ & & Corpus chorioidem & \\
\hline $\begin{array}{c}\text { Lamina } \\
\text { infrachorioidea }\end{array}$ & & Lamina affixa & \\
\hline
\end{tabular}

Ieh teile zur Erläutermng obiger Angaben zwei Schemata der Balkenbildung und der Fornixbildnng mit (Figg. 84 u. 85, S. 130), anßerdem aber den Durelıschnitt durch das Gehirn eines Embryos ron $8.3 \mathrm{~cm}$ SSI. (Fig. 86, 
S. 130). Das Schnittbild ist die Panse nach einem Photogramm des Schnittes, dabei sind der leichten Übersicht halber die nebensächlichen Verlıältnisse weggelassen, anch ist die helle Randschicht nicht nit eingezeichnet, für deren Verlialten die beiden Schemata zn vergreichen sind.

Im Schema der Balkenbildung (Fig. 84) stellt das Bild die noch unverbundenen, aber in der Mittelebene dicht aneinander gereïckten Randlippen dar. Durch deren Verschmelzung entsteht der Balken. Der über der Balkenanlage frei anslanfende Sam der Rindenschicht (dic Ammonsformation einiger Autoren) liefert die Stria Lancisi und den übrigen granen Überzng des Balkens. Die scharf eingeknickte Bogenfurche persistiert als Fissura corporis callosi. In sie treten diinne Fortsetzungen der gefäBführenden Hirnsichel. Unter der Balkenanlage liegen die Taenia, die an der Bildung: des Fornix teilnimmt und die Lamina chorioidea.

Das Schema der Hippocampusbildung (Fig. 85) zeigt die im Schema der Balkenbildnug dargestellten Zonen in umgekehrter Reihenfolge liegrend. Der Limbus corticalis liegt unten, die Lamina chorioidea obcn. Die Rindenschicht läuft als Fascia dentata frei aus. Darïber liegt die weiße Platte des Alvens mit der Taenia. In die Fissura hippocampi oder untere Bogenfurche tritt die dünne Randschicht (Randschleier) ein und aus ihr wird das Stratum reticulare Arnoldi.

Der Schnitt (Fig. 86) ist mit Hilfe der beiden Schemata wohl leicht zu verstehen, da an ihm sowohl die Balkenanlage als die Anlage des Hippocanıurs in einer den Schemata entsprechenden Weise sich darstellen.

Zwischen dem freien Sam der Rinde und dem der Markmasse verläuft am Hippocampns eine Rinne, die, wic dies unten mitgeteilte Schnittplotogramme zeigen (Fig. 92 S. 13! und Fig. 9S S. 144), selır stark klaffen kann. Retzius, der auf die Trennung II is, Die Entwicklung d. mensehl. Gehirns.

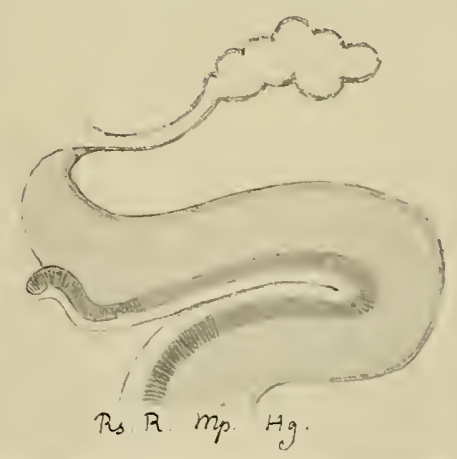

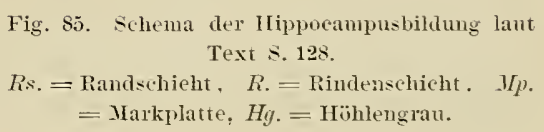
9 
dieser Rimne von der Fissura hippocampi hinweist, nemut sie den Sulcus fimbrio-dentatus. ${ }^{1}$ ) Die obere Fortsetzung der Rinne entspricht der an foetalen Gehirn vorhandenen medianen Unterbrechung des Indusium griseum.

\section{Balkenanlage bei Foetus Ce von $8.3 \mathrm{~cm}$ SSI.}

Obige etwas summarische Angaben bedürfen einer genaueren Begründung, und ich knüpfe an die an einem Foetus von $8.3 \mathrm{~mm}$ SSI. gemachten Be-

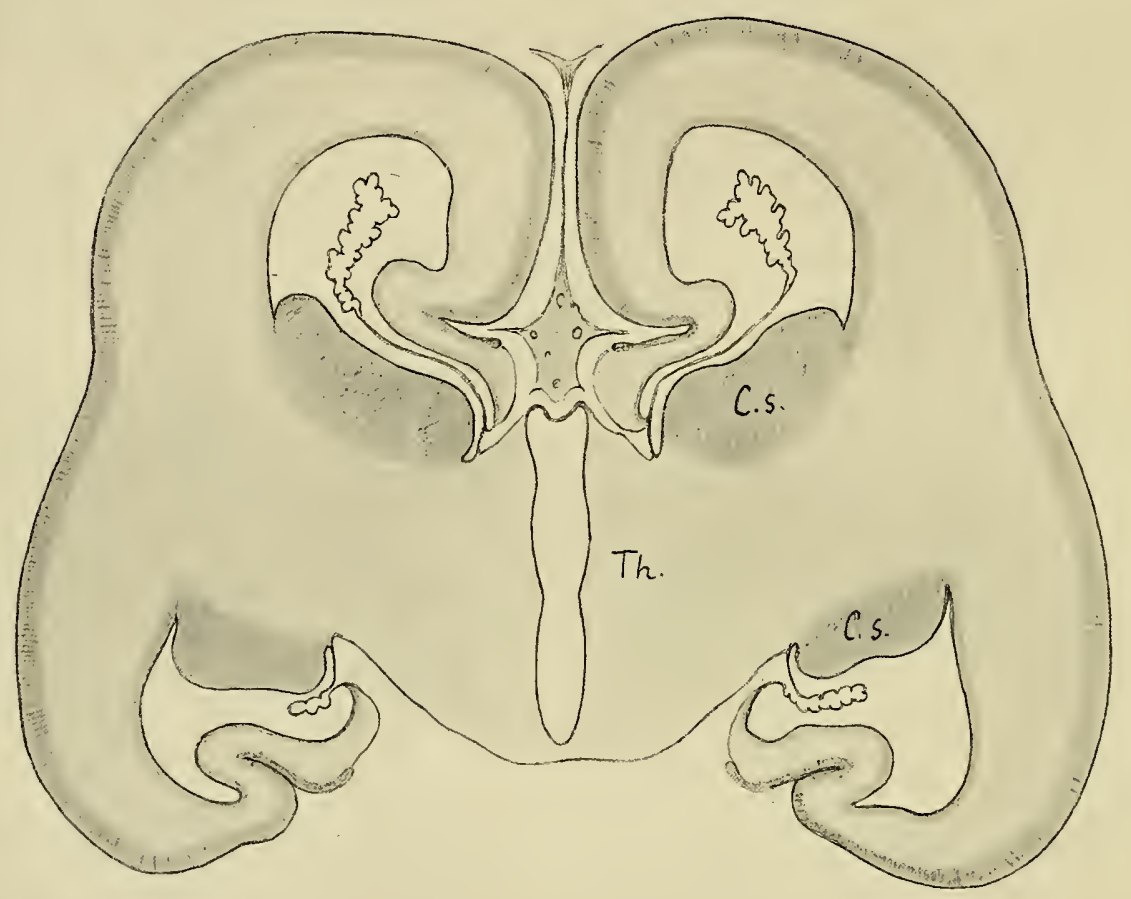

Fig. 86. Durchschnitt durch das Gehion eines Foetus von $8.3 \mathrm{~cm}$ SSl. Nach dem Photogramm des Sehnittes gepaust, unter Weglassung aller für das Verständnis von Balken- und Hippocampusbildung unwesentlichen Verhältnisse. Cs. $=$ Corpus striatum, Th. $=$ Thalamus. $(\mathrm{Zu}$ Seite 128.)

obachtungen an. Das allerdings nicht ganz tadellos konservierte Gehirn war in Scheiben von $25 \mu$ zerlegt und von diesen eine größere Anzahl bei sechsfacher Vergrößernng photographiert worden. Nach den Photogrammen

1) G. Retzius schildert in seinem fundamentalen Werk ïber das Menschenhiru S. 82 speziell auch für das Limbusgebiet ein reiches anatomisches Detail, dessen entwicklungsgeschichtliche Ableitung einer Spezialuntersuchung vorbehalten bleiben muf. 
und teilweise anf Grund direkter Messungen an den Schnitten sind die in den Figuren dargestellten Konstruktionen entworfen. Dabei habe ich alles weggelassen, wobei postmortale Faltungen im Spiel sein konnten.

Die Konstruktion Figur 87 zeigt die von ihrer Verbindung mit dem Thalamus losgelöst gedaehte IJemisphäre. Es sind daran der Limbus und das Ausdehnungsgebiet seiner Blutgefäße dargestellt, die außerhall, des Limbus liegende Fläehe ist nieht ausgeführt. Im vorderen Ilemisphärengebiet tritt bei diesem Konstruktionsbild die schon von juingeren

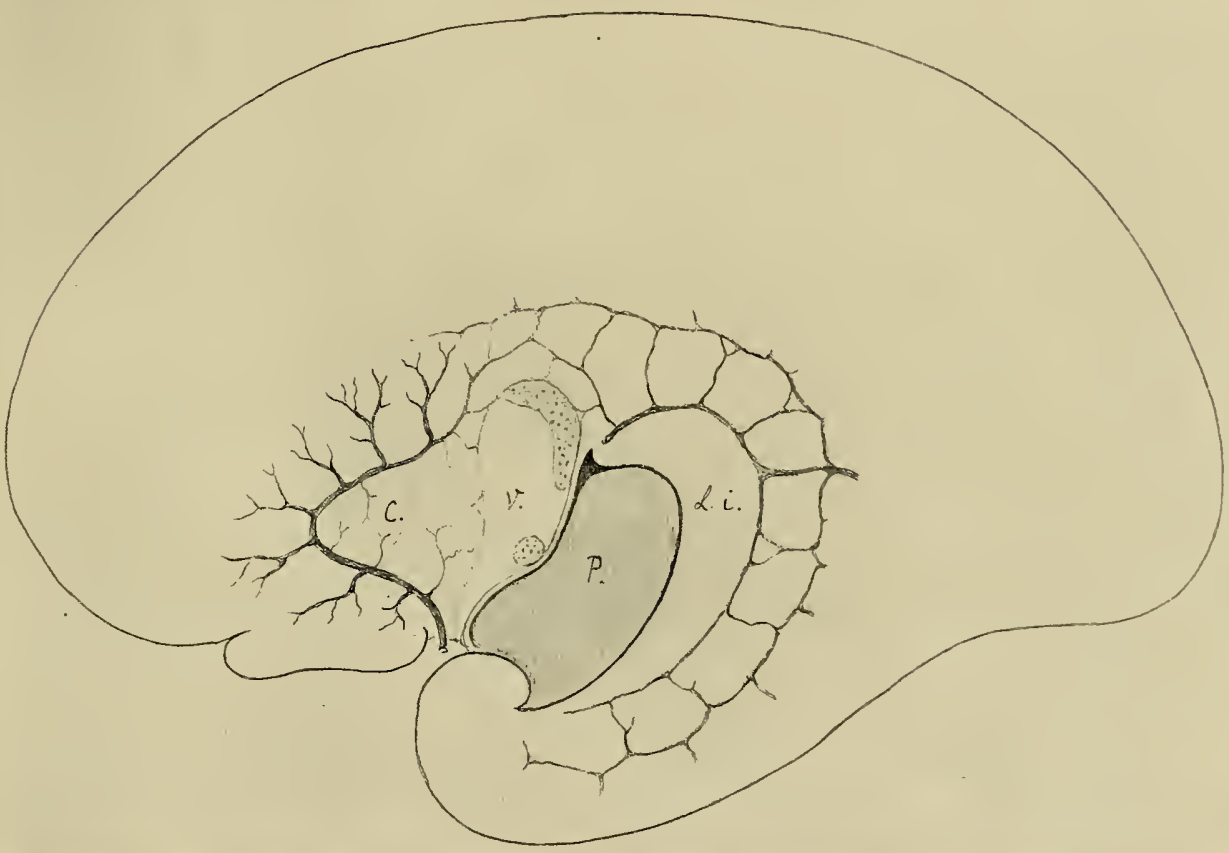

Fig. 87. Konstruktionsbild der mediaien Hemisphärenwand ron Foetus Ce ron 8.3 cm sSl. mit eingezeichneten Blutgefäßen des Limbus. Die Einzelheiten der Verzweigung sind frei dargestellt, dagegen entsprechen die vordere Bogenvene und die Gefäßketten längs der Bogenfurche und längs der Fissura ehorioidea dem Vexhalten der Schnitte. $C .=$ Kontaktfläche, $\mathrm{J}^{*}=$ Verwachsungsfläche, in deren oberem Abschnitt dic Balkenanlage punktiert angegeben ist. $P$. = Schnittfliche des Hemisphärenstiels, $L . i .=$ Lamina infrachorioilea.

Stufen her bekannte vordere Bogenvene anffällig hervor. Die beiden Schenkel ihres Bogens bilden einen naeh rorn spitzen Winkel, und während die Vene aus dem an der Peripherie des Bogens liegenden Gebiet kräftige Wurelstämmehen aufnimmt, erbält sie aus dem ron ihr umschlossenen Feld nur feine Zuflüsse. Im ganzen lïßt nummehr das ror der Sehlußplatte des dritten Ventrikels liegende Feld drei Abteilungen unterscheiden, die wir als freie, als Kontaktfläehe und als Verwaehsungsgebiet bezeiehnen kömnen. 
Letztere beiden Abteilungen sind ans der frïheren Trapezzone abzuleiten. In der davor gelegenen freien Fläche berühren sich die beiderseitigen Hemisphärenwände nicht ummittelbar, und sie sind durch die Hirnsichel mit ihrer beiderseitigen gefäßreichen Piabekleidung voneinander geschieden.

Im Kontaktbezirk legen sich die Wandungen der Hemisphären flach aneinander an, die Sichel reduziert sich anf eine sehr dünne Platte mit feinen kapillaren Blutgefäßen. Zwischen ihr und der Verschlußplatte liegt ein Feld, innerhalb dessen die beiden Trapezplatten zur Verwachsung gelangt sind. Dies Verwachsungsfeld beginnt unten schmal, verbreitert sich nach oben hin und endigt abgerundet. Seine Gesamtform ist somit eine gekriimmt birnförmige. In seinem an die Schlußplatte anstoßenden Rand liegt die oben besprochene vordere Kommissur. In Figur 87 ist das Verwachsungsfeld weiß ansgespart. Hinter dem oberen Ende des Feldes liegt der Anfang der Fissura chorioidea, deren Fortsetzung nunmehr den Thalamus im Bogen umgreift und bis in die Nähe des Unens verfolgbar ist. Parallel mit der Fissura chorioidea verläuft die Fissura hippocampi, die untere Fortsetzung der Bogenfurche. Diese Furchen enthalten starke, untereinander in Verbindung stehende Gefäßzüge.

Das Grundgewebe des Verwachsungsbezirkes ist ein kernreiches, engmaschiges Gliageriist, das von feinen Kapillarlücken durchsetzt wird. Stellenweise erscheint dies Gerïst noch von eingelagerten Fasern frei, im iibrigen wird es, abgesehen von der vordern Kommissur, von Faserzügen der Fornixsäulen und von Balkenfasern durchzogen. In Figur 86 habe ich die ans den Schnitten sich ergebenden Faserverteilung eingezeichnet. Vor dem Verwachsungsfeld steigt der mediale Riechstreifen eine Strecke weit in die Höhe und verliert sich damn allmählich in der Hemisphärenwand.

Das der Fornixsäule angehörige Bündel besteht aus groben Faserzï̈gen, die schräg von oben nach abwärts verfolgbar, hinter der vordern Kommissur vorbei in die Nasse des Sehhïgels eintreten und sich hier, in Bïschel zerteilt, verlieren. Das obere Ende des Fornixbuindels geht vor den gekreuzten Balkenfasern in die Höhe und läßt sich bis zur Randlippe verfolgen. Ein Teil der Fornixbïndel kreuzt sich unter spitzem Winkel mit denen der anderen Seite. Das Verhalten des gesamten Faserzuges und vor allem sein Verhalten zur Balkenanlage zeigt, daß er zum System des Fornix longus gehört, dessen Fasern, den vorhandenen Angaben zufolge, nach abwärts in den Fornixsäulen sich sammeln, während sie nach aufwärts den Balken durchsetzen und großentcils im Gyrus fornicatus sich verlieren. ${ }^{1}$ ) Dies primäre Formixbündel entsteht später als die vordere

1) Man vergl. KöLLıken, Gewebelehre. 1896 6. Anfl. Bd. II S. 779ff. Nach den auf Degenerationsversuchen basierenden Angaben von BECHTEREw (Die Leitungsbahnen im Gehirn und Rïckenmark, dentsch von Weinberg 2. Aufl. 1899 S. $538 \mathrm{ff.}$ ) soll die 
Kommissur. Letztere ist sehon bei Foetus Doed. vorhanden, von Fornixbündel ist aber noeh keine Spur siehtlbar.

Die als Balkenfasern zu deutenden gekreuzteu Fasern nehmen den hinteren, oberen Absehnitt des Terwachsungsfeldes ein, sie sind viel feiner als die Fornixfasern und besehreiben flache Bogen. Der Durchschnitt des zur Zeit vorlıandenen Balkengebietes bildet einen nach vorn etwas konkaven Bogen. Naeh Befunden an median halbierten Gelimen liaben eine Reilıe

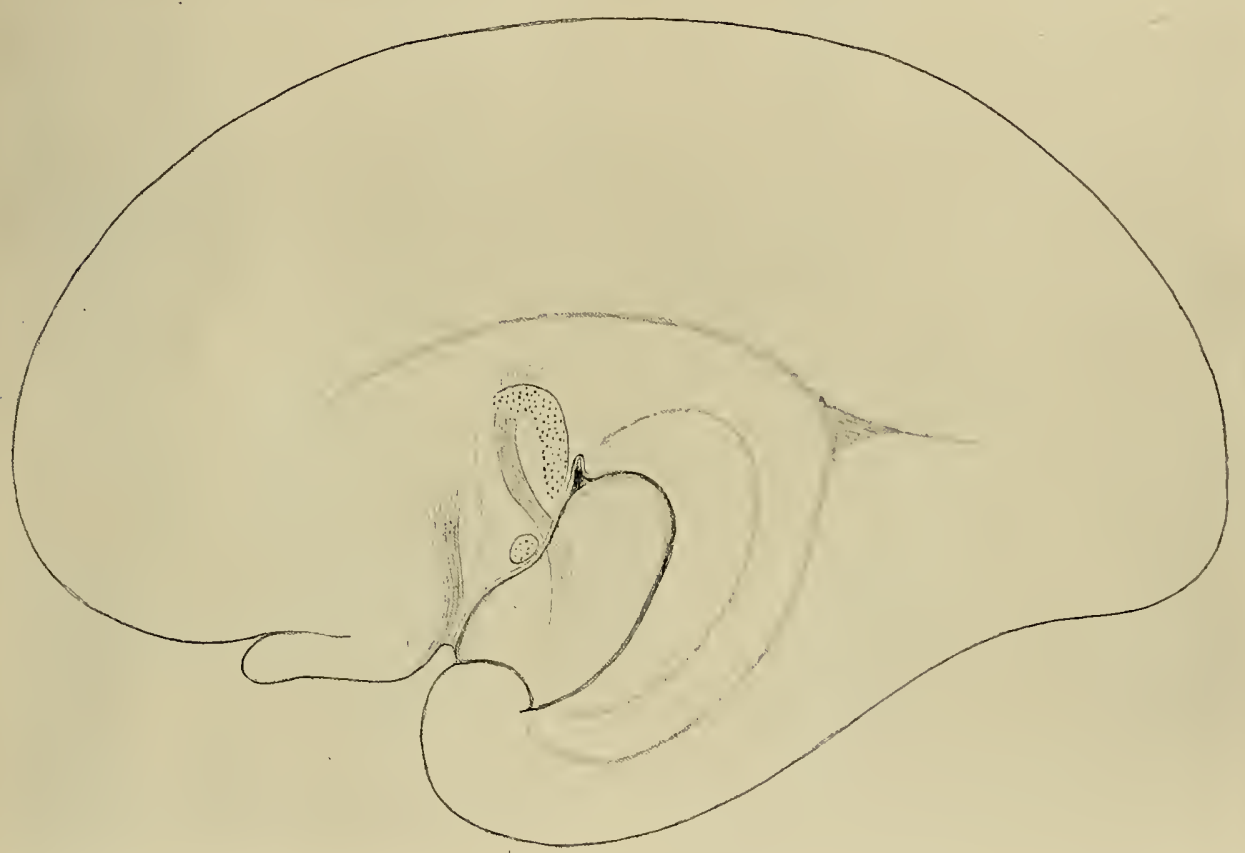

Fig. 88. Dieselbe Hemisphärenwand mit eingezeichneter Anlage des Balkens, der Fornixsäule und des medialen Riechstreifens. Das birnförmige Verwachsungsfeld ist hell ausgespart, die nach vorn konkas gekrïmmte Balkenanlage und die Commissura anterior sind punktiert, die Fornixsäıle und die Stria olfactoria sind gestreift dargestellt. (Zu seite 132.)

von Beobachtem (Retzius, Marchand, Goldsteis) die erste Balkenaulage als eine naeh rorn konkave Platte beschrieben. In der Regel ist diese Platte als die Aulage des Gesamtbalkens und der Ort ihres ersten Auf-

Faserbahn im Fornix longus eine absteigende sein und von der Hirnrinde des sehlïfenlappens znm Septum pellucidum und zum basalen Optieusganglion hinführen. Die von mir beschriebenen frühfoetalen Faserzüge der Fornixsäulen scheinen, soweit ich verfolgen kamn, ihren Ursprung im basalen Teil des Zwischenhirns zu nehmen. Es ist indessen möglich, daß späterhin andere, umgekehrt verlaufende Faserziige ihnen sich beigesellen. 


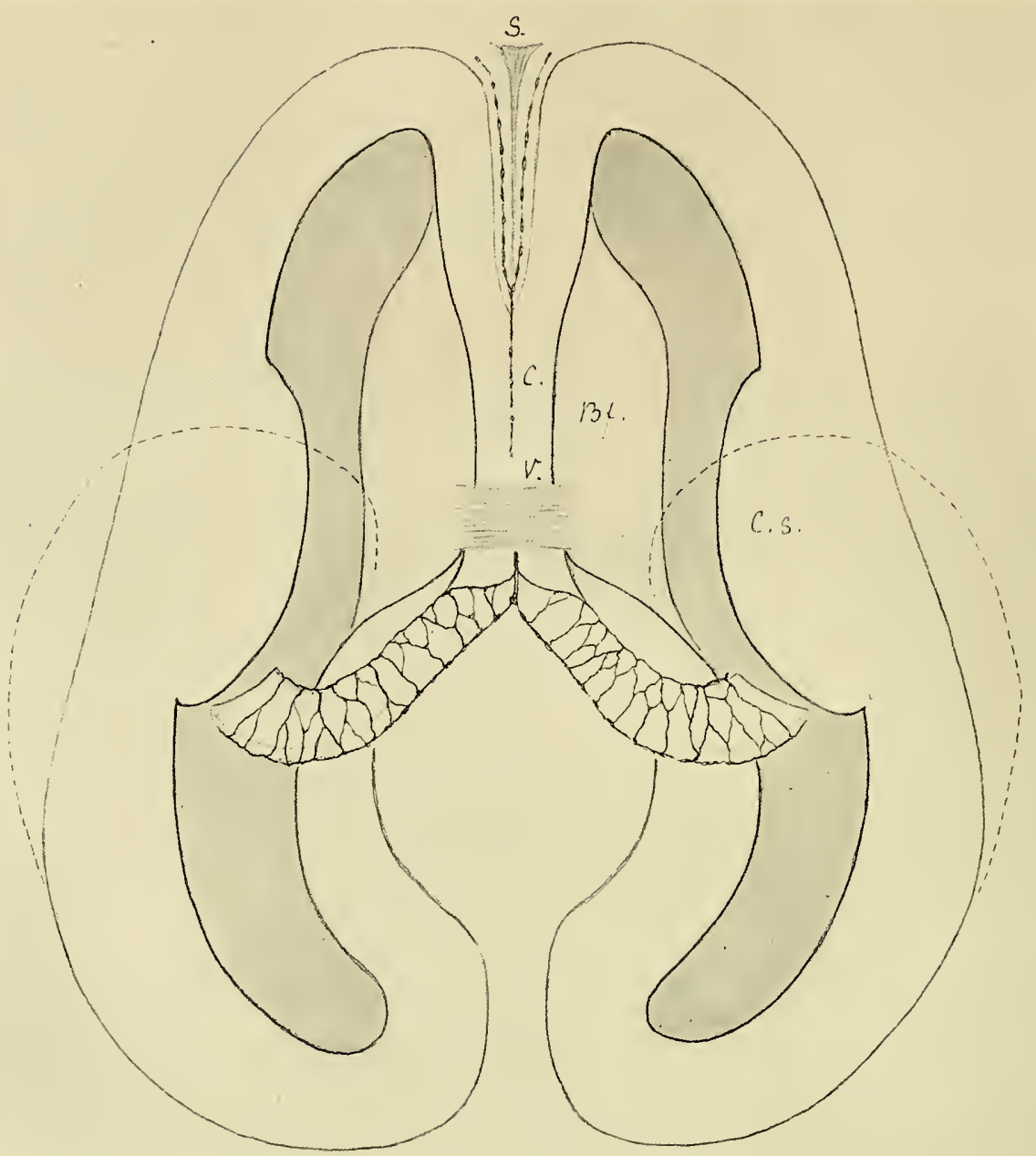

Fig. 89. Flächenkonstruktion der Balkenanlage des Foetus von $8.3 \mathrm{~cm}$ SSl. Die Zeichnung ist so entworfen. als ob man von unten her in die eröffneten Ventrikelhöhlen hineinblickte. Das Corpus striatum ( $C . s$.) ist nur in seinem obersten Teil gestreift, da seine vollständige Einzeichnmng zaviel verdeckt hätte. Dagegen ist der divergierende Abschnitt der Randlippen mit seinem Gefaßßbelag eine Streeke weit eingezeichnet. In dem vorderen Absehnitt der Figur sind die Hemisphärenwandungen unterhalb der Bogenfalten durchschnitten gedacht, man sieht daher eine Strecke weit auf die mntere Fläche der Falten (Bf.). Die mediaten Wandungen der beiden Hemisphären sind vorn durch die Hirnsichel (S.) und die sie bekleidenden zwei Piaplatten geschieden. Hieranf folgt ein längeres Kontaktgebiet $(C$.$) mit diimem, imneliegenden Gefäßfortsatz und am tiefsten liegend das$ Verwachsungsfeld (T.), in dessen hinterem Abschnitt die Balkenfasern liegen. Hinter der Balkenanlage findet sich ein kurzer Einschnitt mit schmalem Gefißfortsatz, und dann weichen die beiden Randlippen stark divergierend auseinander. Die queren Balkenfasern reichen eine kurze Strecke weit in die Wand der Bogenfalte hinein, dann biegen sie um und wenden sich, was an der Figur nicht darstellbar war, scheitelwärts.

tretens als der des Balkenkniees gedeutet worden. ${ }^{1}$ ) Die Frage ist nur durch eingehendes Studium dieser und der späteren Entwicklungsstufen zu

1) Die Angabe, daß das Knie der zuerst gebildete Teil des Balkens sei, findet sich schon bei Tiedemann (Anatomie nnd Bildungsgeschichte des Gehirns 1816 S. 155 ff.), 
entscheiden. Um auf der vorliegenden frühen Stufe etwas klarere Anschaumngen zu gewinuen, habe ich in Figur 89 die Balkenanlage im Flächenbild konstruiert, dessen Einzelheiten in der beigesetzten Erklärung erläutert sind.

Die Übersicht des Gesamtbildes zeigt die Balkenfasern nur wenig vor einer Ebene liegend, die das Gehirn in eine vordere und eine lintere Hälfte zerlegt. Seitwärts verlängert wïrden die Faseru mitten durch den Streifenhügel hindurchgehen. Das sind Beziehungen, die für mittlere Abschnitte des Balkenkörpers passen, nicht aber für das Balkenknie. Ebenso ergibt sich aus dem Verhalten der ersten Balkenanlage zu den Fornixsäulen, daß jene nicht am Orte des späteren Balkenknies gelegen ist. Das zuerst gebildete Stïck Balken liegt noch hinter den Fornixsäulen, während doch das Balkenknie 1 m die ganze Länge des Septum pellucidum dem letzteren voransteht. Eine obere Verlängerung der Fornixsäulen wiirde am ausgebildeten Gehirn die Mitte des Balkenkörpers treffen. Die ersten a uftretenden Balkenfasern gehören, das läßt sich jetzt schon mit Bestimmtheit aussprechen, dem Mittelgebiet des Balkenkörpers an.

Ein noch genaueres Urteil geben numerische Bestimmungen. Setze ich die Länge der Hemisphäre $=100$ und bestimme die proportionale Stellumg vou Balken und Conmissura anterior, so finde ich lant drei Messungen, ron denen eine am medianen Gehirusclmitt eines Erwachsenen, die zweite an dem nachher zu besprechenden Foetus PI (SSI. $12 \mathrm{~cm}$ ) und die dritte am Foetus Ce von $8.3 \mathrm{~cm}$ SSl. vorgenommen sind, folgende Werte:

\begin{tabular}{|c|c|c|c|c|}
\hline & & $\begin{array}{c}\text { I. } \\
\text { Erwach- } \\
\text { sener }\end{array}$ & $\begin{array}{c}\text { II. } \\
\text { Foetus Pl } \\
12 \mathrm{~cm}\end{array}$ & $\begin{array}{l}\text { III. } \\
\text { Foetus Ce } \\
8.3 \mathrm{~cm}\end{array}$ \\
\hline Gesamtlänge der Hemisphäre . & . . . & 100 & 100 & 100 \\
\hline Länge vor dem Balken . & . . & 20.5 & 25.6 & 42 \\
\hline Balkenlänge . . . . . . & . . & 39.2 & 30.5 & Ј \\
\hline Länge hinter dem Balken & . & 40.0 & 43.6 & 53 \\
\hline Ort der vorderen Kommissur & . & $3 \pi .42$ & $3 \varsigma$ & $44 . \overline{7}$ \\
\hline
\end{tabular}

Anschaulich tritt das Verhältnis der drei Messungen in der folgenden graphischen Darstellung hervor, bei der der Ort des Balkens durch einen schraffierten Strich, der der rorderen Kommissur dureh einen kleinen Kreis

sowie bei Friedr. Arxold (Anatomie des Menschen 1551 Bd. II S. 1232). Nach TiedeIAAN soll der Balken aus den umgebogenen Fasern der Hirnschenkel herrorgehen, wogegen ihn ARNoLd als selbständige Bildung entstehen und nach beiden Seiten him in die Bogenfurche der Hemisphäre hineinwachsen läßt. Die Abstammung der Balkenfasern ans der Hirnrinde und ihre Durchkrenzung mit den Fasern der Hirnschenkel war von GaLL angegeben worden, aber Tredenaxx bezeichnet die Angalue als blofes Hirngespinst. 
Ind der der faserfreien Verwachsungsfläche bei III als ein helles Feld angegeben ist.

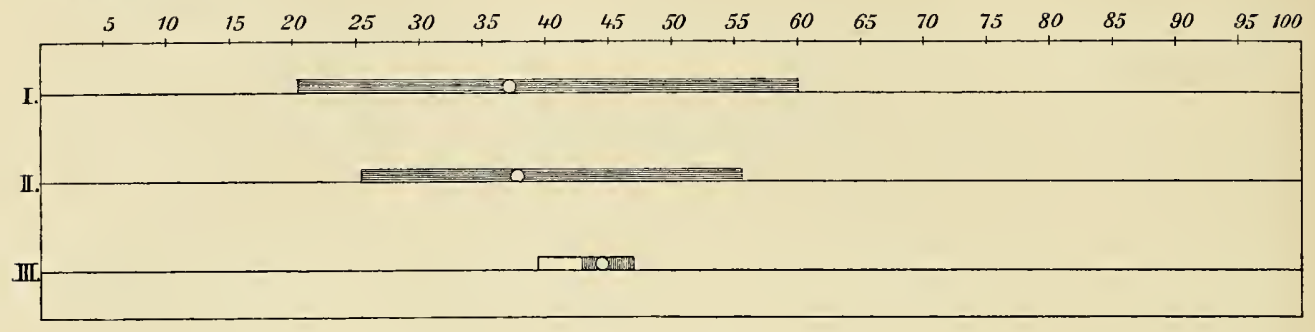

Bei Pl liegt der Ort der vorderen Kommissur ziemlich genan wie beim Erwachsenen, dagegen reicht der Balken sowohl nach vorn, als nach riickwärts weniger weit und damit stimmt anch das Verhalten der Schnitte, das darauf hinweist, daß bei PI der Balken nach beiden Richtungen hin noch tmabgeschlossen ist. Beim Foetus von $8.3 \mathrm{~cm}$ SSI. liegt die vordere Kommissur etwas weiter hinten, als beim Erwachsenen und bei Pl. Das scheint sich darauf zu beziehen, daß die Hinterlappen der Hemisphären noch nicht völlig in ihre Stellung eingerückt sind. Im ïbrigen ist der proportionale Abstand der vorderen Balkenfasern rom vordern Hemisphärenrand genau noch einmal so lang, als beim Erwachsenen. Hier beträgt er gegen 21, dort. volle $42 \%$ der Gesamtlänge.

Die Querschnitte durch das Verwachsungsgebiet der Hemisphären ergeben bei Foetus $8.3 \mathrm{~cm}$ SSl. noch weitere Eigentïmlichkeiten, die für das Verständnis der Balkenbildung bedeutsam sind (Fig. 90, S. 137). Die obere Fläche des Balkens, bez. der Yerbindumgsplatte zeigt einen tiefen medianen Einschnitt, in den ein Gefäßfortsatz hineinragt. Die beiderseitigen Streifen von Rindensubstanz treten unter allmählicher Zuschärfung bis an den Rand des Einschnittes, ohne dessen Grund zu erreichen und ohne sich demnach zu berïhren. Die Furche schneidet, wie auch das Konstruktionsbild Figur 89 zeigt, nach rückwärts immer tiefer ein, bis es dann schließlich zum Auseinanderweichen der Randlippen kommt. Anfangs bleiben die sich tremnenden Randlippen mit ihren konvexen Rändern einander zugekehrt. Ihre oberen Flächen stehen dabei quer, und sie sind fast bis zur Umbiegungsstelle von einer sich zuschärfenden Rindenschicht bekleidet, unter der die Markfaserschicht gegen den Lippenrand sich vordrängt. Beim stärkeren Auseinanderweichen stellen sie sich schräg und gleiten, dem Thalamns anliegend, zı dessen Seitenflächen herab, hier werden sie zur Anlage des Hippocampus.

\section{Balkenanlage bei Foetus Pl von $12 \mathrm{~cm}$ SSl.}

Ich schließe die Besprechtmg des Gehims ron Foetus Pl (12 cm SSl.) an, das ron Frl. PEscheL in Celloidinschnitte ron $80 \mu$ zerlegt worden 
war, und dessen Konstruktionsbilder ich mit Hilfe von fünffach vergrößßerten Photogrammen entworfen habe. - Der Balken ist hier in einem grofen Teil seiner Länge angelegt und erscheint auf Querschitt als eine Faserplatte ron etwa $0.7 \mathrm{~mm}$ Dicke. Die Platte geht ans der, imnerhall, der

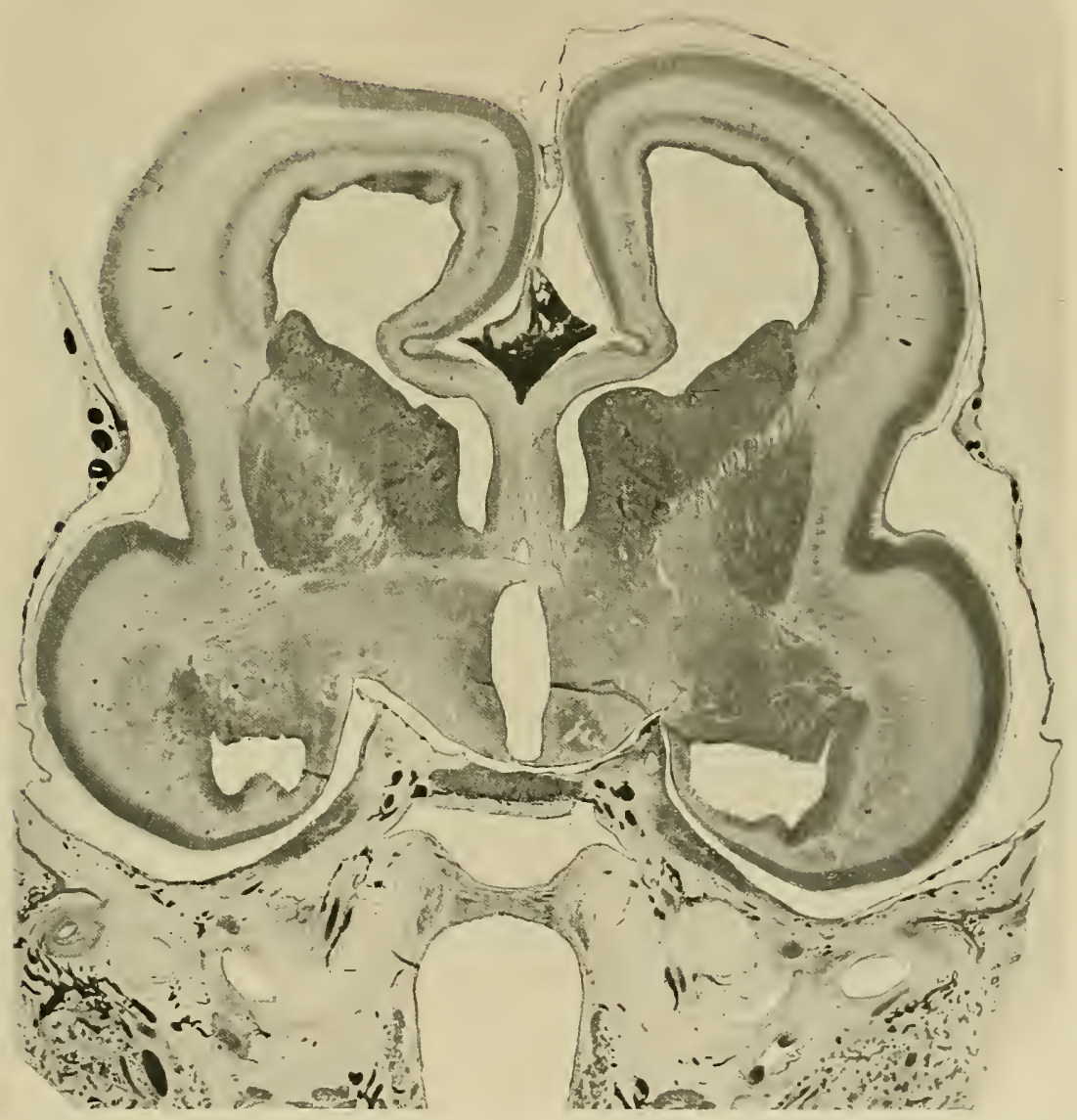

Fig. 90. Quersehnitt durch das Vorderhim des Foetus Cc (SSI. $8.3 \mathrm{~cm})$. Der Schnitt trifft die vordere Kommissur, die Fornixsäulen und die rorhandene Balkenanlage. (Zu Seite 136.)

medialen Hemisphärenwand steil herabsteigenden immeren Markplatte herror. Unmittelbar unter dem Höhlengran liegend, umgreift diese Platte die zur Zeit noch hochgelegene Decke des Ventrikels und sie bildet die unmittelbare Fortsetzung von der in der lateralen Wand gelegenen Markplatte, diese reicht ihrerseits bis zum Rande der imneren Kapsel hin (Figg. 91 11. 92, S. 138 11. 139). 
Fortlanfende Faserzïge lassen sich aus der Seitenwand der Hemisphäre in die mediale Wand und von hier in den Balken hinein verfolgen. Den Verlauf dieser Faserziige habe ich gesncht, in der Konstruktionszeichnung' (Fig. 93, S. 140) wiederzngeben. Die Konstruktion zeigt, daß die zum Mittelgebiete des Balkens gehenden Faserzüge schon beim Überschreiten des Ventrikels transversal gerichtet sind, wogegen die ron vorn und von hinten ber dem Balken zustrebenden Faserzitge schräg verlaufen. Es tritt in dieser Anordnung bereits das bekannte Bild der vorderen und der hinteren Balkenzange zutage.

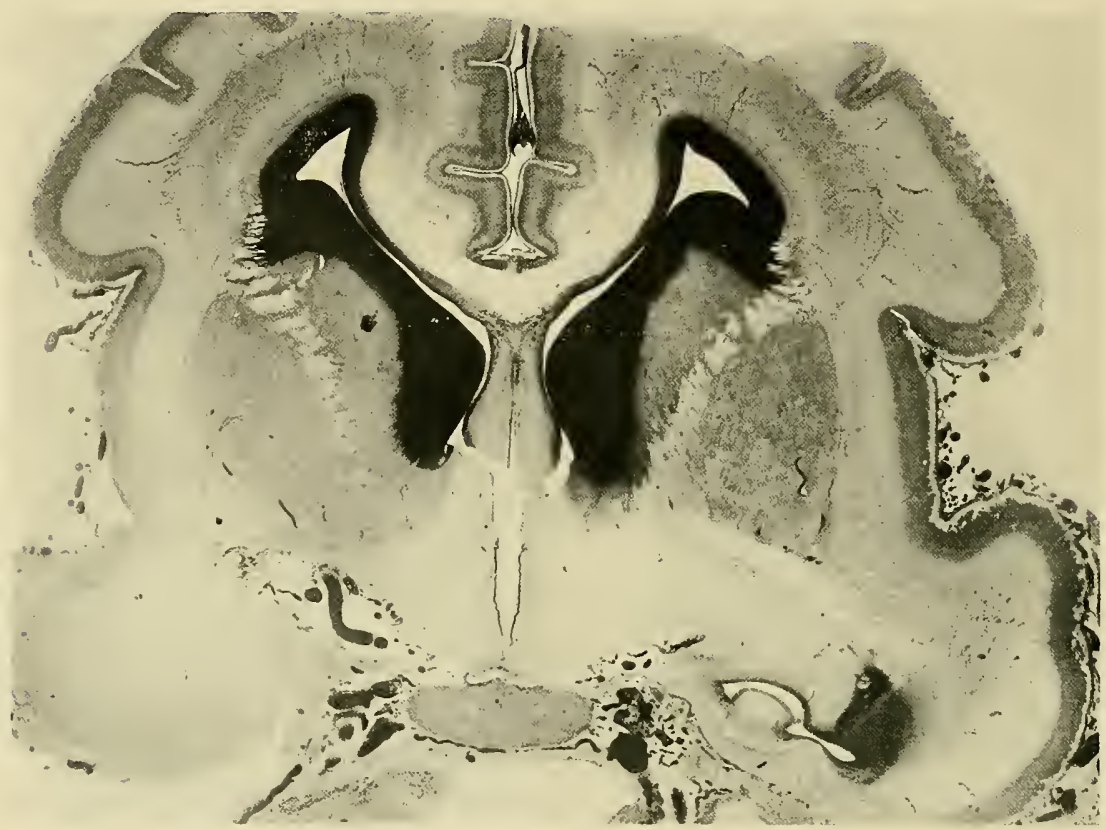

Fig. 91. Querschnitt durch das Vorderhirn von Foetus Pl. Der Schnitt trifft den Balken und eine Strecke weit die Fornixsäulen, die in ihrem unteren Abschnitt eingerissen sind. Die zwischen den letzteren befindliche Spalte gehört der Außenfläche des Gehirns an, durch Einreißen der vorderen Schlußplatte des dritten Ventrikels hängt sie anscheinend nit diesem zusammen. Dic Ausdehnung des dritten Ventrikels am Schnittbild ist an der dunkIen Epitheleinfassung leieht zu erkennen. - Corpus striatum, innere Kapsel, Linsenkern und :̈ußere Kapsel sind queldurchschnitten: rechts streift der Schnitt auch das Claustrum, sowie ein Stiick der vorderen Kommissur. Unter dem Boden des dritten Ventrikels ist die Hypophysis vom Schnitt getroffen. - Über dem Balken, dessen Seitenwände nach aufwirts sich umbiegcn, liegt jederseits eine dïnne Platte von Rindensubstanz, das Indusium griseum aut. Die beiderseitigen Rindenplatten treffen aber in der Mittelebene nicht zusammen, sondern sie bleiben durch einen schmalen Zwischenraum voneinander geschicden. ( $\mathrm{Zu}$ Seite 137.)

Die innere Markschicht der Hemisphärenwand stammt, wie dies oben dargetan wurde, aus den unter dem Höhlengran sich ansammelnden Nervenfortsätzen von Pyramidenzellen, und so sind auch die in den Balken ïbergehenden Fasermassen mittelbar aus der Rindenschicht des Gehirns abzuleiten. Die Lagerung dicht an der Ventrikelwand kommt bekanntlich bleibend 
der Balkenstrahlung zu, die inneren Markblätter sind aber ihrerseits ans den znerst angelangten Fortsätzen von Pyramidenzellen hervorgegangen. Es ergibt sich daraus der Schluß, daß die Balkenstrahlung der Hemisphären die erste Produktion der Rindenpyramidenzellen darstellt. Am Ende des vierten Monats ist diese Bildung im wesentlichen vollendet.

Die obere Fläche des Balkens ist bei $\mathrm{Pl}$ beiderseits von einem frei anslaufenden, dünnen Streifen von Rindensubstanz nebst bekleidender zellenarmer Randschicht iiberzogen. Die beiderseitigen Rindenstreifen endigen

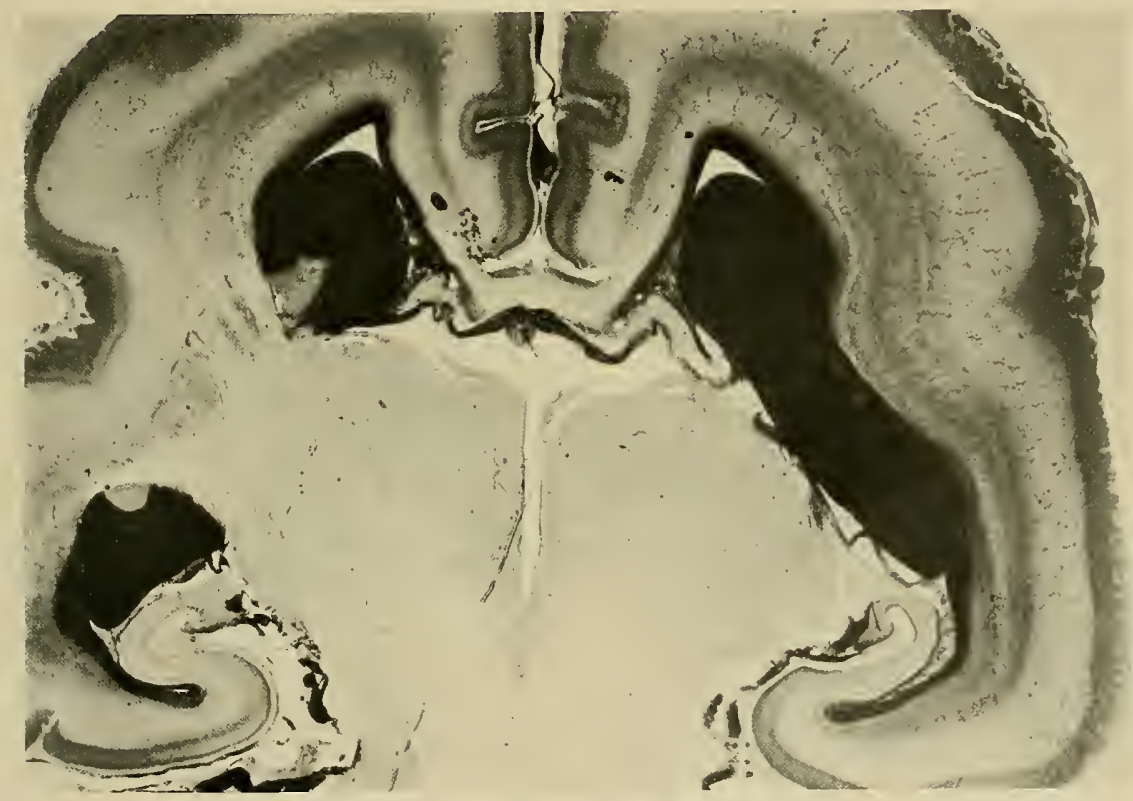

Fig. 92. Foetus Pl. Balken, Fomix und 1Iippocampus. Der Balken zeigt jederseits einen dïnnen Rindeniiberzug, der in der Mitte unterbrochen ist. Hinsichtlich der seitlichen Unterbrechung, die auch an den weiter nach rückwärts folgenden Schnitten dieser Reihe sich findet, nehme ich an dass die Zerreißung eine zufallige sci. Sehr gut zeigt die Figur am Hippocampus die Anlage der Substantia reticularis Arnoldi. (Zu Seite 137.)

mit etwas aufgeworfenem Saum, ohne sieh in der Mittelebene zu erreichen. Beim Foetus ron $8.3 \mathrm{~cm}$ SSI. war auf der freien Balkenseite eine schmale Furche vorhanden gewesen, diese ist bei Pl völlig geschwunden, und die beiden dem Balken aufliegenden Streifen von Rindensubstanz verlanfen in derselben Flucht.

So wie der Balken bei Pl rorliegt, ist zwar der größte Teil seiner Länge angelegt, aber weder das rordere, noch das hintere Ende sind abgeschlossen. Sehon die Flächenkonstruktion (Fig. 93) weist daranf hin, da an ihr vorn sowohl, als hinten ein scharfer Einsehnitt vorhanden ist, gegen den rom den Seiten her Fasermassen rordringen. Ebenso spricht dafür das Ver- 
halten der Querschnitte. Am allervordersten Ende des geschlossenen Balkens erkennt man zwisehen den beiden Hälften noeh dentlich die Trennungslinie

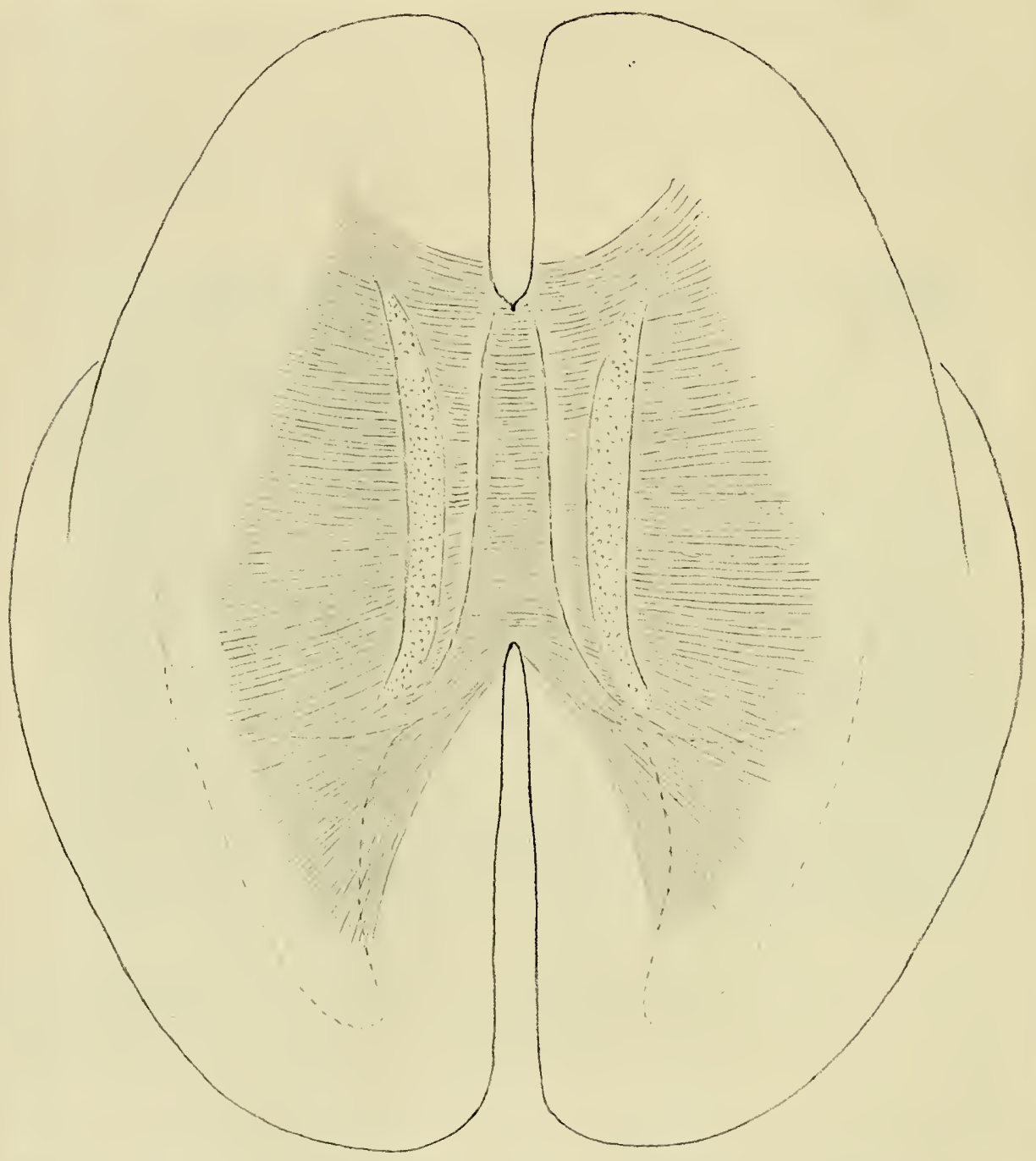

Fig. 93. Konstruktionsbild für die Balkenanlage ron Foetus Pl (12 em Ssi.). Der freiliegende Teil des Balkens nimmt das quergestreifte mittlere, von vorn nach rïekwärts etwas sieh verbreiternde Feld ein. Der seitlieh davon liegende gefaserte und der punktierte Streifen gehören der medialen Wand an; im ersteren verlaufen die Fasern schräg ansteigend, im letzteren steil. Jenseits rom punktierten Streifen ist die Ausbreitung der den Ventrikel iibersehreitenden Fasern angegeben. Die punktierte Linie in der hinteren Hirnhälfte gibt die Ausdehnung rom Hinterhorn des Seitenventrikels an, die Bogenlinie den Verlauf des Hippoeampus. (Zu Seite 138.)

(Fig. 96, S. 143). Unmittelbar davor folgen einige Sehnitte, in denen sieh Querfasern der beiderseitigen Hemisphärenwände bis dieht unter die Ober- 
fläche entg'egentreten, ohne indessen diese zu durehbreehen (Fig. 97, S. 143). Mit zunehmender Entfernung vom gesehlossenen Balken wächst der Abstand zwischen den sieh zugekehrten Faserstimpfen, und weiterhin verlieren sie sich als besondere Vortreibung der Marksehieht.

In dem vorderen Balkengebiet, einschließlieh der eben besehricbenen unverwachsenen Streeke, treten zu den von oben herabsteigenden Fasermassen

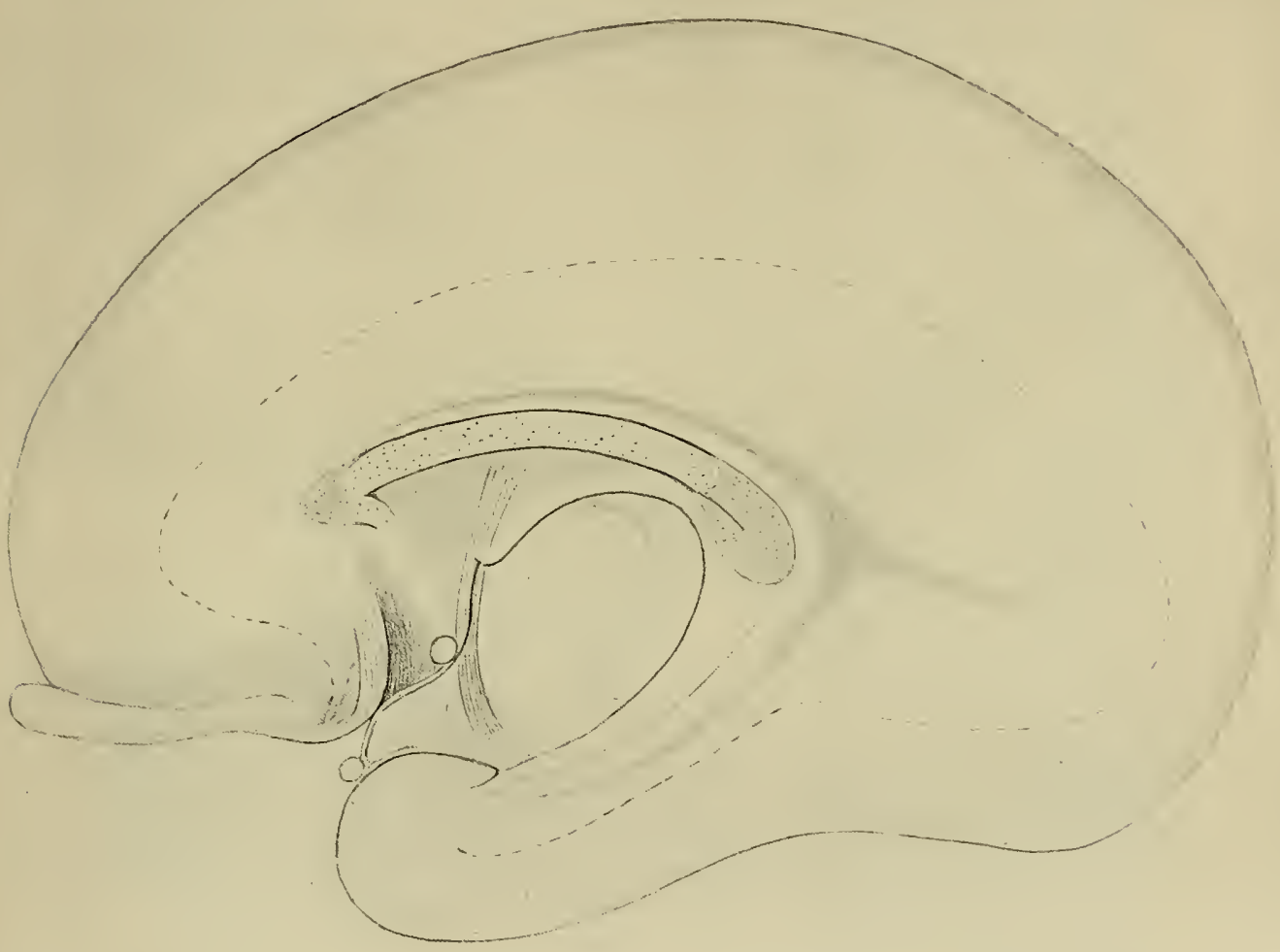

Fig. 94. Konstruktionsbild der medialen Hemisphärenwand von Foetus Pl zur Erlïuterung der Balkenbilduug. Der a usgebildete Teil des Balkens ist punktiert und hell dargestelit, das noeh unfertige Stüek des Balkenknies und der Balkenwulst sind dagegen abgetont; ebenso ist die Fläehe des Septum pellueidnm leieht sehraffiert. Vor der Fissura prima. die hinter dem Trigonum olfaetorium in die Höhe steigt, liegt der mediale Rieehstreifen. Vor der schlusplatte des dritten Ventrikels liegt unten das Chiasma optieum, weiter oben die Commissura anterior, letztere wird von dem aufsteigenden Bündel des Fornix gestreift, das die Balkenanlage etwas vor ihrer Mitte kreuzt. Dex Fornixkörper ist hell ausgespart, naeh rïekwärts sieht man seinen Übergang in die Fimbria. Die Bogenfurehe, die Fissura calearina und Fissura hippocampi sind „nur leicht angedeutet. Die Ausdehnung des Seitenventrikels ist dureh eine punktierte Linie angegeben, die vorn in das Trigonum olfactorium herabreieht. (Zu Seite 142.)

solche, die schräg von unten nach oben hin emportreten (Fig. 95, S. 142). Sie bilden die Anlage des Balkenknies. Nach der Seite hin breiten sieh diese Faserzüge fäeherförmig ans und sie hören damn scharf abgesehnitten auf. Das ron ihnen eingenommene Feld besitzt nur geringe Höhe und es 
ist daraus zu ersehließen, daß die Fasern aus weiter nach vorn liegenden Bezirken stammen, bez. in solehe eintreten. Ein klares Urteil über das Balkengebiet und die an dasselbe herantretenden Fasermassen ergibt die Konstruktion des Mittelsehnittes. Figur 94, S. 141, zeigt eine solehe Konstruktion bei fünffacher Vergrößerung. Die Querfasern, die, ohne sich zu treffen, nach der Mittelebene zu frei auslaufen, sind etwas getont dargestellt, sie bilden unverkennbar die noch ungesehlossene Spitze des Balkenkuies. Der Balkenkörper ist an seiner untern Fläehe von einer düınen Gefäß-

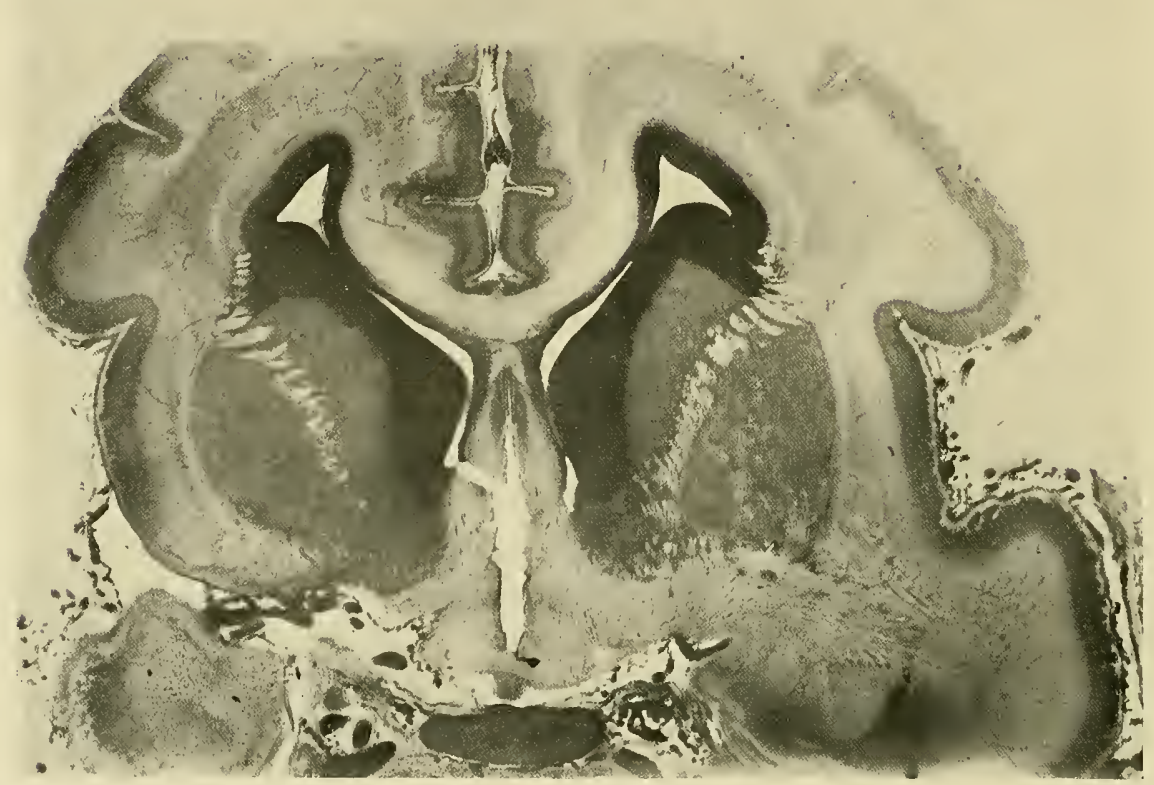

Fig. 95. Durchschnitt durch das vordere Balkenende von Foctus Pl. Unter der Platte, die ihren Faserzuzug von oben herab bekommt, liegt eine niedrigere von der oberen getrennte Platte, deren Fasern schräg von unten her ansteigen. Der Schnitt zeigt, außer verschiedenen, schon bei Figur 91 besprochenen Verhältnissen, auf der linken Seite den von unten her emporsteigenden medialen Riechstreifen. (Zu Seiie 141.)

sehieht begleitet, die im Winkel des Kuies endigt (an der Zeichnung weggelassen).

Ein aus Querfasern gebildetes Rostrum fehlt in der gesanten Strecke voun Knie bis zur vorderen Kommissur. Die dem späteren Ventrieulus septi pellueidi entsprechende Spalte ist daher nach vorn hix nieht abgesehlossen. Im iibrigen ist sie sehr eng, zwisehen ilıre einander flach anliegenden Wandungen selieben sich diimne Blutgefäße eiu. Die aus den Trapezplatten hervorgegangenen Wände der Spalte sind dick (an den dünnsten Stellen etwa $0.5 \mathrm{~mm}$ ) und an ilurem Randteil etwas aufgetrieben. Eine Rindenselieht fehlt. - 


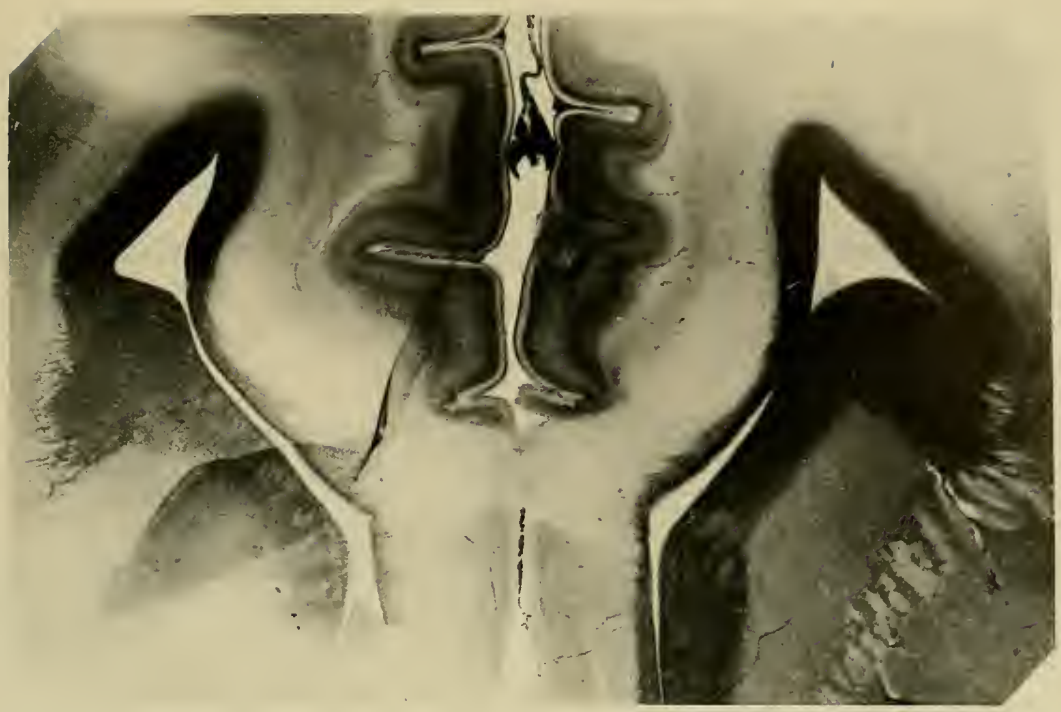

Fig. 96. Schnitt durch das allervorderste geschlossene Ende des Balkens. Zwischen den beiden Seitenhälften ist noch eine Trennungszone dentlich erkennbar als ein schmales helles Zwischenfeld, den rerschmolzenen Randschleiergebieten entsprechend. Dies Verwachsungsfeld steht etwas asymmetrisch, nach der einen Seite hinäbergedrïngt. (Zu Seite 140.)

Hinter der vordern Kommissur findet sich ein derbes Faserbündel, das sich nach abwärts im Sehhügel verliert. Das Bündel streift als Fornixsäule

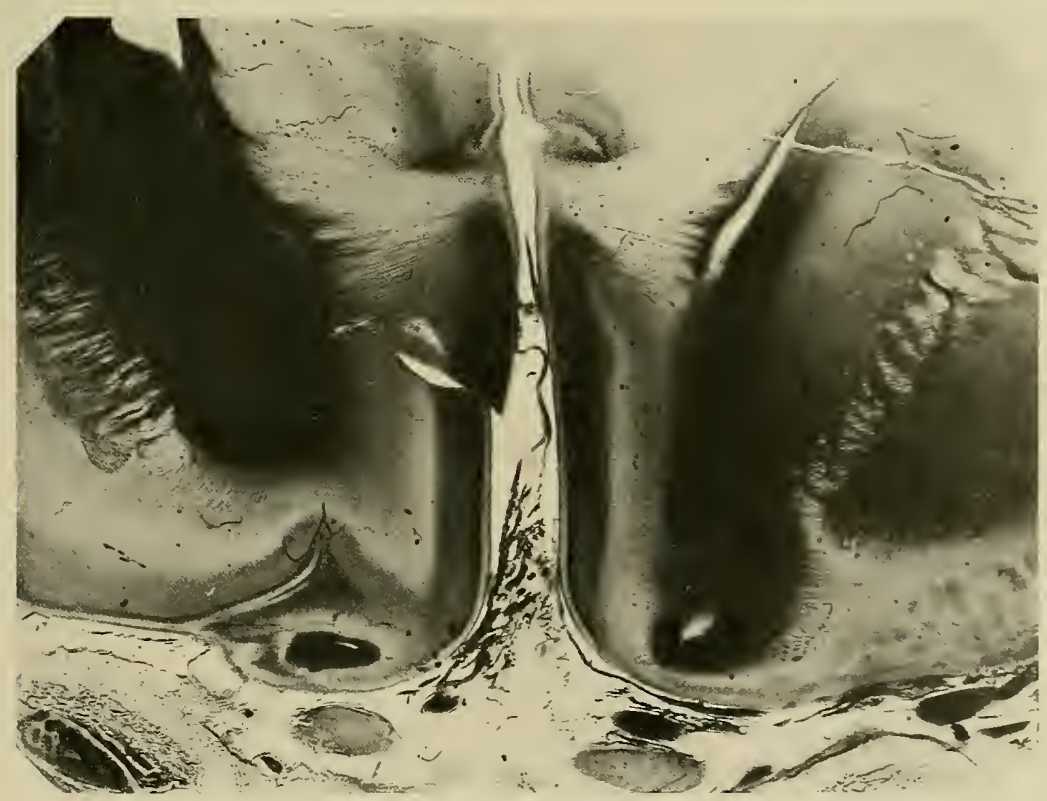

Fig. 97. Schnitt durch die Hemisphüren von Lmbryo Pl dicht ror dem bereits geseh]ossenen Balken. Von beiden Seiten her treten Querfaserplatten bis dicht unter die Oberfläche. Hier sind sie noch durch einen schmalen Spalt und durch die beiderseitigen dïnnen Randschleierschichten roneinander geschieden.

$$
\text { (Zu Seite 141.) }
$$


eine Strecke weit die Wand des dritten Ventrikels, geht aber weiterhin nicht in den Rand des Fornixkörpers iiber, sondern es steigt steil in die Höhe und strebt mit seinem oberen Ende dem Balken zu. Das Bündel gehört, wie schon oben erörtert wurde, dem primären System des Fornix longus an.

Für die Beurteilung des Balkenwachstums gewährt das primäre Fornixbiindel, einem Uhrzeiger vergleichbar, entscheidende Anhaltspunkte. Beim Foetus von $8.3 \mathrm{~cm}$ SSl. war es bereits angelegt, und die bei diesem vorhandenen Balkenfasern lagen hinter und teilweise uiber ihm. Bei PI wird

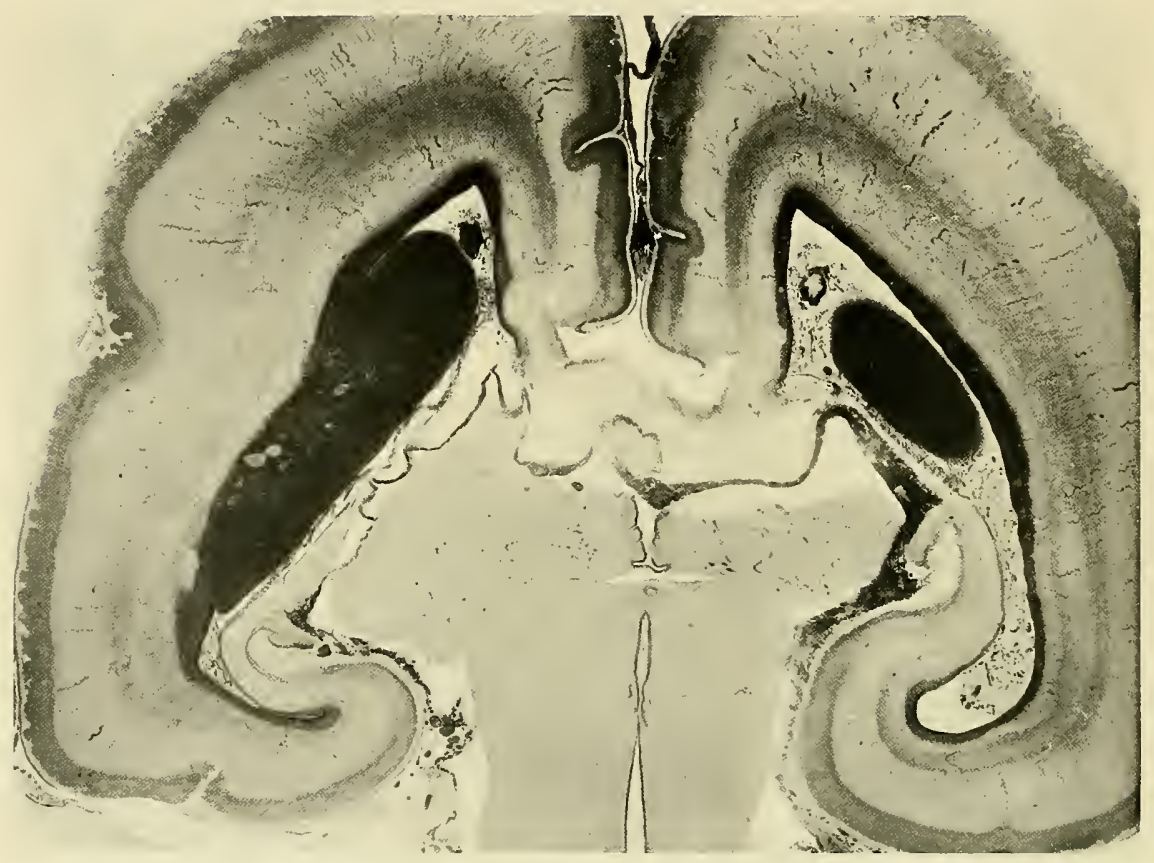

Fig. 98. Querschnitt durch die Balkenanlage von Foetus Pl am hinteren Ende. Beiderseits ist auch der Hippcampus vom Schnitte getroffen und die von da zur unteren Balkenfläche heraufsteigende Fimbria. (Zu Seite 145.)

der vorhandene Balken dureh die verlängerten Fornixbündel nahezu halbiert, und es geht daraus mit größter Schärfe hervor, daß sich die vor dem Biindel liegende Hälfte des Balkens frontalwärts von den zuerst vorhandenen Mittelfasern ne entwickelt hat. Die Annahme bisheriger Forscher, daß die erste Balkenanlage den Ort des späteren Balkenknies bezeichne, muß als unhaltbar verlassen werden.

Das Konstruktionsbild Figur 94 läßt, obwohl das Balkenknie noch unvollendet und das Rostrum noch nicht vorhanden ist, iiber die endgiiltige Ausdehnmg des Balkengebiets keinen Zweifel. Das Rostrum muß, wemn es sich bildet, den Weg vou dem bei P'l rorhandenen Stmmpf des Balkenknies nach der Commissura anterior hinab einschlagen. An Fignr 94 ist dieser Weg durch einen hell ansgesparten Streifen angegeben. Vergleicht 
man Figur 94 mit Figur 87 (S. 131), so zeigt sich an der letzteren das ron der Bogenvene umschlossene, nach rorn spitz auslaufende Gelsiet der Trapezplatte nuverkembar als eben das Feld, das in der Folge rom Balkenschnabel umgrenzt werden soll. Gegenüber den Verluältnissen frïlıerer Stufen rom zweiten bis dritten Monat hat das Gebict an Tiefe gewommen und seine rordere Abgrenzung hat sich nummehr zu einem Winkel zugeschiarft.

Wie nach vorn, so ist der Balken bei Pl auch nach riickwärts noch nieht als abgeschlossen anzusehen. Ein anfang's enger, weiterhin aber rasch

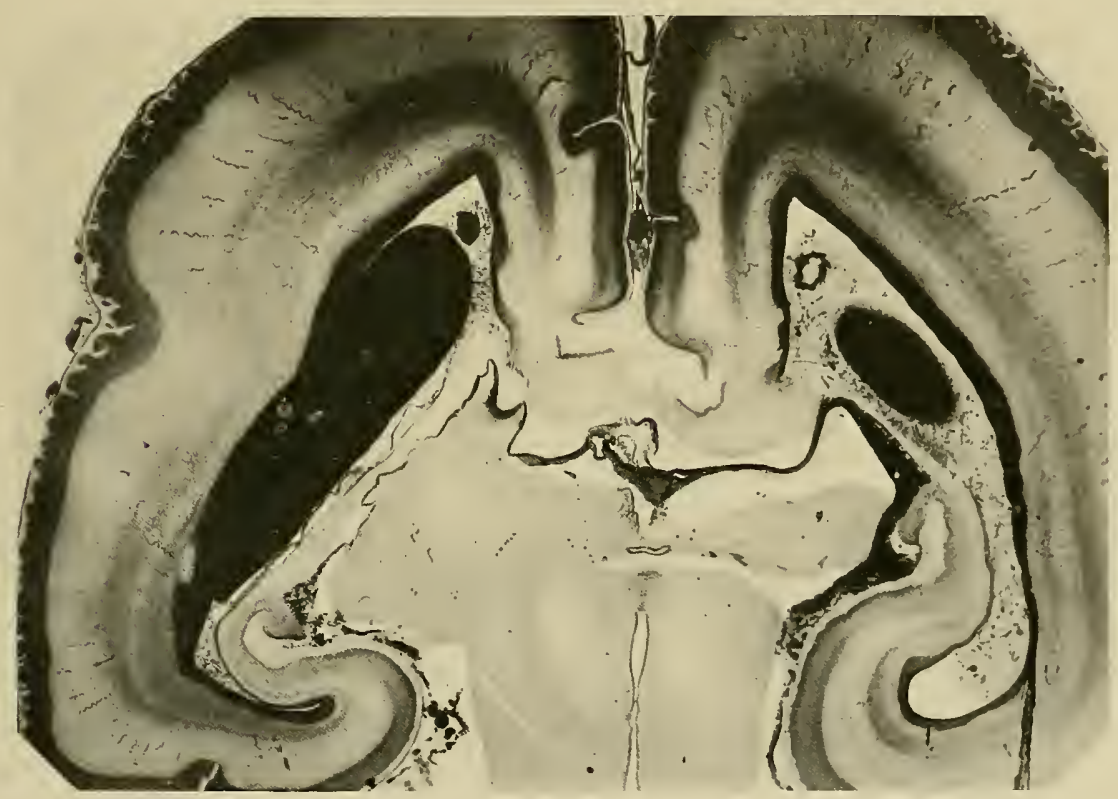

Fig. 99. Schnitt unmittelbar hinter dem rorigen. Die beiderseitigen Balkenanlagen sind in der Nitte romeinauder getremnt. Der Streifenhiigel ist links in gröferer Ausdehnung getroffen, rechts nur an seinem hintersten Ende. Bei dieser und bei der vorigen Figur ist die dünne zum Balken herabtretende sehicht ron Rindensubstanz eine Strecke weit eingerissen.

sich öfnender Schlitz schmeidet anch hier zwischen beiden Seitenhälften ein. Der Balken zerfällt dadureh in zwei frei herrortretende Hälften, die als Alikömmlinge der auf früherer Stufe rorbandenen Randlippen zu rerstehen sind. Jede der beiden Lippen besteht nummehr der Hauptsaehe nach aus einer Fortsetzung der innern Markplatte. Die übrigen schichten der Henisphärenwand hören ïber der Bogenfurche, der mumehrigen F issura corporis callosi, wie abgeschnitten anf, nur eine sehr dünne Fortsetzung: der Rindenschicht ïberzieht noch die obere Fläche der beiden Lippen. An meinen Sehnitten zeigt sich der Rindeniiberzug an Grunde der Fissur anf kurze Strecke unterbrochen, dies ist indessen als ein zufälliges Torkommuis anzusehen (Figg. 98 и. 99). 
Unter den Randlippen des Balkenwulstes verläuft die gefäßreiche Tela chorioidea, und lateralwärts schließen sich ihnen die Anlagen der Fornixschenkel und der Fimbria an. An dem aus der Fortsetzung der Randlippen hervorgehenden Hippocampus ist die räumliche Reihenfolge der Schichten dieselbe wie in den Randlippen der Balkenanlage (Fig. 98); ihre relative Mächtigkeit ist aber eine etwas andere. Auch hier tritt eine Fortsetzung der imem Markplatte, als Tapetum, am Umbiegungsrand der Lippe frei hervor, sie setzt sich in die Fimbria hippocampi fort. Die ubrigen Wandschichten verjüngen sich gleichmäßiger als oben und gehen in den umgebogenen Teil der Lippe über, durch einen Einschnitt, den Sulcus fimbriodentatus von Retzius, von der Fimbria sich ablösend. Sie endigen in der Fascia dentata. Im umgelegten Teil der Hippocampuslippe ist die sonst so mbedentende Randschicht verdickt und sie liefert das Lager für die Substantia reticularis Arnoldi (s. Fig. 92, S. 139).

Das hintere Balkenende und die ihm sich anschließenden, noch iiber dem Thalamus liegenden Strecken der Randlippen nehmen nicht nur von oben, sondern auch ron unten her Fasermassen auf. Letztere entwickehn sich zunächst aus der imnern Markplatte des Hippocampus, dem Tapetum des Unterhorns, und sie verlaufen zum Teil in der frei herrortretenden Fimbria. Folgt man den Schnitten nach abwärts und nach rückwärts, so ist unschwer zu erkennen, daß die Faserzïge, unter dem Boden des Ventrikels durch, ans der lateralen in die mediale Wand iibertreten. Im Hinterhorn halbieren sich die Faserzïge der lateralen Wand, indem ein Teil derselben um die Decke, ein anderer um den Boden des Ventrikels herumgeht. Die beiderlei Züge treffen in der medialen Wand auf eine gemeinsame dicke Faserplatte, in deren Nähe sie ihre Verlaufsrichtung. ändern. Die gegen den Ventrikel sich vordrängende Faserplatte ist nach ihrer Lage als Calcar avis zu bezeichnen. Aus den von unten her kommenden Fasermassen des absteigenden und des Hinterhorns bilden sich die umgeschlagene Lamelle des Splenium c. callosi und die Commissura hippocampi (Psalterium). Die dem Splenium zugehörigen Fasermassen sind der gegebenen Darstellung zufolge sämtlich schon angelegt, aber noch ist das Splenium in der Mittelebene nicht geschlossen. In der Konstruktionsfigur (Fig. 94, S. 141) ist seine ungefähre Ausdehnung, die eher zu kurz als zu lang bemessen ist, schattiert angegeben. Dabei muß ich bemerken, daß ich bei der etwas unsymmetrischen Stellung, die die Randlippen an dem Präparate zeigten, ein mittleres Verhalten eingezeichnet habe. Dies hintere Ende der Balkenkoustruktion ist somit approximativ, das vordere Ende dagegen genaı eingetragen.

Der als Calcar avis über die imere Ventrikelfläche hervortretende Faserwulst ist, im Gegensatz zu andern Strecken der Ventrikelflïche, von einer nur sehr dïnnen Ependymschicht iiberzogen. Ein als Matrix in Betracht kommendes Höhlengran ist karm noch in Spuren vorhanden. 
Von weiter fortgeschrittenen Stufen steht mir die Schnittreihe eines Foetus von $16 \mathrm{~cm}$ SSl. zur Verfïgung. Ich habe die Reihe zwar wiederholt durchkonstruiert, will indessen hier nicht auf dic gefundenen Einzelnheiten eingehen, da infolge ungünstiger Schnittrichtung die Ergelınisse denen vom Foetus PI an Schärfe naehstehen. Anch auf dieser Entwicklungsstufe ist die Balkenbildung noch nicht abgeschlossen, insbesondere fehlt anch hier noch ein Rostrum, und der Ventriculus septi pellucidi klafft naeh roru lin (Fig. 79 S. 116).

Sehr bemerkenswert ist die Unschließung von Balken und Fornix mit reichen Gefäßgeflechten. Die primäre Hirnsichel länft über dem Balkenkörper, ähnlich wie anf frïheren Stufen im Bereich der Fissnra prima, in drei blattartige, gefäßreiehe Fortsätze aus, von denen die beiden seitlichen in die Fissura corporis callosi eindringen, während die mittlere einer medianen Furche folgt, die von hinten und von oben her in die Balkenoberfläche scharf einschmeidet. Die Seitenwand der Furehe wird von starken Zügen von Längsfasern gebildet, die die Lage der Querfaserziige ïberdecken.

Eine zweite stark ausgebildete Gefäßschicht findet sich nuter dem Fornix als die anatomisch wohl bekannte Tela ehorioidea. Allein auch der Rann zwischen Balken und Fornix, bez. der VERGAschen Ventrikel ist ron Blutergüissen eingenommen, deren Quellen in Gefäßen zu suchen sind, die von hinten her, unter dem Balkenrand weg and von vorn durch die noch klaffende Ventiikelliicke an Ort und Stelle grelangen.

Ein besonderes Interesse beanspruchen beim Balken die Randstellen, deren Verwachsungs- und Trennungsbereieh aneinanderstoßen. Der Anschluß pflegt hier durch Übergäng'e vermittelt zu sein. Zunäehst schiebt sich eine dümne, gefäßhaltige Haut zwischen die beiden bis zur Berührung aneinander geriickten Gewebsplatten. Weiterhin wird die zusammenhängende Hant durch Ketten von geschlängelten Gefäßen ersetzt, und schließlich stellen sich diese Gefäße als die naturgemäßen Gefäße der Gehirusubstanz dar. Es kommt also nicht zu einer absoluten Zurïckbildung der Piagefäße, sonderu zu einer mehr oder minder weitgreifenden Reduktion, wobei Reste des ursprïnglichen Systems als Organgefäße persistieren.

\section{Literarische Bemerkungen zur Frage der Kommissurenbildnng.}

Die Literatur der Fornix- und Balkenbildung ist in nenerer Zeit wiederholt zusanmengestellt worden, zuletzt und ziemlich eingehend ron F. MARCHAND, ${ }^{1}$ ) sowie von E. ZUCKERKANDL. ${ }^{2}$ ) Es kamm sich für mich nicht darum

1) Marchand, Über die Entwicklnng des Balkens im menschlichen Gehirn. Archir f. mikr. Anat. 1891 Bd. XXXVII S. $295 \mathrm{ff}$.

2) Zuckerkande, Zur Entwicklung des Balkens und des Gewölbes. Sitzungsber. der Kais. Akad. d. Wissensch. in Wien, Math.-natur. Klasse Bd. CX. III. Oktober 1901. 
handeh, die verschiedenen ansgesprochenen Angaben von neuem aufzuzählen, wohl aber lohnt sich der Versnch, klarzulegen, wie die so verschiedenartigen Anffassungen des Prozesses haben Platz greifen können. In der Hinsicht hat E. ZUCKERKANDL einen Satz ansgesprochen, dem ich völlig beistimme. Er sagt nämlich: "Die Erfolglosigkeit der bisherigen Bemühnnngen, die Balkenfrage zu lösen, ist nicht so sehr der Schwierigkeit des Problems, als der mingeeigneten Methode der Untersuchung zuzuschreiben. Makroskopische Untersuchungen, wie sie vielfach angestellt wurden, ım die Kommissurenbildung zı erforschen, können zu einem befriedigenden Resultate nicht führen, demn es kommen Details in Betracht, die nur mit dem Mikroskop wahrunehmen sind." Anch schließe ich mich an ZUCKERKANDL in der besonderen Würdigung der Arbeiten von v. Minalkovics an, und ich möchte speziell lıervorheben, wie dieser Forscher die ron so manchen andern Beobachtern in Abrede gestellte Rückbildung der gefäßfïhrenden Hirnsichel im Verwachsmngsgebiet klar erkannt und beschrieben hat. ${ }^{1}$ )

Es ist hervorzuheben, daß die Forscher, die ihre Studien nnter Benutzung von queren Gehirnschitten durchgefuilhrt haben, im allgemeinen, sowohl für die Lehre von der Verwachsung der beiderseitigen Hemisphäirenwandungen, als für eine successive, durch Apposition erfolgende Balkenbildnng eingetreten sind (so MiHALKovics beim Foetus des Kaninchens, Blumenau bei dem des Schweins, Zuckerkande bei dem der Ratte). Die Mcinung ron einer simultanen Anlage des gesamten Balken und einem Intussusceptionswachstum desselben, die schon Reichert, F. SCHuIDT und KöLLIKER vertreten hatten, findet sich unter den Nenern besonders bei solchen Autoren, die ihrer Darstellung rorrriegend das Bild des Medianschinittes zugrunde gelegt haben, so bei MarchaNd, bei G. Retzius und nenerdings bei GoLDsteix.

Mehrfach ist in bisherigen Darstellungen ron Verdickungen der Lamina terminalis oder der Schlubplatte die Rede und es wird diesen in der einen

Von sonstigen neueren Autoren iiber Balkenbildung sind anzufülıren:

Blumexau, Zur Entwicklungsgeschichte und feinen Anatomie des Hirnbalkens. Arch. f. mikr. Anat. 1891 S. 1 ff.

G. Retzrus, Das Menschenhirn. Stockholm 1596. Das Kapitel über den Randbogen und die iln nmgebenden Teile S. 5 ff.

Paul Martix, Bogenfurche und Balkenentwicklung bei der Katze. Züricher Inanguraldiss., Jena 1894.

Goldsten, Beitrïge zur Entwicklungsgeschichte des menschlichen Gehirns. His' Archiv 1903 S. $29 \mathrm{ff}$.

Elliot Suith, The relation of the Fornix to the margin of the cerebral Cortex. Journal of Anatomy and Pliysiology Vol. XXXII 1597 und Morphology of the true "limbic lobe", corpus callosum, septum pellncidum and fornix. Ibid. Vol. XXX 1595.

1) v. Mnhalkovics, Die Entwicklung des Gelirnbalkens und des Gewölbes. Zentralblatt f. d. med. Wissensch. 1876 No. 19 und Entwicklungsgeschichte des Gehirns (Leipzig 18i6) S. 120 ff. n. 166. 
oder andern Weise eine Rolle bei der Bildung der Konunissuren zugeschrieben (so bei Marchand, bei Martin und bei Elliot Surthi). Die Vorstellung von Verdickungen der Schlußplatte halte ich für unzutreffend, sie lä̈lt vor dem Studium der Durchschnitte nicht Stich. Dic Schlußplatte, bez. die aus ihr hervorgehende Lamina terminalis ist eine quergestellte, ausschließlich ans epenmdymalen Elementen bestehende Schicht, die ilıre Selbständigkeit noch auf späteren Stufen, nach Bildung der vorderen Kommissur und der ersten Balkenanlage erkemen läft (s. o. S. 125). Sie bleibt diunn, und das was irrtimmlicherweise als Verdickung der Schlußplatte gedeutet worden ist, das sind die Verwachsungsflächen der sagittal gestellten Trapezplatten. Es geht, wie oben gezeigt wurde, dem Durchtritt der ilıren Seitenabschnitten angelegten vorderen Kommissur die Verwachsung der beiderseitigen Trapezplatten bez. ihres Gliagerüstes voraus. Auch bei der Balkenbildung treffen zunächst die beiderseitigen dïnnen Randschleier der Glia zusammen, ehe es zu einem Austausch der dahinter aufgehäuften Fasermassen kommt. ${ }^{1}$ )

1) Ähnlich lautet die Angabe von Zuckerkandu (1. c. S. 53): ,Stets sind die primären Verbindungen mit den Großhiruhemisphären aus Zellen anfgebant. An keiner Stelle konnte beobachtet werden, daf die symmetrischen Fasersystemhälften der Hemisphären direkt miteinauder verwachsen wären; immer wachsen diese in vorher entstanclene Zellkommissuren hinein.“ 


\section{Über intramedullare Faserbahnen und die Zeit ihres ersten Auftretens.}

\section{Die Reihenfolge der Entwicklung intramedullarer Bahnen.}

Die aus den Neuroblasten der nervösen Zentralorgane hervorwachsenden Fasern können sich zwischen den vorhandenen granen Massen, dem Gliagerïst und den Nervenzellen mehr diffus ausbreiten, oder sie kömnen sieh zu kompakten Strängen sammeln. Die ersten Stranganlagen erscheinen mit imbedeutenden Anfängen gegen Ende des ersten Monats. Im Rückenmark haben sich zu der Zeit angelegt: die Vorderstränge, die Vorderseitenstränge, die Hinterstränge und die vordere Kommissur. Im Gehin erseheinen als die getrennten Vertreter von sensiblen Hintersträngen der Fasciculus solitarius und der Fasciculus Trigemini. Anferdem sind hier die basalen aus dem Vorderhirn ins Mittelhirn ïbertretenden Faserbündelchen zu erwähnen. Diese verschiedenen Stranganlagen stimmen darin ïberein, daß sie dicht unter der Außenfläche des Markes in den zuror freien Lückenräumen des Randschleiers sich ansammeh.

Von der fünften Woche ab nehmen alle diese Bildungen an Mächtigkeit zu. Auch erfolgt von der Zeit ab im Gehirn eine Zunahme der neuroblastenführenden Mantelsehicht, sowohl naeh Dicke, als nach Flächenausdehnung. Die Ausbreitung der Schichten schreitet scheitelwärts und rostralwärts fort. Bald zeigt sich das gesamte Thalamushirn, abgesehen von einem schmalen oberen Streifen, von einer neuroblastenführenden Gewebsschicht umkleidet. Eine ähnliche, aber erheblich langsamer sich ansbreitende Schicht tritt späterhin in der Seitenwand der Hemisphären anf und schreitet hier von der Basis ans scheitelwäirts vor.

Mit der Zunahme der Mantelsehicht verwickelt sieh aneh die Anordnumg: der von den Neuroblasten ansgehenden Faserzüge. Soviel läßt sich immerhin noch erkennen, daß die der dorsalen Wandhälfte entstammenden Fasern der verschiedenen Gehirnabschnitte rorwiegend in basalwärts geriehteten Bogenlinien verlanfen, wogegen im basalen Teil der Mantclschicht ein rom 


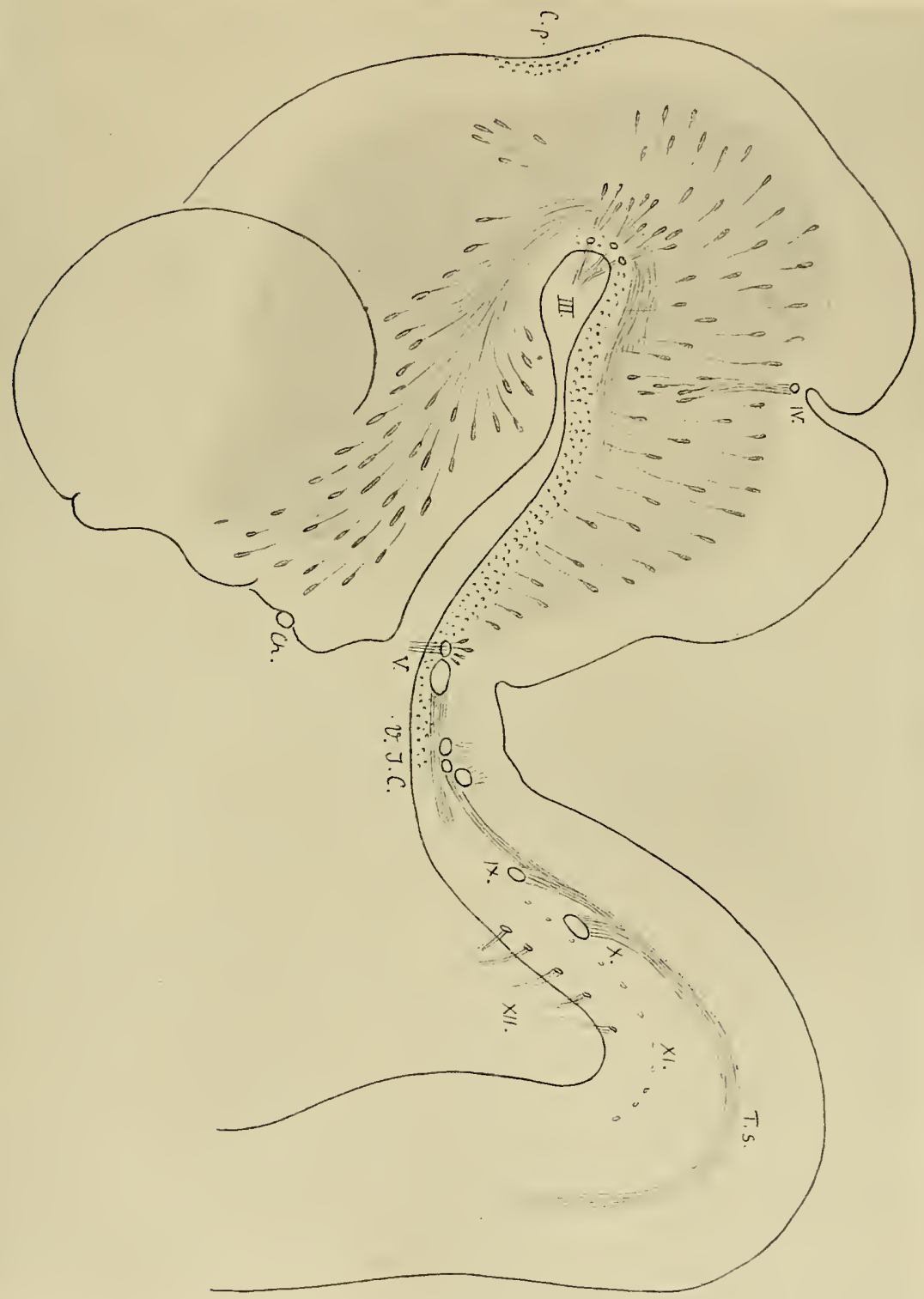

Fig. 100. Gehiru von Embryo Sch. Vergr. 20 fach. Konstruktionsbild. Die Ausdehnung der Mantelschicht
ist durch Schraffierung eingetragen und, soweit angegeben: $C \cdot p \cdot=$ Commissura posterior, $C h=$ erkenubar, sind auch die Verlaufsrichtungen der Neuroblasten $\mathrm{I}$. N. trigeminus, $\mathrm{r}$. $=\mathrm{N}$. vestibuli, $I$. $=\mathrm{N}$. intermedius, $C$ pticum, III. N. oculomotorius, II. N. trochlearis,

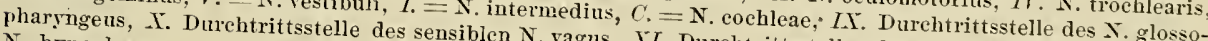
N. hypoglossus. Der N. abducens und der motorisch, XI. Durchtrittsstellen des N. accessorius und $Y I T$. des sind in der unteren Hälfte des Rautenhirns dietorische Teil des $\mathrm{N}$. facialis sind nicht eingezeicbnet. Auch angegeben, wohl aber der Fascienlus solitarius Neuroblasten sowie die Ausdehnung der Mantelschicht nicht Im Bereiche des Vorderhirns zeigt die Zeichnum $(T . s$.$) und der Anfang des Tractus spinalis N$. trigemini, den Boden des Mittelhirns konvergieren. Diesenen basalen Zug von Neuroblasten und Fasern. die gegen mamillaris aı. Das gekrümmte, am Boden des Dittelhirn schließt sich basalwärts der Tractus tegmentomedialen Längsbü ndeI. Die Mantelschicht reithtrns rerlaufende Längsbündel entspricht zum Teil dem hin und ihre Ablösung innerhalb der Hemisphärent noch nicht bis zur Decke rom Mittelhirn und Thalamus Commissura posterior angelegt $(Z$ nicht begonnen. Dagegen ist bereits eine 
Riechhirn bis zum Mittelhirn verfolgbarer Zug von Längsfasern, ein Tract $\mathrm{ns}$ hypothalamieus auftritt, der sich den schon frïher angelegten Längsbündeln anschließt, und dem sich anch starke Zuschüsse ans der Wand des Mamillarkörpers beigesellen.

Zun Vergleich mit der S. 43 mitgeteilten Figur 23 gebe ich Figm 100, S. 151, die Zeichnung vom Gehim eines Embryo vom Beginn der sechsten Woche (Sch, Nl. $13.8 \mathrm{~mm}$ ), in der die Ausbreitung der Mantelschicht und, soweit wie möglich, anch die Anordnnng der Neuroblasten konstruktiv eingetragen sind. Ein von Neuroblasten freier Saum zieht sich längs der dorsalen Seite des Hinterhirns, des Mittelhirns und des Zwischenhirns. An zwei Stellen wird dieser Saum überbrïckt, am Isthmus durch die gekrenzten Bündel des $\mathrm{N}$. trochlearis und am Hals des Zwischenhirns durch die früh vorhandene hintere Kommissur. Die Großhirnhemisphären sind zu der Zeit in ihrer Entwicklung noch sehr zurück. In der spinalen Hälfte des Rantenlirms ist der Fasciculus solitarius nunmehr zu voller Länge ausgewachsen, der Fasciculus spinalis Trigemini gegen früher bedentend verlängert. Beide Gebilde waren bei Br 3 (Fig. 23, S. 43) nur in ihren ersten Anfängen vorhanden.

Eine vollständige Geschichte der Faserbahnen des Gehirns verlangt als Unterlage die sorgfältige Durcharbeitung sämtlicher Gehirnabteilungen, und dabei ist anch die Scheidung der grauen Massen mit in Betracht zn ziehen. Ich hoffe bei späterem Anlaß dieser umfassenden Anfgabe, wenigstens teilweise, näher treten zu kömen. Was ich für diesmal bieten kamn, das ist die Anfzihlung einer Anzahl von gesondert in Erscheinung tretenden Faserbahmen und die Angabe von der zeitlichen Reihenfolge ihres Anftretens. Es sind meine hierauf bezïglichen Befunde ein Nebenprodukt der seit manchen Jahren fortgeführten konstruktiven Durcharbeitung embryonaler Schnittreihen. Die an verschiedenen Reihen gewonnenen Ergebnisse hatten sich dabei zı ergänzen, denn je nach Schnittrichtung und sonstigen Eigenschaften der Präparate sind die Einzelheiten nicht in jeder Reihe gleich gut feststellbar. Ich habe übrigens an den als Beispiel mitgeteilten Zeichnungen nur das eingetragen, was sich ïbersichtlich wiedergeben ließ.

Naturgemäß sondem sich die auftretenden Faserbahnen $\mathrm{Im}$ so auffälliger von ihrer Ungebung, je geschlossener ihre Gruppierung und je gröber ihre Faserung. Als Beispiele scharfer Sonderung lassen sieh ans früherer Zeit das MeYnent sche Bündel, die Mamillarhanbenbündel und das Solitïrbündel anführen, im Gegensatz zu den diffus verteilten feinfaserigen Längsbündeln der Haube. Mit Rücksicht auf die Verschiedenheit des Verhaltens erscheint es wohl zweckmäBig, zwischen Fa serz ii gen und Fasersträngen, Tractus und Fasciculi zu unterscheiden. Die diffus verteilten Fasermassen der Formationes reticulares können sonach als Tractns bezeichmet werden, wogegen für den bisherigen Tractus solitarins die Bezeichnung Fasciculus besser paßt. Dabei ist allerdings zu bemerken, daß 


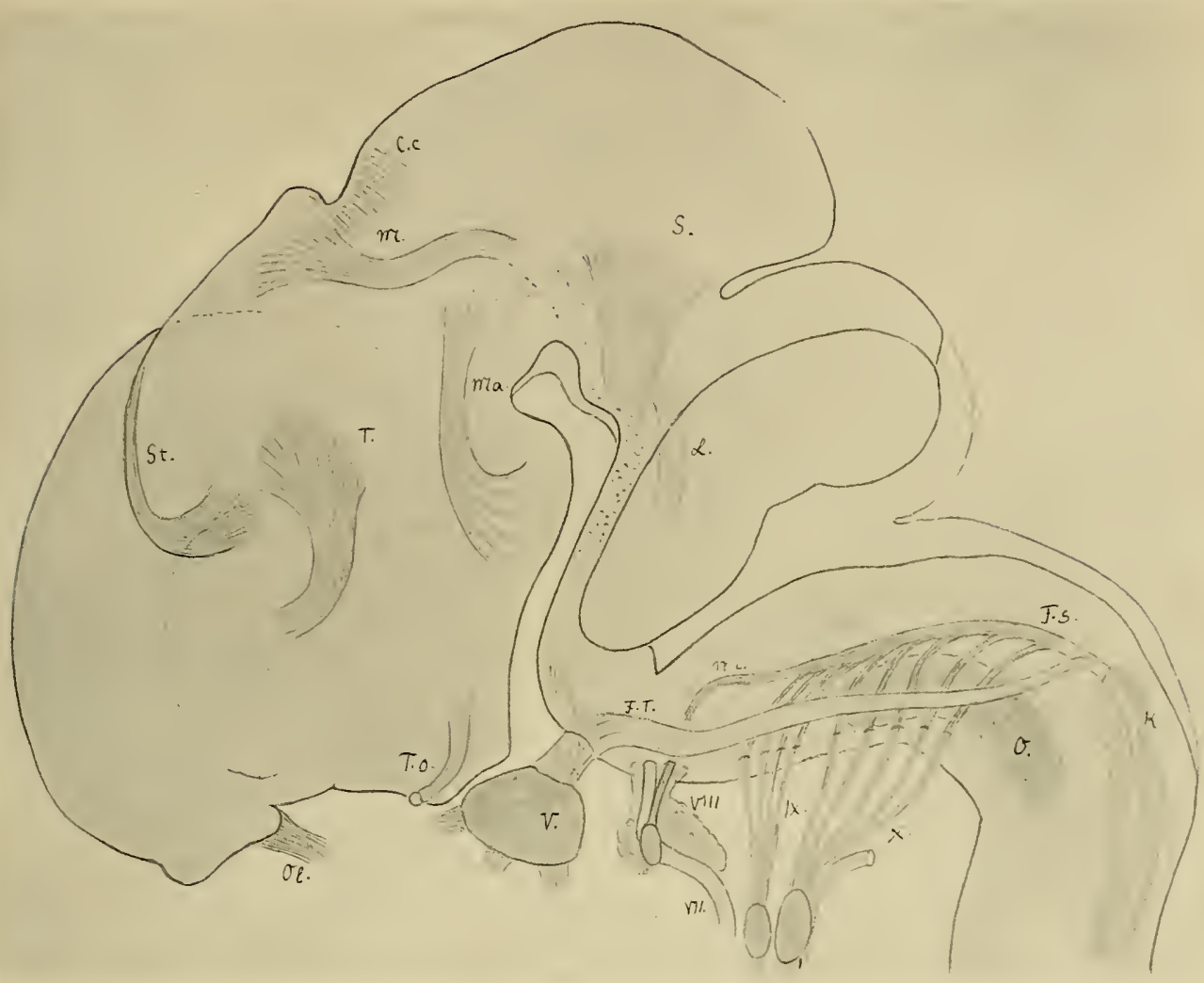

Fig. 101. Konstruktion des Gehirns von Embryo My. Vergr, 15 fach. Im rerlïngerten Mark sind eingezeichnet: die untere Olive, der Fasciculus solitarius und Fasciculus spinalis Trigemini. Die Verbindung des N. intermedius mit dem Fasciculus solitarius habe ich nach dem Glasmodell des Embryo Wi eingetragen, bei dem sic vorziiglich klar herrortritt. Im Mittel- und Vorderhirn sind gezeichnet: das mediale Längsbündel, die querverlaufeulen Fasern der basalen Hinterhirnfläche (Corpus trapezoides), der Anschluß der Schleifen an die Scitenfläche des Mittelhirns, der vordere Abschnitt der Commissura cerricalis, das M e y n e r t sche Bündel. die Mamillarbïndel, das Stammbündel des Thalamus uud die Stria medullaris. Vom Me y nertsehen Bïndel ist das Endstïck nur punktiert angegeben, es hob sich dieses an den Schnitten nicht scharf genug ab. Da ich das Bündel ron jüngeren Stufen (Se, So u. a.) bis in den Isthmus verfolgen kann, so ist auch hier am Vorhandensein des betreffenden Abschnittes nicht zu zweifeln. Im ïbrigen zeigt die vorliegende Stufe eine Reihe von Faserbündeln nur in ihrem Anfangsteil angelegt: 1. Der N. opticus, das Chiasma uud der Tractus opticus sind noch fascrarm. 2. Die Stria medullaris thalami steigt eine Strecke weit vom vorderen Rand des Thalamus in die Höhe, hört aber schon frühzeitig zugeschärft auf, der Deekenabschnitt fehlt. 3. Das Stammbündel des Thalamus sammelt seine fächerförmig zusammenstrahlenden Fasern in einem kompakten, der Seite des Thalamus anliegenden Stamm, ron hier aus tritt es an die Basis des Streifenhïgels, dringt aber nicht tief in diesen ein, sondern endigt stumpf, ohne daß es zur Bildung einer Capsula interna kommt (man vergl. anch die Figg. 104 u, 105, S. 164). Inwieweit die Mamillarbündel und das mediale Längsbündel vollständig angelegt sind, mag ich nicht entscheiden, da die Schnitte dafür keine beweisende Bilder geben. Dagegen erreicht 4, der an das Mittelhirn tretende Teil der Schleifen noch nicht seine spätere Höhe. 5. Dex Fasciculus restiformis ist. falls iberhaupt schon vorhanden, nur in seinen ersten Anfängen angelegt. Ol. $=\mathrm{N}$. olfactorius, $T .0 .=$ Tractus opticus, $S t .=$ Stria medullaris thalami,$C . c .=$ Commissura cervicalis, $T .=$ Thalamusstrahlung und Stammbündel, $M .=$ II e y nert sches Bïndel, $Y_{a}$. = Mamillarbïndel, $S .=$ Schleife, $L .=$ mediales Längsbiindel, $F . s .=$ Fasciculus solitarius, $O .=$ untere Olive, $F . T .=$ Fasciculus spinalis Trigemini, I. G. Gaßeri, FII. N. facialis mit G. geniculi und X. i. $=$ N. intermedius, VIII. Acusticusganglien, $I X$. . glossopharrngeus. $\mathrm{X}$. X. vagus, $K .=$ Kernmassen der Hinterstränge. (Zu Seite 15t.)

auch solche Bündel, die stellenweise scharf umgrenzt sind, nach ihrem Anfangs- und Endpunkte hin diffus auslaufen können. 
Das Ideal der Methode wïrde sein, für einen jeden Faserzug das Herrorgehen der Fasern ans den zugehörigen Neuroblasten d. h. den Anfang und die Auswachsrichtung der Fasern festzustellen. Dies Ideal ist iiberall da erreichbar, wo wir das stufenweise Fortschreiten der answachsenden Faserziig.e verfolgen können. Als interessantes Beispiel hierfür kann ich auf die Verhältnisse des in Figur 101, S. 153, dargestellten Embryo My hinweisen, bei dem eine Anzahl der großen Faserbahnen zwar angelegt, aber noch nieht in ihrer ganzen Länge und Mächtigkeit ansgebildet sind. Bei solchen ist das Anfang'sgebiet der betreffenden Bahnen scharf genng charakterisiert. Allerdings ist dabei noch mit der Möglichkeit zı rechnen, daß in solchen Bahnen gegrenlänfige Faserzüge sekundär anftreten. Durch RAMON Y CAJAL haben wir ja das Yorhandensein entgegengesetzt geriehteter Faserbahnen im N. opticus, durch HELD ein solches in den akustischen Bahnen des Gehirns kennen gelernt. ${ }^{\mathbf{1}}$ )

Berreisend für den Ursprung ron Faserzügen sind natürlich nnt die Präparate, die den Zusammenhang der Fasern mit den Nenroblasten unmittelbar erkennen lassen. In den Fällen aber, wo uns das eine und das andere Kennzeichen im Stich Iassen, da haben andere Methoden, wie ror allem die Silbermethode und die Degenerationsmethode, in die Liicke zı treten. In der Hinsicht enthält die Literatur schon ein sehr beachtenswertes Material, anf das ich indessen im vorliegrenden Anfsatz nur nebenher eingehen kann.

Ich gebe zunächst eine Übersichtstabelle, in der für Embryonen und Foetus verschiedenen Alters ${ }^{2}$ ) die nachgewiesenen Faserbahnen eingetragen sind. Die Faserzüge sind in der Reihenfolge ihres Anftretens angeführt, und von den nicht nachweisbaren Faserziigen ist jeweilen der oberste mit einer Null angegeben. Nit einem positiven Zeichen labe ich die Stränge eingetragen, wenn sie anch nur mit ihren ersten Anfängen nachreisbar waren. So sind z. B. sehon bei Br 3 der Fasciculus solitarius, der Fascieulus spinalis Trigemini und die medialen Längsbïndel als vorhanden angegeben, obwohl sie erst als kurze Stümpfe angelegt sind.

1) HeLd, Die zentrale Gehörleitung. His' Archiv 1 S93 S. $201 \mathrm{ff}$.

2) Über den Gebrauch der Worte „Embryo" und „Foetus" habe ich mich seinerzeit in der Anatomie menschlicher Embryonen (Heft II S. 44 ff.) ausgesprochen. Das Wort Embryo paßt fïr das sich entwickelnde Wesen, solange es die provisorische embryonale Gliederung (Urwirbel, Schlundbogen, WoLfFsche Körper usw.) hat. Da, wo die Gliedernng den bleibenden Charakter angenommen hat, brauchen wir besser die Bezeichnnng Foetus. Der Übergang vom Embryo zum Foetus fällt beim Menschen in die Entwicklungsstufen ron $13-16 \mathrm{~mm}$ Nl., also in die Mitte des zweiten Monats. Nach Überschreitung dieser Stufe sind die Gestalt des Kopfes, des Rumpfes und die Gliederung der Extremitäten ansgesprochen menschliche geworden. Will man aucl die Grenze etwas weiter stecken, so wird man doch jedenfalls rom dritten Monat ab zweckmäßigerweise die Bezeichnung „Embryo“ gegen die ron Foetus vertauschen. 


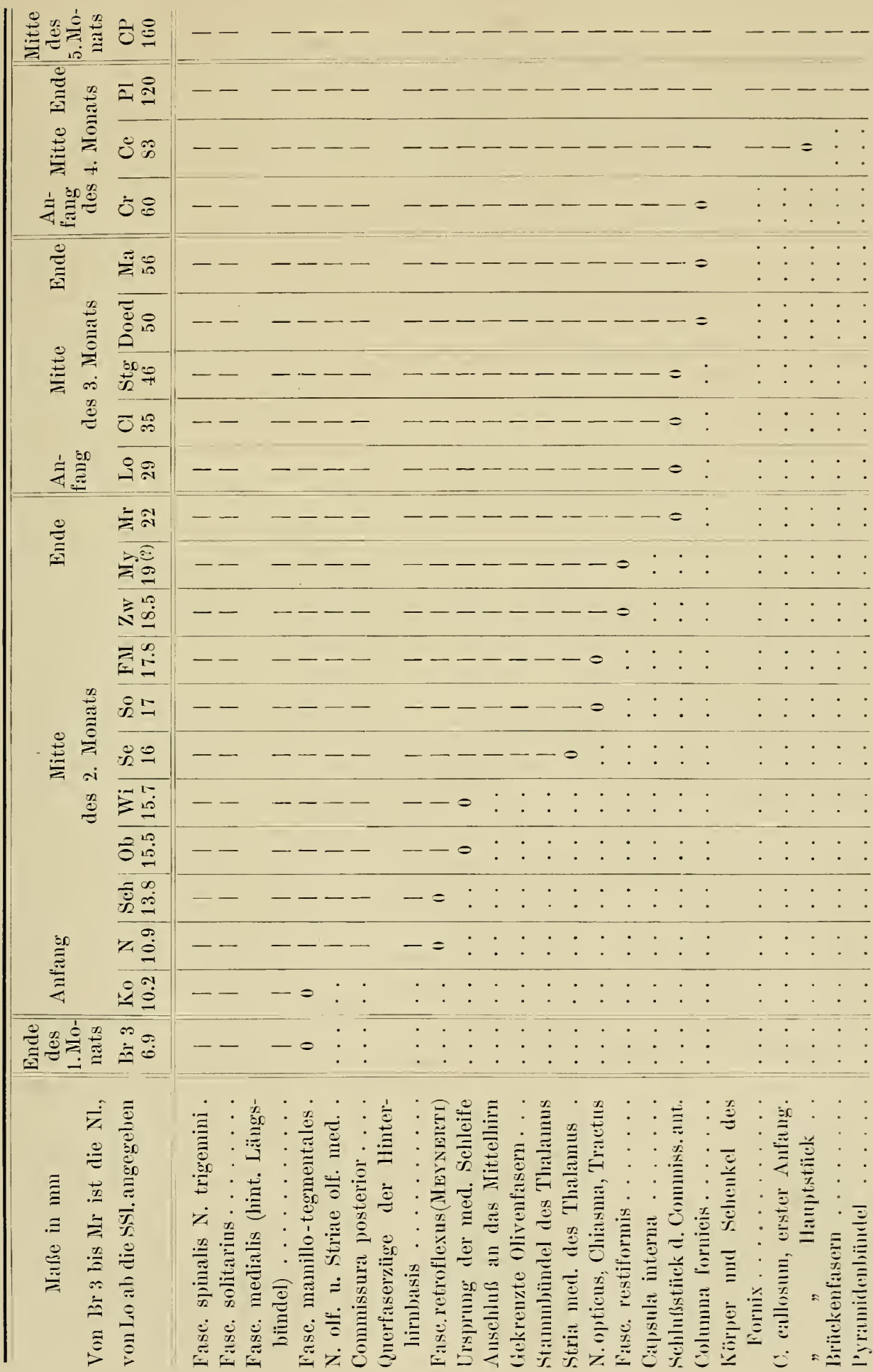




\section{Bemerkungen zu einzelnen Strängen.}

Fascieulus spinalis N. trigemini und Fasciculus solitarius. In betreff dieser beiden Stränge kann ich anf meine frïheren Arbeiten verweisen. Nach ihrer Lagerung und ilurer Bedentung entsprechen sie dem Hinterstrang des Rückenmarkes. Ihr getrennter Verlanf erläntert sich, wie dies seinerzeit gezeigt wurde, dadureh, daß das Auswaehsen der Faserzüge eine gewisse Zeit beansprucht: während die Trigeminusfasern bis zum verlängerten Mark vordringen, hat der Fasciculus solitarius seine oberflächliche Lage bereits aufgegeben, und er ist von Zellen- und Faserschichten umgeben, die an der Bildnng der Formatio retieularis teilnehmen Diese schichten schieben sich demnach trennend zwischen die beiderlei Faserzüge ein.

Der Fasciculus solitarius sammelt Fasern aus den Nn. glossopharyngeus und vagus. Ihm gesellt sich aber auch die spinale Wurzel des $\mathrm{N}$. restibularis bei, sowie der $\mathrm{N}$. intermedius. ${ }^{1}$ ) Seine Herkunft ist also in die Ganglien dieser vier Nerven zn verleg'en. Sein Auslanfen erfolgt, wie man weiß, in den granen Massen an unteren Ende des verlängerten und am oberen des Halsmarkes. Dazu kommen die durch die Silbermethode festgestellten Endig'ungen abgehender Kollateralen in der den Strang begleitenden grauen Substanz.

Unterhalb der Rantengrube verläuft das Solitärbündel als wolılumgrenzter Strang inmitten der dichten Zellenmassen der dorsalen Markhälfte, weiterhin zweigen sich Büschel von ihm ab, die sich zwischen den angrenzenden Zellenmassen verlieren. Der untere Auslänfer des Stranges wird hierdurch dïnner und er beschreibt nummehr im oberen Halsmark einen seitwärts konkaven Bogen. Schließlich gelangen seine seitwärts gekehrten Endfasern in ein Gebiet, in das anch aufsteigende Hinterstrangfasern eintreten. Ich muß mich daher KöLLIKER anschließen, ${ }^{2}$ ) wemn er bemerkt, daß es sehr schwer ist, das distale Ende des Solitärbündels zu bestimmen. Das von RAMON y CA.JAL an Sängetiergehirnen aufgefundene nnd als einer der Endpunkte des Solitärbiindels nachgewiesene Ganglion intereonmissurale ${ }^{3}$ ) war an meinen Präparaten nicht erkenubar.

1) Üher die Beziehungen des N. intermedius und N. vestibularis zum Faseienlus solitarius gibt ein aus Sagittalsehnitten des Embryo Wi hergestelltes Glasmodell sehr anschanliche Bilder. Den Anschluß des N. intermedius habe ich oben in Figur 101, S. 153, eingezeichnet, der des $\mathrm{N}$. vestibularis ließ sich, ohne die Figur nnklar zu machen, nicht eintragen, und ich habe ihn daher wegelassen.

2). Kölliker 1. c. S. 244. Köllikers am angegebenen Ort mitgeteilte Figur 465 stimmt in allen wesentlichen Punkten mit dem, was meine Frontalschnitte zeigen.

3) Ramon y Cajal, Textura del Sistema nervioso del Hombre y de los Vertebrados. Ifadrid 1900. Fasc. IV. S. 73. 
Tractus hypothalamici mol Formationes reticulares. Laut der in Figmr 23 S. 43 wiedergegebenen Konstruktionszeichumng finden sich schon sehr frühzeitig Neuroblasten- und Faserzüge, die von der Basis des Vorderhirns durch die Regio hypothalamica hindureh den Wegr nach dem Nittelhirn einschlagen. In der Folge nimmt die Menge dieser Faserzüge erheblich zu, und man findet demnach anf späteren Stufen die Seitenwand des Hypothalamus ron ilmen reichlich durehsetzt, aber sie sind fein und dabei diffus rerteilt, demnach treten sie nicht als anffällige Bildmgen gesondert hervor.

Den ans dem Hypothalamus in den Haubenwulst übergehenden diffus verteilten Faserzuige schließen sich hier ähnliche Züge an, die ron Nittelhirn ab dureh das gesamte Rantenhim hindurch sich ausbreiten mo deren Menge im Verlanfe des zweiten Monats erheblieh zunimmt. Sie werden weiterhin durehkrenzt ron Radiärfasern und ron Systemen ron Bogenfasern, deren Verhalten in den verschiedenen Bezirken innerhalb gewisser Grenzen weehselt. Es bilden sich so die Formationes retienlares, hinsiehtlich derer ich anf meine ältere Arbeit über das Rantenhirn rerweisen kam.

Das mediale (hintere) Lä ngsbuindel. Abgesehen ron den Nerrenwurzehn ist das sog. lintere Längsbündel embryologisch das erste seharf nmschrieben anftretende Faserbündel des Gehirns. Es ist schon beim rierwöchentlichen Embryo, wenn anch nur anf knrze Strecken, nachweisbar. Es tritt zuerst im Isthmus und weiterhin im Boden des Mittelhirns anf, mnd hier ist es auch in der Folge am schärfsten von der Umgebmng gesondert. Bei Br 3 (siehe oben S. 52) tritt es anf in der Form ron 3-4 rmudiehen. seharfumgrenzten Bündelchen, die dicht unter der Oberfläche liegen. Noch sind sie knrz und verlieren sich beim C̈bergang ins Mittelhirn mo bei dem in die Brïeke. Anßer von diesen Bündelehen zeigen sieh der Randschleier des Isthmus und des Mittelhirnbodens ron feinen Fasern durehsetzt, die zerstrent liegen und keine Bündel bilden. Dieselben Bündelchen und zerstrent liegenden Fasern wie bei Br 3 finde ieh anch bei dem nur wenig älteren Embryo Dl. Bei $R u$ ist das mediale Längsbündel scharf umgrenzt, aber nieht mehr so oberflächlich gelegen. Es ist von einer Schicht ron Bogenfasern und ron Zellenlagen umgriffen. Es rerliert sich beim Übergang ins Mittelhim mnd nach abwärts beim Übergang in die Briicke. Schon anf frühesten Stufen zeigt das mediale Längsbündel Beziehmngen zn den Kernen der Angenmuskeherven. Lant EDINGER ${ }^{1}$ ) gehört das mediale Lüngsbündel zu den konstanten, dureh die gesamten Wirbeltierreiche rorkommenden Gebilden, mnd es wird zn den Bahnen mit kurzem Faserverlanf gerechet. Es sehließt sich mit seiner spinalen Fortsetzung den Vorderstrïngen des Riiekenmarks an. Seine Zusammengehörigkeit mit den Grmubündeln der

1) Edinger 1. c. S. 73. 
spinalen Vorderstränge ist am frühembryonalen Mark noch viel auffälliger, als am ansgebildeten, da in früherer Zeit die uibereinstimmende Lagerung. neben der Nittellinie und nahe an der ventralen Oberfläche schärfer und unverhïllter hervortritt. Bei diesem Verhalten des Längsbündels erscheint die von Mexnert stammende Bezeichnung als „hinteres“ Längsbüindel unzweckmäßig, denn sie besagt das genaue Gegenteil von dem, was das Bündel charakterisiert. Es ist dies der Grund, weshalb die BNA. vorgeschlagen haben, von einem ,medialen“ Längsbündel statt von einem „hinteren" zu sprechen.

Die Angaben über das vordere Ende des medialen Längsbündels lauten sehr verschieden, ${ }^{1}$ ) und ich bin meinerseits nicht in der Lage Entscheidendes darïiber beizubringen. An guten Sagittalschnitten finde ich das Bündel fächerförmig in den Teil des Haubenwulstes ausstrahlend, der gegen den dritten Ventrikel vorspringt.

Die Fasciculi mamillo-tegmentales oder kurzweg Mamillarb ï n d el ${ }^{2}$ ) gehören zu den früh sich sondernden Bildungen. Ihre grobe Faserung und ihre kompakten Bündel lassen sie auffällig aus ihrer Umgebung hervortreten. Mit Sicherheit finde ich sie schon auf den Stufen $N$ und Sch. Der von früh ab gegen die Sattelspalte sich vorwölbende Mamillarkörper besteht längs der Mittellinie aus einer dünnen, auf der Ependymstufe verbleibenden Gewebsplatte. Dagegen entwickeh sich aus seinen dicken Seitenwandungen zahlreiche, zum Teil netzförmig unter sich zusammenhängende Faserbüıdel, die nach oben hin zu stärkeren Stämmchen sich sammeln, weiterhin aber sich wiederum zerspalten, und, spinalwärts sich nmbiegend, in die Haubenwïlste iibergehen. Im allgemeinen verlaufen die Bündel von unten nach aufwärts, an Sagittalschnitten findet man indessen anch solche Bündel, die erst eine Strecke weiter abwärts biegen, bevor sie einem der aufsteigenden Bündel sich anschließen. Die Mamillarbïndel setzen sich von Anfang ab sehr scharf von ihrer Ungebung ab. Die Richtung der in die Haube eintretenden Bündel führt anscheinend gegen das mediale Längsbündel, und bei der Interpretation bloßer Quersehnittreihen kommt man leicht in die Versuchung, einen unmittelbaren Übergang zu konstruieren. Sagittalschnitte geben aber hierfür keine Anhaltspunkte. An solchen erkennt man, daß die Mamillarbündel bei ihrem Übertritt in den Haubenwulst fächerförmig anseinandergehen und in die diffusen Faserzüge der Haube umbiegen. Nach GUDDEx sollen sie in einem besonderen Ganglion, dem

1) Eine eingehende Zusammenstellung gibt KöLLIKer l. c. S. 438 ff. Man vergleiche auch Bechterew, „Die Leitungsbahnen im Gehirn und Rückenmark" deutsch von Weinberg, 2. Auflage 1899. Nach diesem Forscher (1. c. S. 350) enthält das hintere Längsbïndel auf- und absteigende Fasern, womit meine eigenen Beobachtungen ïbereinstimmen.

) „Haubenbündel des Corpus mamillare“ von Gudoex. 
sog. tiefen Ganglion VON GUDDEN endigen. ${ }^{1}$ ) Nach der von KöLLIKER bestätigten Entdeckung von RAION Y CAJAL geht das VICQ D'AzYrsche Bündel, der Fase thalamomanillaris durch Faserteilung ans den Elementen der Mamillarbündel hervor. ${ }^{2}$ ) Es ist nun bemerkenswert, daß ich an foetalen Sagittalschnitten aus dem dritten Monat das VICQ D'AzYrsche Büudel nie zu Gesicht bekommen habe, während doch die Mamillarbündel so frïh und so dentlich zutage treten. Die Zeit, in der das VICQ D'AzYrsche Bündel anftritt, vermag ich vorläufig nicht anzugeben.

Nn. olfactorii und Striae olfactoriae mediales. Die erste Bildungsgeschichte des Riechnerven und sein Herauswachsen aus dem Epithellagen der Riechgrube habe ich in einer früheren Arbeit einläßlich besprochen. ${ }^{3}$ ) Der Zeit nach fällt der Vorgang in die fünfte Woche (Embryo N). Die frühe Geschichte bietet noch allerlei Stoff für spätere eingehende Forschung'en, ich beschränke mich aber hier auf kurze Andeutungen. Die aus den verschiedenen Bezirken des Riechfeldes hervortretenden Nervenbündel sammeln sich bei ihrem Aufsteigen zum Gehirn zu einem ziemlich dicken Stamm, der in schräg nach vorn geneigtem Verlanf an die Bulbusanlag'e herantritt. Die Existenz des anscheinend ungeteilten Olfactoriusstammes hat auf den ersten Blick etwas Befremdendes, da ja späterhin der Durchtritt der Olfactoriusbahnen durch den Schädel in zerteilten Bündeln erfolgt. Der Schlïissel zum Verständnis dieses Verhaltens liegt in der Insertionsweise des Riechnervenstammes in den Bulbus. Die Insertion rerteilt sich nämlich über ein größeres Feld, inden der Bulbus von den herantretenden Bündelchen becherartig umgriffen wird. Es betrifft somit die Zusammenfassung der Faserbuindel zu einem Stanm nur eine mittlere Strecke, vor nnd hinter der die Bündel anseinanderweichen. Anch scheint es innerhalb des Stammes nur zu einer Aneinanderlagerung, nicht aber zu einer geflechtartigen Durchkreuzung der Bündel zu kommen, so daß deren Sonderumg dureh Zwischenschiebung von Mesenchym in Verlanfe weiteren Wachstums keine Hindernisse findet. Die in der ersten Hälfte des zweiten Monats vorhandene Zusammenfassung der Olfactoriusbündel zu einem kompakten Stanm rerliert sich ïbrigens bald, und schon im Beginn des dritten Monats liegen die Bündel in viel loserer Gruppierung.

Fast gleichzeitig, oder jedenfalls nur um weniges später, tritt an der hinteren Grenze des vorderen Rieehhirnes ein rundes, krïftiges Faserbündel auf, die Stria olf a ctoria medialis. Das dem rorderen Riechlirn entstammende Bündel verläuft eine Strecke weit vor der Fissura prima an der medialen

1) ron Gudden, Gesammelte und hinterlassene Abhandlungen herausgeg. ron Grasher Is99. „Das Corpus mamillare und die sog. Schenkel des Fornix" S. 173 und Taf. XXX.

9) KöLLIKER 1. c. S. 515 ff.

$\left.{ }^{3}\right)$ „Formentwicklung des menschlichen Vorderhirns." $\$$. 71 ff. 
Hemisphärenwand in die Höhe und verliert sich dann, indem seine Faserziige in die Wand eintreten (Fig.g. 94 u. 95, S. 141 11. 142).

Commissura cervicalis. Unter diesen gemeinsamen Namen läßt sich eine frïlı anftretende dorsale Qnerkommissur zusammenfassen, die ihre mächtigste Entwicklung ïber dem Einschnitt des Vorderhirnhalses erreieht und vou da aus unter beiderseitiger allmählicher Verjüngnng anf die Deeke des anstoßenden Zwisehenhirns und des Mittelhirns ïbergreift. Der vordere Abschuitt dieser Kommissur wird in der Hirnanatomie als Comm is sura posterior bezeichnet, der hintere, anf das Mittelhirn iibergreifende Teil ist die sog. Kom missur der vorderen $\mathrm{V}$ ierh ü grel. ${ }^{1}$ ) Während erstere an ihrer dorsalen Seite frei bleibt und in bekannter Weise sich faltet, wird die Kommissur des oberen Vierhügels in der Folge von Zellensehichten und von Ausstrahlungen des Sehnerven iiberlagert. Die dorsale Nackenkommissur tritt schon im Verlanf der fünften Woche auf, ich finde sie noch nicht geschlossen bei Embryo Ko, wohl aher bei den Embryonen CR, N u. ff. Sie besteht aus vertikal gestellten parallelen Blättern, die dureh schmale Streifen zellenhaltigen Gewebes roneinander geschieden sind. Die vordere Grenze der dorsalen Kommissur bezeichnet den Ort, wo sich dic Decke des dritten Ventrikels als Zirbelanlage emporzuwölben beginnt. ${ }^{2}$ ) Die hintere Fortsetzung der Kommissur iiberlagert das Mittelhirn in seiner vorderen Hälfte. Die Faserzïg'e zcigen einen schräg nach vorn ansteigenden Verlauf. So früh und so dentlich sie sich aber in ihrem oberen Absehnitt zu erkennen geben, so schwierig ist es, ïber ihre Herkunft und über ilır Endgebiet klare Anschanungen zu gewinnen. Sie verlieren sich in die Seitenwand des Mittellinns, bez. bein Übergang in die Haube. Die Zellenstränge, die die Bïndel roneinander scheiden, haben, soweit ich an meinen Präparaten crsehen kann, mit der Bildung derselben nichts zı tu1. Wo die Stränge vom Schnitt längsgetroffen sind, zeigen sich die Kcrne der zwischenliegenden Zellen quer durchschnitten. Weiter seitwärts stoße ich wohl auf einzelne Neuroblasten, deren Spitzen in der Richtung der Kommissur, dicser zu- oder abgekelıt liegen, aber eigentlich ïberzengende Bilder habe ich keine gewonnen. Bei dem schrägen und gebogenen Verlauf der Kommissurenfasern ist es verständlich, daß man den Zusammenhang mit den zugehörigen Zellenleibern nicht leicht in den Schnitt bekommt. Nach der Angabe nenerer

1) Die Kommissur der vorderen Vierhïgel findet sich abgebildet bei KöLLIKER l. c. S. 444, Fig. 100, sowie Fig. 568, S. 407 und Fig. 569, S. 408.

2) Die hintere Kommissur ist vorhanden, ehe sich die Zirbel als selbständige Ausbuchtung der Zwischenhirndecke hervorwölbt. Erheblich später als die hintere entwickelt sich die sog. obere Kommissur der vergl. Anatomen, oder die Commissura h a be nularum der BNA. Es liegt nahe, die Ausbuchtung der Zirbel anf eine Stanung der diinnen Deckplatte des dritten Ventrikels durch den Querfaserstrang der hinteren und später vielleicht auch der oberen Kommissur zurückzuführen. 


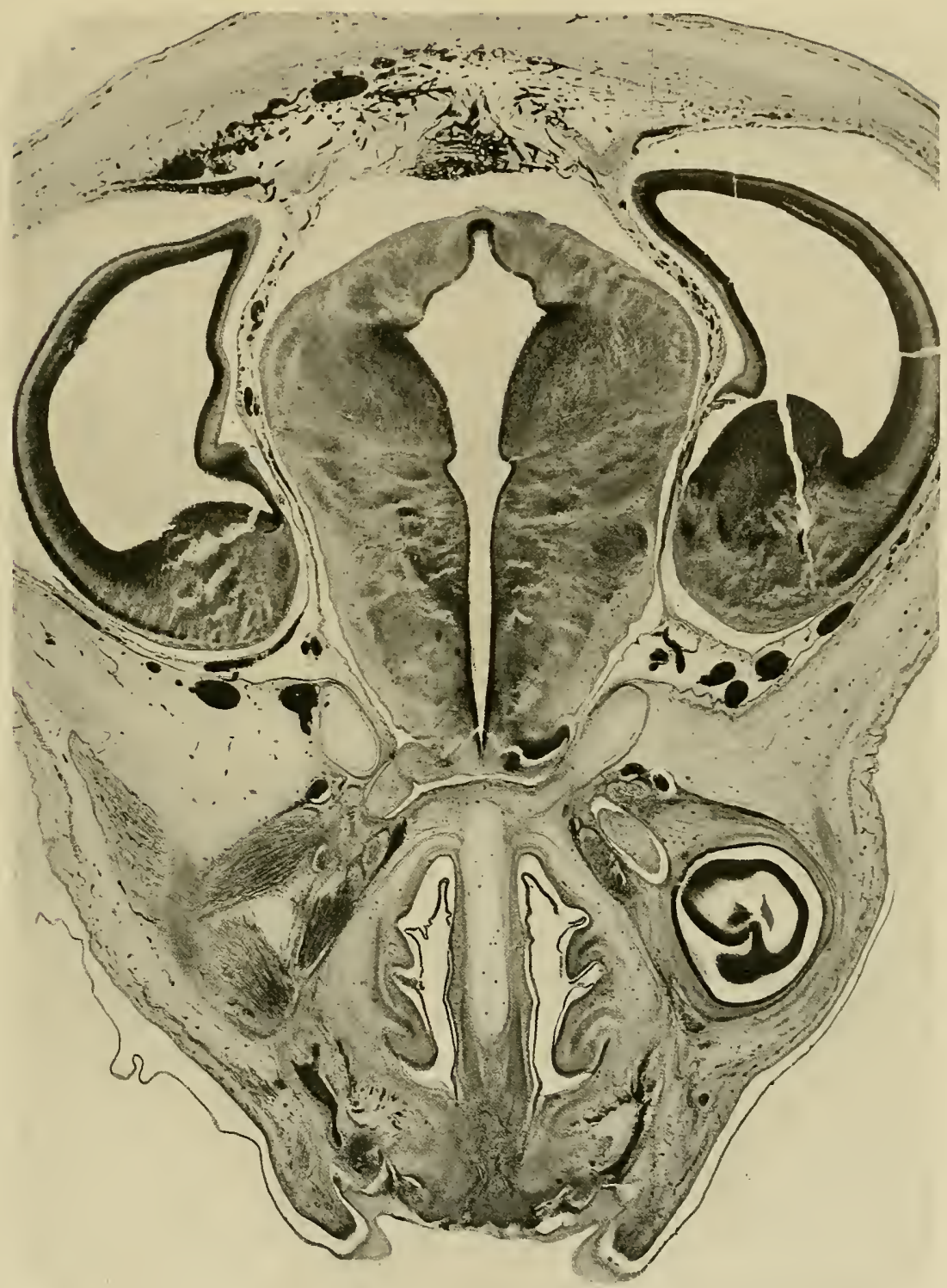

Fig. 102. Querschnitt dureh den Kopf ron Foetus Stg $(46 \mathrm{~mm}$ SS1.). Der Schnitt geht durch den hinter dem stiel liegenden Teil der Hemisphären. Letztere zeigen beiderseits den schweif des Streifenhïgels und an der medialen Oberfläche den Limbus mit der Bogenfurche, rechts anch noch einen Streiten ron der Lamina infrachorioidea. Das $Z$ wischenhirn ist in schräger Richtung getroffen, ohen in seinem hinteren Abschnitt, unten am hinteren Rande des Chiasma. Die quergestellte Furche im oberen Teil res Thalamushirns, die den Epithalamus rom eigentlichen Thalamus scheidet, ist der Recessus geniculi. Die an der Grenze des Recessus liegenden querdurchschnittenen Faserbündel gebören zum Mernertschen Bündel. Das Chiasma ist in seinem hintersten Abschnitt rom Schnitt gestreift, links sieht man noch die Abgangsstellen des N. opticus; rechts liegt der Schrägschnitt des letzteren bereits außerhalb der schädelhöhle. Zwischen dem Sehnerven und dem nmgebenden Gewebe liegt eine klaffende Spalte. die sich beim Eintritt in den Schädel in den epicerebralen Raum öfnet. Wie dieser, so bezeichnet die möglicherweise dureh Gewebsschrumpiung erweiterte) Spalte den Zwischenraum zwischen der Gliascheide des Nerren und seiner Bindegetrebsseheide, beide sind zur Zeit noch seharf voneinander gesondert. Jenseits vom Chiasma rerfolgt man auf jeder Seite eine Strecke weit den Verlauf des Tractus opticus. (Zu Seite 162.) 
Hirnforscher sollen die medialen Längsbündel und die hintere Kommissur einen gemeinsamen Kern besitzen. ${ }^{1}$ )

Soweit die hintere Kommissur dem Zwischenhirn angehört, liegen ihre Bündel im Epithalanus. Dieser bildet noch beim Foetus des dritten Monats eine quergelagerte, medialwärts sich verdiunnende und schließlich in die ependymatöse Deckhant iibergehende Platte. Durch eine scharfe, im Grund des Recessus geniculi auslaufende Furche scheidet sich der Epithalamus vom Thalamus (Fig. 102, S. 161). Unmittelbar an den Ventrikelraum grenzt auch beim Epithalamus eine dunkle Schicht von Höhlengrau, über dieser, und teilweise noch in sie eingegraben, liegen die blattartigen Bündel der hinteren Kommissur. In ihrer scharfen Ungrenzung sind sie nur eine kurze Strecke weit in die Seitenwand verfolgbar. Nach voru werden im Epithalamus die Kommissurenbündel durch die Ursprungsbiundel des Fasc. retroflexus abgelöst, die auch ihrerseits in das Höhlengran des Recessus geniculi sich eingraben und in ihrem weiteren Verlauf den letzteren seitwärts umgreifen.

Die Schleifen. Bei denr winkligen Verlauf der beiden Schleifen ist es auf früheren Stufen keineswegs leicht, deren gesamten Verlauf an einer und derselben Schnittreihe iibersichtlich zu verfolgen. Das erste, was davon leicht 'zur Anschanumg

Fig. 103. Basis des Rautenhirns eines Foetus von $5 \mathrm{~cm}$ SSI Man sieht das freiliegencle Corpus trapezoides, den Anfangsteil der akustischen Schleifo und den Anschluß von Schleifcnfasem an die Seitenfliiche des Mittelhirns. ( $\mathrm{Zu}$ Seite 163.)

gelangt, ist der an das Mittelhirn herantretende Abschnitt, und den findet man in der zweiten Hälfte des zweiten Monats an Querschnitten als eine helle, das Mittelhirn seitlich umgreifende Belegschicht, an Sagittalschnitten als eine scheitelwärts schräg ansteigende Faserplatte. In der Zeit muß anch der Ursprung der Schleifen schon vorhanden sein, und für die sensible (mediale) Schleife ist er nuverkemmbar in dichten Zügen von Bogenfasern gegeben, die aus den dorsalen Zellenmassen des verlängerten Markes, dem Gebiete der späteren Hinterstrangkerne hervortreten und ventralwärts in der 
Richtung der Olivenkerne verlaufen, und deren Durchkreuzung in der Nittelebene an Quersehnitten konstatierbar ist. Weniger klar bin ich iiher den genanen Zeitpunkt, in dem der Ursprung der akustischen (lateralen) Sclleife und des Trapezkörpers auftreten. Querfasern finden sich an der basalen Fläche des Hinterhirns schon sehr frïh, im lieginn des zweiten Monats, allein diese früh auftretenden Fasern sind dem System der Formatio reticularis zuzuweisen, sie liegen also in der Folge tiefer als der Trapezkörper.

Die laterale Schleife liegt, wem sie eimmal vorhanden ist, oberflächlich, und so finden wir sie in dritten Monat als cine von bloßem Auge bez. mit der Lupe sichtbare Bildung (Fig. 103, s. 162). Man sieht an Gehirnen ans dieser Zeit den die Seitenfläche des Corpus restiforme umgreifenden Anfangsteil, seinen Übergang ins C. trapezoides und den Anschluf des letzteren an die das Mittelhirn erreiehenden Faserziige. Entsprechend zeigen anch Querschnitte aus der Zeit die oberfläichliche Lagerung des Trapezkörpers.

\section{Der Thalamus und seine Verbindungen; das Stammbiindel des Thalamus.}

Gegen Ende des zweiten und im Beginn des dritten Monats zeigen sich die dem Thalamushim entstammenden Faserzïge ziemlich uibersichtlich angeordnet. Es sondern sich nämlich zu der Zeit drei Ursprungsgebiete, ron denen jedes ein Hauptbïndel entsendet. Das erste dieser Bündel, das den Stabkranz des Thalamus in sich aufuimmt, kömen wir als Stammb ïndel bezeichnen, das zweite ist das MEYNERTsche Bündel oder der Faseiculus retroflexus, das dritte die Stria medullaristhalami.

Das Ursprungsgebiet des Stammbündels unfaßt weitaus die Hauptmasse der Thalamuswand. Zunächst gehört ihm das obere Thalamusgebiet bis zum Recessus geniculi an, allein auch das mutere, mittlere und hintere Gebiet entsenden Fasern zum Stammbündel, wie dies am dentlichsten an g"uten Sagittalschnitten sich feststellen läßt (Fig. 104, S. 165). Die aus diesen rerschiedenen Bezirken stammenden Fasern treten zunächst zu zahlreichen kleinen Büscheln zusammen, die sehräg basal- nud lateralwärts rerlaufen. Ën großer Teil derselben tritt in eine der Außenfliiche des Thalamns anliegende Fasersehicht, das Stratum zonale ein. Weiterhin sammeln sich sämtliche Fasern zu einem kompakten runden Bündel, das ron hinten und muten her an das Stielgehiet der Hemisphären herantritt. Dies Bündel, das S ta mnb in del, liegt anfangs noch oberflächlich, seine Fortsetzung dringt aber in den Streifenluiigel ein, und hier findet man es gegen Ende des zweiten Nonats, als stumpf auslaufendes, ziemlich abgeschlossenes Gebilde Fig. 101, S. 153.) Zn der Zeit gibt es noch keine innere Kapsel, dann aber, wemn die Rindenbildung beginnt, breitet sich das Stammbündel zu einer flachen nach vorn vordringenden Platte ans, die weiterhin ron Zellenscharen durchsetzt und in grobe Bündel zerlegt wird. Die innere K apsel, diesich numelur bildet, ist zur Zeit ihrer ersten Entstehug aus- 
164 Über intramedullare Faserbahnen und die Zeit ihres ersten Auftretens.

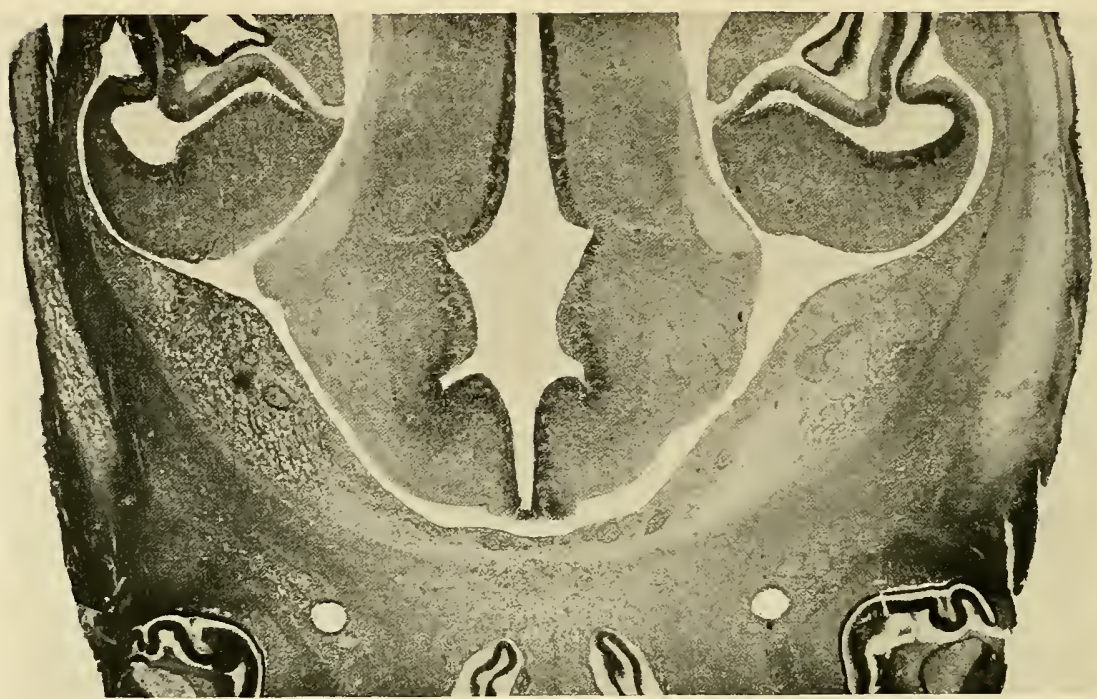

Fig. 104. Quersehnitt dureh das Vorderhirn des Embryo My (NI. $19 \mathrm{~mm}$ ?). Der Sehnitt zeigt die basale Hälfte des Zwisehenhirns und beiderseits ein Stiiek von den das Stielgebiet ïbcrragenden Hemisphären mit dem Sehweife des Streifenhïgels. Das Stammbündel des Thalamus liegt als heller Streifen dem letzteren seitlich an und ist dem Streifenhügel zugekehrt. (Zu Seite 163.)

schlieBlich aus dem Stammbïmdel des Thalamus abzuleiten, und dasselbe gilt von den früher besproebenen aus der inneren Kapsel in die Hemisphären eintretenden Faserzügen.

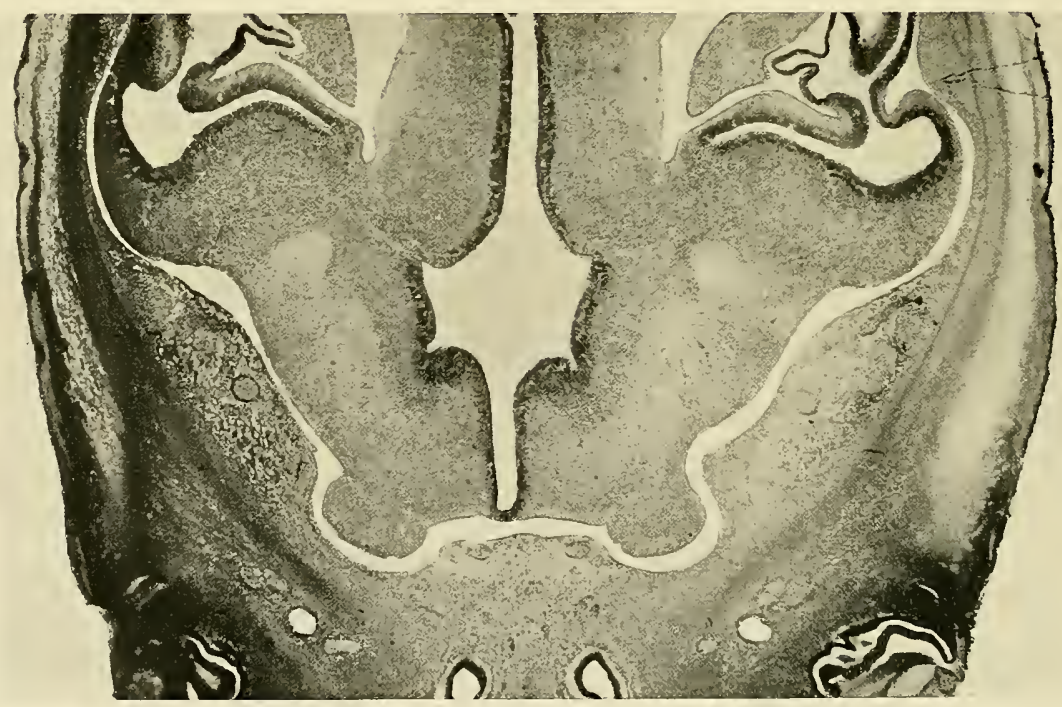

Fig. 105. Schnitt durch dasselbe Gehirn etwas weiter nach vorn. Der Sehnitt trifft bereits das Stielgebiet und zeigt das Stammbündel des Thalamus als rundliches helles Feld unter dem Streifenhiigel liegend. Von einer inneren Kapsel ist noeh nichts vorhanden, das Stammbündel endigt stumpf im Streifenhügel. 
In den Figuren 104 und 105 habe ich zwei Qnersehnittshilder dureh das Vorderhirn des im übrigen nicht tadellosen Embryo My nitgeteilt. Iie erste der beiden Figuren (104) zeigt die Bildung des Stammbindels an der Seitenfliche des Thalamus; Figur 105 zeigt dessen Lage nach Eintritt in den Streifenhiigel. Das Bündel endigt noch stumpf und es verliert sich in den näehstfolgenden Schnitten spurlos. Sehon bei dem etwas älteren Embryo Mr

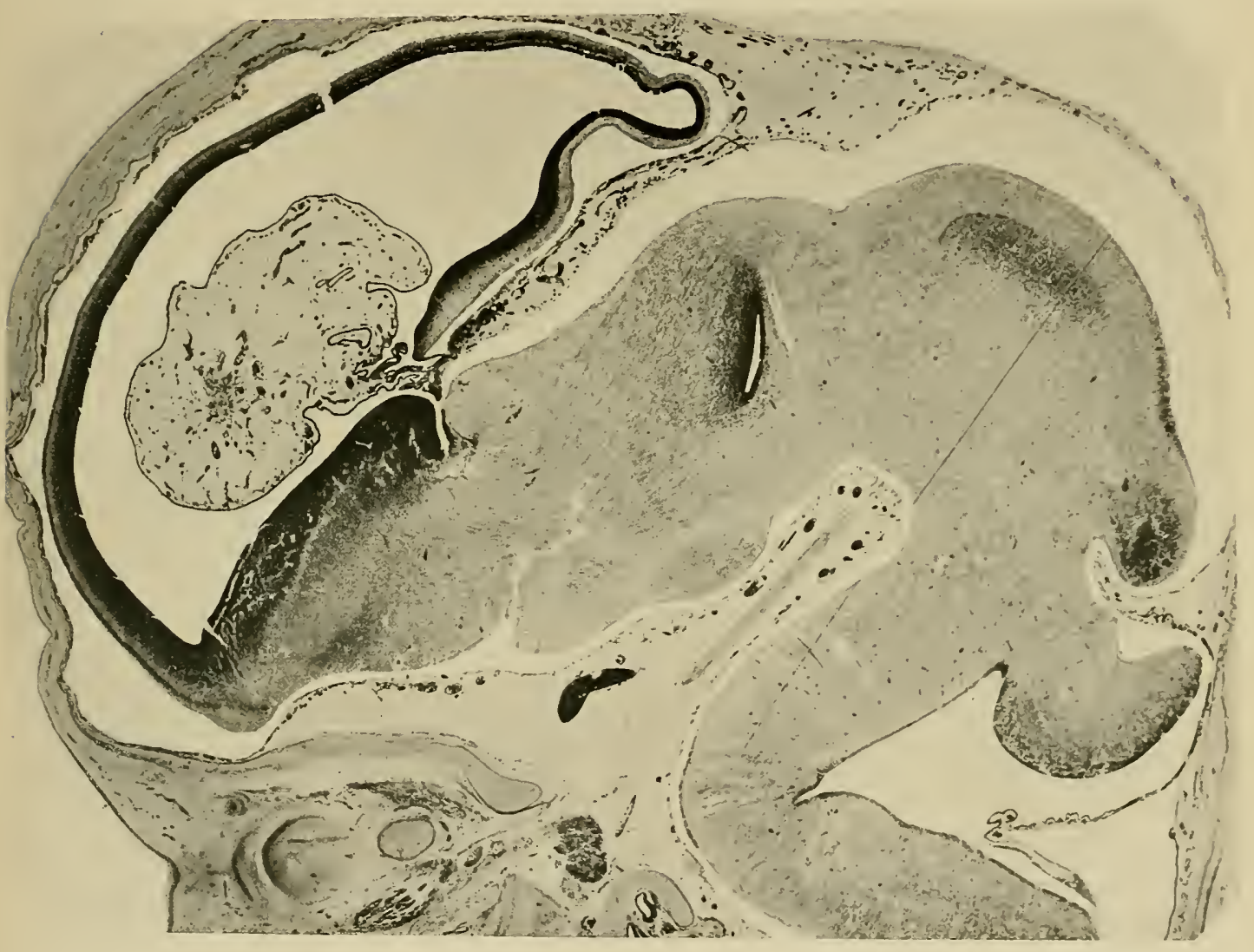

Fig. 106. Seitlich rerlaufender Sagittalschnitt durch das Gehirn ron Embryo Cl. Es sind Cerebellum, Mittelhim, Thalamus. Streifenhïgel nud Pallium rom Schnitte getroffen. Die dunkel eingefabte spalte im Thalamus ist der Recessus geniculi, hinter ihm ist als heller streifen ein Stïck des Mernertschen Bündels zu sehen. Nach rorn rom Recessus kommen die Ziige des Stabkranzes des Thalamus zur Anschaumng, die. nach rorn und basalwärts gerichtet, in das Stammbïndel ïbergehen. Ein Teil des letzteren bildet einen die Oberfläche iiberragenden rundlichen Wulst. Im übrigen sieht man die Fasern des Stabkranzes des Thalamms unter dem Streifenhügel in die innere Kapsel ibergehen. (Zu Seite 166.)

(Nl. $22 \mathrm{~mm}$ ) tritt es dureh den Streifenhügel in die Hemisphärenwand ein, nnd noch weiter ansgebildet finde ich es bei den Embryonen Oe und Stg̈, ron denen ich (Figg. 41-43, 49 ॥. 59) eine Reihe ron Schnitten mitgeteilt habe. Instruktiv sind anch Sagittalschnitte aus dieser und den nachfolgenden Perioden. An solchen rerfolgt man leicht das konvergente Zusammenlaufen 
der ans den verschiedenen Bezirken des Thalamus stammenden Faserziige. Das Stammbündel zeichnet sich vor seinem Eintritt in den Streifenhïgel als rundlicher Vorsprung. Es erreicht den Streifenhügel hinter dessen

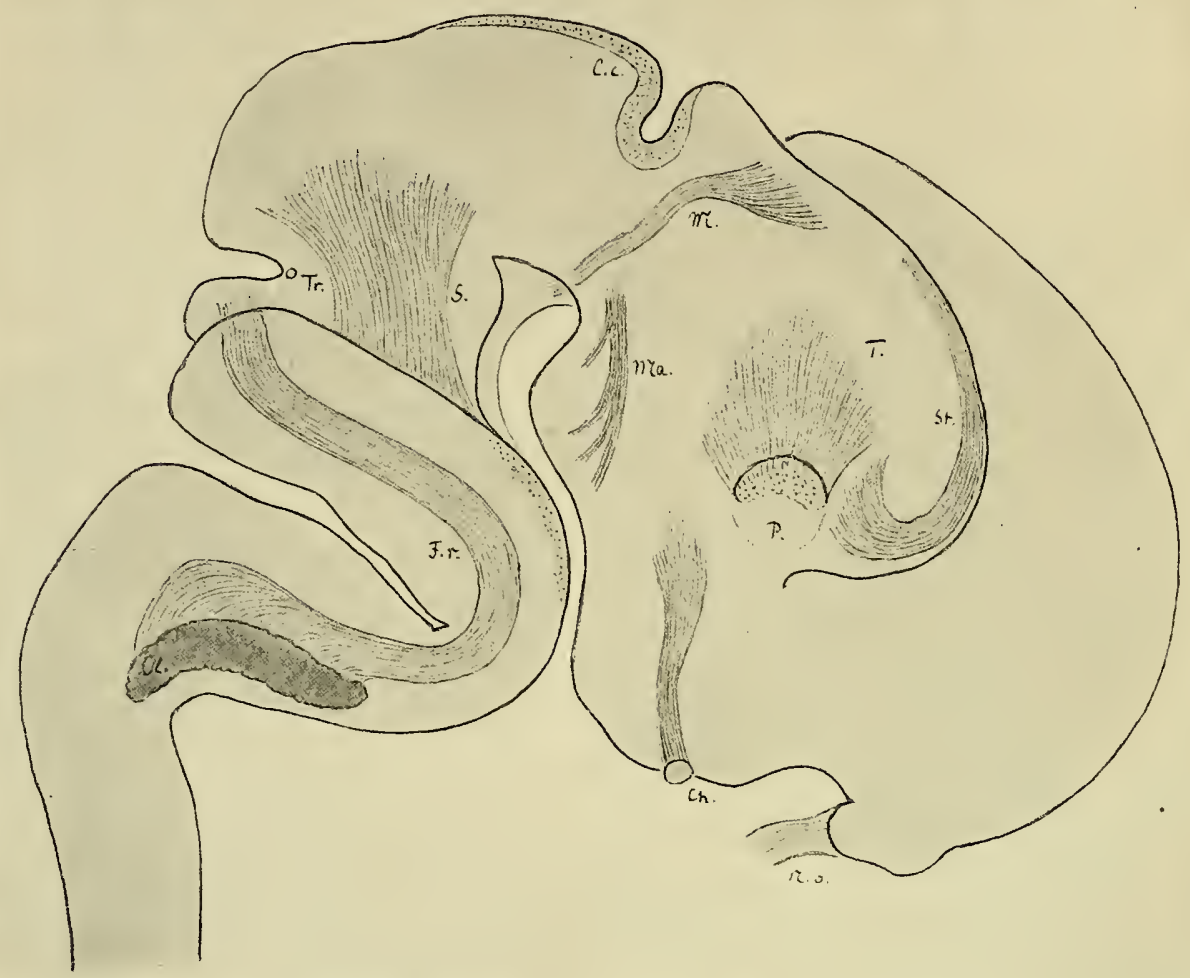

Fig. 107. Gehirn des Embryo Nr (Nl. $22 \mathrm{~mm}$ ) Profilkonstruktion innerer Faserbahnen. Vergr. $10 \mathrm{fach}$. Es sind in der Zeichnung nicht alle vorhandenen Bahnen dargestellt, so sind der Tractus solitarius, der Tractus Trigemini und das mediale Längsbündel weggelassen, da durch deren Einzeichnung das Bild unklar geworden wäre. Von den Schleifen ist nur die an der Seitenwand der Vierhïgel emporsteigende Faserplatte (S.) eingezeichnet. Im iibrigen sind gezeichnet: die Thalamusstrahlung nach dem Stammbiindel $T$. hin, die Stria medullaris Thalami (St.), das II eynertsche Bündel ( $\left.M_{*}\right)$, die Mamillarbündel (Ma.), das Chiasma $(C h$.) und der Tractus opticus, die cervikale bez, die dorsale Kommissur $(C . c$.$) , der Fasciculus restiformis (F, r$.) und der N. olfactorius ( $N$. o.). Die sonstigen Bezeichnungen bedeuten: $P$. den Hemisphärenstiel, in dessen oberen Teil das Stammbïndel des Thalamus eintritt, $T$. den Austritt des N. trochlearis, Ol. die untere Olive. Die durchschnittenen Querfasern an der basalen Oberfl̈̈che des Hinterhirns, oberhalb von der Brickenkrïmmung, gehören dem Corpus trapezoides an. Einige der vorhandenen Bündel sind noch nicht in ihrer gesamten Länge angelegt. So hört die Stria medullaris schon in der halben Länge der oberen Thalamusfläche zugeschärft auf. Auch die Überschreitung der Mittelebene durch den Fasciculus restiformis ist noch nicht erfolgt. (Zu Seite 168.)

hinterem Schenkel, zwischen ihm und dem Streifenhügelschweif (Fig. 106, S. 165).

Das, was ich hier als Stammbuindel des Thalamus beschreibe, stimmt in zallreichen Punkten mit EDINGERs bas a lem Vorderbirnbiondel 
oder seiner Radiatio striothalamica iberein. ${ }^{1}$ EDINGER Abluillung (Fig. 193 S. 273) scheint für eine Identität beider Gebilde beinahe beweisend. Immerhin differieren unsere Angaben noch in wesentlichen l'uukten. Nach EDINGER entspringen die Fasermassen des basalen Vorderhirnbindels aus den Streifenhuigel und endigen in Thalanus. Mein Stanmbindel des Thalamus dagegen entspringt nuzweifelhaft in diesen, und es wächst, wie sich ans den oben nitgeteilten Beobaehtungen ergibt, sehrittweise gegen den Streifenhiigel vor. Auch ist, naehdem es sich zur Capsula interna entwiekelt hat, sein anfängliches Ausbreitungsgebiet nieht der Streifenhïigel, sondern der Hemisphärenmantel, in den seine Faserzïge unter dem Nuelens eaudatus hindureh eindringen.

\section{Das Meynert-}

sehe Biindel (Faseiculus retroflexus ${ }^{*}$ ) sammelt seine $\mathrm{Fa}$ serbüudel ans dem hinteren Absehnitt des Epithalamus, dem späteren $\mathrm{G}$. habenulae, seine Ursprïnge liegren in



Fig. 108. Vorderer Gehirnabschnitt desselben Embryo Mr, Flächenkonstruktion. Vergr. 10 fach. Die Faltungen der medialen Hemisphärenwand sind nicht eingczeichnet. Die Figur zeigt die zur Decke emportretende Stria medullaris und ihr zugeschärftes rorläufiges Ende (St.), sodann das Stanmbüudel des Thalamus $(T$.), seinen Weg durch die innere Kapsel unter dem Nuclens caudatus hindurch und seinen Eintritt in die laterale Wand des Palliums. Die Ausdehung des Streifenhiigels ist punktiert angegeben. In ler hinteren Hälfte des Thalamus ist das Me ynertsche Bündel (II.) eingezeichnet, das rorn mit fächerförmig zusammenstrahlenden Faserziigen beginnt. Ferner übersieht man die Flichenausdehnung der cervikalen foommissur (Ce.), die bis weit iiber den oberen Vierhiigel sich erstreckt. (Zu Seite 16s.) der Deeke des Recessus genienli mnd nehmen hier einen relatir breiten Flächenraum ein, sie sammeln sich, wie dies an Sagittalschnitten am leichtesten zu verfolgen ist.

1) Edinger 1. c. S. 144 u. S. 172. Edinger hält die Linsenkernschlinge fiï einen Teil des basalen Vorderhirnbündels.

2) Von MeYverT (1. e. S . 737) urspriinglich als ,Haubenbündel ans dem Zirbelstiel“ beschrieben. Mersert läßt das Bündel aus dem Ganglion habennlate entspringen und nit seinem unteren Ende den roten Hambenkern von der medialen seite her umfissen. 
zul anfangs getrennt verlaufenden, dann aber konvergierend zusammentretenden Bündehn, welche den Cervix des Vorderhirns seitlich umfassen, weiterhin mit dem medialen Längsbïndel sich kreuzen und schließlich im vorderen Teil des Mittelhirnborlens nahe an der Mittelebene und dicht unter der Oberfläche auslaufen (Fig. 107, S. 166). In der Flächenprojektion beschreibt das Mexnert sche Bündel einen lateralwärts konvexen Bogen (Fig. 108, S. 167), im Profil zeigt es einen leicht wellenförmigen Verlauf. Die unteren Enden beider Bündel kouvergieren nach der Mittelebene hin, aber bis zu Stufe Stg vermag ich keine Krenzung der Endfasern zu erkennen, und auch von einem abgesonderten Ganglion interpedunculare ist zu der Zeit noch nichts vorhanden. Das Ende des Bündels verliert sich nahe neben der Mittellinie, ohne in Zellenhaufen einzutreten. ${ }^{1}$ )

Das Ursprungsgebiet des MEYNERTschen Bündels schließt sich im linteren Abschnitt des Epithalamus an das Ausbreitungsgebiet der hinteren Kommissur an und seine Faserzïge streifen gleich denen der Kommissur die Riickwand des Recessus geniculi.

Die Stria medullaris des Thalamus erseheint etwas später als das Stammbündel. Am iibersichtlichsten zeigen sich ihre Verhältnisse an Sagittalschnitten, die unweit von der Mittelebene geführt sind. Hier erscheint die Stria mit retortenartig gestaltetem Profil, sie beginnt am vorderen unteren Ende des Thalamus breit, indem sie die fächerförmig ans der Umgebung zusanmmenströmenden Faserbündel sammelt; dann verjüngt sie sich und biegt num nach oben und oceipitalwärts um. Sie verläuft dem Rande des Epithalamus entlang, dicht vor Beginn der Taenia und der Lamina chorioidea thalami. Ihr hinterer Abschnitt erreicht nach rollendeter Ausbildung das Gebiet des späteren Ganglion habenulae. Nach Angabe der Autoren soll sie teils in diesem endigen, teils in die Commissura habenularum ïbergehen. ${ }^{2}$ ) Beim Embryo Mr (22 mm Nl.), ron dem oben (Figg. 106 and 107) zwei Konstruktionsbilder mitgeteilt worden sind, hört die Stria jederseits schon im vorderen Drittel des Thalamus zugeschärft auf, ein Beleg dafür, daß deren Fasern von unten nach oben, und im Epithalamus von vorn nach rückwärts hin wachsen. Noch kürzer, obwohl schon vorhanden, ist sie bei Embryo My (Fig. 100).

Gudpex (1. e. S. 171) zeigt, daß nach Wegnehmen des G. habenulae das Mernertsche Bündel zugrnode geht, aber doch läßt er es nicht aus diesem, sondern aus dem von ihm aufgefundenen G. interpeduneulare entspringen. Die neueren Antoren (s. KöLLıKer I. c. S. 484) sind mit Recht zur Vorstellung MErNents vom oberen Ursprung des Bündels zuriickgekehrt. Auch meine Beobachtungen an Foetus des dritten Monats (Ma, Stg u. a.) lassen keine andere Deutung zu.

1) Kölliker sagt (1. c. S. 434), daß sich das Merrnertsche Bündel bei Tieren in das G. interpednnculare verliert, beim Menschen aber unmerklich in der Sulst. perforata posterior ausläuft, zum Teil mit Andeutungen einer Krenzung.

2) KöLlikeR 1. c. S. 484 . 
N. optieus und Chiasma. Der Augenblasenstiel liefert die erste Anlage des Sehnerren vom Chiasma bis zum Bulbus. Seiner Entstelıugsweise gemäß umschließt er auf früheren Stufen eine Höhlung, die einerseits nnit dem Ventrikelraum des Gehirns, bez. mit dessen Recessus opticus, anderseits mit dem periretinalen Spaltraum zusammenlängt. Eine zweite, in der Verlängerung des Augenbeehers gelegene Höhlung entwickelt sich an peripherischen Ende des Augenblasenstieles durch Einstiilpung der Wand. Als offene Rimne sieh anlegend, schließt sich diese zweite Höhlung in der Folge gleichfalls zum geschlossenen Kanal, und in ihr treten die Yasa centralia retinae zum Bulbus hin. Wir können die beiden genetisch versehiedenen Höblungen als ventrikuläre und als raskuläre roneinander unterseheiden (Fig. 109). Erstere hat im allgemeinen eine kreisrunde Gestalt, nimmt aber in der Nähe des Bulbus Halbmondform an, entspreehend der rinnenförmigen Einbiegung der Wand.

Die ventrikuläre Höhlung wird bei zunehmender Entfernung des Bulbus rom Gehirn zu einem feinen Gang, und dieser schließt sieh in der Mitte des zweiten Monats, so daß in der näehstfolgenden Zeit der ursprïngliche Röhrencharakter des Stieles nur noeh an einer kranzförmigen Anordnumg der radiärgestellten Kerne erkennbar bleibt. An den beiden Endstiieken des Stieles erhält sich die Lichtuug an längsten. Nebenstehende Fig'ur 109 zeigt sie von Embryo Ob noch in der Nähe des Bulbus, bei demselben Embryo ist auch das Gehirnende des Stieles noch eine

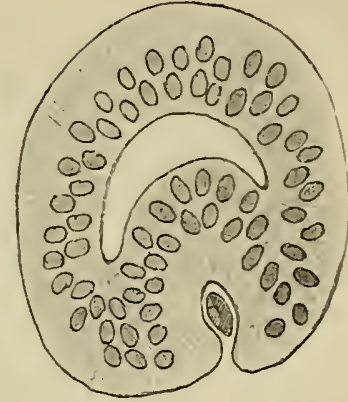

Fig. 109. Quersehnitt des Augenblasenstieles mahe am Bulbus. Embryo $\mathrm{Ob}$ (15.5 num Nl.). Vergr. 350 fach. Prismenzeichnung. Die ventrikuläre Lichtung ist noch offen und hat Halbmondform, die raskuläre Liehtung mit inneliegender Gefäßanlage liegt exzentrisch.

kleine Streeke weit offen. Noch weiter klafft die Lichtung an der Abgangsstelle vom Bulbus. Allein auch bei dem Embryo Wi, ron dem Figur 110 (S. 170) stammt, ist die Lichtung nur in allernächster Nähe des Recessus optiens als ein von diesem ansgehender feiner Kanal erkennbar, und die halbmondförmige Liehtung im peripherisehen Ende beschränkt sich auf das dem Bulbus unmittelbar anhaftende Stiiek, sie reicht kaum weiter, als der Pigmentgehalt des äußeren Blattes. Anch hier kann die spur der früheren halbmondförmigen Liehtung eine Strecke weit an der Gruppierung der Zellenkerne erkennbar bleiben.

Der Angenblasenstiel besteht aus Gliagewebe und, beror es zum Einwaehsen von Nervenfasern kommt, entwiekelt sich in ihm ein durehbrochenes Gerïst. Die Entwicklung der Optiensfasern erfolgt, wie aus obiger Tabelle hervorgeht, erst gegen Ende des zweitens Monats. Nunmehr verwischen sich anch die letzten Spuren, die rom ursprünglichen 
Röhrencharakter des Angenstieles ïbrig geblieben waren (Fig. 111, S. 171). Nachdem der Nerv faserhaltig geworden ist, bleibt er immer noch dureh eine feine M. limitans von umgebenden Gewebe geselieden, und auch gegen die vaseuläre Höhlung hin sehließt er sich durch eine solche ab (Fig. 112, S. 172). Von einer Beimengung von mesenchymatösem Gewebe zum Optiensgeriist ist noelı in der ersten Hälfte des dritten Monats niehts wahrzunehmen. Bogenförmig gekrümmte Kapillaren finden sieh bis dicht

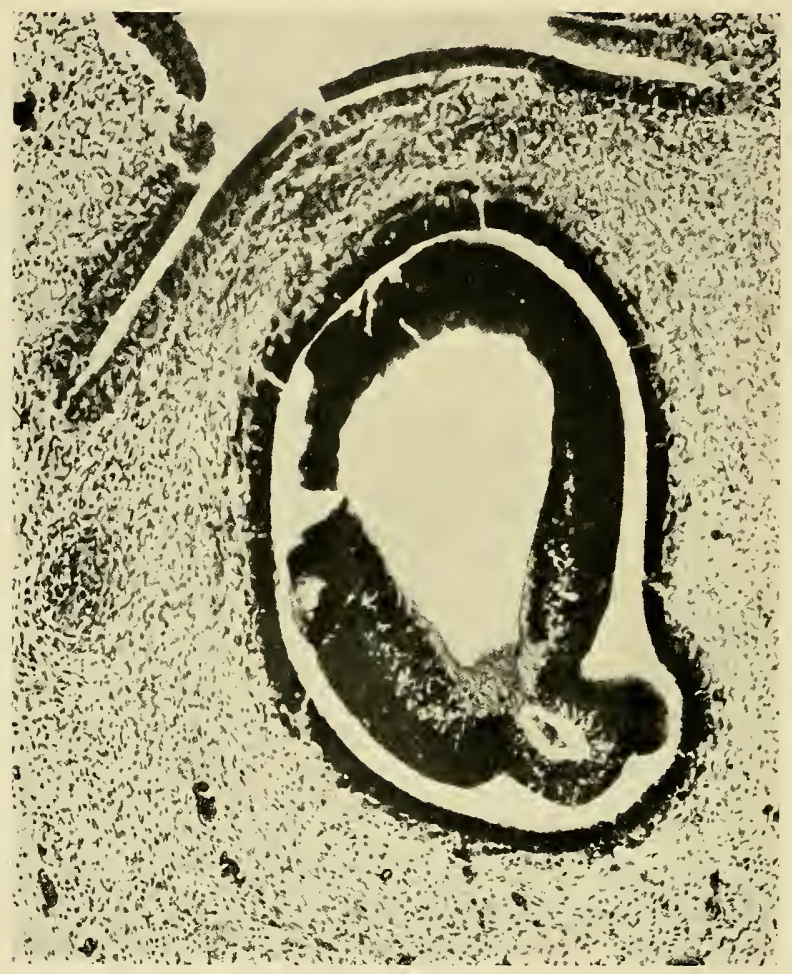

fig. 110. Stielanlage des N. optieus, Embryo Wi (N1. $15.7 \mathrm{~mm}$ ). Es sind zu der Zeit noeh keine Nervenfasern vorhanden. Die von der Retina sich abhebende Anlage des Selnerven, bez. des Augenblasenstieles, zeigt im Innern eine rolativ weite vaskuläre Höhle, und sie wird in diesem ihren Anfangsteil von einer rentrikulären IIöhle umfaßt, die ihrerseits mit dem Spaltraum zwisehen Retina und Pigmenthaut жusammenhängt. (Zu Seite 169.)

an den Sehnervenstamm herantretend, aber weder von ihnen, noch von den Zentralgefäßen ans sind in der Zeit Fortsetzungen in die Substanz des Stammes hinein verfolgbar. Von Interesse ist zn der Zeit das Verhalten des Sehnerven zum Recessus optiens des dritten Ventrikels. Im Bereich des Chiasma ist der Recessus ringsherum von seinem Höhlengraı selbständig abgegrenzt, und es schieben sich zwischen ihn und den Nerven helle Gewebsschichten ein. Anders verhält sich's da, wo der Nervenstamm an die Gehirnbasis von anßen her herantritt. Da hildet der Nerrenstamm 
eine Strecke weit eine dicke, gekrïmmte Platte, die den Alsschlnß des Recessus bilden hilft. Die an den Recessus anstoßentlen Gliazellen schicken strahlige Fortsaitze in die Nervenplatte hinein und verleihen dieser anf dem

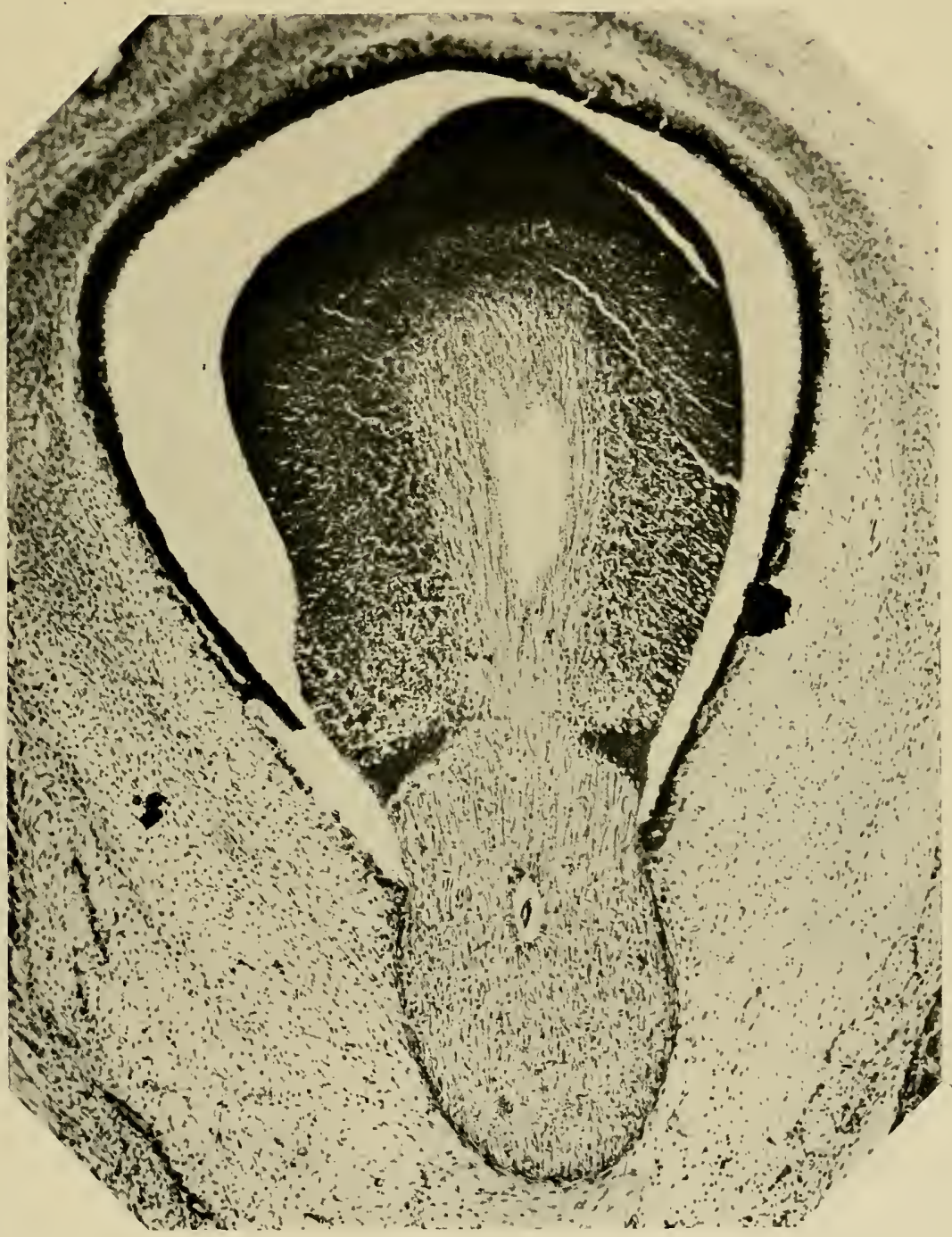

Fig. 111. Austritt des $\mathbf{N}$. opticus aus den Auge, Sagitfalsehnitt von Foetus ('l. Immitten des Stammes zeigt sich đie vaskuläre Höhlung mit dem Gefäßdurchschnitt. Eine selbstïndige rentrikulïre Hählung ist im Nervenstamm nicht vorhanden, die periretinale Spalte endigt zugeschärt, hald nach Beginn des Optieusstammes. ( $/$ n seite 170.$)$

Durchschnitt eine fächerförmige Gliederung. Hier tritt also ein Teil der Gliazellen an die Stelle des Höhlengranes, das den ïbrigen Recessns anskleilet (Fig. 11:3, S. 173). 
Zwischen dem Opticusstamm und dem umgebenden Bindegerrebe finde ich an den meisten meiner Schnittpräparate aus dem dritten Monat einen klaffenden, beiderseits glatt abgegrenzten Spaltraum (Fig. 102, S. 161). Es mögen bei dem Anftreten dieses klaffenden Raumes Schrumpfungsvorgänge mit im Spiele sein, wesentlich bleibt aber dabei die scharfe Trennung zwischen den beiden genetisch rerschiedenen Geweben, dem des Nervenstammes einerseits und dem Bindegewebe anderseits. An den Grenzflächen begegnen wir den beiden Mm. limitantes, die wir auf den frïheren Jugendstufen des gesamten Zentralnervensystems kennen gelernt haben, der M. limitans externa

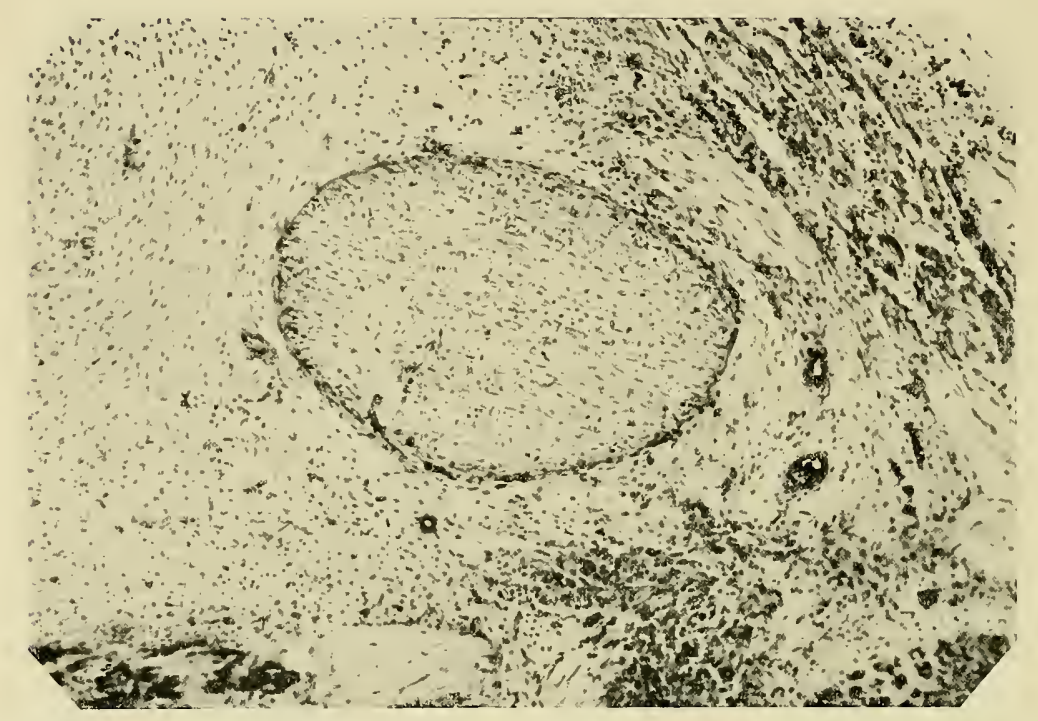

Fig. 112. Querschnitt des N. opticus desselben Embryo CI in kurzer Eutfernung rom Augapfel. Man sieht den Eintritt der Gefäßanlage in den vaskulären Raum des Nervenstammes. Dieser Raum ist von ciner feinen das Gliageriist umsïumenden M. limitans umschlossen. (Zu Seite 170.)

des Gliagerïstes und der M. limitans meningea des umgebenden Mesenchyms. Verfolgt man den perineuralen Spaltraum nach dem Bulbus hin, so findet man ihn an der Grenze des letzteren blind auslaufend, seine virtnclle Fortsetzung ist die Spalte zwischen Pigmenthant und Chorioidea. Nach dem Gehirn zu offnet sich die perinemrale Spalte in den epieerebralen Zwischenraum zwischen Gehirnoberfläche und Pia mater (Fig. 102, S. 161). Im vierten Monat geht die Entwicklung einen Schritt vorwäirts, beim Foetus Ce (8.3 cm SSl.) finde ich den Zwischenraum zwisehen Nerv und Bindegewebsscheide von zahlreichen strahlig angeordneten Gefäßsprossen durchsetzt. Diese dringen von anßen her in den Nerrenstamm ein. Ihr Ansgangspunkt wird nunmehr zur Piascheide des Sehnerven.

Der N. opticus verhält sich dem Obigen zufolge nach seiner gesamten Entwieklung wie ein echter Gehirnteil, und er weicht in allen Punkten vom 
Verhalten peripherischer Nervenstänme ab. Wie der N. opticns, so entwickeln sich anch das Chiasma und die Tractus optici innerhall, eines von der Gehirnsubstanz gelieferten Gliagerïstes.

Cerebellum und Fascieulus restiformis. Die Entwicklnng des Kleinhims erfolgt im allgemeinen noch später, als die der Großhirnhemisphären, und sie bietet eine Anzahl besonderer Probleme, die eine eingeliende monographische Bearbeitung beanspruchen. Eine solche anf später versparend, beschränke ich mich hier auf wenige Bemerkmg'en. 'Zu Ende des zweiten Monats erseheint die ans der Rantenlippe des Hinterhirns hervor-



Fig. 113. Aus einem Sagittalschnitt durch denselben Embryo C1. Der Sehnerv hat den Recessus opticus erreicht und erscheint als eine rinnenförmig gebogene Platte. Das Gliageriist des Stammes hängt mit der Ependymbekleidung des Recessus zusammen. Von dieser Ependymbekleidung treten radiäre Strahlen in den Nervenstamm ein. (Zu Seite 171.)

gegangene Anlage des Cerebellum als eine dicke, seitwärts herrortretende Platte, die rom basalen Teil des Hinterhirns durch eine breite Furehe, die $\mathrm{H}$ in te rh ir n $\mathrm{fur}$ che sich absetzt. In diese Furche lagert sich ein kräftiges, aus Fasern der jenseitigen Olive hervorgegangenes Bündel, der Fasciculus restiformis. Seine Lage ist im größeren Teil scines Verlanfes eine oberflächliche. Von der Seitenfläche des rerlängerten Markes hervorkommend, beschreibt das Bündel den vollen Bogen der Briickenkrümmmnng, sein dorsales Ende wendet sich mehr und mehr medialwärts und erreicht schließlich das Verbindungsstiick der beiden Kleinhirnhälften, die Anlage des Wurmes (Figg. 114 u. 115, S. 174 u. 175). Hier kommt es im Verlaufe des dritten Monats zu einer Durchkreuzung der beiderseitigen Fasern. Beim zweimonatlichen Embryo $\mathrm{Mr}$ (Fig. 107) treten die beiden Faseiculi restiformes 
zwar in den Wurm ein, aber noch hat sich keine Querverbindnng über die Mittellinie hinweg entwiekelt. Bei Embryo $\mathrm{My}$, der etwas jünger als $\mathrm{Mr}$ ist, sind zwar die ersten Olivenanlagen vorhanden und anch Faser\%iige 'nn sehen, die die Mittelebene durchsetzen, aber einen dem Seitenrand der

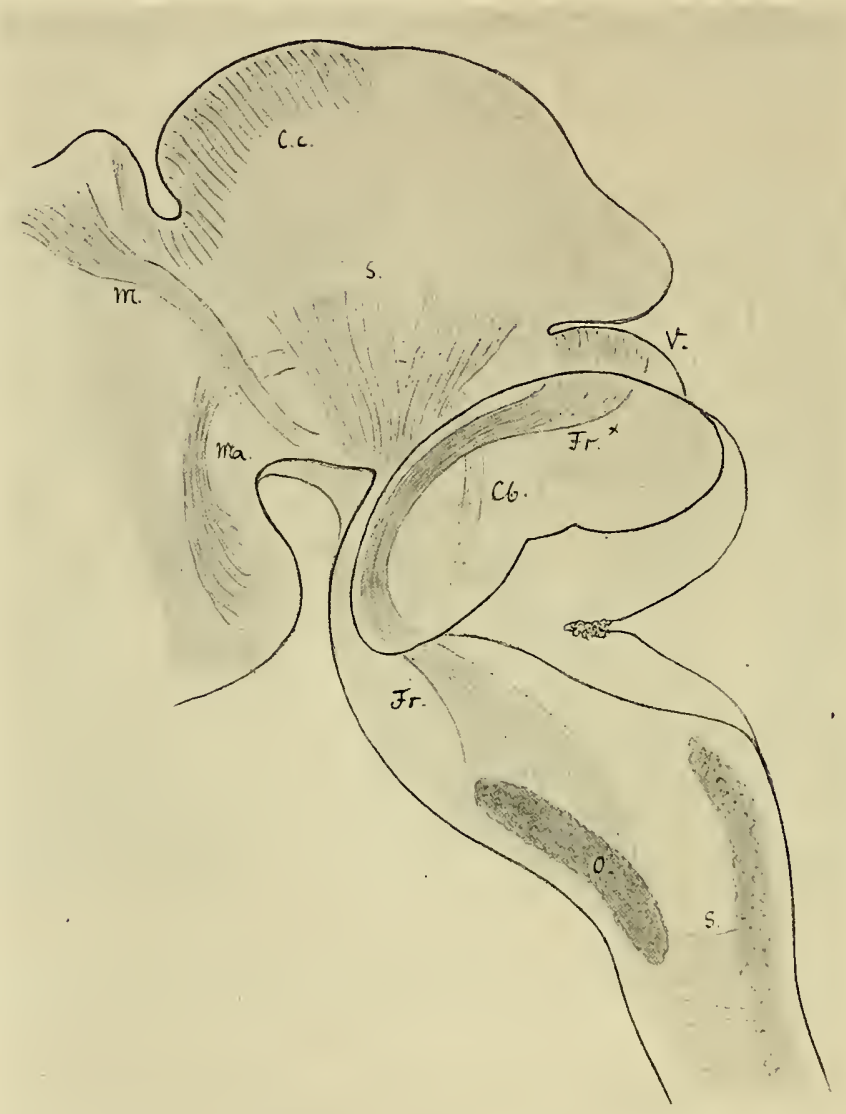

Fig. 114. Protilkonstruktion des Rautenhirns ron Foetus stg nit eingezeiehnetem Fasciculus restiformis. Vergr. 10 faeh. Der Weg des letzteren ist vou der Olivengegend ab bis zur Anlage des Kleinhirnwurmes rerfolgbar. Das Bündel beschreibt einen der Brüekenkrümmung entsprechenden, naeh vorn konvexen Bogen. $U . b .=$ Cerebellumbemisphäre, $V .=$ Vermis cerebelli, $0 .=$ untere Olive, $F . r .=$ Faseieulus restiformis, unterer Absehnitt, $F \cdot r . *=0$ berer Absehnitt. Dieser Figur 114 habe ieh anch die naeh anderen Präparaten (Se) konstruierten Anfünge der sensibeln Sehleifen eine streeke weit eingezeichnet.

(Zu Seite 173.)

Medulla oblongata sich anlegrenden Fasciculus restiformis vermag ich nicht anfzufinden. Sollten einzclne Bündel zu der Zeit schon bis dahin vorgedrungen sein, so schließen sie sich noch nicht zn einen kompakten Strang znsammen, und ein solcher läßt sich anch in der Kleinhirnfurche nicht 
nachweisen. Die Bildung des Fasciculus restiformis ist demnach an das Ende des zweiten Monats zu verlegen.

Unsicher bin ich ïber das erste Auftreten der lijudearme. Sie sclieinen erst zu erheblicher Ausbildung zu gelangen, wenn die solange verzögerte Gliedermug des Kleiuhirns eingetreten ist. Inmerhin stoße ich schron an den Sagittalschnitten von Wi, Fo und $\mathrm{Cl}$, also von der zweiten Hälfte des zweiten Monats ab, auf ausgeprägte Faserzinge in diffuser Terteilung, die von der Deeke des Isthmus und teilweise noch von der konkaven Vorderfläche des Cerebellum aus schräg zum Haubenwulst des Mittelhirns herab-

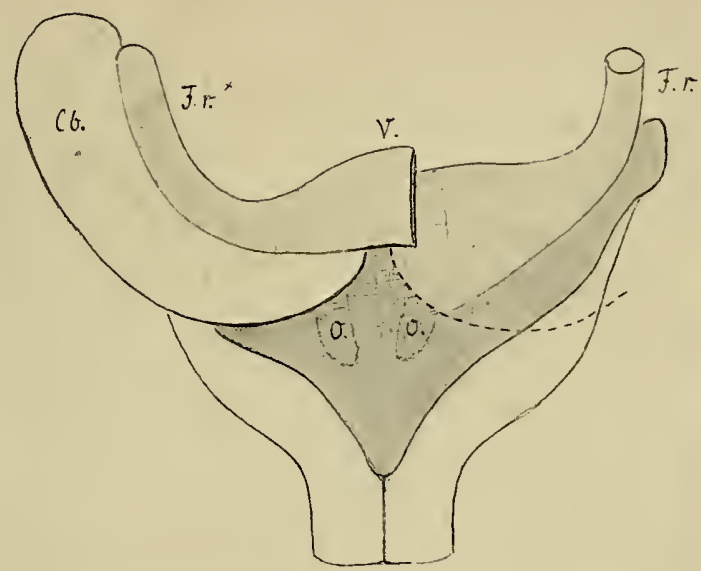

Fig. 115. Flächenkonstruktion rom Rautenhirn desselben Foutus. Rechts ist der Abgang des Fasciculus restiformis $(F, r$.) ron der Olive ab auf die Zeichnung projiziext, links der Weg des Bündels entlang den oberen Rand der Hemisphäre ( $\left.F, r^{*}\right)$. (Zu Seite 173.)

steigen und sich hier dessen diffusen Längsfaserziigen beimengen. Ich möchte vorläufig die Entscheidung darïber offen lassen, ob diese Faserzụ̈ce dem System der Bindearme zuzuzählen sind.

Dic Basis pedunculi nebst den Pyramidenbiindelu und den Q uerfasern der Brïcke erscheinen in meiner obigen Tabelle erst spät. Die verschränkte Lage der Längs- und Querfaserzïge innerhalb der Briicke weist daranf hin, daß die Entwicklung beider eine alternierende sein $u n$. Über das Einzelne dieser Entwicklıng vernag ich indessen zur Zeit noch nichts mitzuteilen, da mein Material hierzu nicht ausreicht.

Ieh schließe diesen in jeder Hinsicht fragmentarischen Aufsat\% iiber die intramedullaren Faserbahnen des Gehirns mit der Benerkung, daß el zur Zeit nicht viel mehr zu bieten vermag, als ein Arbeitsprogramm fiil kommende detailliertere Forsclungen. Noch sind wir eben in Erkenntnis 
176 Über intramedullare Faserbahnen und die Zeit ihres ersten Auftretens.

diescr Dinge in den allerersten Anfängen, und es bedarf hier, wie anderwärts, zäher Arbeit bis die Entwicklungsgeschichte des Gehirns nach ilıren verschiedenen Richtungen hin befriedigend kann klar gelegt werden. Zur Zeit kann ich nur angeben, wo diesc Arbeit einzusetzen hat. Frïher oder später wird man anch anf diesem Gebiet zum System organisierter gemeinsamer Arbeit ïberzugehen haben. 

LEIPZIG

DRUCK VON FISCHER \& WITTIG. 



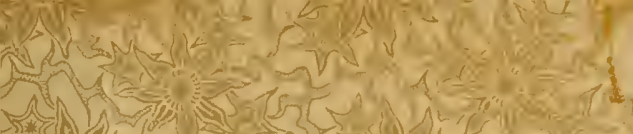

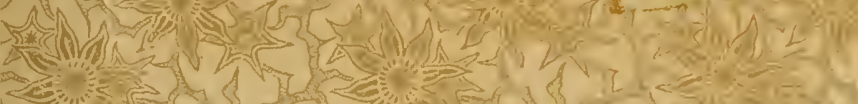
2)

(n)

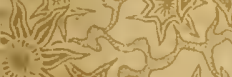

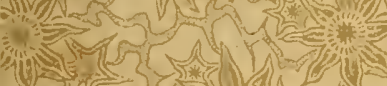

然

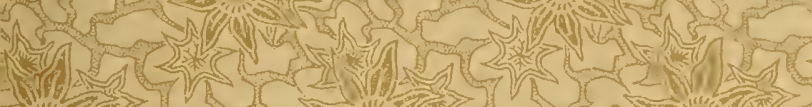

.

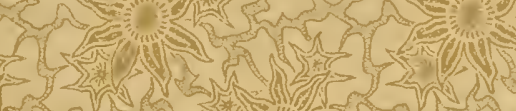

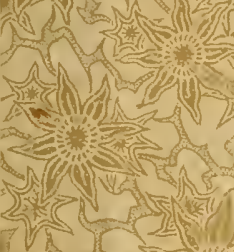

(5)

(1)

(B)

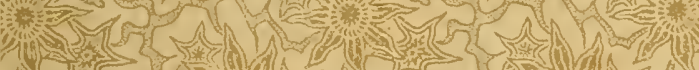

SII

1)

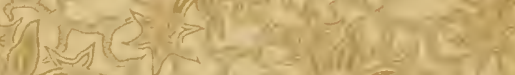

(U)

$=\frac{1}{2}$

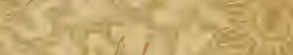

is



E. N 3

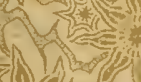

20:3

N(u)

in 2 (2)

-2 .

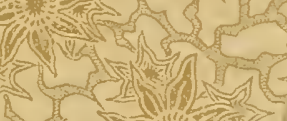

(1)

iNi(1)

(1)

A 1

(1)

a.

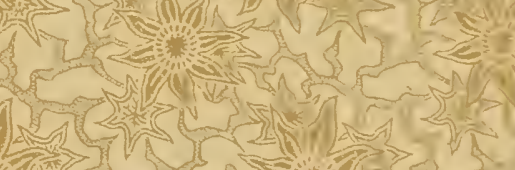

(5) (6)

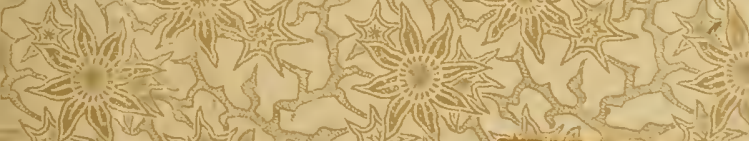

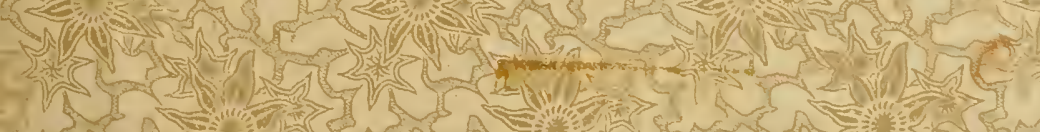
1) $1 / 2$

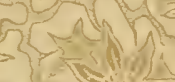

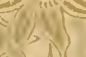


